\title{
LANDSCAPE AESTHETICS, TOURISM, AND CHANGE: CASE STUDIES IN NEPAL
}

\author{
BY \\ JHARNA JOSHI
}

\begin{abstract}
A thesis
Submitted to the Victoria University of Wellington In fulfilment of the requirements for the degree of
\end{abstract}

Doctor of Philosophy

Victoria University of Wellington

2019 



\begin{abstract}
This research explores how residents and tourists perceive landscape aesthetics in tourism-based landscapes that are continuously changing. Three case study sites in Nepal are examined. Landscapes are dynamic, multifunctional and an amalgamation of natural and human-made components that are constantly evolving, both naturally and due to human activities. Landscape aesthetics, related to experiences within and with multiple dimensions of landscape that engage all human senses, are perceived differently by different groups of people and have implications for their preservation and modification. Tourism, an integral part of contemporary society, reflects and influences changes in society and the landscape. The interrelationships amongst landscapes, change, perceptions and tourism are complex with paradoxical tensions that arise from their interconnections and interdependence.
\end{abstract}

Researchers have studied and interpreted the interrelationship between landscape and tourism from different perspectives that are sometimes contradictory. The literature is fragmented with similar aspects of the landscape-tourism relationship described and conceptualized using different terminologies (landscapes, cultural landscapes, environment, place, space, nature) and with an absence of an integrated approach and a holistic concept of landscape. This research addresses this fragmentation and multiple interpretations to build an integrated approach of landscape taken as a holistic entity, where the natural, cultural, social and economic dimensions, including tourism, interact, integrate and overlap. This study adds a new perspective by looking closely at landscape aesthetics and its relation to change and tourism incorporating the perspectives of both residents and tourists.

This research adopts a qualitative methodology using case studies in three geographically, culturally and contextually different locations in Nepal (Ghandruk, Bandipur and Sauraha). A multi-layered approach is used to explore the dynamic nature of landscape and nonlinear drivers of change that add layers and dimensions to landscape aesthetics and how it is perceived by different residents and tourists, both domestic and international. This research applies an interpretivist paradigm using in-depth interviews with photo-elicitation (incorporating past and repeat photographs with in-situ interviews), field observations and visual data analysis. 
Different themes emerged when the data were analysed but the overarching one was the often-antagonistic relationship between conservation and development. Participatory conservation and local development were key in Ghandruk, while the emphasis was on built heritage and expansion in Bandipur with the national park and indigenous Tharu traditions clashing with current landscape use in Sauraha. Key findings also indicate that the residents perceive landscape aesthetics holistically incorporating multiple dimensions that include traditions, culture, food, occupation and historical associations as well as contemporary societal changes and modern conveniences interwoven into their everyday landscapes. The tourists, with their fleeting presence, focus on the visual aesthetics, engaging with the non-material values of landscapes through different activities and are often accommodating of landscape changes perceived as improvements based on their background and worldview. The pace of change in the present context of globalisation influences the perceptions of both tourists and residents that are reflected in the landscapes and landscape aesthetics. In order to effectively manage landscape change and tourism development, it is pertinent to understand drivers of change and the society within a holistic concept of landscape. 


\section{ACKNOWLEDGEMENTS}

This page is not enough or even the right platform to thank all the people that I have crossed paths with who have inspired me since the seeds of this thesis were planted somewhere in the many conversations with friends and colleagues I had while working in Nepal. Nevertheless, there are some people I would like to mention here who have helped to nurture the seed and bring this thesis to completion.

Firstly, I would like to thank my excellent supervisory team, Professor Karen Smith, Professor Adam Weaver and Dr Eerang Park for enduring this journey with me. You have patiently listened to me, guided me and helped me manoeuvre through this research that at times seemed overwhelming. Your sound advice and calm encouragement kept me focussed on the end goal. It is a pleasure and a privilege to have such a committed supervisory team and I have learned a lot from you.

I would also like to thank all the staff members and colleagues at SOM and VUW who have offered support and encouragement. I am also indebted to VUW for the financial support through the completion scholarship and research funding. A special thank you to Megan Key for the wonderful administrative support. A big thank you and best wishes to all my PhD colleagues and friends for making this journey pleasant.

I am grateful to all the individuals that I interviewed and had conversations with, who took time from work and leisure to talk about landscape and tourism. This thesis is based on what they shared with me and is invaluable to this research. A special thank you to Douglas Hall for providing the high-quality photographs from the Peace Corps Nepal Photo Project. I also have to thank Bais Gurung and Chij Kumar Shrestha for providing a home and place to work in Bandipur.

A special thank you to my Wellington family, Mary Stacey, Stuart and Alison Lavin for making us feel at home from day one. Knowing your home was always available was invaluable to enable me to focus on completing this thesis. Most importantly, thank you to my parents, Amir and Saroj Joshi, and family, especially, Mamata, Santosh, Sushil, Wenting, Gaurav, Kshitij, Sawan, and Ina for your love and support. 
This thesis is for my partner, Manoj, without whom this project would not have started, let alone be completed. Words cannot express how grateful I am. 


\section{TABLE OF CONTENTS}

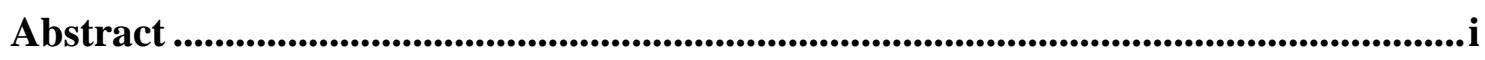

Acknowledgements ..............................................................................................................ii

1. Introduction............................................................................................................................ 1

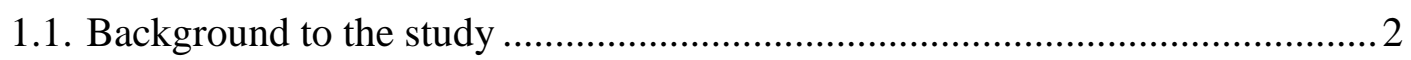

1.2. Research questions............................................................................... 7

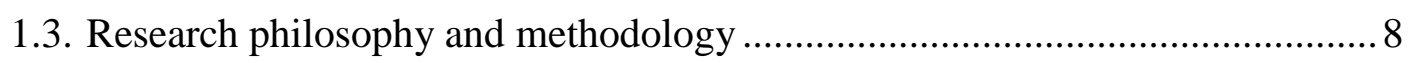

1.4. Research context: Ghandruk, Bandipur and Sauraha in Nepal........................ 10

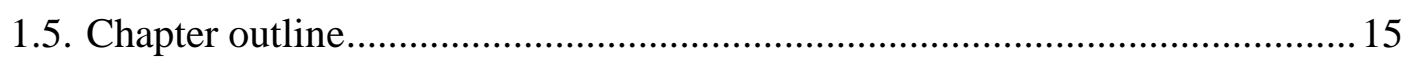

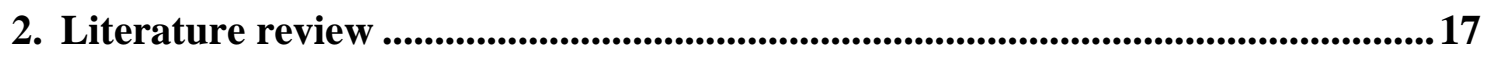

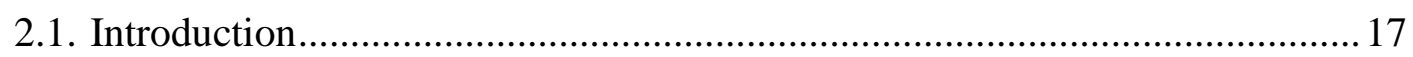

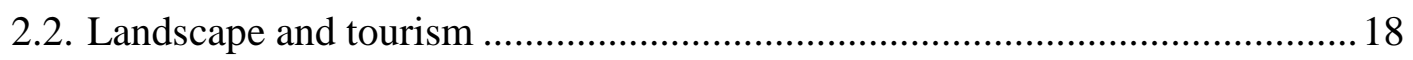

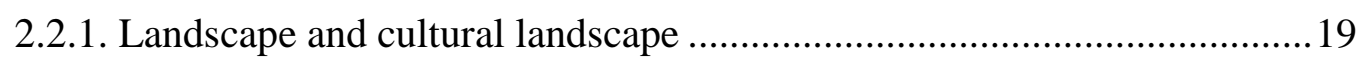

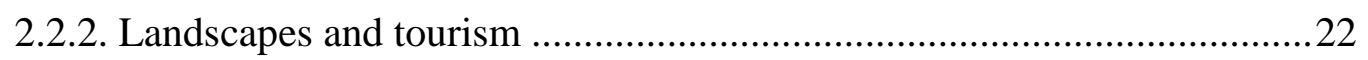

2.2.3. Different landscape perceptions: residents and tourists .........................26

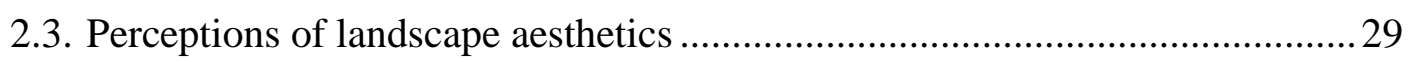

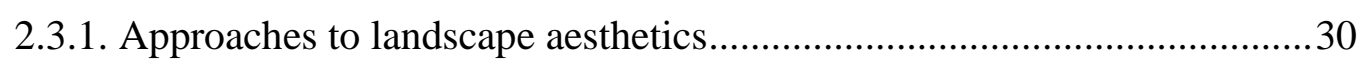

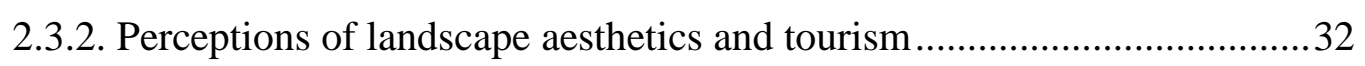

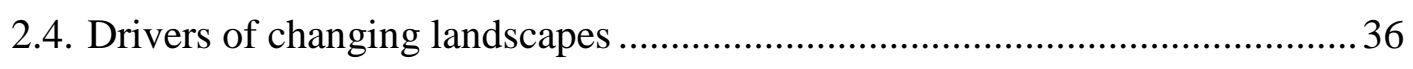

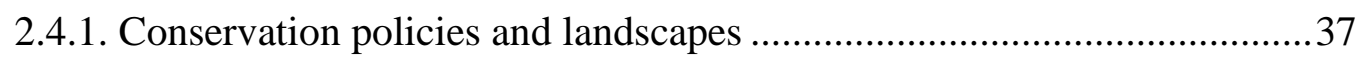

2.4.2. Urbanisation, globalisation and landscape change .................................41

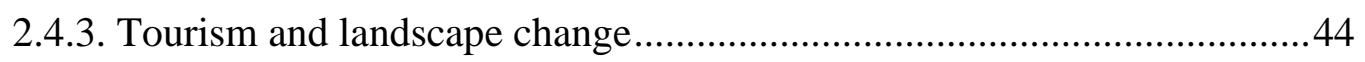

2.5. Landscapes - change - perceptions: a conceptual framework ...................... 47

2.6. Tourism research in Nepal: an overview ..................................................50

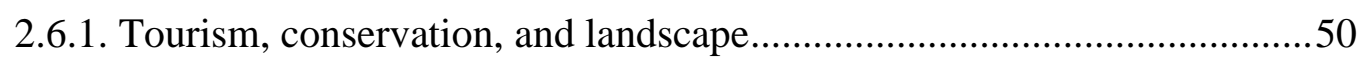

2.6.2. Recent research: Conservation, community and tourism ........................53

2.6.3. Landscape change and tourism...........................................................5

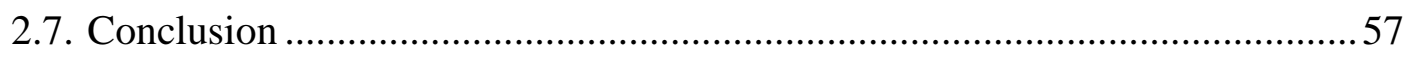

3. Methodology and research strategies................................................................58

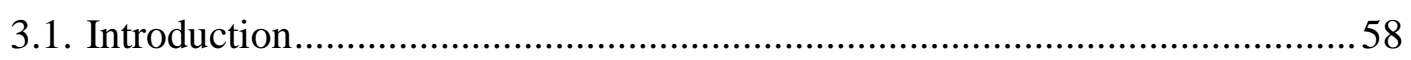

3.2. Identifying the research problem: Research questions .................................58

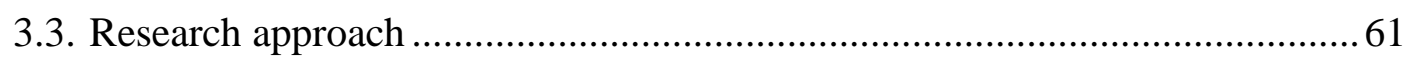


3.3.1. Case studies: a comparative case studies approach .63

3.3.2. In-depth interviews with photo elicitation .67

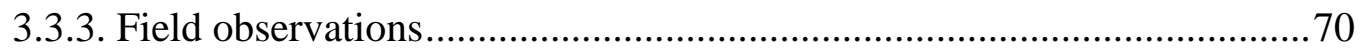

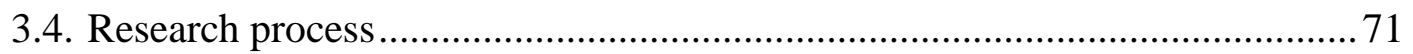

3.4.1. Research design (Phase 1) .................................................................... 71

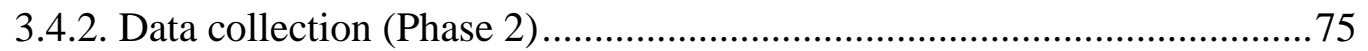

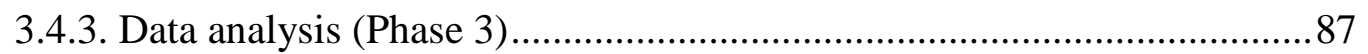

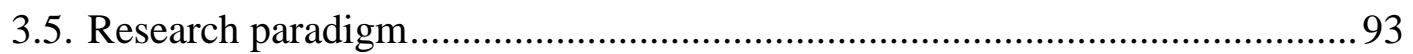

3.6. Strengths and limitations of methodology and data..................................... 95

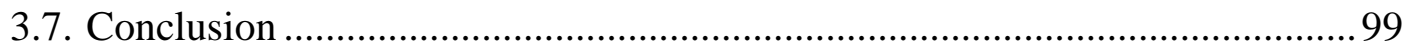

4. Ghandruk: Co-existance between conservation and road development ...........101

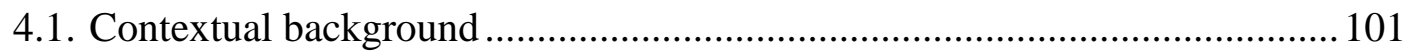

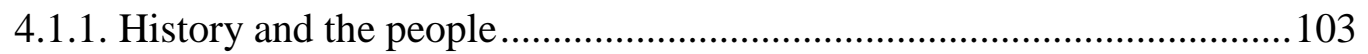

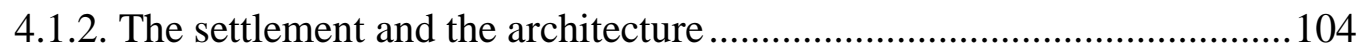

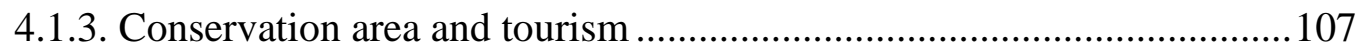

4.2. Mountain vistas, the village and Gurung culture ........................................ 109

4.2.1. The Himalayan vista and the village ..................................................... 109

4.2.2. The Gurung culture............................................................................ 117

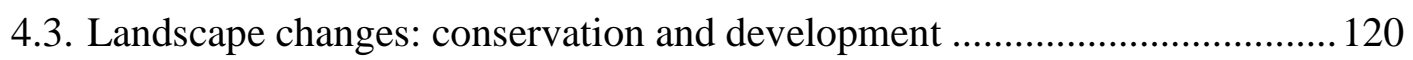

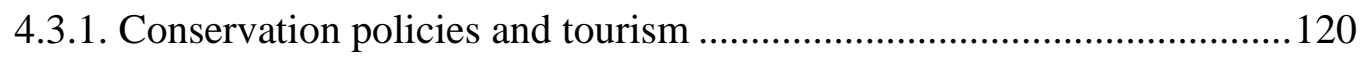

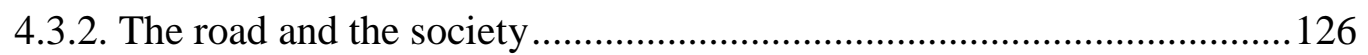

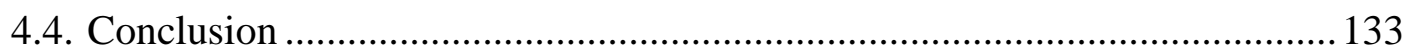

5. Bandipur: Preserved historic bazaar and the developing periphery................ 136

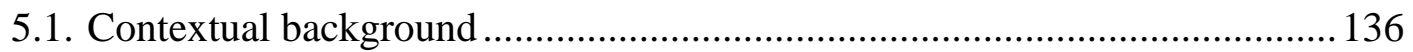

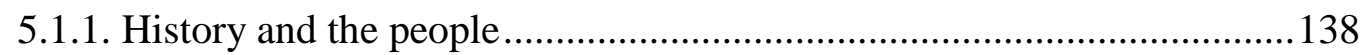

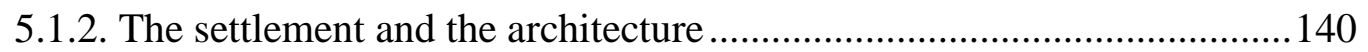

5.1.3. Preserved zone and tourism.............................................................. 143

5.2. Perceptions: The Bazaar and the vista .......................................................... 144

5.2.1. Bandipur bazaar: the heart of Bandipur................................................ 145

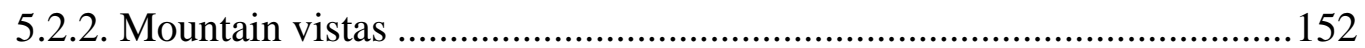

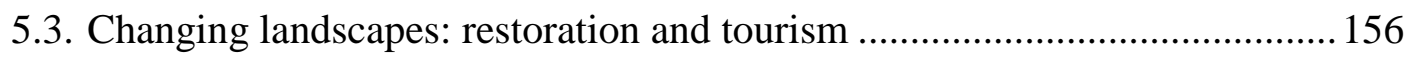

5.3.1. Conservation policies, tourism and the society ................................... 156

5.3.2. The Bazaar: past and present ................................................................ 161

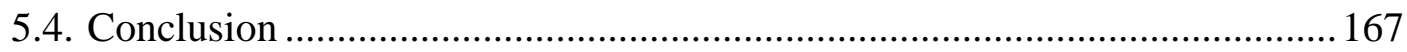


6. Sauraha: Contested landscape between the park and the city 169

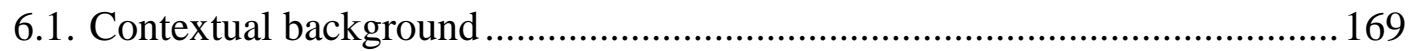

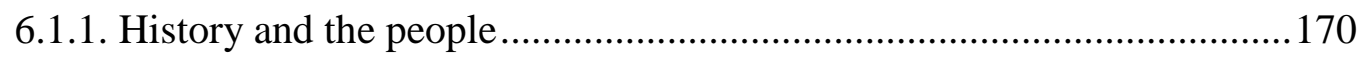

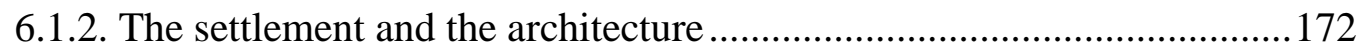

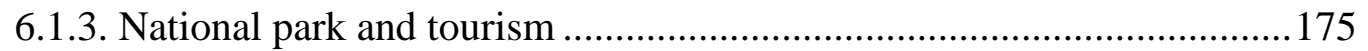

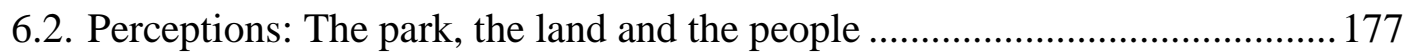

6.2.1. The national park and the farmlands ..................................................... 178

6.2.2. The village and the community ............................................................ 182

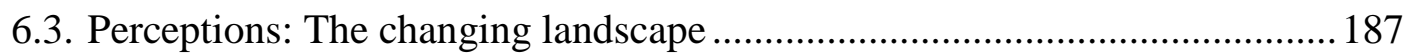

6.3.1. Conservation policies and Tharu culture ................................................. 188

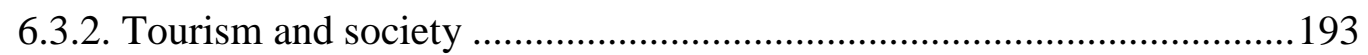

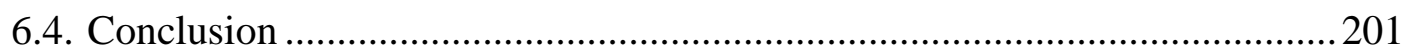

7. Perceptions of landscape change and landscape aesthetics ..............................203

7.1. Framework for landscape, change and landscape aesthetics .........................203

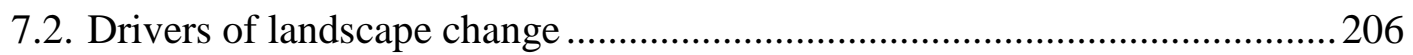

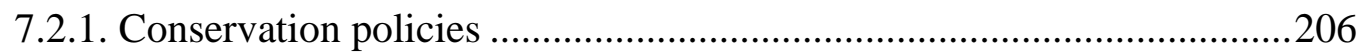

7.2.2. Urbanisation and globalisation .............................................................2212

7.2.3. Tourism and the local economy …....................................................2. 218

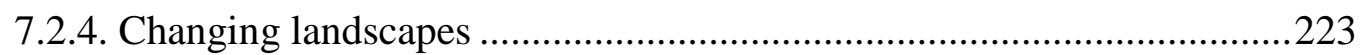

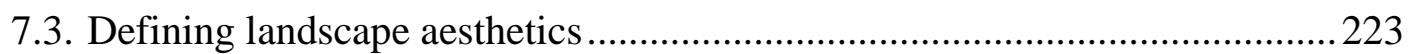

7.3.1. Attachments with the land (natural, built and cultural) ........................222

7.3.2. Everyday life and everyday aesthetics ...............................................22 227

7.3.3. Change and landscape aesthetics......................................................22

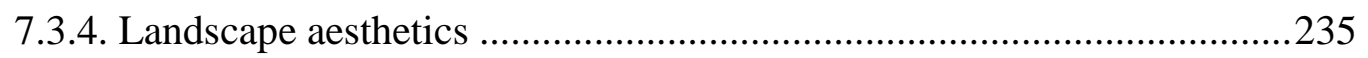

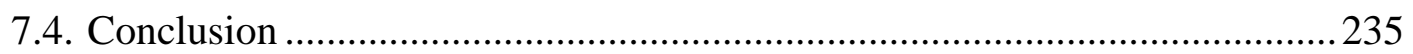

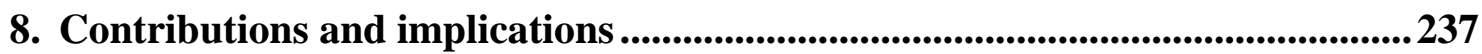

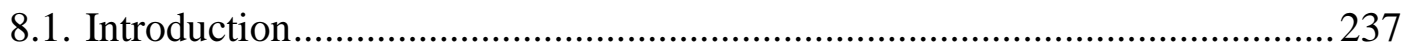

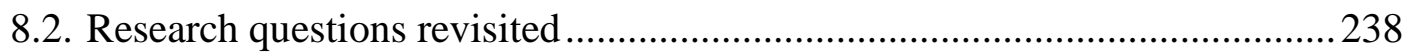

8.3. Methodological and theoretical contributions ..............................................2 245

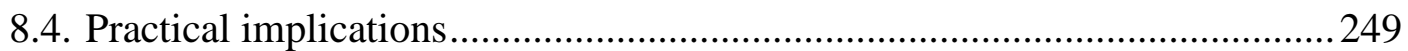

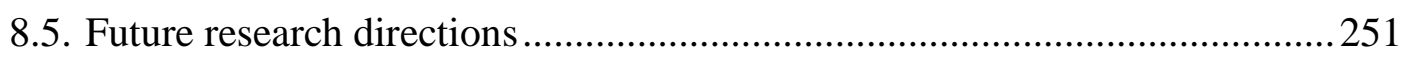

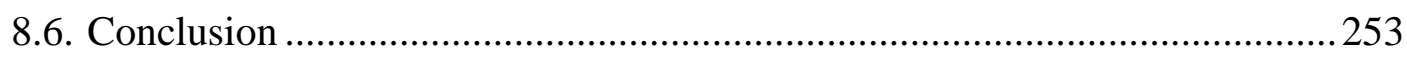

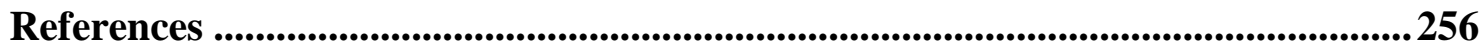


Appendix A: Information sheet and consent form

Appendix B: Interview guidelines (tourists and residents)

Appendix C: Examples of past and repeat photograph sets used in the interviews 


\section{LIST OF TABLES}

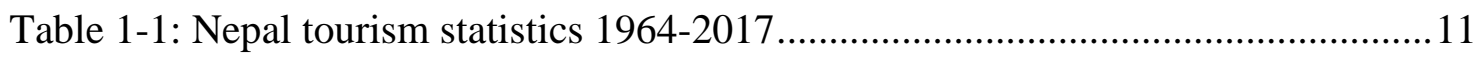

Table 1-2: Tourist arrival by major nationalities...................................................... 12

Table 1-3: Number of trekkers in major Conservation Areas (CA) and National Parks

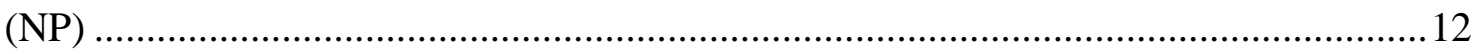

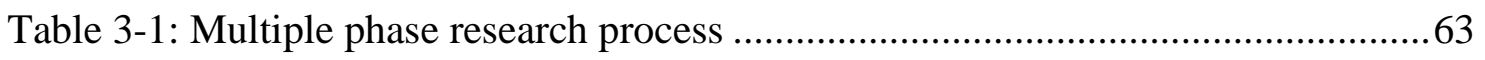

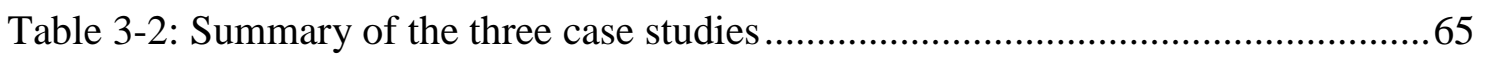

Table 3-3: Sources and quantity of photographs used in the main interviews ................74

Table 3-4: Profile summary of in-depth interview participants ..................................79

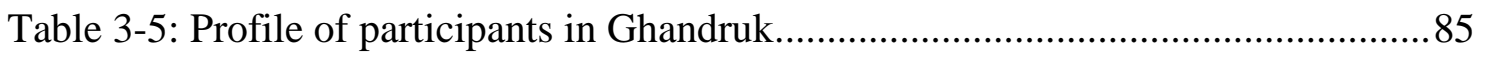

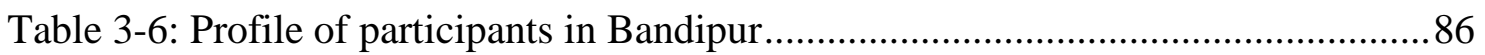

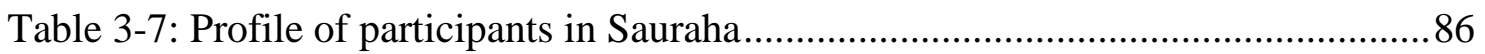

Table 3-8: Example of initial coding of interviews in Bandipur ..................................92 


\section{LIST OF FIGURES}

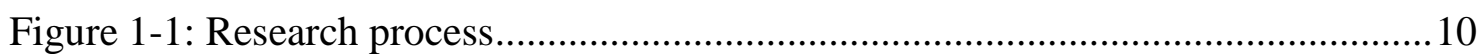

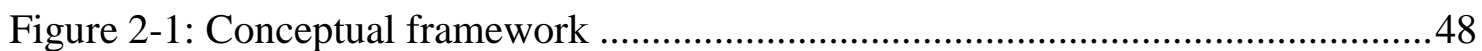

Figure 3-1: Analytical framework: Data analysis and comparison across themes and case studies

Figure 7-1: Framework for landscape, change and landscape aesthetics .204 


\section{LIST OF PLATES}

Plate 1-1: Map of Nepal showing the location of the case study sites (in red) .13

Plate 3-1: Past and repeat photographs of Gitanagar junction, Chitwan .77

Plate 3-2: Example of past and repeat photograph set of Ghandruk village .81

Plate 4-1: Ghandruk with Annapurna range in the background. 102

Plate 4-2: Location of Ghandruk in relation to Kimchi, Birethanti and Pokhara. 103

Plate 4-3: The historic stone trail in Ghandruk 106

Plate 4-4: Seating along the trail 106

Plate 4-5: Typical Gurung dwelling in Ghandruk with paved front courtyard 107

Plate 4-6: The historic stone steps in the village 113

Plate 4-7: Past and repeat photographs showing increase in forests and decrease in cultivated terraces

Plate 4-8: The new (right) in contrast to the old (left) building 124

Plate 4-9: New larger buildings dominating the traditional buildings 125

Plate 4-10: New building in non-conforming architectural styles in Kimchi, the last stop for vehicles

Plate 4-11: Past and repeat photographs showing the corn stack in 1974. 130

Plate 5-1: Location of Bandipur and access routes from Dumre and Bimalnagar 137

Plate 5-2: View of Marshyangdi valley (300m) and Annapurna range $(8000 \mathrm{~m})$ from Bandipur 138

Plate 5-3: Bandipur settlement against the terraced farms 139

Plate 5-4: Typical buildings in Bandipur bazaar 142 
Plate 5-5: Covered passage with balconies on the first level

Plate 5-6: Increasing building activities in non-conforming style in the periphery ......158

Plate 5-7: Past and repeat photographs showing more cafes and painted houses

Plate 5-8: Past and repeat photographs showing cultivated terraces and increased greenery

Plate 6-1: Past and repeat photographs showing cultivated terraces and increased greenery

Plate 6-2: Main centre of Sauraha with non-descript buildings

Plate 6-3: Traditional Tharu house with pitched tile roof and veranda 174

Plate 6-4: Map showing land use in the buffer zones

Plate 6-5: New colourful building alongside a traditional cottage 198

Plate 7-1: Unpaved new road near Kimchi that is flooded in the monsoon seasons ....214 


\section{LIST OF ABBREVIATIONS}

$\begin{array}{ll}\text { ABC } & \text { Annapurna Base Camp } \\ \text { ACA } & \text { Annapurna Conservation Area } \\ \text { ACAP } & \text { Annapurna Conservation Area Project } \\ \text { BECTP } & \text { Bandipur Eco Cultural Tourism Project } \\ \text { BSDC } & \text { Bandipur Social Development Committee } \\ \text { CNP } & \text { Chitwan National Park } \\ \text { ICOMOS } & \text { International Council on Monuments and Sites } \\ \text { IUCN } & \text { International Union for Conservation of Nature } \\ \text { NTB } & \text { Nepal Tourism Board } \\ \text { PCNPP } & \text { Peace Corps Nepal Photo Project } \\ \text { UNESCO } & \text { United Nations Educational, Scientific and Cultural Organisation } \\ \text { VDC } & \text { Village Development Committee } \\ \text { WHS } & \text { World Heritage Site }\end{array}$




\section{INTRODUCTION}

This thesis aims to conceptualise the relationship between landscapes and tourism in Nepal, focusing on the perspectives of residents and tourists towards landscape change and landscape aesthetics. Landscapes have been studied in various ways across a wide spectrum of fields that include geologists, social and cultural geographers, planners, ecologists, environmentalists, historians and art historians, architects, archaeologists, and anthropologists (Tilley \& Cameron-Daum, 2017). Scholars have also studied a range of changes in tourism and its influences on landscapes; however, these concepts are mostly studied independently of each other and it is often unclear how they relate to each other (Butler, 1995). With the growing popularity of tourism as a global industry and its potential for alleviating poverty, there is a rise in countries adopting tourism for the purpose of economic development (Goulding, Horan, \& Tozzi, 2014; SK Nepal, 2005) ${ }^{1}$. This trend, along with globalisation and the development of communication technology, is changing landscapes significantly (Terkenli, 2008). An important component of the landscape is aesthetic characteristics and values, which have implications for the preservation and modification of landscapes. The diverse perspectives regarding landscape aesthetics that drive landscape changes have not received sufficient consideration in the existing literature.

The interrelationships amongst landscapes, change, tourism, residents and tourists, as well as perceptions of landscape aesthetics, are complex with paradoxical tensions that arise from their interconnections, interdependence and overlays. Some of these tensions have been explored in the existing literature, such as the traditional landscapes that provide identity to the community but are also shaped by a desire for modern convenience (Merey Enlil \& Dincer, 2004; Pitkänen, 2008). It is proposed that a tension between distinctiveness and placelessness (Relph, 1976) stems from this sometimes contradictory relationship between the traditional and the modern. While the existing literature has studied the changing patterns of landscapes, this study adds a new perspective by looking

\footnotetext{
${ }^{1}$ Professor Sanjay K. Nepal is one of the leading researchers on tourism and geography in Nepal. In order to distinguish between the researcher and the country, citations for Sanjay K. Nepal will appear as SK Nepal.
} 
closely at landscape aesthetics and their relation to change, including tourism, incorporating the perspectives of both residents and tourists.

This research takes a people-centred approach for a qualitative study of landscape aesthetics in three different landscapes in Nepal. Personal interest and experience traverse this research and provide context and rationale for the study. This introductory chapter presents the background to the study, defines the scope and direction and outlines the position in the literature. This chapter also presents the research questions and an overview of the three selected case study sites (Ghandruk, Bandipur and Sauraha) concluding with an outline of the organisation of this thesis.

\subsection{BACKGROUND TO THE STUDY}

Landscape-tourism interactions and the on-going changes have been studied in a wide range of literature, including tourism and geography; however, there is a lack of consensus on their approach. There is also a continuing discussion on the definition and interpretation of the scope of landscape and cultural landscapes with additional concepts and terms such as tourism landscape and geotourism (Stoffelen \& Vanneste, 2015). The concepts of nature, environment, region, place, and space have also been used to describe landscape. In addition, different approaches have been adopted, such as the ecosystem services and geotourism suggested recently by Stoffelen and Vanneste (2015). Various themes related to specific landscape contexts have been studied, such as impacts on landscapes (Gkoltsiou \& Terkenli, 2012; Terkenli, 2008), landscape and place experiences and practices (Crang, 1999), spectacle and performance (Hollinshead, 1999) and the gaze and surveillance (Crang, 1999; Hollinshead, 1999; Urry, 2002). However, most of the studies consider specific aspects of landscape, mainly due to the different approaches to viewing the landscape with the focus on either the natural or the cultural components (Cosgrove, 2003).

This study uses the term landscape to refer to socially constructed landscapes that encompass the natural and built landscape along with the associated cultural dimensions of the people residing and interacting in it. The traditional definition of landscape based in geography or history evolved from the Sauerian concept as "a perceived segment of the earth's surface" to cultural landscape to incorporate socio-cultural and political 
processes (Antrop, 2006; Stoffelen \& Vanneste, 2015; Terkenli, 2001). The cultural landscape concept accepts that landscapes are produced by people and in turn, people and their culture are products of the landscape (Buckley, Ollenburg, \& Zhong, 2008). Landscapes originate from a "continuous dynamic interaction between the natural processes and human activities" (Antrop, 2006, p. 188). This interaction is considered as an essential characteristic (Antrop, 1997; Naveh, 1995) and thus, landscapes are inherently culturally constructed. For this study, I use the term landscape to reflect this view of landscape that has evolved from merely being a view and highlight the holistic character where natural and built components are both culturally constructed. It also reflects the dynamic phenomenon of landscape that evolves through time as the result of the activities of nature and people, highlighting the role of people in the centre of the process (Berleant, 2005a). The interaction of culture with landscapes is reciprocal; not only do cultural impacts shape landscapes but perspectives of landscapes are also products of culture which, in turn, affects our relation to the landscapes (Naveh, 1995). This concept of people within the landscape where nature and culture co-exist, depending on and changing each other, is fundamental in traditional eastern concepts of landscapes and ways of thinking (Han, 2006; Taylor, 2009) and appropriate for this research in the context of Nepal.

Unlike art, which is generally contemplative and detached, landscape aesthetics is built on experiences and is an active and participatory process that engages all human senses (Berleant, 2005a). It also encompasses the everyday lives of the people living in the landscape and their perceptions have implications and consequences in the preservation or transformation of landscapes (Saito, 2007). People perceive and describe the landscapes that they view in different ways that relate to their standpoint, interests and values that sometimes can be radically different, where their "past experiences feed into the present, anticipating the future" (Tilley \& Cameron-Daum, 2017, p. 9). The environmentalists and ecologists may regard landscapes from their perceptual experience, which stimulate their desires to protect the natural environment from human influences. For some communities, they may be taskscapes where they live and work (Tilley \& Cameron-Daum, 2017). For the tourists, landscapes may be pleasure grounds to pursue their adventures, foster personal development or well-being. This inevitably gives way for conflicts in interests, purpose and value, where possibilities and 
potentialities that are good for one group may not necessarily be agreed upon by another (Palmer, 2014). This difference also produces conflicts between some who may want to preserve the landscape and others who may want to change, develop or enhance it.

Researchers have approached landscape aesthetics from the perceptions of experts and non-experts (residents and tourists) on different aspects of landscape aesthetics, such as sense of place (Davenport \& Anderson, 2005), visual aesthetics (Kalivoda, Vojar, Skřivanová, \& Zahradník, 2014), cultural ecosystem services (Tekken et al., 2017; Zoderer, Tasser, Erb, Stanghellini, \& Tappeiner, 2016), rural landscape (Carneiro, Lima, \& Silva, 2015), and agricultural landscape (Grammatikopoulou, Pouta, Salmiovirta, \& Soini, 2012). This study adds to the literature by studying the perceptions of both residents and tourists on the multiple cognitive and sensory aspects of landscape aesthetics incorporating their changing characteristics. The focus of this research is the aesthetic values of the changing landscapes and its relationship with tourism, which have not been studied. The focus on the perspectives of different groups with respect to landscape and aesthetics has the potential to interest those involved in policymaking to prepare policies and management plans that protect the landscapes and promote sustainable tourism that leads to overall economic development.

Tourism is both an agent of preservation and change (Wall, 1998). Destinations noted for specific landscapes attract tourism, which is an impetus for economic development in many countries. At the same time, the introduction of tourism into an area necessitates facilities to cater for the tourists and inevitably results in changes in the landscape, such as accommodations built specifically for tourists and what J.B. Jackson (1970, p.62) has termed the other-directed architecture (Relph, 1976). Tourism becomes an integral part of communities and as such, reflects the changes and challenges of global environmental and social changes. The resulting landscapes face a range of changes homogenising the landscape and threatening the local and regional characters.

The impact of uncontrolled growth of the tourism industry has already altered landscapes significantly, mainly through the change in land use patterns abandoning agriculture and growing urbanism (Gkoltsiou, Terkenli, \& Koukoulas, 2013; Urry, 2002). There is growing concern for the changing aesthetic character of the rural and urban landscape, especially in historic landscapes (Zurick \& Rose, 2009). Limited studies have looked into 
the changing built landscapes, such as seaside resort towns (Palmer, 2014) and heritage towns (Avieli, 2015). However, tourism has been used as a vehicle to revive the economies of many traditional villages that witnessed human migration from rural to urban regions in developed as well as developing countries (Graburn, 1995). The changes brought by tourism development include increases in tourist accommodation units, loss of environmental/landscape diversity and replacement of local cultural and natural elements by touristic structures (Gkoltsiou et al., 2013).

With the rapid rise of globalization, the world will become increasingly homogenised and a desire to live a modern and good life will prompt humans to conform to international standards rather than promote local cultures (SK Nepal, Verkoeyen, \& Karrow, 2015). The existing literature is limited to quantifying the on-going change of spatial arrangements such as land use patterns, building density, connectivity and distribution networks and land cover changes (Gkoltsiou et al., 2013; SK Nepal, 2005). Studies on the impact of the changes brought by tourism development on the distinctive characteristics of landscape and their aesthetic values are, however, scarce. This study aims to extend the concept of change currently established in the study of tourism and landscapes and apply it to the landscape aesthetics. Specifically, it explores the changing landscapes in Nepal where tourism is becoming a major economic activity transforming the socio-cultural dynamics and the landscapes. The rationale for studying the changing landscape is the long-term impact of this process on the sustainability and resilience of traditional landscapes that depend significantly on tourism.

This research topic evolved from my own experience working and travelling in my home country, Nepal, and abroad. Starting my professional life as an architect trained abroad primarily in modern materials and technology and living in a historic city in Nepal, I found myself in an interesting juxtaposition of modern and traditional building technologies and styles. Trained in western philosophies and working in non-western conditions, I often found myself challenged between scientific rationale and traditional belief systems. Subsequent work and travel further exposed me to the changing landscapes, especially in towns and villages that were seeing growth in tourism and transitioning from traditional lifestyles to adopting modern technologies. In most cases, there existed a dichotomy of development and conservation with the focus on either the 
conservation of natural resources or the built environment that were rarely considered holistically.

My interest in this topic developed from the need to integrate natural and built components of the landscape and understand the role of tourism in their conservation, especially in the context of Nepal, where conservation is not a high priority when basic development needs such as health and education are critical. However, local authorities are increasingly accepting tourism as an economic driver that is changing the traditional landscapes but planning decisions rarely include local values and perceptions of landscapes (Chapagain, 2011). Historically, visual aesthetics is the major criteria for design reviews of buildings and enforced by governmental institutions usually with nebulous guidelines such as proposed new buildings should fit into the context (Stamps, 2000). In the course of this study of natural and built landscapes, the role and significance of people in their landscapes and the way different individuals and groups engaged with it became prominent and led to the recognition that human presence is the centre of environment (Berleant, 2005a). Although the participation of people has gained importance in recent years, conservation policies for natural and built landscape are still considered independently. This research focuses on the perceptions of the residents and tourists in order to explore landscape aesthetics holistically, which includes the multiple sensory and cognitive aspects of the changing landscapes.

My interest is to contribute to the study of tourism-landscape relationships, focussing on the different perspectives of landscape aesthetics and changes and its subsequent impact on the sustainability of a destination. I have visited and worked in the selected sites in different capacities at different stages of my career as my interests evolved from architecture to broader concepts of cultural landscapes and tourism. Part of my work, especially in Bandipur, was to build up the knowledge and infrastructure and promote the town as a tourism destination; that work has contributed to the change to some extent. Conversations with residents on their perspectives of their landscape made me contemplate my own approach as an expert and the divergences on what was considered an aesthetically pleasing landscape. It is in this context that I recognised the importance of collecting the perspectives of the residents in developing policies for successful implementation. Planners and planning processes have not given local values and perspectives adequate importance when landscapes are the products of the deep 
involvement of the people who live in the place and have profound attachments and relationships with the land (Relph, 1976; Stephenson, 2008). The decision to also include the perspectives of the tourists in this research emerged to present an outsider and wider perspective as landscape planning issues are often negotiated between the residents and the tourists in tourist destinations (Daugstad, 2008). This research addresses this gap to investigate the complex relationship between different users of landscapes and the impact of their perceptions in shaping landscapes. This research provides a new understanding of the diverse aesthetic values of landscape and the processes that drive change in the landscape.

This research expands the study of the relationship between tourism and changing landscapes, especially in regions beyond European sites, which has not received sufficient attention in the existing literature. Focusing on landscape aesthetics, this research adds to the study of the relationship between changing landscapes and tourism development and include the perspectives of a diverse range of residents and tourists (international and domestic). This research also makes recommendations regarding policy development and site management by providing a clearer view on the perspectives and expectations of stakeholders. Although this thesis does not explicitly address sustainable development, the holistic concept of landscape adopted acknowledges and is situated in the broader scope of sustainable development.

\subsection{RESEARCH QUESTIONS}

The conceptual framework of this study (section 2.5), based on the theories of tourism, landscape, change and perceptions of landscape aesthetics, developed from the challenges in the different concepts and approaches in the existing literature. Existing literature demonstrates that the local and the tourist may view, approach and experience the landscape and the change differently (Urry, 2002). The implication of differing perceptions on the management of landscapes requires this research to address the perceptions of the changing landscapes from the insider and outsider perspective. In order to understand the changing landscape and landscape aesthetics, it is essential to understand the drivers of change. On this basis, this study investigates the following overarching research question: 
How do residents and tourists perceive the aesthetic values of Nepal's changing landscapes?

Supplementary questions are:

1. What are the drivers of change in the landscape that are influenced by tourism?

2. What are the perspectives of residents and tourists with respect to the changing landscapes and landscape aesthetics?

3. How do the perceptions of residents and tourists compare or inter-relate with respect to different landscapes?

The focus of this study is on the perceptions of residents and tourists with regard to landscape change and landscape aesthetics. The dynamic nature of landscapes requires an understanding of the drivers and implications of change. The supplementary questions address the drivers of change and how residents and tourist perceive the change as well as its impact on landscape aesthetics. The perceptions of the different groups in three case study sites are intended to compare the impact of the drivers of change on landscape and landscape aesthetics in different contexts and cultures. The overall aim is to develop a framework of landscape aesthetics that looks at landscapes in totality, considering its changing characteristics and different perceptions.

\subsection{RESEARCH PHILOSOPHY AND METHODOLOGY}

This research applies an interpretivist paradigm with qualitative methods using case studies, in-depth interviews with photo-elicitation, and field observations. With roots in philosophy and the human sciences, particularly in history, philosophy and anthropology, the interpretivist paradigm believes that understanding human experiences is as important as focusing on explanation, prediction and control (Phillimore \& Goodson, 2004). This approach was selected to examine landscape aesthetics from the participants' point of view and research was conducted in a conversational or dialogic style to encourage the interviewees to participate more (Foley \& Valenzuela, 2005). The experiences of people are essentially context-bound and thus, complete objectivity and neutrality were not sought and the values of participants and the researcher become integral parts of the research (Phillimore \& Goodson, 2004). For this research, the 
residents lived in the location, were long-term residents and/or recent migrants, and mostly held multiple roles within the community, such as a teacher, councillor and business owner, social worker, or even work away from the community at times (e.g. guides). The tourists included domestic and international, first-time and repeat visitors.

This study of the drivers of changing landscapes and perceptions of landscape aesthetics requires a combination of different research methods. Initially, available data such as maps, documents and photographs were collected and analysed to assess the visual change. This provided the context for the subsequent interview segment. While the analysis of documents and photographs provided data on the physical changes, the interviews focused on the perceptions of landscape and landscape aesthetics. To study the perceptions of the diverse aspects of landscape aesthetics, this research used photoelicitation interview technique, where past and repeat photographs were used as stimuli to guide the open-ended interviews and provoke discussions. In total, fifty-one interviews were conducted using 84 photographs. The past photographs were collected from various sources, while the repeat photographs were taken at the same locations prior to the main data collection. In addition, the interviews were conducted on site providing participants a wide range of landscape experiences.

This study takes a comparative case studies approach to explore the similarities and differences in the processes and outcomes due to the different geographic regions and culture on landscape change and landscape aesthetics. The three selected case studies are located in three different geographic regions (high hills, low hills and the plains), and climatic conditions. The location and the associated cultural identity of the case studies have resulted in distinctive characteristics, which provide sufficient range for the research topic. Several sites were considered before selecting Ghandruk, Bandipur and Sauraha. The selected sites are representative of their regions and well-known destinations in international and domestic tourism markets. Ghandruk started as a trekking destination on the popular Annapurna trail, whereas Sauraha borders Chitwan National Park and Bandipur is an emerging destination on heritage tours. The selected sites developed as tourism destinations and are showing signs of change with the increasing investments in tourism and thus are suitable for comparison. 
The field research was carried out in three phases that are interconnected and iterative (Figure 1-1). The first phase (research design) mainly collected background information for the main data collection (phase 2) in the three case study sites that formed the basis for the third phase (data analysis) and will be explained in detail in chapter three.

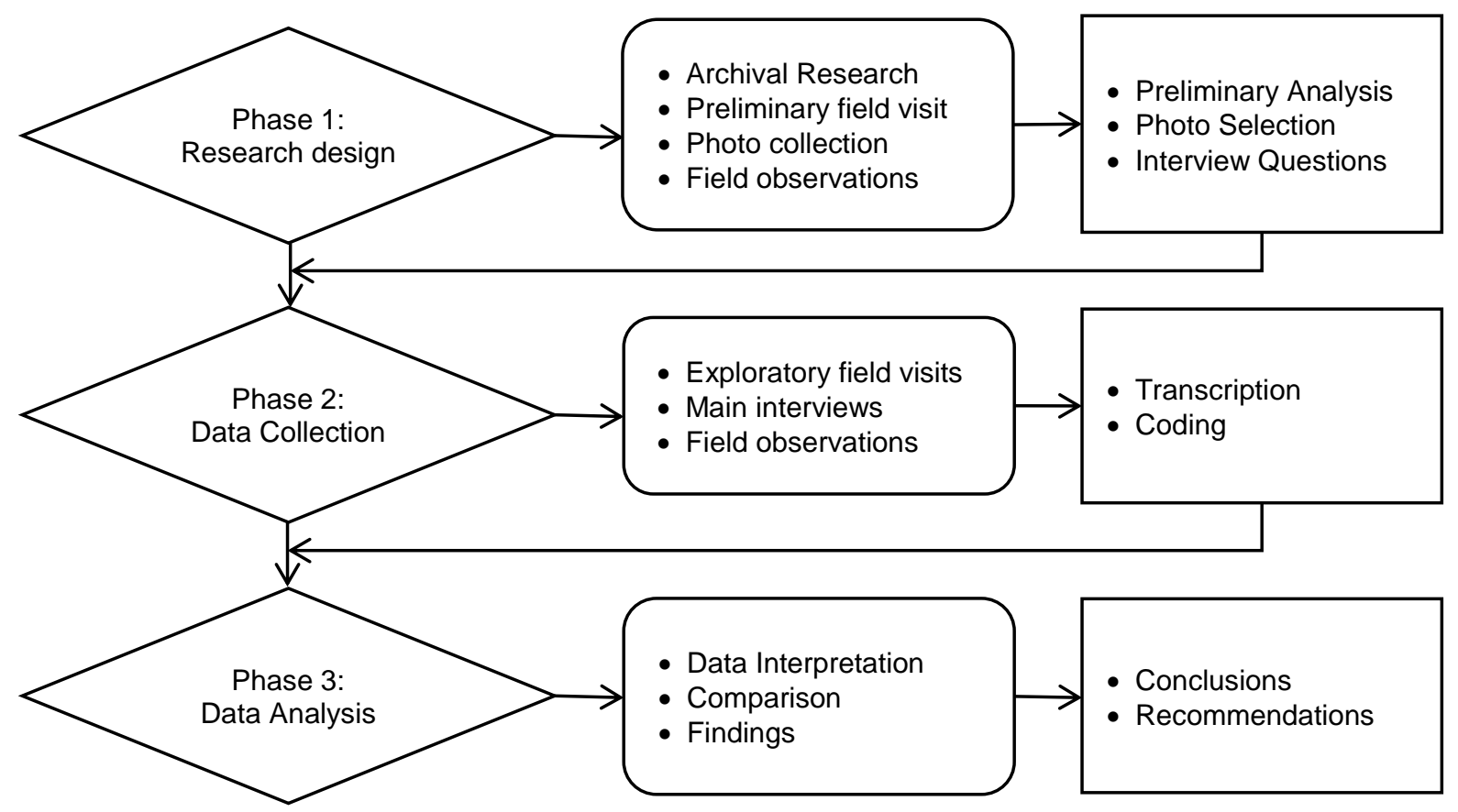

Figure 1-1: Research process

\subsection{RESEARCH CONTEXT: GHANDRUK, BANDIPUR AND SAURAHA IN NEPAL}

Tourism is a relatively new phenomenon in Nepal. Nepal opened to the western world in the 1950s after more than a century of closed autocratic rule. In the early years, the attraction was mountains, and Nepal was viewed as a Shangri-La detached from modern civilisation. The 1960s saw an influx of western tourists mainly attracted by the notion of an exotic land and easy availability of marijuana and Nepal became a popular destination in The Hippie Trail (Liechty, 2017). With eight out of the 10 world's highest mountains, including Mount Everest, mountaineering has continued to be an attraction and promoted by the Nepal Tourism Board (NTB). This national body was established in 1998 to develop and market Nepal as an attractive tourist destination. Given the 
geography and the state of underdevelopment, the natural landscape has continued to be an attractive adventure and mountain tourism product of Nepal.

Following international trends, tourism is on the rise in Nepal, with a significant $25 \%$ growth in arrivals reported in 2017 rebounding from the repercussions of the 2015 Gorkha Earthquake (Table 1-1). Tourism is the second highest source of foreign exchange for Nepal, after remittance, contributing directly to $3.6 \%$ of GDP (total contribution $7.5 \%$ of GDP) in 2016 and is forecast to rise by $6.8 \%$ in 2017 (WTTC, 2017). The total number of foreign visitors arriving in Nepal was 940,218 in 2017, an increase of $25 \%$ from the previous year (Table 1-1). Although this figure is a small segment of the global tourism market, tourism generated 427,000 jobs directly in 2016 (2.9\% of employment) and indirectly contributed to $6.4 \%$ of total employment (WTTC, 2017). Despite the good location and rich resources, Nepal ranks low in the World Economic Forum's Travel and Tourism Competitiveness Index at 103rd over 136 countries (WEF, 2017) and its tourism potential has not been fully exploited.

\begin{tabular}{l|lllll}
\hline \hline YEAR & NUMBER & $\begin{array}{l}\text { ANNUAL } \\
\text { GROWTH (\%) }\end{array}$ & $\begin{array}{l}\text { LENGTH OF STAY } \\
\text { (DAYS) }\end{array}$ & TREKKING/MOUNTAINEERING & $\begin{array}{l}\text { EARNINGS US\$ } \\
\text { (MILLION) }\end{array}$ \\
\hline \hline $\mathbf{1 9 6 4}$ & 9,526 & 30.9 & - & - & - \\
$\mathbf{1 9 7 4}$ & 89,838 & 32.0 & 13.20 & - & - \\
$\mathbf{1 9 8 4}$ & 176,634 & -1.5 & 11.55 & - & - \\
$\mathbf{1 9 9 4}$ & 326,531 & 11.2 & 10 & $76,865(23.5 \%)$ & - \\
\hline $\mathbf{2 0 0 4}$ & 385,297 & 13.9 & 13.51 & $69,442(18.0 \%)$ & 245.9 \\
$\mathbf{2 0 0 5}$ & 375,398 & -2.6 & 9.09 & $61,488(16.4 \%)$ & 145.2 \\
$\mathbf{2 0 0 6}$ & 386,926 & 2.3 & 10.20 & $66,931(12.7 \%)$ & 132.1 \\
$\mathbf{2 0 0 7}$ & 526,705 & 37.2 & 11.96 & $101,320(19.2 \%)$ & 143.6 \\
$\mathbf{2 0 0 8}$ & 500,277 & -5.0 & 11.78 & $104,822(21.0 \%)$ & 286.9 \\
$\mathbf{2 0 0 9}$ & 509,956 & 1.9 & 11.32 & $132,929(26.1 \%)$ & 363.7 \\
$\mathbf{2 0 1 0}$ & 602,867 & 18.2 & 12.67 & $70,218(11.6 \%)$ & 377.5 \\
$\mathbf{2 0 1 1}$ & 736,215 & 22.1 & 13.12 & $86,260(11.7 \%)$ & 340.4 \\
$\mathbf{2 0 1 2}$ & 803,092 & 9.1 & 12.16 & $105,015(13.1 \%)$ & 379.0 \\
$\mathbf{2 0 1 3}$ & 797,616 & -0.7 & 12.60 & $97,309(12.2 \%)$ & 388.9 \\
$\mathbf{2 0 1 4}$ & 790,118 & -0.9 & 12.44 & $97,185(12.3 \%)$ & 472.2 \\
$\mathbf{2 0 1 5}$ & 538,970 & -32 & 13.16 & $9,162(1.70 \%)$ & 544.1 \\
$\mathbf{2 0 1 6}$ & 753,002 & 40 & 13.4 & $66,490(8.83 \%)$ & 392.7 \\
$\mathbf{2 0 1 7}$ & 940,218 & 25 & 12.6 & $75,217(8.0 \%)$ & 510.0 \\
\hline \hline
\end{tabular}

Table 1-1: Nepal tourism statistics 1964-2017

Source: Ministry of Culture, Tourism and Civil Aviation

Nepal's unique location between the two emerging economies India and China is important as the two countries contributed $30 \%$ of total visitors to Nepal and this is expected to grow in the foreseeable future (Table 1-2). As a new federal democracy, with the demarcation of states and the new constitution still in its nascence, the future direction 
for tourism development is yet to be finalised. However, tourism has significant potential to drive economic growth and development with multi-dimensional effects on the economy generating foreign currency, employment and contributing to the conservation of heritage and environment and is likely to be adopted by the federal governments (Gautam, 2014).

\begin{tabular}{l|llllllll}
\hline \hline NATIONALITY & $\mathbf{2 0 1 0}$ & $\mathbf{2 0 1 1}$ & $\mathbf{2 0 1 2}$ & $\mathbf{2 0 1 3}$ & $\mathbf{2 0 1 4}$ & $\mathbf{2 0 1 5}$ & $\mathbf{2 0 1 6}$ & $\mathbf{2 0 1 7}$ \\
\hline \hline AUSTRALIA & 16,243 & 19,824 & 22,030 & 20,469 & 24,516 & 14,816 & 25,507 & 33,371 \\
BANGLADESH & - & - & - & 22,410 & 21,851 & 14,851 & 23,440 & 29,060 \\
CHINA & 46,360 & 61,917 & 71,861 & 113,173 & 123,805 & 64,675 & 104,005 & 104,664 \\
FRANCE & 24,550 & 26,720 & 28,805 & 21,842 & 24,097 & 10,885 & 20,863 & 26,140 \\
GERMANY & 22,583 & 27,472 & 30,409 & 22,263 & 18,028 & 12,216 & 23,812 & 29,918 \\
INDIA & 120,898 & 149,504 & 165,815 & 180,974 & 135,343 & 75,124 & 118,249 & 160,832 \\
JAPAN & 23,332 & 26,283 & 28,642 & 26,694 & 25,829 & 14,165 & 22,979 & 27,326 \\
SOUTH KOREA & - & - & - & 19,714 & 23,205 & 18,112 & 25,171 & 34,301 \\
SRI LANKA & 45,531 & 59,884 & 69,476 & 32,736 & 37,546 & 43,117 & 57,521 & 45,361 \\
USA & 36,425 & 42,875 & 48,985 & 47,355 & 49,830 & 53,897 & 53,645 & 79,146 \\
UK & 35,091 & 39,091 & 41,294 & 35,668 & 36,759 & 24,469 & 46,295 & 51,058 \\
\hline \hline
\end{tabular}

Table 1-2: Tourist arrival by major nationalities

Source: Ministry of Culture, Tourism and Civil Aviation

Currently, due to the weak infrastructure and marketing, tourism is limited to a handful of sites (Table 1-3). This concentration in limited areas is showing early signs of landscape change, especially in the popular trekking trails such as the Annapurna and Everest regions (SK Nepal, 2005; Vallejo et al., 2015).

\begin{tabular}{|c|c|c|c|c|c|c|c|}
\hline PROTECTED AREA & DISTRICT & ESTABLISHED & 2012 & 2013 & 2014 & 2015 & 2016 \\
\hline ANNAPURNA CA & Kaski & 1986 & 113,123 & 124,998 & 114,418 & 83,419 & 144,409 \\
\hline GAURISHANKER CA & $\begin{array}{l}\text { Dolakha, } \\
\text { Sindhupalchok, } \\
\text { Ramechhap }\end{array}$ & 2010 & 1,993 & 2,914 & 2,818 & 1,840 & 2,770 \\
\hline MANASLU CA & Gorkha & 1998 & 4,268 & 5,331 & 5,658 & 2,287 & 5,745 \\
\hline BARDIYA NP & Bardiya & 1988 & 12,974 & 13,207 & 13,548 & 10,638 & 17,959 \\
\hline $\begin{array}{l}\text { CHITWAN NP } \\
\text { (WHS) }\end{array}$ & Chitwan & 1973 & 153,749 & 173,425 & 178,257 & 87,391 & 139,125 \\
\hline LANGTANG NP & $\begin{array}{l}\text { Nuwakot, } \\
\text { Rasuwa, } \\
\text { Sindhupalchok }\end{array}$ & 1976 & 13,370 & 12,552 & 12,265 & 5,016 & 8,254 \\
\hline $\begin{array}{l}\text { SAGARMATHA } \\
\text { (EVEREST) NP } \\
\text { (WHS) }\end{array}$ & Solukhumbu & 1976 & 36,550 & 35,157 & 34,412 & 27,794 & 45,112 \\
\hline $\begin{array}{l}\text { SHIVAPURI } \\
\text { NAGARJUN NP }\end{array}$ & $\begin{array}{l}\text { Kathmandu, } \\
\text { Nuwakot, } \\
\text { Sindhupalchok }\end{array}$ & 2002 & 165,904 & 180,464 & 138,084 & 143,352 & 205,747 \\
\hline
\end{tabular}

Table 1-3: Number of trekkers in major Conservation Areas (CA) and National Parks (NP)

Source: Department of National Park and Wildlife Conservation, Nepal 
In Nepal, change in the traditional livelihood is a major factor that is transforming the landscapes. The shift from traditional occupations that were primarily subsistence-based agriculture to the more service-based industries such as tourism is showing effects on the landscapes. For example, the growth in tourism is increasing demands for new structures that are altering the built landscapes. Unlike villages in Europe (such as the villages which are members in the Association of the Most Beautiful Villages), where conservation of the historic fabric is strictly followed (Goulding et al., 2014), in the absence of government building regulations in Nepal, the changes are strongly guided by the owner's decisions and economic status, contemporary trends in tourism and demands of hospitality services (SK Nepal, 2005). In addition, as one of the major source of national income, tourism has often guided conservation issues with the emphasis on providing amenities for the tourists (Chapagain, 2008).

This comparative study explores three popular destinations in Nepal that represent different geographical regions with distinct population and culture that reflect on the landscape (Plate 1-1). The location of Ghandruk and Bandipur on hilltops limits their economic potential, whereas Sauraha is located in the plains with alternative development potential such as agriculture and industries. This section provides a brief introduction to the three case study sites with further background in the findings chapters (four to six).

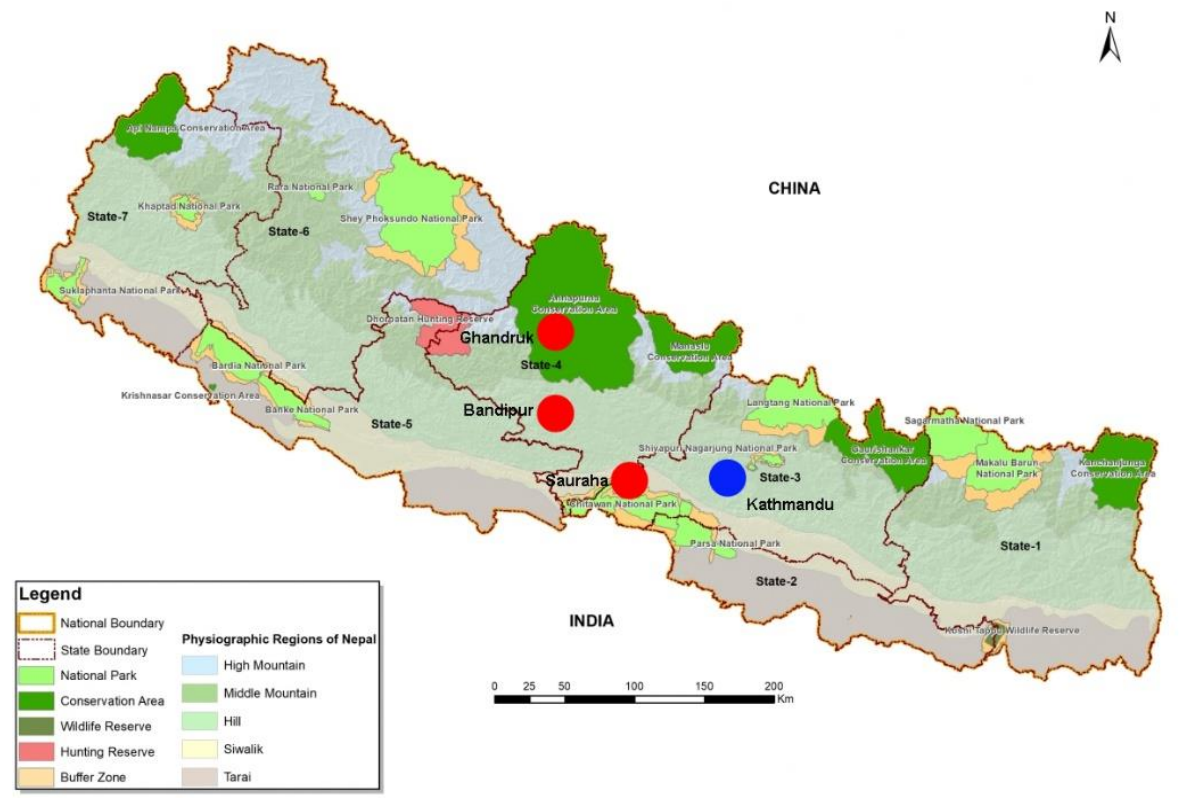

Plate 1-1: Map of Nepal showing the location of the case study sites (in red)

Source: National Trust for Nature Conservation, 2018 


\section{Ghandruk}

Ghandruk located 1,975 metres above sea level in the Annapurna Conservation Area in western Nepal, is a popular stop on the trail to the Annapurna Base Camp with approximately 30,000 trekkers visiting annually. The settlement is spread across a moderately steep hill facing south with a total population of 6,158 people (CBS, 2012). Stone is the dominant building material and the buildings are generally one to two storey. The local economy depends on tourism and the forest and their management is a key priority in this region (Adhikari \& Fischer, 2011). The view of the Annapurna range and the lifestyle of the Gurung people are the main attractions. A recently constructed road has reduced the trek to this village from a day's hike to a couple of hours, and now Ghandruk attracts families and domestic visitors on short holidays. This road access has the potential to change the buildings from prevailing trekkers' lodges to resorts to cater to the new type of tourists.

\section{Bandipur}

Bandipur is five hours drive west from Kathmandu and two hours from Pokhara and Chitwan, the three most visited places in Nepal. Located at 1,000 metres, the settlement is located on a ridge with brick, timber and stone roof tiles the main building materials. This is an emerging destination with a good road link making it easily accessible. The traditional architecture of Bandipur and nearby villages is attracting domestic and international visitors (Sigdel, 2014). According to the Bandipur Tourism Development Committee, the number of visitors to Bandipur in 2012 was approximately 10,000 international and 90,000 domestic (including day visitors). The town centre was recently declared a protected zone with building controls, but the easy access and growing popularity is attracting investment with increasing building activities in the surrounding agricultural fields.

\section{Sauraha}

Sauraha is the biggest settlement bordering Chitwan National Park, a World Natural Heritage Site that was established in 1973 as Nepal's first national park. Until the beginning of this century, this region was under forest and sparsely populated by the indigenous Tharu community. Successive re-settlement efforts by the government since 
1950s has seen an influx of people from hill communities settling in the bordering towns of the park introducing building styles and land patterns different to the prevalent Tharu huts built of adobe (Agergaard, 1999). Located in the plains, this national park is popular for wildlife as well as the culture of the indigenous Tharu population. Tourism is regarded as a benefit and an incentive for the conservation of the natural resources (SK Nepal \& Spiteri, 2011). However, the warm climate, flat land and transportation access is attracting larger developments limiting the traditional buildings and settlements to a village cultural walk.

\subsection{CHAPTER OUTLINE}

This thesis is presented in eight chapters. Chapter one has introduced the background to the study, scope of the study and outlined the research questions to be investigated.

Chapter two begins with an exploration of the relationship between landscape and tourism. This is followed by a review of the different approaches to and perceptions of landscape aesthetics. Various drivers of change in the landscape are examined next. This forms the basis for the conceptual framework that builds from the literature reviewed. This chapter concludes with an overview of the literature on tourism development and changing landscapes in Nepal.

Chapter three outlines the methodological and analytical frameworks that have guided this study and the interpretation of the results. This chapter describes the methodological approach and the different phases of research, including data collection and analysis. In addition, this chapter outlines the research paradigm and concludes with the strengths and limitations of the method applied.

Chapters four to six present the findings on the three case study sites in turn. Chapter four discusses the first case study site, Ghandruk, in the context of conservation areas and development pressure, such as road construction and their influence on the perceptions of landscape aesthetics and landscape change. Chapter five discusses the significance of historical narratives and the preservation of built landscape in Bandipur for sustainable tourism while accommodating development process. Chapter six discusses the contested landscape of Sauraha as a world-renowned national park, the granary of Nepal and a 
bustling tourist destination. These three findings chapters look at each case study site independently while comparing the perspectives of the residents and tourists.

The next chapter (seven) revisits the conceptual framework and compares the findings across the three sites. This chapter first discusses the drivers of landscape change in the three sites, followed by the final section that distils the findings on various perspectives of landscape and landscape aesthetics.

Chapter eight is the conclusion and includes implications of this research, contributions to theory, policy and practice, finishing with recommendations for further research. 


\section{LITERATURE REVIEW}

\subsection{INTRODUCTION}

This chapter reviews the study of the interrelationships between tourism, landscapes, drivers of landscape change and the perceptions of landscape aesthetics to work towards a conceptual framework. As outlined in chapter one, the focus of this research is to explore the perceptions of the residents and tourists on the changing landscape aesthetics in three destinations in Nepal. This review adopts a broad concept of landscape to include the natural and the built landscape along with the people living, working and interacting within it. Landscape aesthetics in this research also goes beyond the tangible and visible to incorporate the experiential and cognitive aspects of landscape. Landscapes are dynamic and constantly changing, which requires this review to explore drivers of change that impact upon the landscape and perceptions of landscape aesthetics. Tourism is a major driver of landscape change and this review explores the interrelationships between landscape change and tourism. Local, regional and national governments use various policies and regulations to guide landscape transformation that contribute to economic development. The two main groups that these policies target to accommodate are the residents and the tourists, hence their perceptions are important in shaping landscapes.

This chapter first examines the concept of landscape, mainly in tourism literature but also in the wider environment, geography and conservation literature, to identify the gaps in the study of landscape as a social construct (section 2.2). This is followed by a review of the perceptions on landscape aesthetics (section 2.3) and drivers of change with a focus on tourism and its interrelationship with landscape (section 2.4). These form the basis of a conceptual framework to explore this relationship between landscapes, change and perceptions (section 2.5). This conceptual framework provides the foundation for the methodology to explore landscape from the perceptions of the residents and tourists and work towards identifying the drivers of landscape change and the multiple aspects of landscape aesthetics (chapter 3). This chapter concludes with a review of tourism in Nepal that will inform the context of the case study sites selected for this research (section 2.6). 


\subsection{LANDSCAPE AND TOURISM}

As outlined in the introductory chapter, the term landscape in this study takes on a holistic meaning and encompasses the natural environment, the built settlement and the associated cultural dimensions. Landscapes, in general, are contextual and polysemic, formed by the interactions between people and nature. They are formed as a result of human interaction with nature assimilating the history, traditions, expectations and sociocultural context of people as individuals and groups and the geological, geographical and biological aspects of nature. As people interact with their landscapes, they constantly rework them, creating and recreating landscapes that are often contested (Bender, 1993). The way in which people interact and understand the landscape depends on the specific time, place and historical conditions.

Landscapes, especially traditional landscapes, generally reflect the integration of natural and cultural environments and are regarded as sustainable, utilising local resources, materials, and labour (Phillips, 2003). They are developed over generations and adapted to local climatic conditions producing distinctive characteristics (Bodach, Lang, \& Hamhaber, 2014; Phillips \& Yannas, 1999; Relph, 1976). With increasing interest in alternative and niche markets that promote experiences and holistic well-being, the potential for places that offer distinctive landscapes will also grow (Terkenli, 2002). The importance of the relationship between landscape and tourism lies in the interdependence of the two. While the tourism industry needs distinctive landscapes, places need tourism for economic sustainability, especially those that have limited alternative economic potential. As the tourism industry develops resulting in increasing numbers of visitors, it leads to changes, expanding settlements and transforming landscapes (Dyer, 2009; Hoskins, 1953).

This section first reviews the study of landscapes and cultural landscapes. Next, the relationship between landscape and tourism (section 2.2.2) in the context of tourism studies in general and more broadly in geography, ecology and heritage conservation studies is explored, followed by the review of the different perceptions of landscape (section 2.2.3). 


\subsubsection{Landscape and cultural landscape}

Throughout history the term landscape has had a range of interpretations from natureonly to a social construct, where natural, cultural, social and economic worlds overlap, interact and integrate (Stoffelen \& Vanneste, 2015). Early landscape researchers viewed landscape as a way of seeing the world that was visual and detached based on the concepts introduced by Carl Sauer (Setten, 2006). Sauer (1963) defined cultural landscape as a geographical area "fashioned from a natural landscape by a culture group" where "culture is the agent, the natural area is the medium, the cultural landscape the result" (p. 343). There is continuing discussion on the interpretation of landscape and cultural landscape with additional concepts and terms such as tourism landscape, geotourism, nature, environment, region, place, space used in landscape and tourism studies (Jones, 2003; Stoffelen \& Vanneste, 2015). Despite the different terminologies, there are similarities that seek to capture the meaning rather than view landscape as something to be understood in a detached, objective manner.

The concept of cultural landscape as heritage was picked up in the 1990s as a convergence of landscape studies in the fields of anthropology, archaeology, historical geography, ecology, garden history, landscape architecture (Jacques, 1995). It is widely used in cultural geography, landscape planning and World Heritage literature with the United Nations Educational, Scientific and Cultural Organisation (UNESCO) listing properties under the cultural landscape category since Tongariro National Park in New Zealand was inscribed in 1993. UNESCO defines cultural landscapes as the cultural properties that represents the "combined works of nature and of man" (UNESCO World Heritage Centre, 2015, p.11).

The European Landscape Convention defines landscape as "a zone or area as perceived by local people or visitors, whose visual features and character are the result of the action of natural and/or cultural (that is, human) factors" (Council of Europe, 2000). It further recognises the important role of landscapes in the well-being of the people and promotes their active participation in decision-making, which leads to greater attachment and protection of landscapes. In other words, it includes the ordinary everyday landscapes and is not limited to remarkable and historic landscapes (Antrop, 2013; Déjeant-Pons, 2006). These definitions reflect the evolving character of landscapes and consider the 
natural and cultural components as a continuum and not separately. However, a natureculture divide exists in the heritage domain; one example of this divide is the two consulting bodies of UNESCO, International Union for Conservation of Nature (IUCN) for nature and International Council on Monuments and Sites (ICOMOS) for culture with different agenda, guidelines and categories.

The complexity of the concept of landscape and cultural landscapes is also reflected in its ambiguity, meanings and the wide range of interpretations that emphasise human presence, activity and social structures in various levels. In particular, there exists a divide between the terminologies environment and landscape (Meier, 2012). Meier (2012) explains the difference where environment stands humans "outside the world looking upon it as a globe, with strict separation between culture and nature, humans and their environment" while in the concept of landscape humans create and become part of their surroundings (p. 507). However, the distinction is blurred with the major conflict in landscape studies between the humanities and the natural sciences (Palang \& Fry, 2003). It mainly arises from two ways of looking at the landscape: visual and cultural approaches (Appleton, 1997). According to Appleton (1997), the visual approach mainly addresses the impact of a landscape on the observer and studies various aspects of landscape perception such as aesthetic appreciation, landscape evaluation, emotional response to scenic experience. Those who take the cultural approach are concerned with the study of landscape as a product of the processes that have impacted the landscape (Appleton, 1997).

Place or sense of place are other terms that have been used to describe a similar concept of lived-in landscapes, however, distinction between place and landscape is blurred. Attachment to a place mostly relates to personal connections like growing up in it, whereas attachments to a landscape is associated with physical features, both natural and human-made and reflects scenic or recreational preferences (Lowenthal, 1978). The concept of place or sense of place reflects the diversity and intensity beyond the physical features and includes the lived-world experiences of people such as hopes, frustrations and confusions of life (Relph, 1976; Tuan, 1974). Relph (1976) argues that an understanding of the diverse meanings of place to people contributes to maintaining existing places and making of new places that are distinct. An insensitivity to this understanding would result in placelessness that he describes as "the weakening of 
distinct and diverse experiences and identities of places" (Relph, 1976, p. 6). Personal experiences and interactions create places and people attach values to them binding them with a sense of place (Tuan, 1974). J.B. Jackson relates sense of place to the vernacular landscape as everyday places where the residents associate themselves not so much with the physical manifestations such as the hills, open spaces or architecture but with daily, weekly or seasonal events that they look forward to and share with family and friends (Jackson, 1995). As a result, the event becomes more significant than the place itself. The value of place and sense of place that creates and maintains distinctive landscapes as well as produces different perspectives of landscapes is incorporated into the concept of landscape adopted in this study.

The recent models to conceptualise landscape include Terkenli's (2001) aspects of landscape model where form (visual), function (experiential) and meaning (cognitive) aspects of landscapes are shaped both inherently and culturally. Soini (2001) provided a similar three-poled model of landscape multi-functionality with landscape qualities (ecological, aesthetic, historical or symbolic), functions (services) and value systems (interaction with landscape). Tress \& Tress (2001) offer a more complex model dimensions of landscape based on five different approaches as a spatial entity, a mental entity, a nexus of nature and culture, a complex system with an added temporal dimension. Based on these concepts, Stephenson (2008) proposes a cultural values model in which landscapes are understood in "an integrated way through considerations of forms, relationships and practices" where some values may be surficial while others are dynamic interactions that create a time-deep embedded landscape (Stephenson, 2008, p. 136). Although these models are useful to analyse the components of landscapes, they assume a homogeneous community and fail to capture the complex interrelationships and overlaps between the landscape components and values that are evolving with societal changes. This research builds on these concepts emphasising the role of people in creating distinctive landscapes with a sense of place.

Recent research has suggested that emphasis on linkages between people and the landscape along with landscape history, drivers of change, landscape values and meaning, and landscape stewardship can improve the understanding of the multiple aspects of the landscape (Plieninger et al., 2015). This growing interest follows the adaptation of the European Landscape Convention in 2000 (Rovai, Andreoli, Gorelli, \& 
Jussila, 2016). These Europe-centred studies fail to take into consideration the complexity of communities and weak institutional structures that are present in developing economies. This research explores the institutional frameworks, such as conservation policies and development pressures, such as urbanisation and globalisation as well as tourism in order to build a holistic concept of landscape (section 2.4).

In summary, the concept of landscape has evolved and currently the interrelationships between nature and culture as essential characteristics of landscapes is widely accepted. However, the approaches to landscape study vary according to the interest and focus on one or the other component. The current study adopts a holistic concept acknowledging and considering the cultural processes and emphasising people and their role in shaping the landscape, which is a continuous process. A holistic approach is at the interface between the different approaches and has not been clarified in the present literature. This study aims to develop new insights in landscape-tourism studies that take into consideration the multiple dimensions of landscape that include the historic context and future changes. In order to achieve this, the next section reviews the literature on the interrelationship between landscape and tourism.

\subsubsection{Landscapes and tourism}

The study of landscapes has continuously evolved with the complexities, diversity and dynamic nature of tourism and landscapes (SK Nepal, 2009). Tourism and geography researchers have studied landscape-tourism interactions and the on-going changes; however, there is a lack of consensus on their approach and interpretation (Terkenli, 2008). Although it is well-established that landscapes are the fundamental assets to various tourist destinations, research approaches to the interactions between landscape and tourism are either tourism-centred or landscape-centred (Stoffelen \& Vanneste, 2015). The tourism-centred approach builds on the commodification of landscape for tourism purposes with divergent views on the natural and cultural aspects of the landscape. On the other hand, the landscape-centred studies focus on the significance of the physical landscape, especially the natural landscape, while recognising the contribution of tourism that can lead to financial means to support and protect them (Buckley, 2003). They also recognise that landscapes are built on layers over time, open 
to multiple interpretations, continuously recreated and contested as social process (Knudsen, Soper, \& Metro-Roland, 2007). In other words, landscapes that tourists visit have layers of local insider and broader outsider meanings that have been studied through different perspectives. Further review of these two approaches follows.

\section{Tourism-centred perspectives}

Early tourism-centred landscape studies were mostly concerned with the classification of the scenic quality of destinations and land use (Aitchison, MacLeod, \& Shaw, 2000). These studies are mainly quantitative and also dominate landscape studies in the environmental sciences (Terkenli, 2008). Terkenli (2008) adds that various models were developed from the 1960s to the 1980s dealing with tourism and landscape but they did not build on previous models and lacked a conceptual or theoretical base. A key research theme in the tourism-centred studies is related to stereotypical and symbolic representations of landscapes for tourism development that are disconnected with the resources of the landscapes and become staged for the purposes of tourist consumption (Terkenli, 2008). This raises the issues of authenticity in tourist destinations, where the tourism industry actively produces selective representations of landscape features through images that are to be promoted (Saarinen, 2008). Such selectivity results in reducing landscapes to sceneries or romanticised notions of landscapes creating place myths that are removed from the local context (Butler, 1998; Daugstad, 2008; JansenVerbeke, 2008; Knudsen, Metro-Roland, Soper, \& Greer, 2008; Ringer, 1998). However, tourists are increasingly seeking landscapes that provide meanings beyond simple observations through experiences and interactions with the residents creating a demand for distinct landscapes (Knudsen et al., 2008).

Cultural tourism is well-established in tourism-centred studies but the research is focused separately on cultural and natural landscape tourism or tourism landscapes and cultural geographies. At many destinations, the natural landscape and cultural landscapes are packaged as two different products, such as national parks and wilderness destinations as natural attractions, and dance, arts, architecture, food, music as cultural heritage with a few select destinations such as the Mongolian steppes, promoted as a cultural landscape (Buckley et al., 2008). 
This nature-based and cultural tourism divide in tourism-centred studies is further divided into rural and urban tourism. Rural tourism and landscapes interconnections are well established, especially with the potential of tourism for economic revival as well as protection of rural landscapes (Oliver \& Jenkins, 2003; Saarinen, 2008). In contrast, studies on tourism are comparatively neglected in urban studies or urban geography despite the contribution of cities as established destinations (Ashworth \& Page, 2011). A key issue in this tourism-city link is the complexity of how much change can be attributed to tourism and non-tourism activities in urban environments (Wall \& Mathieson, 2006).

\section{Landscape-centred perspectives}

While most landscape-centred studies emphasise the physical characteristics of the landscape, contrasting interpretations, mainly from social geographers, exist. Stoffelen and Vanneste (2015) cite the example of geotourism, where contrasting interpretations between geological/geomorphological and geographical exists. An emerging tourism niche, one definition of geotourism is "a form of natural area tourism that specifically focuses on geology and landscape. It promotes tourism to geosites and the conservation of geo-diversity and an understanding of earth sciences through appreciation and learning" (Dowling \& Newsome, 2010, p.3). Geotourism has also been adopted by transnational agencies such as Unesco's geoparks that are "living, working landscapes where science and local communities engage in a mutually beneficial way" (UNESCO, 2015). Although these landscape interpretations are more holistic and attempt to take into consideration the cultural and socio-economic contexts, they mainly focus on the tangible physical features (Stoffelen \& Vanneste, 2015).

Another landscape-centred approach is the mainly quantitative methods taken by ecologists that perceive landscapes as formal structures. An example is the concept of ecosystem services that natural systems provide benefits that support human well-being (Costanza et al., 2017; Plieninger, van der Horst, Schleyer, \& Bieling, 2014; Willis, 2015). In a recent article looking back at twenty years of ecosystem services history, Costanza et al. (2017) state that while ecosystem services recognise the dependence of human well-being on nature, as an integral part of nature, they use natural resources for existence and hence their survival depends on nature, making humans and nature 
interdependent. This view aligns with the holistic concept of landscape, however the social and cultural capitals are marginal.

Cultural ecosystem services (CES) is one of the four broad categories of ecosystem services that address the non-material benefits through "spiritual enrichment, cognitive development, reflection, recreation, and aesthetic experiences" (Millennium Ecosystem Assessment, 2005, p. 40). The existing literature emphasises the quantifiable attributes of CES such as recreation, ecotourism, cultural heritage and educational values and is mainly focused on the natural landscape (Milcu, Hanspach, Abson, \& Fischer, 2013; Simmons, 2013; Willis, 2015). However, studies have demonstrated both material and non-material benefits are significant to residents and participatory methods are key to management and evaluation of their benefits to human well-being (Fagerholm, Käyhkö, Ndumbaro, \& Khamis, 2012; Smith \& Ram, 2017). Smith and Ram's (2017) study of the benefits of CES for tourists demonstrates the close connections between the concepts of landscapes and CES and points out the need for further studies. Although CES studies have identified built landscape as an important component, most studies are focused on natural components and the well-being of the people.

Meanwhile, architects and planners use tools such as Landscape Character Assessment (LCA) to understand the on-going changes and base their analysis on the ways that landscapes are structured by humans (Swanwick, 2009; Tveit, Sang, \& Fry, 2006). Other frameworks include the Scenic Beauty Estimation (SBE) developed by the US Forestry Department and applied in forestry planning and Visual Resource Management (VRM) developed by the Bureau of Land Management to maintain and enhance scenic quality of public lands (Tveit et al., 2006). These frameworks are mostly limited to evaluating visual characteristics and quality with different overlapping concepts and terminologies. Although these frameworks combine both subjective and objective approaches, they are limited to physical aspects of landscape and are not linked to tourism.

This thesis bridges the gap between tourism-centred and landscape-centred approaches and sometimes contradictory interpretations of the interactions between tourism and landscapes. In order to achieve this, this research positions itself by interpreting landscape as a holistic entity, where natural, cultural, social and economic dimensions interact, integrate and overlap (Antrop, 2006; Jansen-Verbeke, 2008; Stoffelen \& 
Vanneste, 2015). Landscapes are no longer "spatially enclosed, bound and tied to a restricted notion of locality" (Terkenli, 2005, p.175) and attachments and meaning of landscapes are equally significant besides the scenic satisfaction (Lowenthal, 1978). The economic potential of tourism can drive landscape changes that conflict with the local perspectives of landscape that have meanings beyond the physical (Palmer, 2014; Rojo, Vacas Álvarez, Alcántara, Díaz, \& Pino, 2015). The potential growth of tourism to become a vehicle of change in the landscape necessitates the understanding of the interconnections of landscape and tourism, including the different perspectives of residents and tourists.

\subsubsection{Different landscape perceptions: residents and tourists}

Studies have found significant differences between the perceptions of residents and tourists regarding landscapes (Palmer, 2014; Stefanou, 2000; Urry, 2002). There are also multiple interpretations of the same landscape within these groups as each individual interprets their landscape differently based on their own experience, worldview, daily lives, and class structure (Palmer, 2014). Views may also vary within the same group according to age, generation, gender, background, ties to place and region (Guachalla, 2018; Palmer, 2014; Petrzelka, Krannich, Brehm, \& Trentelman, 2005). However, there are similarities in reading and interpreting landscapes within social groups with shared culture, history or knowledge (Knudsen et al., 2008). While residents and tourists both share similar perceptions, for example of landscape characteristics, their meanings and significance may differ (Kianicka, Buchecker, Hunziker, \& Müller-Böker, 2006). Tourists' perceptions are built upon their experiential interpretations drawing from other texts, personal experiences and social dialogue prior to the visit in anticipation of the visit, the experience itself and the subsequent reflection (Terkenli, 2005). For locals, the priority is to modernise and break from the past, while the government and nongovernment sectors plan for continuity of traditional landscapes for wider interests (Terkenli, 2001). For example, the Hellenic Organization of Tourism promoted Greece as a tourist destination through images of the Aegean landscapes as the land "chosen by the Gods", while for the locals, it is the quintessential representation of home, which often translates to insularity and underdevelopment (Terkenli, 2001). Residents' desires 
for economic development may conflict with tourists' preference for conserved landscape for their recreational needs (Kianicka et al., 2006).

For the residents, the land is interwoven with their culture and way of life. As the residents are in the landscape and familiar with the landscape, the landscape tends to become ordinary. Their immediate landscapes may hold little interest in their everyday lives and merely frame the context for their daily chores with occasional memories and reflections without much profound impact. However, they may provide brief experiences of topophilia giving joy, ecstasy, awe or despair when vision becomes selective, seeing only the perfections and blocking out the everyday ugliness (Relph, 1976). Landscapes also face modifications leading to the destruction of distinctive characteristics because the residents regard them as too ordinary, out-dated and inadequate for contemporary use, hence not worthy of preservation (Knapp, 1992).

On the other hand, when one is unfamiliar with the landscape the visual experience becomes profound, which allows tourists to appreciate the scenery (Daugstad, 2008). It may not be possible for the tourists to understand the many layers of meanings and stories within a landscape and hence they are more focused on the natural and aesthetic aspects (Knudsen et al., 2008). Lacking depth of knowledge of the landscape, they are rarely connected with the people who created them but rather perpetuate the images that have been projected and promoted by different agencies.

Contested perceptions, especially between the residents and tourists may lead to negotiations resulting in changes in the landscape (Daugstad, 2008). Rural tourism is an example where landscape perceptions are negotiated between residents and tourists resulting in physically and aesthetically changed landscape. Landscapes that are restored for their visual characteristics as pure nature for tourism purposes often neglects the imprints of farming activities which is a major asset (Daugstad, 2008). Vinge \& Flø's (2015) study in Norway demonstrated that for some tourists, abandonment of agricultural land leading to afforestation and monotonous landscapes are associated with stressful modern life and not aesthetically pleasing. This study also found both older and younger tourists showed a strong sense of nostalgia for agricultural landscapes of the past that symbolised manual labour and something morally good (Vinge \& Flø, 2015). This indicates that tourists are also looking for historical context in the landscape. While 
tourists preferred agricultural landscape that represented the life of farmers in Norway (Vinge \& Flø, 2015), research in Taiwan found tourists preferred landscapes designed for tourism purposes that were well maintained compared to farmlands that were organic (Huang, 2013). Personality traits such as actively or passively exploring the landscapes and the extent of control they have while exploring influences tourist perceptions (Uusitalo, 2010). Studies have also proved that independent travellers are more aware of their surroundings and spatially oriented compared to guided tourists without previous knowledge of the area (Pearce, 1977; Young, 1999).

There are also cross-cultural differences in assessing landscapes and travel culture (Mackay \& Fesenmaier, 2000). Mackay and Fesenmaier (2000) study found eastern cultures were more likely to be concerned about a harmonious relationship with nature with regard to human relationship with nature than western cultures. Unlike the traditional western tourists challenging themselves while enjoying nature, a new group of tourists, mostly from Asian countries is more hedonistic and prefer to enjoy nature in comfort eating sumptuously, which constitutes part of their travelling experience (Han, 2006). In addition, due to the high competition and stress at work and society, urban travellers seek comfort and relaxation resisting activities that require physical or mental energy (Burch, 1969; Han, 2006). Local authorities and the tourism industry in their haste to cater to this new rapidly growing group of tourists that can drastically transform traditional landscapes with large accommodations and modern facilities.

Researchers from different fields have studied perceptions of residents and tourists on a variety of landscape related themes such as sense of place (Davenport \& Anderson, 2005), visual aesthetics (Kalivoda et al., 2014), cultural ecosystem services (Tekken et al., 2017; Zoderer et al., 2016), rural landscape (Carneiro et al., 2015), and agricultural landscape (Grammatikopoulou et al., 2012; Pouta, Grammatikopoulou, Hurme, Soini, \& Uusitalo, 2014). Studies have also demonstrated the relevance of built landscape and local culture in the overall experience of landscapes for tourists (Carneiro et al., 2015; Krausler \& Pröbstl-haider, 2016; Van Zanten, Verburg, Koetse, \& Van Beukering, 2014). The current study adds to this knowledge by studying the perceptions of the residents and tourists regarding landscape that includes the visual and non-visual, especially the meanings and values attached. 
In summary, this research views landscape as a synthesising and integrating concept that takes into consideration the dynamic interaction between the natural processes and human activity. The background of the people, their motivations and histories are linked with the process of perception and experience of the landscapes (Kaplan \& Herbert, 1987; Kianicka et al., 2006; Uusitalo, 2010). For the residents, the landscape as their home is associated with a myriad of aspects that includes, relationships with other people, events, memories along with the physical manifestations. People, especially the farmers, as custodians of landscape are important for tourists seeking authentic rural life and they appreciate landscapes which have evidence of a distinctive history (Daugstad, 2008; Kianicka et al., 2006; Vinge \& Flø, 2015). This research emphasises the role of people in their landscapes and examines changing landscape and landscape aesthetics from the perspectives of the residents and tourists.

\subsection{PERCEPTIONS OF LANDSCAPE AESTHETICS}

As a branch of philosophy, aesthetics as the study of sensory or sensory-emotional values (Knudsen, Metro-Roland, \& Rickly, 2015) has its foundations in nature and people in addition to its links to ethics and morals (Ramsay, 2015). Although the origins of aesthetics in the western approach mainly identifies with art, the appreciation of landscape having aesthetic value is increasing (Ramsay, 2015) with the relationship between tourism and landscape aesthetics attracting attention (Knudsen et al., 2015). As landscapes are not static, meanings are drawn to give rise to aesthetic values, the understanding and interpretation of which occurs over time. When people experience landscape, the aesthetic values are expressed in a variety of sensations related to harmony, diversity and beauty but are also influenced by the observer's background and environmental conditions. However, visual perception is also significant because people tend to change landscapes that are perceived as undistinguished and protect those that are regarded as aesthetically pleasing (Daniel, 2001; Gobster, Nassauer, Daniel, \& Fry, 2007; Zube, Sell, \& Taylor, 1982).

This section first reviews the different approaches to landscape aesthetics, followed by the relationship between tourism and perception of landscape aesthetics. 


\subsubsection{Approaches to landscape aesthetics}

Landscape aesthetics, as one of the main fields of aesthetics that examined philosophical issues beyond the art world, emerged in the second half of the twentieth century (Carlson, 2005). The early works emerged from the fascination of the natural world and landscape was viewed distanced from the everyday lives. This theory of disinterestedness was the foundation for the conceptualisation of nature as the beautiful such as the European gardens and cultivated landscapes, the sublime that evolved awe and even terror, such as mountains and wilderness, and the picturesque that fell in-between the beautiful and the sublime to include the complexities, irregularities and vibrancy of nature (Carlson, 2016). Of the three, the picturesque gained dominance in later studies, especially in landscape design and tourism, providing an aesthetic ideal for destinations such as the English Lake District (Carlson, 2016; Ramsay, 2015). The concept of the picturesque extended to the built environment, however, it was exclusively visual appreciation, such as views of the countryside with cottages, glorifying the ruins while ignoring the people (Berleant $\&$ Carlson, 2007).

Within the field of landscape aesthetics two theories are widely cited, Appleton's (1975) prospect-refuge theory and Kaplan and Kaplan's (1989) information-processing theory (Huang, 2013; Tveit et al., 2006). Appleton's (1975) prospect-refuge theory positions landscape aesthetics as a dimension of human survival and hence preferences reflect the need to survive and thrive in an environment that offers both prospect and refuge, allowing the possibility to "see without being seen" (p. 66). Kaplan and Kaplan's (1989) information-processing theory is based on human need for information and the ability to process it for survival. This theory maintains that landscapes with easily distinguishable characteristics are preferred by natural selection and the genetic basis for such preference still exists in people today. In this approach, innate human characteristics of people direct their landscape preferences.

Lothian (1999) identifies two paradoxical paradigms researchers have applied in assessing landscape aesthetics. One approach posits that landscapes have inherent physical qualities that can be evaluated and establishes assumptions that some characteristics such as mountains and rivers have higher qualities. This approach assumes landscape to be a quality present in the scenery and is used by the tourism industry to 
promote destinations as places to see, experience and enjoy. The alternative and more recent subjectivist approach considers landscape aesthetics as a social construct that is perceived and interpreted through individual memories, associations, imagination and symbolism that it evokes at the particular time (Lothian, 1999). Bourassa (1990, p.788) attempts to resolve this conflict between what he terms "biological and cultural explanations of aesthetic behaviour" by proposing a tripartite paradigm that combines the biological, cultural and personal bases for landscape aesthetics. He proposes this framework would "admit the importance of biological motivation while at the same time respecting the uniqueness of culture and the significance of personal creativity and idiosyncrasy" (Bourassa, 1990, p.790).

The concerns of environmental degradation renewed the interest in landscape aesthetics at the end of the twentieth century. Critics argued earlier studies focussing on formal properties of landscape assessment influenced by the picturesque and scenic beauty did not address other expressive aesthetic qualities (Carlson, 2016). In response, Ronald Hepburn (1966) laid the foundation for a new paradigm that links our understanding of nature and the significance of our aesthetic experience that is emotional and cognitive (Carlson, 2005; N. A. Hall, 2014). Berleant (2005) extends this notion and associates aesthetic values with human experience and relationships as social aesthetics with people and their everyday life at the centre of the environment. Everyday aesthetics goes beyond appreciation of the special or sublime experiences to permeate every aspect of everyday life that in turn are constructed by our perceptions of aesthetics (Mandoki, 2007; Saito, 2007). This thesis builds on this premise that everyday life is significant in people's perception of landscape aesthetics and has implications in landscape change (Berleant, 2005a; Saito, 2007).

Everyday aesthetics goes beyond the study of the quotidian objects and experience. It is the relationship between the everyday objects and experiencing those objects that makes the object and/or the experience aesthetically pleasing (Leddy, 2005). Berleant (2005) believes several conditions need to be met or combined for aesthetic experiences to occur in everyday lives. These include suspending judgement and believing that aesthetic experience exists to have an aesthetic experience in any situation and being fully aware to perceive it using all senses, where there is no separation between the objects but a continuous relationship between the objects and the experience. Berleant uses the term 
aesthetic engagement, where four main components, the appreciator (people), the object of appreciation, the act that brings the object to be experienced and the factors that activate the situation, interconnect to provide aesthetic experience (Berleant, 2017). For Berleant, the reciprocal relationship between people and objects and conditions that we live in necessitates landscape aesthetics to be understood in relation to humans. For example, buildings are not only physical objects but organise the surrounding environment and neighbourhoods as places of activity that determine the movements and activities around them. This transforms the buildings that are an everyday part of life into a complex social organisation that engages multiple senses for an aesthetic experience (Berleant, 2005b).

Everyday aesthetics where people constantly make judgements about their surrounding environment is dependent on our attitudes and subsequent actions, negative or positive, regarding them. Everyday aesthetics may be present in trivial, insignificant and innocuous objects, however, their prevalence in everyday lives leads to consequences that go beyond our daily life and affect the state of our society and the world (Saito, 2007). In today's style conscious society, our purchasing decisions are influenced by our aesthetic tastes, aspirations and expectations as well as the marketing of the products and perceived status of the product. For example, salvaged or recycled objects (such as architectural elements or furniture) made of rare or other types of wood are mainly reused as decorative objects rather than being used as the building parts for which they were originally intended (Saito, 2007). Although individual decisions on everyday aesthetics seem inconsequential, their collective and cumulative ramifications on the overall landscape may change not only the immediate landscapes but impact landscapes in faraway countries (e.g. the destruction of rainforests for rare wood).

\subsubsection{Perceptions of landscape aesthetics and tourism}

Landscapes are multi-sensory, they surround the observer with the sounds, weather, light and shadow, smell, flora and fauna and other people. They change as we move through them, "each step, each turn of the head, engages new vistas" (Lowenthal, 1978, p.375) and thus our perception changes with our interaction at the given moment and circumstances. Researchers have studied this complex relationship between landscapes 
aesthetics and people across a wide range of disciplines and used the terms attitudes and preferences to evaluate this link (Knudsen et al., 2007). Swanwick (2009, p.63) defines the terms attitude to mean a deeply held mental stance, preference as liking one area of land or landscape better than another and perception as concerned with both sensual (usually visual) responses to landscape and with the way that people attach meaning and value to it.

Two main approaches, expert-based and non-expert based, have been applied in perceiving landscape aesthetics (Daniel, 2001; Molnárová, Skřivanová, Kalivoda, \& Sklenička, 2017; Zube et al., 1982). While both approaches accept that landscape quality derives from the interaction between the landscape and the viewer, they differ in the significance of the landscape and viewed components (Daniel, 2001). In other words, the expert-based approach assumes that trained professionals are capable of objectively quantifying aesthetic characteristics of landscape and does not take into consideration the cultural conventions of people that is the focus of the non-expert or perception-based approaches. The existing work is mostly the expert-based assessment of landscape with limited research that considers the aspirations of residents or the expectations of the tourists within the criteria for landscape aesthetics. However, both expert-based and perception based approaches mostly address the visual aesthetic quality of landscapes and the experiential and sensory perceptions or cognitive interpretations are not clear (Daniel, 2001).

The expert-based approach assumes aesthetic qualities to be independent of the observer and those living in the landscape. The selective and romanticised representation can potentially alienate the local communities that have different meanings and attachments to the landscape (Daugstad, 2008; Stoffelen \& Vanneste, 2015; Terkenli, 2002). This may also lead to promoting one aspect of landscape in preference of another and neglecting narratives that may hold significance to one group (Buckley et al., 2008). This approach examines identifiable and quantifiable visual aesthetic characteristics on the basis of the experience of the experts and defined criteria that are grounded in general methodologies (Molnárová et al., 2017). In addition, criteria to evaluate aesthetics are mostly divided into natural and cultural elements (Ryan, 2002). 
While experts seek value in the material and the physical, for non-experts, aesthetic values reflect contemporary development and societal values (Gifford, Hine, MullerClemm, Shaw, \& Gijford, 2002; Palmer, 2014). The non-expert or perception-based approach takes a broader public view of landscape as a social construct and products of the perceptions of people (Lothian, 1999). In this approach landscape characteristics are used to stimulate non-visual senses such as the auditory and tactile in addition to the visual (Daniel, 2001). The perception-based approach is usually qualitative providing deeper knowledge beyond categorisation of visual aesthetics to include meanings and attachment, sense of place, memories, significances (historical, cultural, social) as well as obligations and values (Daniel, 2001). This approach emphasises the responses of the human viewer, while acknowledging the inherent physical qualities of landscapes.

In addition, most studies are based in western perspectives, conducted in or by western scholars. Western scholars' view of the eastern concepts and relationships with nature as biocentric is also narrowly defined, where east constitutes the non-western other and the complex and inherently different religious traditions are grouped together (Guha, 1997). The spiritual essence of the human-nature relationships and their knowledge of the natural environment in the east are products of the working in and farming the land. In the developing nations, there is an added responsibility for the landscape to provide opportunities for and contribute towards local development (Han, 2006). This creates conflicts between the proponents of conservation, the residents, and the local authorities under pressure from developers.

Although there is no conclusive evidence of preference and attitude towards landscapes a number of factors such as age, social and economic status, ethnic origin, familiarity, place of upbringing and residence, particularly urban or rural, and environmental value orientations influence perceptions of landscapes (Kaltenborn \& Bjerke, 2002; Swanwick, 2009). There is also a general preference of nature over urban environments for human well-being that has also directed the designs of urban parks (Parsons, 1991). Researchers have also established that different perceptions of landscape aesthetics that can have complementary or contradictory implications for management and the overall sustainability of landscapes (Gobster et al., 2007; Parsons \& Daniel, 2002). In addition, studies demonstrate that both visual and non-visual aesthetics influence human perceptions and preferences (Bourassa, 1988; Howley, 2011; Jorgensen, 2011; Parsons 
\& Daniel, 2002). The perceptions and preferences further lead to emotional place attachments leading to implications for local and regional planning (Brown \& Raymond, 2007; Parsons \& Daniel, 2002).

Research on residents' preferences on landscapes aesthetics, such as managed urban forests underpins the value of the participatory approach in planning and successful management of landscape (Tyrväinen, Silvennoinen, \& Kolehmainen, 2003). However, the available research focuses on specific landscape components, such as the aesthetic values of forests for recreational uses, agricultural landscapes and forest cover and does not integrate the built landscape into the larger setting. Although visual aesthetics and public preferences are encouraged for agricultural or forest landscape management (Krause, 2001), research on the aesthetic values of the built landscape is lacking and fails to take into account the changing architectural styles and settlement patterns. This may be due to the associated impact of the change in the natural environment bundled together with pertinent issues such as climate change and agricultural productivity or spirituality, while the changing building patterns are attributed to the process of westernisation or development.

The academic literature has warned that the decline in environmental quality would result in a decline in the aesthetic appeal for tourists (Pons, Crang, \& Travlou, 2009). However, tourism in coastal resorts in the Mediterranean has grown steadily despite the allegedly degradation of the environment (Caletrío, 2011). Caletrío (2011) attributes this paradox to the tendency of academia to focus on specific cases without considering the voices of the tourists that are more complex with varying tolerances to landscape change. In his study in Costa Blanca in Spain, tourists seeking an escape from the pressures of urban life in the natural and healthy environment resented the changing landscapes but had formed strong attachments and loyalty to return every year. Recently, some studies have examined the significance of the overall aesthetic experience of landscapes for the tourists and their influence on the preservation or transformation of it (Daniel et al., 2012; Kalivoda et al., 2014; Kirillova, Fu, Lehto, \& Cai, 2014; Kirillova \& Lehto, 2015; Maitland \& Smith, 2009). The scope of art and aesthetics has also transferred from formal spaces such as museums, concert halls and theatres that were removed from everyday life to street and city plazas that are part of public life, thus bringing residents and tourists together (Wang, Niu, Lu, \& Qian, 2015). Limited studies such as Berleant (2005) 
broadens the scope to include not only the natural and the built but also people in the environment and the reciprocity of the aesthetic experience between the perceivers and the environment. This thesis builds on Berleant's concept that neither the natural or human environment stands alone with people embedded in the landscape and their relationships, perceptions and experience are part of the landscape.

In summary, most studies on perceptions of landscape aesthetics are limited to visual perceptions and the examination of the multi-sensory experiences that take place in different contexts and the non-visual aspects of tourism is still under-researched (Jacobsen, 2007; Janusz, Six, \& Vanneste, 2017). This research draws from the perspectives of both residents and tourists on the changing landscapes where people live and work. This research takes a multi-sensory approach goes beyond the visual to include the community as part of the landscape. As society and landscapes are continuously transforming, an understanding of the changes is essential. The next section reviews the various internal and external forces that are driving landscape changes.

\subsection{DRIVERS OF CHANGING LANDSCAPES}

Change in landscapes usually involves the reorganisation of existing structures to optimise their functions according to new demands and thus are evaluated by people as improvement or deterioration of the previous or existing state. They may be conflicting depending on a particular view or in relation to achieving a particular goal. For example, altering architectural characters that are mostly driven by tourism may create cultural conflicts in the functions of sacred spaces (Wall, 1998) or the addition of a large picture window to provide a room with a view may alter the unique architectural character (SK Nepal, 2005). The conflicts between different social groups often go beyond the aesthetics to differing visions of the future and power balance in decision making processes regarding local development (Palmer, 2014).

Change is always related to the time factor and is comparative between two different time situations. It is also closely related and dependent on the rate/frequency and magnitude of change, which may be periodic or random, temporary or irreversible (Antrop, 1998). Although individual components may change, or even disappear, the landscape as a whole does not necessarily appear to change in the same way or rate. Therefore, a holistic 
approach to landscape is necessary that states that the whole is more than the sum of its component parts (Antrop, 1998). The intrinsic character of landscapes to adapt to the changing environment is a natural process, which is usually a slow process but can be abrupt due to natural disasters. For example, the April 2015 earthquake in Nepal not only flattened settlements but the subsequent landslide swept away forested areas that will take many years to replace. On the other hand, changes due to human activities are usually consciously planned to achieve predetermined goals. The rate of change is important as it manifests in wide-ranging impacts that occur at different scales and builds up resilience distorting perceptions of change. While sudden and large changes and their impacts are easily visible, the impacts of slow and moderate change may be gradual and thus, indiscernible. These slow variables include changes in the ecosystem with the gradual extinction of species in response to conditions such as climate change and cultural shifts due to globalization that may take a generation to become visible (Lew, 2014).

Landscape change has mostly been documented in maps focussing on documentation and analysis of spatial patterns with less attention to the processes of change (Hersperger \& Bürgi, 2009). A sound understanding of the drivers of change is required to understand landscape change. In order to study the changing landscapes, this section reviews the literature on the key drivers of change focusing on conservation policies, urbanisation and globalisation, and tourism. Distinct landscapes are protected for conservation for future generations yet are also tourist attractions and under pressure from development. This section first reviews the literature on the interrelationships between conservation policies and landscape (section 2.4.1), followed by a review of development processes such as urbanisation and globalisation on the landscape (section 2.4.2). Next, the relationship between tourism and landscape change is reviewed (section 2.4.1) before conclusions are drawn.

\subsubsection{Conservation policies and landscapes}

Both natural and cultural landscapes have been conserved, restored and modified for and by tourism. In the west, natural areas that were primarily wilderness or hunting areas were preserved for recreational and tourism purposes with the intent to protect the 
ecology. Historic areas and villages have also been preserved and promoted as attractions for cultural exploration. However, focus on highly valued landscapes potentially crowd a selected few landscapes and blind people to the ordinary and familiar everyday landscapes resulting in irreversible landscape changes and threaten local identities (Lowenthal, 1978). Pressure for economic development puts landscape resources and conservation efforts at risk in preference to tourism development (Han, 2006). Landscapes may be protected or threatened by conflicts between planners from conservation or development approaches. This conflict is particularly present in developing countries where adequate planning and implementation mechanisms are weak.

Conservation policies also tend to emphasise one aspect of the landscape, often negotiating other aspects and affecting the communities living within it (Eagles \& McCool, 2002). For example, when conservation policies focus on the natural landscape, biodiversity may be protected, however, the lives of people living and working may be transformed (Guha, 1997; Thing, Jones, \& Jones, 2017). The role of protected areas for biodiversity conservation and the well-being of people is irrefutable, however, their costs for local people, especially in subsistence-based rural communities in developing countries may be substantial (Guha, 1997; Han, 2006). Protected areas are often seen as a playground for foreigners and wealthy urban residents and resented when benefits are not shared with the local communities (Adams \& Infield, 2003; Guha, 1997).

The emergence of the interest in wilderness and the preservation of unspoilt nature was the result of the increasing urban population seeking new amenities and experiences, to enjoy nature away from modern everyday lives (Guha, 1997). In the US, National Parks were established with the concept of wilderness defined in the Wilderness Act of 1964 as "an area where the earth and its community of life are untrammelled by man, where man himself is a visitor who does not remain" (USFS, 1964, p.1). This definition effectively divides human interaction with nature, a concept predominantly based in western societies (Eagles \& McCool, 2002), challenged strongly by Ramachandra Guha. Guha (1997) criticised this concept arguing that preserving natural sites for the rich tourists effectively took the resources from the poor locals who have been depending on them for generations. He provides the example of India, where rural populations have been imposed with externally driven projects such as the internationally acclaimed 
Project Tiger that places the interests of the tigers ahead of the villagers living and utilising the resources sustainably for generations.

The imitation of western conservation policies of wilderness and pristine nature in nonwestern countries has resulted in conflicts over the use of the park's resources and unprecedented removal of villagers and settlements (Cochrane, 2012; Guha, 1997; Han, 2006; Thing et al., 2017). This process of removing the evidence of human presence, albeit thousands of years of cultivation and settlement, in order to return to the pristine past that has not existed in modern history disconnects people who are historically and culturally embedded in and dependent on the natural resources for their livelihood (Thing et al., 2017). This also creates conflicts between local authorities and residents, when the concept of international standards that are based in the western philosophies and context are taken as more advanced and civilised putting traditional landscapes and technology in danger of rejection for the fear of appearing uncivilised (Han, 2006; Honggang \& Chaozhi, 2012). Furthermore, restricting traditional access to natural resources such as gathering wood for cooking and warming houses, not only creates conflicts between the management and residents but also hinders conservation efforts (Eagles \& McCool, 2002; Ghimire \& Pimbert, 2009).

While the focus of natural landscape protection has shifted from resource conservation to participatory processes, park planning and management frameworks have also shifted their orientation from ecology to social values (Frost \& Hall, 2012). Recent planning approaches have attempted to address the significance of the link between the protected areas and people with local participation in decision making processes and benefit distribution. Studies have shown that while resentments and resident-management/local authority conflicts have not contributed to conservation, benefits such as social services, agricultural improvements and tourism revenue sharing have been seen as incentives for conservation (Spiteri \& SK Nepal, 2008). However, in some cases, although the conservation paradigm has shifted from earlier protectionist focus towards a more participatory approach, the old conservation thinking still persists (Thing et al., 2017). In the conservation of natural heritage, the prevailing concept of parks and conservation areas has not been able to view the landscape holistically embedding the people and their culture fully into the landscape. 
On the other hand, conservation of built cultural heritage is a complex and interdisciplinary field that needs to address the different narratives and memories of significant values in dynamic communities (Amar, 2017). Traditionally, conservation of built landscape focussed on restoration and preservation of buildings and monuments with historic, architectural, memorial and national significance. In recent decades, built heritage increasingly encompasses the vernacular and everyday landscapes as well as their associated intangible values. However, there exists a dichotomy between preserving the past for intrinsic values, historicity or nostalgia and the need for development in response to changing societal values (Nasser, 2003).

The built environment within the landscape is important documentary evidence of change that is not taken into consideration in modern landscape studies (Howley, 2011; Stephenson, 2008). The few studies that have looked into the changing architectural characteristics are limited to seaside resort towns (Palmer, 2014) and heritage towns (Avieli, 2015). Those who study buildings tend to detach them from the surroundings and hence do not link the influence of the context on the built environment (Dyer, 2009). According to Harrill \& Potts (2003), these studies are usually urban sites detached from natural landscapes or villages situated within picturesque natural landscapes with high premium on the conservation of the physical and symbolic heritage values (Scott, 2010) and strict regulations justified by strong place-branding (Assche \& Lo, 2011).

Conservation of built landscape is multidimensional and goes beyond building fabric to include the settlement pattern, surrounding natural areas and the vista as well as the people who live and use the services (Orbasli, 2000). However, there exists a divide between rural and urban landscapes where rural landscapes are taken as more natural and traditional, while urban landscapes are considered cultural (Watson, 2014). Urban conservation movement started in Europe in opposition to development and large scale destruction of traditional physical fabric and the dislocation of social groups (Appleyard, 1979). Interestingly, it was also growing urbanisation and the degradation of urban life that led the movement to preserve the rural landscapes (DuPuis, 2006). The resulting rural landscapes are viewed as idyllic and places of leisure rather than working, where the resident farmers become an intrusion (DuPuis, 2006) and urban centres have become gentrified (Orbasli, 2000). This creates conflicts when landscape conservation policies are seen to be driven by the interests of one group over another. When conflicts between 
commercial values of tourism and heritage conservation arises, tourism becomes dominant as the dependence of the local economy on tourism increases (Nasser, 2003). The literature on heritage and tourism also highlights this somewhat awkward relationship with two opposing views. On one hand, the cultural heritage sector sees conflicting interests with tourism where heritage values are compromised for commercial gain (Avieli, 2015; Harrison \& Hitchcock, 2005; Joshi, 2014; Urry, 2002) and communities are adversely affected (Harrill \& Potts, 2003). On the other side, there are suggestions of mutual benefits where tourism reconnects people to their identity and national history. In developing countries, with pressing demands of health, education, sanitation, budget restrictions and weak legislation, heritage conservation becomes a product for tourism development (Orbasli, 2000). The situation is exacerbated when villages and towns are declared national or world heritage with strict restrictions imposed that are guided by government policies targeted at promoting tourism (Avieli, 2015).

In summary, policies initiated to conserve the natural or cultural landscapes create demands that makes it unaffordable to the local community, displacing them for tourism investors and second-home markets (Goulding et al., 2014; Kaltenborn, Andersen, Nellemann, Bjerke, \& Thrane, 2008; Phillips, 2003). There is increasing recognition that landscapes are dynamic processes that include both natural and cultural values. It is also acknowledging the crucial role of the indigenous community and knowledge to sustainably manage the resources. The division of culture and nature may have detrimental effects, severing the historic linkages between nature and people. The consequences of an emphasis on either the natural environment or the cultural components and their separation sacrifices one in preference of the other. On the other hand, tourism provides economic opportunities that can contribute to landscape conservation. The significance of tourism in changing and conserving landscapes requires an understanding of the context as well as other drivers of change.

\subsubsection{Urbanisation, globalisation and landscape change}

The landscape, both natural and built continually transforms under the influence of local, regional and international economic and political shifts as well as technology and climatic conditions. The physical fabric of the landscape changes to accommodate the 
needs of the residents with increased number or size of the buildings, structures and spaces (Phillips, 2003). Similarly, local, regional, or international economy and politics influence and continually change the nature of tourism and impact destinations by increasing or decreasing popularity (Butler, 1995). In addition, the development of new technology in transportation and communications will reduce the perceived distances and increase universal accessibility. This development is bringing remote areas closer to the cities, not only linking the two physically with highways and air connectivity, but also importing and exporting cultures and resources that blend and change the local context (Phillips \& Yannas, 1999; Relph, 1976). Some changes are perceivable such as the growth and variety of businesses, while others may be indiscernible such as the change in local cultures, language, and practices.

Urbanisation is defined by Marc Antrop (2004) as the complex process that transforms the natural or rural landscapes into urban or industrialised lifestyles which is intimately linked to new modes of transportation and mobility. In Europe, the use of automobiles after the Second World War started the urbanisation process transforming rural landscapes that is currently accelerated by globalisation (Antrop, 2004). The changes usually result in generalisation and homogenisation of traditional landscapes that creates mass-produced and standardised structures and materials. The loss of the richness and diversity of the traditional landscapes have resulted in the loss of vista quality (Nohl, 2001) and a sense of mystery (Kaplan \& Kaplan, 1989), replaced by standardised and disconnected landscapes. This loss of distinctive characteristics and cultural significance breaks the continuity with the past (Antrop, 2005) leaving the people in a state of rootlessness in places lacking distinct culture, traditions and landscapes (Relph, 1976).

In recent decades, globalization and the rapid development of transportation have changed landscapes dramatically, especially in the rural settings that had mostly avoided changes due to their remote locations and lack of convenient infrastructure (SK Nepal, 2000a). In the context of rural landscapes, with improved road or air connections, nonnative building materials can be easily imported changing the architectural style of the settlement (Relph, 1976). Road access is an important requirement for development and has proved to contribute significantly to the local economy. However, studies have also demonstrated negative sociocultural impacts such as rapid deforestation, influx of migrants, change in traditional farming techniques, cultivation patterns and types and in 
extreme cases armed conflicts and displacement of indigenous population (Beazley \& Lassoie, 2017; Kreutzmann, 1991). Road construction also becomes a contested issue in rural destinations known for pristine landscapes and adventure tourism such as trekking and mountaineering; on one hand it is seen as a threat to the tourism industry, while it brings additional social benefits such as better access to education and health for the local communities (Beazley \& Lassoie, 2017; Hussain, Fisher, \& Espiner, 2017).

Contemporary scholars have viewed modern developments with caution, while until the early twentieth century, industrial and infrastructure development was welcomed despite the increase in pollution and degradation of the environment. The changes were welcomed for the improved convenience in lifestyle (Antrop, 1998). In recent years, change is not limited to physical improvements and encompasses social, cultural, and economic well-being that are not easily discernible, and more recently with globalisation, these changes are rapid and widespread and visible. On one hand, road access and development in communications is increasing alternative employment opportunities in societies that were primarily based in agriculture. On the other hand, the rejection of farming practices is not only changing landscape but also changing the demographics of rural societies with out-migration to cities or abroad for work. This creates a shortage of labour, which may result in in-migration from other parts and communities or stagnate growth.

The accelerated pace of change in the modern world is also producing a sense of irretrievable loss and increasing nostalgia, leading to protection and preservation of buildings and settlements as heritage centres, where the past is commoditized as part of the heritage industry (Cohen, 1995). The growing scarcity and diminishing attractiveness of natural or authentic attractions has also increased staged or contrived attractions. One extreme is the disneyfication of places combining exotic styles, decorations, history and myth that are devoid of local values. On the other hand, museumisation occurs where places and sites are preserved or reconstructed in an idealised period of history blurring the distinction between the authentic and replica (Relph, 1976). The built landscape transforms to service facilities for the tourism industry, segregating the local community and gentrifying to the extent of disneyfication that blurs the authentic experience (Relph, 1976).Tourists are only temporary visitors, however, changes in the landscape is driven 
by the perceived requirements to modernise and cater to the needs of the tourists and are driven by profit (Weaver, 2009).

\subsubsection{Tourism and landscape change}

Landscapes play a vital role between tourist and destination; however, the tourism industry has been repeatedly criticised as an exploiter of landscapes (Terkenli, 2008). Landscape represents the first medium of contact between the tourist and the place of travel, eventually becoming travellers' memoirs through photographs. As one of the dominant industries of consumption and the world's leading export earner, tourism creates landscapes and cultural industries (Terkenli, 2002). This has also led to landscapes being staged by tourism planning and development for the purpose of tourist consumption. Destinations noted for specific landscapes attract tourism, while the introduction of tourism necessitates facilities to cater for the tourists and inevitably results in changes in the landscape, for example accommodations built specifically for tourists that J.B. Jackson describes as other-directed architecture (Jackson, 1970). Usually these buildings emulate the traditional architecture, mostly borrowing styles and decorations, built specifically for outsiders such as tourists creating other directed places that are detached from local communities (Relph, 1976).

Tourism is not the only driver and factor of change and it becomes impossible to separate the role of tourism from the other forces of change. In addition, tourism is an agent of both landscape preservation and change (Crang, 2006; Wall, 1998). Tourism becomes an integral part of communities and as such, reflects the changes and challenges of global environmental and social changes. The resulting landscapes face a range of changes homogenising the landscape and threatening its local and regional character. The form (buildings, structures, and spaces) of the landscape changes, which in turn has an impact on the tourism industry. As the demand for accommodation rises with the increase in the popularity of a destination, larger structures are built that may not conform to the traditional form or scale. Rapid unplanned expansion results in straining the resources such as water supply, which in turn can build up conflict between the residents and visitors, tourism entrepreneurs and those not directly benefitting from the tourism industry. Increased growth may also re-organize the local governing bodies and attract 
external institutions that may influence the historic traditions and cultural balance. An increase in the number of tourists would also bring in greater cultural exchange, in most cases diluting the cultures of both the host and the visitor. Some changes may be rapid and perceivable, such as the growth of the settlement. However, most changes are slow to manifest themselves, such as the change in the character and culture that require repeat visitors or returning residents to discern.

Terkenli (2002) describes the processes of change as enworldment, unworldment, deworldment, and transworldment, where the break-down of geographical barriers synthesises the distinction between cultures and places (enworldment), leading to the loss of authenticity (unworldment), and commercialisation and objectification (deworldment) and finally rapid turnover and globalisation of landscapes (transworldment). This loss of traditional character and blending of global trends potentially creates places that lack the local distinctiveness and placelessness (Relph, 1976). In addition, tourism businesses are driven by profit-making and their design aesthetics are often guided by the commodification of traditional architecture and culture (Weaver, 2009). This change is usually slow to be perceived and endangers the sense of place for the local residents, while the attractiveness of the destination may decrease for the tourists. As the interdependence of tourism and the destination increases, the distinction between the natural and contrived landscapes become blurred with the nivellation (reducing the level of or levelling, fr.) of attractions, both natural and contrived (Cohen, 1995). Contrived places over time become part of the physical, historical, or cultural environment and a natural destination (Ritzer \& Liska, 1997).

Another recent process that has contributed to the increase in landscape change since the 1990s is the rise in demand for amenity migration in rural and countryside regions (SK Nepal, 2007). This recent movement of people from the urban to rural areas and the consequential change in settlement systems defined as counterurbanization by SK Nepal \& Jamal (2011) is changing the mainly agrarian based rural areas to service-based industries. Established tourist destinations are an attraction for amenity migration due to the available facilities and convenience. This leads to gentrification and the emergence of segregated housing, displacing local communities who can no longer afford to live there due to rising costs of living. 
In the context of increasing cultural homogenisation globally, destinations are also striving to assert their spatial and cultural distinctiveness to compete in the global tourism market (Ringer, 1998). However, for aesthetics to gain importance and validation in landscape management decisions, a demonstration of social and economic contributions to improving human condition is necessary (Zube et al., 1982). The perceptions of the groups such as residents, especially indigenous people that have emotional attachments and traditional practices of conserving the landscape have been overlooked in the decision making processes (Amar, 2017). This results in conflicts between the planners and the residents' perceptions and understandings of the significance of the values and priorities for conservation.

The role of tourism in the transformation of places and its contribution in the preservation of traditional landscapes has been established (Phillips, 2003; SK Nepal, 2005). However, in-depth investigations of processes of change are lacking, and these are vital in developing strategies for planned development. The landscape changes to accommodate the needs of the local residents and tourists potentially results in the increased number or size of the buildings, structures and spaces (Gkoltsiou et al., 2013; SK Nepal, 2005). Studies in seaside towns have indicated the early signs of landscape identity loss as the result of the increased building activities (Gkoltsiou \& Terkenli, 2012; Gkoltsiou et al., 2013; Palmer, 2014). However, these studies have not considered the changes holistically regarding landscape aesthetics, incorporating the natural and built characteristics, sense of place and everyday aesthetics of the landscape that this research aims to address. The impact of the drivers of change on both tourism and landscape form is an on-going process, while tourism and landscape in turn also influence some of the drivers such as the economy, politics, technology, communication, infrastructure, and culture. It may induce some impact on the local micro climate and long-term consequences on the climate, which is beyond the scope of this study.

In summary, the drivers of change are multi-layered arising from internal and external factors in varying scales. The scale and type of change also varies by location, context and perceptions which is driven by internal and external factors that are increasingly becoming homogenised across the globe. Societal transformation is one of the factors of change as well as an outcome. This in turn influences our perceptions of landscape change and aesthetics. Tourism has been used as a vehicle to revive the economies of 
many traditional landscapes that have witnessed human migration from rural to urban regions in developed and developing countries (Graburn, 1995). Tourism has also been a strong factor in new settlement development in Europe, mainly in the coastal areas, and their spatial and temporal development patterns have been well recorded. However, studies of the changes influenced by tourism development in landscapes have been limited, especially outside of the European context (SK Nepal, 2005).

\subsection{LANDSCAPES - CHANGE - PERCEPTIONS: A CONCEPTUAL FRAMEWORK}

Drawing from the preceding literature review, this section presents the conceptual framework of the relationship between landscapes, change and perceptions of landscape aesthetics. This conceptual framework is based on the theories of tourism, landscape, change and perceptions of landscape aesthetics that are constantly changing and the interrelationship between them. As discussed in the above sections, landscapes are constantly changing and the role of tourism in the landscape is complex; it is a key driver of changing landscapes, at the same time a vital component of it. The literature review has also demonstrated that researchers have studied and interpreted the interrelationship between landscape and tourism from different perspectives that are sometimes contradictory. This research builds an integrated approach and landscape is taken as a holistic entity, where the natural, cultural, social and economic dimensions, including tourism, interact, integrate and overlap (Antrop, 2006). In addition, internal and external forces of change constantly act upon landscapes, transforming the landscape and the perceptions of landscape aesthetics. This conceptual framework is developed to address this interrelationship to contribute towards the study of landscape and tourism literature and specifically the perceptions of residents and tourists on landscape aesthetics.

The conceptual framework (Figure 2.1) has been developed to examine the variety of drivers of change with regard to the landscape and landscape aesthetics. Awareness of the drivers of change will better enable destinations to protect their identity, at the same time sustainably manage and build up resilience. The purpose of this framework is to examine the drivers of change that are transforming the landscapes and their aesthetic values, from the perspectives of the residents and tourists. For this research, the emphasis is on the role of the people (residents and tourists) as an integral part of landscape, 
shaping and changing it, and their perceptions on the change and landscape aesthetics. It is also recognised that the residents will live and work in the landscapes and may hold multiple roles within the community, such as a teacher, councillor and business owner, or even work away from the community at times (e.g. guides). On the other hand, the tourists may or may not have prior knowledge of the landscape and will build on their own culture, worldview and knowledge to their perception of landscape aesthetics.

The framework depicts two main components, (i) landscape and (ii) change, that are inter-related and constantly changing on local, national, regional, and international levels. Tourism, in this framework is a continuous phenomenon that impresses upon both the landscape and change. Perceptions, the third component in this framework, is positioned to take an overview of changing landscape, considering the inherent characteristics of the landscape and the forces of change that act upon it along with the individual and collective cultural dimensions of the people.

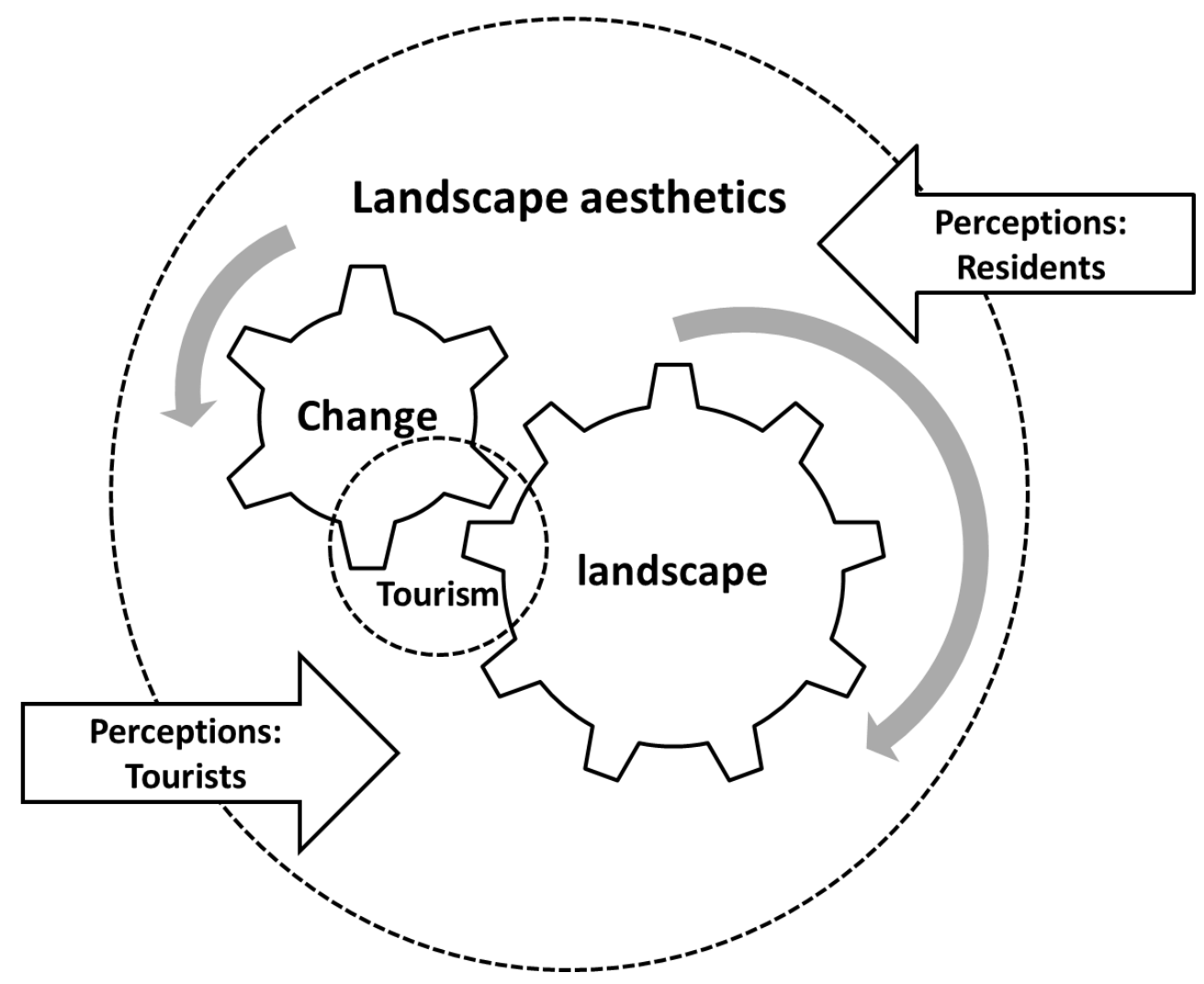

Figure 2-1: Conceptual framework

As stated in the introductory chapter, the concept of landscape in this research incorporates the natural and built environment along with the people living, working and 
interacting within the landscape. Hence, the concept of landscape aesthetics also broadens to include the experiential and the cognitive aspects of the inherent landscape characteristics along with the individual and collective culture of the people. Drawing from the review of the drivers of changing landscapes in section 2.4, change is influenced by internal and external forces. Landscapes play a vital role in attracting tourism, yet tourism becomes a factor and driver of landscape change.

The curved arrows in the framework indicate that landscapes and drivers of change are constantly changing, internally and driven by external forces. As tourism develops, imposing upon the landscapes, they adapt to accommodate the changing needs of tourism as well as the people that live and work within them. Landscapes change to accommodate societal changes that are increasingly becoming influenced by globalisation. This may lead to disintegration of the components within the landscape creating internal and external conflicts. The above literature has shown that landscapes, such as seaside and heritage towns have illustrated the early signs of landscape identity loss as the result of the expansion and increased building activities with the growth of tourism (Avieli, 2015; Gkoltsiou et al., 2013; Palmer, 2014). However, these studies have not considered the perceptions of residents and tourists on landscape aesthetics that this framework aims to address. Residents and tourists are two main groups that influence governments and planners in their decisions and policies regarding landscape changes, and hence their perceptions become vital in landscape protection or development.

Tourism and landscapes are inter-dependent. The tourism industry needs distinctive landscapes as destinations, while places need tourism for economic sustainability, especially those that have limited alternative development potential. As the tourism industry changes from mass tourism to alternate forms, rural and distinctive places will attract increasing numbers of visitors. This increase becomes a vehicle for urbanization and globalization which in turn will boost economic activities, changing landscapes with this rise and fall of local economy (Dyer, 2009; Hoskins, 1953). On the other hand, landscapes also face modifications leading to the destruction of distinctive characteristics because of the residents' perception of landscape aesthetics that regard them as too ordinary, out-dated and inadequate for contemporary use, hence not worthy of preservation (Knapp, 1992). 
The perceptions of the residents and tourists on the changing landscapes and their aesthetic values are the focus in this framework. In this framework, the residents and tourists are inside experiencing the landscape and outside observing it (Figure 2.1). Existing literature demonstrates that residents and tourists may view, approach and experience the landscape and the change differently (Urry, 2002). The implication of differing perceptions on the change and management of landscapes requires this framework to address the perceptions of the changing landscapes from the resident and tourist perceptive.

In summary, drawing from the literature review the conceptual framework for this study is based on the three concepts of landscapes, change and perceptions. The complexity of these three concepts lies in their dynamic, nonlinear and multi-layered interconnectedness. This complexity necessitates a multi-layered interpretative research methodology to address the key research question on the perceptions of the residents and tourists on landscape aesthetics in three different geographic locations in Nepal.

\subsection{TOURISM RESEARCH IN NEPAL: AN OVERVIEW}

This section reviews the literature on tourism development in Nepal and its relationship with landscape, mainly in the protected areas, to provide a context to the case study sites. The literature (prior to 2000) when the primary concern was the impact of tourism on the environment is reviewed first, followed by the shift towards the role of the community in conservation. This trend reflects the global paradigm shift in the management of protected areas from biocentric policies to community participation. This section concludes with a review of the changing landscape and landscape aesthetics in tourist destinations in Nepal.

\subsubsection{Tourism, conservation, and landscape}

Following the focus on mountain and adventure tourism, the literature on tourism in Nepal is also dominated by mountain tourism and ecotourism in conservation areas and national parks. The earlier researchers are mostly European and American scholars and not surprisingly, the early studies focussed on the mountains in the Khumbu or Everest region and the Sherpa people, the indigenous people of the region (Adams, 1992; Fisher, 
1990; Parker, 1993; Pawson, Stanford, Adams, \& Nurbu, 1984). The impact of the growing number of tourists on the natural resources, environment and culture were the key concerns (Adams, 1992; Banskota, 2012; Brown, Turner, Hameed, \& Bateman, 1997; Pandey, Chettri, Kunwar, \& Ghimire, 1995; Pawson et al., 1984; Sparrowhawk \& Holden, 1999; Stevens, 1993b, 1993a; Wells, 1993; Zurick, 1992). However, the impact varied from village to village with new centres emerging such as Namche Bazaar, on the Everest route, with extensive tourist-related constructions with town-like character and some villages retaining their traditional characteristics (Pawson et al., 1984). Although the living conditions of the inhabitants had seen improvements benefiting from the boom in tourism, the mountain region, especially the Everest region was already showing signs of environmental degradation and change in settlement patterns (Stevens, 1993b).

In addition to the impact on the natural environment, potential transformations of the built landscape were also observed even in one of the remotest parts of Nepal, Lo Manthang (Upper Mustang) that was closed to western tourists until 1992 (Shackley, 1994, 1996). Two years after the opening of this region, Shackley (1994) warned that Lo Manthang already exceeded its carrying capacity with minimum benefits to the local community and recommended inscribing Lo Manthang as a World Heritage Site (WHS). In her 1996 study, Shackley reinforces the significance of the built heritage that had been underutilised with tour groups preferring tents to local accommodations limiting the benefits of tourism to the locals. However, more than two decades since the recommendation, debates are continuing regarding the inscription of Lo Manthang as a WHS, especially the conflict between the interests of the experts focused on heritage conservation and the local inhabitants' interest for economic improvements (Chapagain, 2007).

The landscape studies also focused on the mountain regions and concerns were raised in the 1980s regarding widespread deforestation due to tourism and development (Byers, 1987). However, the Byers (1987) study using repeat photography of landscape panoramas from 1955-1963 and contemporary photographs found no widespread deforestation with little change in forests but several distinctive tourist and park related structures such as the airport and a large hotel (Byers, 1987). The scale of the photographs did not allow identification of new buildings of smaller household sizes. 
Another significant study conducted by one of the leading Nepali geographers, late Dr Harka Gurung (2004) also used repeat photographs to examine changes in the landform, land use, and cultural features based on temporal data extending over four decades in Lamjung, his hometown (Gurung, 2004). He used his own repeat photographs taken in 1962, 2000, 2001, 2002 for comparison in addition to analysing aerial photographs (1958 and 1996) and topographical maps (1960 and 2001) and his work is based on personal observations that spanned over four decades with additional interviews. According to Gurung (2004) transportation was the key in the landscape change. The change from mule to vehicular transport and construction of bridges resulted in varying impact on the landscape; the location of bridges created new settlements or gateway communities (Messerschmidt, 1980), but the most significant change was road construction that "opened gashes on hillsides through excavation and affected some forest and cultivated land" (p. 50). Contrary to widespread notion of deforestation in the hills of Nepal, he found an increase of forest land and a marginal increase in cultivated land that he attributes to the shift in population and migration. He concludes "the changing landscape in the central hills is the outcome of the interplay between natural and cultural processes in which the former remains dominant even if the latter seem more apparent" (p.56).

Recently, Nyaupane et. al. (2014) used photo-elicitation interviews to investigate residents' perception of historical changes compared to their current conditions and impact on their daily lives in the Everest region. The changes were mostly perceived as positive due to the improvements in social services and economic growth with some concern regarding impact on local culture (Nyaupane, Lew, \& Tatsugawa, 2014). Although there were concerns for the loss of traditional architecture, the change in the built environment, such as the growth of Namche Bazaar reflects their economic growth and is also perceived positively. This research builds on the methods used in these studies, especially Gurung's use of past and repeat photographs with in-depth interviews and extends the study of landscape change to include the perceptions of landscape aesthetics. 


\subsubsection{Recent research: Conservation, community and tourism}

Recently, there has been a rise in the number of Nepalese scholars and the focus has expanded to include the conservation areas and national parks. The focus is mostly on the Annapurna Conservation Area that is seen as a successful example of local participation in conserving biodiversity using indigenous knowledge and benefit sharing of resources, including tourism (Adhikari \& Fischer, 2011; Baral \& Stern, 2011; Dahal \& SK Nepal, 2016; Ewen, 2007; Gurung, 2008). However, western influenced initiatives in establishing protected areas without proper understanding of the symbolic relationship between the local communities and their traditional ways of environmental protection do not support traditional stewardship (Taylor, 2014). Most studies are again centred on the impact of tourism on the environment and biodiversity conservation and include, management issues (Bajracharya, 2011; Bajracharya \& Dahal, 2008; Baral, Stern, \& Heinen, 2010; Chakraborty, 2010; Daconto \& Sherpa, 2010; Heinen \& Kattel, 1992; Sacareau, 2009; SK Nepal, 2000b, 2000a), energy consumption patterns (SK Nepal, 2008), impact on local employment (Banskota, 2012) and tourist-resident interactions (Hepburn, 2002; Lim, 2008), community participation (Dahal, SK Nepal, \& Schuett, 2014; Gurung, 1993; Gurung, Buckley, Castley, \& Jennings, n.d.; Khadka \& SK Nepal, 2010; Mehta \& Heinen, 2001; Nyaupane, Morais, \& Dowler, 2006; Nyaupane \& Poudel, 2011, 2012; Spiteri \& SK Nepal, 2008; Spoon, 2012), and tour guiding (Poudel \& Nyaupane, 2013; Poudel, Nyaupane, \& Timothy, 2013). Solid waste management is seen as one of the most adverse outcomes of adventure tourism in Nepal, especially in the high mountains (Brown et al., 1997; Guzzella et al., 2016; Kuniyal, 2005). Although most studies have noted the benefits of tourism to the local community through conservation, the two sometimes have conflicting goals (Folmar, 2003). Recent studies have also examined the impact of climate change in the high mountain and subsequently tourism (Adler, McEvoy, Chhetri, \& Kruk, 2013; KC \& Thapa Parajuli, 2014).

Researchers have also studied the perceptions of different groups such as trekkers, lodge owners, guides, managers and residents regarding the various aspects and relationships between tourism, community, conservation and development (Allendorf, 2007; Allendorf, Smith, \& Anderson, 2007; Bajracharya, 2002; Bajracharya, Furley, \& Newton, 2006; Baral, Stern, \& Bhattarai, 2008; Baral, Stern, \& Heinen, 2007; Baral, Stern, \& Hammett, 2012; Holden, 2010; KC, Paudyal, \& Neupane, 2018; Nyaupane et 
al., 2014; Nyaupane \& Poudel, 2011; Nyaupane \& Thapa, 2004, 2006; Pandit, 2012; Poudel, Nyaupane, \& Budruk, 2016; Poudel et al., 2013; SK Nepal \& Spiteri, 2011; Stone \& Nyaupane, 2018). Studies have also highlighted the potential contribution of ecotourism to the local economy in the lower hills and national parks (Bhusal, 2009; Ruska, 2012; Sigdel, 2014). However, benefits of ecotourism to the local economy in terms of employment generation and residents' perceptions are varied (Bajracharya et al., 2006; Baral, 2013; Dinerstein, 2003b; Holden, 2010; Karanth \& SK Nepal, 2012; KC, Rijal, \& Sapkota, 2015; KC et al., 2018; Schuett, Dahal, \& SK Nepal, 2016). In addition to ecotourism, homestays are also seen as viable potential in developing countries with limited resources to spend on extensive infrastructure in addition to the richness of authentic experiences and contributing to local economy (Acharya \& Halpenny, 2013).

Although heritage tourism has high potential in Nepal, few studies have focused on cultural historical and religious sites and their linkage to tourism (Folmar, 2003; Neupane, KC, \& Pant, 2013; Nyaupane \& Budruk, 2009; Pandey et al., 1995; Pradhan, 2014). The changing traditional societies have also been studied (Raspaud \& Hallé, 2014). After the Maoist conflict and political change, a few studies have looked at the relationship between tourism, conflict and peace and national identity (Bhandari, 2010; Bhandari \& Bhandari, 2012; Croes, 2007; Thapa, 2004; Upadhayaya, Müller-Böker, Sharma, \& Umar Upadhayaya, 2011). There is a clear lack of literature on the relationship between tourism and landscape change and landscape aesthetics, especially from the perceptions of residents and tourists that this study undertakes.

\subsubsection{Landscape change and tourism}

The advent of tourism in Nepal since the 1950s has led to significant changes in settlements and landscapes, especially along the main trekking routes (Pawson et al., 1984). The change in the traditional functions of the villages, from farming and herding to tourism, has brought significant changes in the sizes, characteristics, functions, and spatial distribution of the traditional settlements (SK Nepal, 2005). As the ownership of new tourism enterprises has largely remained in local hands, Nepal has avoided conflicts that are emerging in other destinations, e.g. San Gimignano in Italy (Phillips, 2003). 
Increasing tourism may potentially displace the residents, due to the growing ownership of homes by non-permanent residents or those who rent to the tourists, artisans and producers. Locals are increasingly put under pressure to sell properties and are also becoming unable to afford the rising costs of living in popular tourist destinations (Goulding et al., 2014). The development of modern facilities in tourism destinations is also attracting second-home owners, which may lead to conflicts with local residents and concerns about environment impacts and influences on local life and cultural traditions, as in the case of Norway (Kaltenborn et al., 2008).

There is also a lack of coordination between the different government agencies, which creates conflicting programmes and projects, such as the recent increase in constructing roads to popular trekking destination without proper assessments of its impact on the environment, local economy or culture (Lama \& Job, 2014). The roads are perhaps perceived by the locals as their means to easier access to cities, and hence development. Development agencies also consider road construction as a tool for poverty alleviation that generates employment and provides access to markets and economic opportunities. This tends to lead to the import of non-traditional construction materials such as cement that alters the built landscape. The use of local materials that resulted in distinctive characteristics which is particular to a place is gradually decreasing with uniform developments across different geographic regions (Phillips \& Yannas, 1999). This trend endangers the settlements to become uniformly undistinguishable losing their unique characteristics and making standardised landscapes that result from insensitivity of the significance of the place and placelessness (Relph, 1976).

SK Nepal (2005) views the changes taking place in traditional landscapes on the trekking trails in Nepal positively as results of economic, social and cultural changes but limits his discussions on the size, function and characteristics regarding the type of accommodation. However, he emphasises the importance of understanding the process of change and the characteristics that evolve to develop strategies for sustainable tourism development. His research presents the development stages and factors contributing to change but is limited to the change in density of the built-up area and use of buildings and does not consider architectural change, which has significance for landscape aesthetics with loss of distinctive character. As decisions are mostly guided by the lodgeowner's overriding concern for profit, this change potentially could drive change in the 
vernacular landscape (Lim, 2007). In a later study, SK Nepal (2007), reflects on the tourism-induced growth in the rural settlements in Nepal, resulting in a hierarchical structure with core and peripheral traits. He does not discuss the impact of the changes on the overall landscape but concludes that these changes will influence tourism in rural Nepal recommending further studies. Similarly, Pandey, Chettri, Kunwar, and Ghimire (1995) analyse separately the impact of tourism on the two interdependent issues of culture and landscape and make recommendations accordingly without looking into the impact of one on the other.

Beza (2010) surveyed tourists' and residents' perception of aesthetic values of mountain landscape in Everest region and found that the values attached go beyond biophysical aspects such as mountains and trees to include concepts of wilderness and emotions of attachment. This study used 68 photographs and 10 distinct aesthetic criteria derived from personal experience and expert descriptions to rate mountain aesthetics on a sevenpoint scale. Significant differences were not observed between the two groups and the study is limited in terms of solely using photographs to rate the complexities of landscape based on the scale from beautiful landscape to ugliest landscape. However, the study has shown that perceptions of landscape aesthetics are linked closely with emotions as well as cultural and personal backgrounds (Beza, 2010).

In summary, the literature on tourism-landscape relationship in Nepal is dominated by studies on mountain, conservation areas and national parks. The focus is on the impact of tourism on the environment, which has been expanded to include the communities in the recent studies. The limited studies on the changing landscapes and landscape aesthetics have not looked beyond the physical natural elements to include the cultural processes or the perception of the people. The research on perceptions are also on the impacts of tourism on the environment and community. The recent studies on landscape change (SK Nepal, 2005) and landscape aesthetics (Beza, 2010) are limited in terms of their concepts of landscape and aesthetics, however, there is growing concern for the changing landscape aesthetics (Zurick \& Rose, 2009). The available literature clearly demonstrates the need to expand the scope of study to include the vast potential of tourism in Nepal from different perspectives and fields that until now has focussed on the environment. Recently, international symposiums in Nepal have highlighted pertinent issues including the linkage between cultural heritage and tourism (Wickens, Bakir, \& 
Avgeli, 2017). In order to contribute to the limited studies on the interrelationship between landscape and tourism in Nepal, this study examines the perceptions of the residents and tourists on landscape aesthetics in three geographically and culturally different landscapes in Nepal. In doing so, this study also contributes to the broader study of this landscape-tourism interrelationship.

\subsection{CONCLUSION}

This chapter presented the conceptual framework of this research that explores the complex relationship between the landscape, the drivers of landscape change and the perceptions of people on landscape aesthetics where tourism is one of the key components as well as a driver of change in the landscape. The dynamic nature of landscape and the nonlinear patterns of change add multiple layers and dimensions to landscape aesthetics and how it is perceived by different groups of people. This conceptual framework was drawn from the review of literature on the concepts of landscape, drivers of change and perceptions of landscape aesthetics also highlighted the gaps that this research intends to address. The review of literature on tourism and landscape in Nepal also highlighted the research gaps.

Drawing from the conceptual framework and literature review the next chapter presents the methodological framework and the multi layered interpretative research used to address the key research question and the supporting research questions. 


\section{METHODOLOGY AND RESEARCH STRATEGIES}

\subsection{INTRODUCTION}

Chapter two provided an overview of the relevant literature on landscape, the drivers of landscape change and the perceptions of landscape aesthetics as well as the context in Nepal. This review of existing literature identified the research gaps and led to the conceptual framework that has set the direction for this research methodology. In order to address the research question, this study adopts a qualitative approach using case studies, in-depth interviews with photo-elicitation and field observations. This chapter presents the methodology with the aim of providing an outline of how this research was conducted and why the different methods and data sources were used.

This chapter first discusses the research questions in detail outlining the rationale for examining the residents' and tourists' perspectives on the changing landscapes and landscape aesthetics (section 3.2). Section 3.3 outlines the three main methodological approaches: case studies, interviews using photo-elicitation and field observations. The next section provides detailed explanation of how the key phases of the research process were conducted at the sites (section 3.4). The research paradigm follows in order to rationalise the multi-layered approach in conjunction with my research reflexivity (section 3.5). It outlines the interpretivist research paradigm applied to explore the different perspectives of landscape aesthetics to address the overarching research question. Next, section 3.6 discusses the strengths and limitations of the selected methodology and data collection before conclusions are drawn (section 3.7).

\subsection{IDENTIFYING THE RESEARCH PROBLEM: RESEARCH QUESTIONS}

The main challenge in the literature on landscape, landscape aesthetics, and drivers of change is the multiple concepts and different approaches to landscape-tourism studies. Previous research focussed on specific components of landscape with an emphasis on either the natural or cultural component depending on the field of study and interest. This study goes beyond these restrictions to view landscape holistically as a dynamic social construct that draws from its past and accepts change as an essential component of 
landscapes. Drawing from the literature review, the conceptual framework presented in section 2.5 provides an overview of the interconnections and overlaps in the key concepts of this thesis taking into consideration the different perceptions of the residents and the tourists. This provides a foundation for the case studies in Nepal to determine the information needed to address the overarching research question:

\section{How do residents and tourists perceive the aesthetic values of Nepal's changing landscapes?}

The perceptions of the residents and tourists on the changing landscapes and landscape aesthetics are the focus in this study. Existing literature demonstrates that the local and the tourist may approach, view and experience the landscape and the change differently (Orland, 1988; Urry, 2002). Likewise, the reciprocal relationship between people and landscape also influence their views and experiences of landscapes (Nassauer, 1995; Van Eetvelde \& Antrop, 2009). The implication of different perceptions on the change and management of landscapes requires this research to address the perceptions of the changing landscapes from the residents' and tourists' perspectives. As explained in the conceptual framework, the approach to landscape in this research places people in the centre of landscape that is dynamic and continuously transforming. As an integral part of the landscape, their perspectives are essential in understanding the multiple aspects of landscape aesthetics.

\section{Supplemental question 1:}

\section{What are the drivers of change in the landscape influenced by tourism?}

In order to understand the changing landscape, it is important to first explore the drivers of change. Change is an inherent characteristic of landscape that is influenced by internal and external factors. While the different components within landscapes transform, they change the overall landscape and are in turn shaped by it. Distinctive landscapes are important assets for tourism development, at the same time tourists seek unique landscapes and experience. This inter-dependence leads to landscape changes and becomes a vehicle for urbanization and globalization, which in turn boosts building and expansion of settlements (Dyer, 2009; Hoskins, 1953). Rapid and drastic changes may lead to the destruction of distinctive characteristics when the residents regard them as too 
ordinary, out-dated and inadequate for contemporary use, hence not worthy of preservation (Knapp, 1992). Therefore, this first supplemental question addresses the forces that are driving the changes. The focus on tourism is due to the dependence of the case study sites on different forms of tourism.

\section{Supplemental question 2:}

What are the perspectives of residents and tourists with respect to the changing landscapes and landscape aesthetics?

Residents and tourists are the two main groups that landscapes are changed to accommodate, however the motivations and interests differ. The residents live and work in the landscape and interact with the landscape in their everyday life. The tourists are temporary visitors, yet, as part of the tourism industry that is vital to the local economy, play a significant role in the development and modification of landscapes. In economies that are driven by tourism, polices and planning tend to serve the tourists and can potentially create conflicts with the residents (Janusz et al., 2017). In addition to planning and policies, the residents and tourists also change landscapes with their perceptions of the landscape and landscape aesthetics. In order to provide a holistic perspective on landscape aesthetics, this study takes into consideration the perceptions of both the residents and tourists. The perceptions of these two groups have potential implications on future tourism development and management as well as subsequent change in the landscapes.

\section{Supplemental question 3:}

How do the perceptions of residents and tourists compare or inter-relate with respect to different landscapes?

In order to identify and understand the different aspects of landscape aesthetics this research question compares the perceptions of the residents and tourists in each site and across the selected case study sites. In addition, comparisons are drawn on the drivers of change. This helps reveal the impact and influence of the different drivers on the landscape and the interrelationships related to their historic and socio-economic context as well as geographic location. In addition to the practical contribution to management 
strategies, in-depth analysis and comparisons of the different perceptions contribute towards understanding and defining landscape aesthetics.

\subsection{RESEARCH APPROACH}

This empirical research adopts a qualitative approach, utilizing case studies, in-depth interviews with photo-elicitation, and field observations to address the complexities of landscape, landscape aesthetics and change. The multi-layered approach is adopted due to the dynamic nature of the phenomenon under study that requires an open-ended enquiry process. According to Morgan \& Smircich (1980), the selection of methods, quantitative or qualitative, is linked directly to assumptions about ontology, epistemology and human nature. The emphasis should be on the nature of the phenomenon to be researched and orientation of the researcher, rather that the method or approach. The focus of this study, perceptions of residents and tourists on landscape change and landscape aesthetics, recognises that both change, and landscapes are dynamic, and people are part of the process, changing landscapes and being shaped by them.

This multi-layered approach follows the literature gap and the conceptual framework to obtain insights from participants that have interpretive depth and goes beyond objective responses on the physical characteristics of the landscape. Landscapes are multi-sensory surrounding the observer with light, sound and smell that are changing as we move through them and in turn influencing our perceptions of landscape aesthetics. In addition, this research addresses the issue of change, both within the landscape and as an external driver. The perception of residents and tourists on landscape aesthetics and landscape change requires a combination of different approaches and methods. Change in the landscape and landscape aesthetics are complex concepts that cannot be addressed adequately by simply interviewing the participants. This research uses past and repeat photographs with in-depth interviews on site to capture the multiple evocations of landscape and landscape aesthetics.

People are part of the landscape, they observe and experience the landscape and are gazed upon as part of the landscape. People and the landscape are also continuously transforming under various drivers. This creates complex processes and multiple roles 
that impact upon the people and their views of landscape aesthetics that requires in-depth understanding beyond conventional interviewing. I used past and repeat photographs to access deep-seated perceptions and evoke memories that the participants associated with the landscape. While the past photographs evoked memories for the residents, they offered a new perspective of the landscape for the tourists. In addition, the interviews were carried out in-situ, observing the landscape live, which provided the participants a setting to reflect upon the change in landscape with the past and repeat photographs in hand.

This research was carried out in three phases: research design, data collection and data analysis (Table 3-1). The research design phase (phase 1) reviewed literature (chapter two) to identify the research problem and included a preliminary field visit to confirm the case study sites and develop the research questions. During this preliminary field visit, in addition to collecting available documents and photographs, I had informal discussions with key informants who were familiar with the case study sites and presented an exploratory paper on the changing landscape of Bandipur, one of the selected case study sites at a symposium in Korea. This visit provided context for the subsequent data collection (phase 2) that included at least two visits to each case study site over a 7-month period: an exploratory field visit and main interviews. In the final data analysis (phase 3) I transcribed the interviews followed by multiple in-depth analysis and interpretations of the data to address the research questions. While the overall analysis examined the drivers of landscape change, the emphasis of the interviews was on landscape aesthetics from the perceptions of the residents and the tourists. Prior to a detailed explanation of the three phases of the research process (section 3.4), the next section presents the rationale for the selection of the methodology: case studies (section 3.3.1), in-depth interviews with photo-elicitation (section 3.3.2) and field observations (section 3.3.3). 


\begin{tabular}{|c|c|c|}
\hline Phase & Activity & Purpose \\
\hline \multirow{6}{*}{ 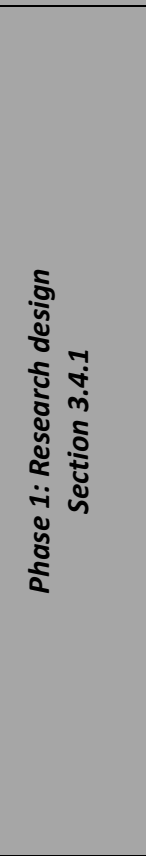 } & \multicolumn{2}{|l|}{ Identifying research problem } \\
\hline & $\begin{array}{l}\text { Literature review on landscape, } \\
\text { perceptions of landscape aesthetics, } \\
\text { drivers of change, and tourism in } \\
\text { Nepal } \\
\text { Obtain approval from Human Ethics } \\
\text { Committee }\end{array}$ & $\begin{array}{l}\text { To identify the research gap } \\
\text { To develop the research question }\end{array}$ \\
\hline & \multicolumn{2}{|c|}{ Preliminary field visit (October - November 2015) } \\
\hline & $\begin{array}{l}\text { Meetings with key informants (in } \\
\text { Kathmandu and Bandipur) working } \\
\text { in the fields of tourism, planning and } \\
\text { the potential case study sites }\end{array}$ & $\begin{array}{l}\text { To select sites for the comparative study } \\
\text { To identify sources of information and photographs } \\
\text { To identify potential informants }\end{array}$ \\
\hline & Site visit to Bandipur & $\begin{array}{l}\text { To confirm the selection of sites, including landscape } \\
\text { change } \\
\text { To connect with the potential key informants }\end{array}$ \\
\hline & $\begin{array}{l}\text { Paper presented at the International } \\
\text { Symposium, Re-thinking Lifescape: } \\
\text { Linking Landscape to Everyday Life, } \\
\text { Jeju, Korea, Nov } 2015 \\
\text { Title: Changing landscapes and } \\
\text { tourism development: a case study } \\
\text { in Bandipur, Nepal }\end{array}$ & $\begin{array}{l}\text { To further develop research question, especially on the } \\
\text { criteria and connotations of landscape aesthetics } \\
\text { To get a better understanding and consolidate the } \\
\text { appropriate methodology to assess landscape change and } \\
\text { landscape aesthetics }\end{array}$ \\
\hline \multirow{7}{*}{ 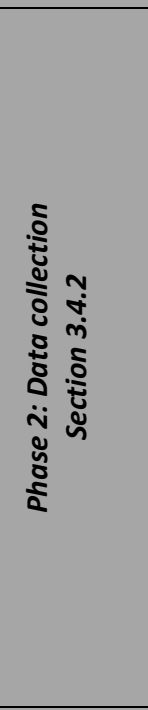 } & \multicolumn{2}{|c|}{ Exploratory field visit (May - November 2016) } \\
\hline & $\begin{array}{l}\text { Meetings with key informants, } \\
\text { which included tourism } \\
\text { entrepreneurs, community leaders, } \\
\text { professionals and residents }\end{array}$ & $\begin{array}{l}\text { To assess the current situation regarding tourism in the } \\
\text { area } \\
\text { To identify potential participants for interviews }\end{array}$ \\
\hline & Field observations & $\begin{array}{l}\text { To take repeat photographs at the same locations as the } \\
\text { earlier photographs found } \\
\text { To assess and collect data on landscape change }\end{array}$ \\
\hline & Initial data analysis & $\begin{array}{l}\text { To fine-tune the interview questions } \\
\text { To identify the gaps in resource available } \\
\text { To assess landscape change } \\
\text { To select photographs for the interviews }\end{array}$ \\
\hline & \multicolumn{2}{|c|}{ Main interviews (May - November 2016) } \\
\hline & $\begin{array}{l}\text { Total of } 48 \text { interviews in three sites } \\
\text { ( } 21 \text { Bandipur, } 16 \text { Ghandruk and } 11 \\
\text { Sauraha) lasting from } 30 \text { minutes to } \\
2 \text { hours }\end{array}$ & $\begin{array}{l}\text { To collect data to answer the research questions } \\
\text { To examine the perceptions of the residents and tourists } \\
\text { on the changing landscape }\end{array}$ \\
\hline & Field observation & To assess and collect data on landscape change \\
\hline \multirow{3}{*}{ 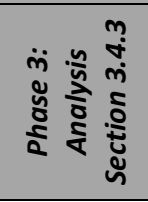 } & \multicolumn{2}{|l|}{ Data analysis } \\
\hline & Preliminary data analysis & $\begin{array}{l}\text { To transcribe data and develop the coding and data } \\
\text { analysis system }\end{array}$ \\
\hline & Final data analysis & $\begin{array}{l}\text { To answer the research questions } \\
\text { To interpret data for comparisons, findings and discussion }\end{array}$ \\
\hline
\end{tabular}

Table 3-1: Multiple phase research process

\subsubsection{Case studies: a comparative case studies approach}

A case study is a common research methodology that has been used in intensive and extensive studies in the social sciences (Gerring, 2007; Starman, 2013), including tourism research, to study a variety of phenomena both single and multiple cases, such as landscape preferences (Chen, Xu, \& Devereux, 2016; Conrad, Christie, \& Fazey, 
2011; Van Zanten et al., 2014), tourists' perceptions (Zoderer et al., 2016), host communities' perceptions (Tosun, 2002), tourism planning (Russo \& Van Der Borg, 2002) and tourism impacts (Banskota, 2012; Gotham, 2005; Lundberg, 2017; Scott, 2010). Despite the long history and widespread use, disagreements exist whether case studies are a research method or type (Gerring, 2007; Starman, 2013). They are mainly but not exclusively qualitative research type, and can be either quantitative, qualitative or mixed (Starman, 2013). The characteristics of case studies are linked closely to the subjective views and emphasises an individual's perspective of qualitative research that are central to the interpretative paradigm, a basis of qualitative research.

The different concepts of what is considered a case study has also resulted in unclear definitions (Starman, 2013). Stake (2005) identifies three types of case study, based on the emphasis placed on understanding the particular case (intrinsic), to provide insight into an issue to draw generalisation (instrumental) or cases studied jointly in order to investigate a phenomenon, population or general condition (multiple). Multiple case studies are instrumental studies extended over two or more cases that may or may not be similar or dissimilar, selected for their value in understanding and theorising a larger collection of cases (Stake, 2005). The complexities of landscape aesthetics and the drivers of landscape change requires an intensive study. In order to gain a thorough understanding of the residents' and tourists' perceptions on landscape aesthetics and drivers of change, this research utilises multiple cases of intrinsic interest to compare the findings across the sites, themes and participant groups.

A comparative case studies approach explores the similarities and differences in the processes and outcomes of the phenomenon between two or more locations or timeframes. Earlier comparative studies in tourism are used mostly in cross-national contexts for their practical values in transferring knowledge with questionable success, especially when western cases are transferred to non-western countries (Pearce, 1993). In later studies, comparative studies have looked at identifying basic patterns and a more general understanding of the processes to develop theories. Pearce (1993) has identified three broad approaches to comparative research in tourism, 1) comparative case studies, 2) element by element comparisons, and 3) quantitative and graphical analysis. This study employs a basic comparative case studies approach, where the three cases are analysed and interpreted with the subsequent findings identified, compared and 
interrelated. However, some comparisons occur throughout as each of the research questions is examined and discussed.

Comparative studies also have the potential to demonstrate the application and utility of new analytical techniques (Pearce, 1993). The use of past and repeat photographs in the interviews conducted in-situ provided opportunities for the participants to compare the landscapes in a different context. Comparative studies go beyond providing explanations or conceptual research to potentially developing generalisations and explanations that stimulate development of theory with practical implications of transfer of knowledge (Pearce \& Butler, 1993). This research compares the finding across the sites to draw out a holistic concept of landscape aesthetics.

According to Stake (2005), to achieve the greatest understanding of the phenomenon, representative cases and sample size are critical when selecting cases. The rationale for selecting three case studies is to assess and compare the influence of different geographic locations on the change, landscape aesthetics and perceptions. All three case studies are showing early signs of change with the increasing investments in tourism and thus are suitable for comparison. The location and the associated cultural identity of the case studies have resulted in distinctive characteristics, which provide sufficient range for the research topic (Table 3-2). A background on each case is presented in the findings (chapters four to six).

\begin{tabular}{|c|c|c|c|c|c|c|}
\hline $\begin{array}{l}\text { CASE } \\
\text { STUDY }\end{array}$ & POPULATION & DISTRICT/PROVINCE & LOCATION & $\begin{array}{l}\text { DESTINATION } \\
\text { TYPE }\end{array}$ & ALTITUDE & $\begin{array}{l}\text { MAJOR } \\
\text { ETHNIC } \\
\text { GROUPS }\end{array}$ \\
\hline GHANDRUK & $4,748(1991)$ & Kaski, Province 4 & $\begin{array}{l}\text { Annapurna } \\
\text { Conservation } \\
\text { Area }\end{array}$ & Trekking & $1975 \mathrm{~m}$ & Gurung \\
\hline BANDIPUR & $\begin{array}{l}15,591 \\
(2011)\end{array}$ & Tahahun, Province 4 & $\begin{array}{l}\text { Bandipur } \\
\text { Preservation } \\
\text { Zone }\end{array}$ & Cultural & $1030 \mathrm{~m}$ & $\begin{array}{l}\text { Newar, } \\
\text { Magar, } \\
\text { others }\end{array}$ \\
\hline SAURAHA & 2,699 (1991) & Chitwan, Province 3 & $\begin{array}{l}\text { Chitwan } \\
\text { National Park }\end{array}$ & National park & $150 \mathrm{~m}$ & $\begin{array}{l}\text { Tharu. } \\
\text { others }\end{array}$ \\
\hline
\end{tabular}

Table 3-2: Summary of the three case studies

Three case studies were selected to examine the effects of the difference in location, landscape quality, type of tourist activity and conservation policies on landscape change and landscape aesthetics. They are studied concurrently to examine the similarities and differences at a given timeframe. Multiple case studies also broaden the scope of the 
overarching research question to produce credible results and conduct comparative studies (Yin, 2012). Critics of multiple case studies in qualitative studies point to the potential bias on the limited number of cases that can be selected and the impact of the research's prior knowledge and preference (Starman, 2013). However, prior knowledge also provides a strong theoretical base for the research and rigorous procedures and methodology can deflect researcher bias. Although I am more familiar with one case (Bandipur) than the other sites, I have taken care to use diligence and consistency in the data collection and analysis processes to avoid potential bias.

The selected sites are representative of their regions and are well-known destinations in international and domestic tourism markets. They developed as tourism destinations at different times with a focus on different type of tourism and are undergoing changes in landscape and tourism activities. Ghandruk is mainly a trekking destination in a Conservation Area, while the attraction for Sauraha is the National Chitwan Park, a World Heritage Site (natural) and Bandipur is emerging as a cultural destination. The selection of different types of tourism activity (trekking, cultural, national park) in the three sites was deliberate to examine the influence of destination type on the perspectives of the participants on landscape aesthetics and the degree of acceptable change.

The three cases represent three geographic regions in Nepal: high hills, low hills and the plains (Table 3-2). The variation in the attitude and geographic location has resulted in a difference in the pace, scale and type of change, which was expected to add another dimension to the degree of acceptable change as well as the perception of change. All the sites are situated outside the main urban centres of Nepal and were consciously selected because of the limited research in these regions. In urban centres, the separation between the natural and built environment is more evident than smaller towns or villages. Although the population diversity found in urban centres would have added another dimension to this research, in-depth interviews to include the diversity would be beyond the limited timeframe of this research. While drivers of change are complex in the cities, the emphasis of this study is on the changes driven by tourism and the effects on the landscape. The three selected case studies are tourist destinations undergoing changes that have potential to impact on their future as tourist attractions. The location of Ghandruk and Bandipur on hilltops limits their economic potential, whereas Sauraha is 
located in the plains with alternative development potential such as agriculture and industries.

Other sites considered included Laprak and Chimang. Laprak is a picturesque Gurung village in the foothills of the Himalayas in Gorkha District in Central Nepal. The village was completely damaged in the April 2015 earthquake and current efforts are directed towards rebuilding houses for the community. The dramatic change in the landscape as the result of natural disaster is beyond the scope of this study. Chimang is a charming village in the higher Mustang region with authentic architecture and landscape, however, it is currently not included in the major trekking routes in the region and has not developed facilities or infrastructure for tourism, hence, landscape change is not as visible. Both these sites are also relatively remote adding to the costs of travel and research expenses.

\subsubsection{In-depth interviews with photo elicitation}

Interviews go beyond merely responding to questions to a collaborative process between the researcher and the participant or participants that leads to a contextually bound narrative. As both researcher and participants are humans with individual and collective values, motive, desires, feelings and biases, the interview process is bound to be subjective and neutrality is not possible. This compels the researcher to take a stance that may direct the interviews and hence becomes politically and contextually bound (Fontana \& Frey, 2005). In addition, the researcher also evolves in the process of interviewing and Holstein and Gubrium (2005) urges researchers be to reflexive on both the accomplishments of the interview and the process of the accomplishment (Fontana \& Frey, 2005; Holstein \& Gubrium, 2005).

Structured interviews with a series of pre-established questions and a limited set of responses allow for little flexibility in the way questions are asked or answered. Unstructured interviews are mostly used in ethnographic studies and are open-ended allowing for greater depth and flexibility (Fontana \& Frey, 2005). Semi-structured interviews are formal, yet allow the researcher to prepare a set of instructions and questions, at the same time follow topical trajectories in the conversation that may stray from the guide when appropriate (Cohen \& Crabtree, 2006). To study the different 
perceptions of landscape aesthetics, this research employed semi-structured in-depth interviews that included photo-elicitation techniques. The semi-structured interview was selected to account for variations in participant responses and the diversity of respondents. At the same time, some structure is needed to collect relevant data that can be compared across the cases and the participant groups. In addition to general questions on the background of the participants, the key topics were focused on landscape, tourism, community and changes (Appendix B). Details of the interviews and participants are presented in section 3.4.2.

Different fields have used visual methods for various studies, including landscape change (Gurung, 2004; Nyaupane et al., 2014), that adds to the ways of capturing layers of knowledge as well as ways of knowing (Pink, 2012). Visual methods have been used in tourism research with an emphasis on community to engage, empower and collaborate in the research process for local development (Janusz et al., 2017; Johnson, 2014). Research in the context of tourism using visual methods is mainly focused on tourism experiences (Matteucci, 2013), destination images (Mackay \& Fesenmaier, 1997) and destination management (Lo \& McKercher, 2015), and is still under-developed (Park \& Kim, 2018; Rakić \& Chambers, 2012). Photographs have been used as a valid surrogate for the real landscape in the context of tourist experiences with high levels of consistency and are also useful to evaluate and compare several landscape or landscape aspects (Jacobsen, 2007). However, people experience the multiple dimensions of landscapes when they are actually in the location (Scott \& Canter, 1997) and a multi-sensory approach is considered advantageous to understand different perspectives and experiences of landscapes (Jacobsen, 2007). Limited studies of landscape perceptions using photographs on-site are available and are mostly focused on the perceptions of tourists and their preferences (Hull \& Reveli, 1989; Múgica \& De Lucio, 1996; Yang \& Brown, 1992).

The values embedded in landscapes extends beyond the visual and requires consideration of the relationship between visual and other senses. The use of photographs during the interviews mediates the relationship between the researcher and the participant and encourages a reflexive approach to visual representation of the photographs (Pink, 2006). Images can clearly and quickly communicate details that take long textual descriptions and offer access to aspects of the past that other sources do not reach (Burke, 2001). First 
employed by Collier (1957) several approaches of photo-elicitation have developed, mainly showing respondents the photographs taken by others (Harper, 1987) and autodriven photo-elicitation that allows respondents to take the photographs themselves (Clark, 1999). This study used past photographs taken by others and collected from various sources and repeat photographs that I took. I photographed the same locations for the repeat photographs to guide open-ended interviews and provoke discussions to understand the perceptions of landscape change ${ }^{2}$. Repeat photography, where one photographer's camera position becomes another's location provides a useful record for assessing the extent of landscape change (Webb, Boyer, \& Turner, 2010).

This research uses past and repeat photographs and in-depth interviews to examine the participants' perceptions on landscape change to gain comprehensive understanding that may not have been fully expressed in the interviews (section 3.4.2). Without these visual aids, the question on change would depend solely on the residents' memories and there was a risk of not getting rich data. In addition, the perceptions of the tourists, as temporary and first-time visitors, on the landscape change over time would not be possible. While some local community members and repeat visitors would be aware of change in the landscape, the photographs help to recollect the memories and help with comparisons to the past landscapes. Although the interviews were conducted in-situ, where the participants could observe and reflect on the wider landscape values, the photographs captured and framed the images for comparison. Comparing the image seen in a small 7"X5" photograph to what they are observing live during the interview could present limitation of the scale between the two images. Therefore, the newer set of photographs taken of the same view provided the participants with the image at different points in time. The photographs also presented a wider perspective of the town that the participants may not be familiar with or did not have the time to observe. These photographs were also captured through a set of different eyes and provide additional layer of perspective on the landscape. All photographs used were printed in the same size, in colour and mostly in high quality.

\footnotetext{
${ }^{2}$ The repeat photographs that I took in 2016 and other photographs from my personal collection are credited as JJoshi.
} 
Although some tests of the proposed semi-structured interview were carried out in Wellington prior to the field visit, the initial interviews (in Bandipur) were also used to test the format of the interview, especially when to introduce the photographs during the interview. The format adopted, introducing the photographs at the end of the interview, was agreed by the initial participants to be appropriate, as they felt that if viewed at the beginning, the photographs may influence their perceptions on landscape change.

\subsubsection{Field observations}

Yin (2018) identifies six main sources of evidence for case study research methods: documents, archival records, interviews, direct observations, participant observation and physical artefacts (Yin, 2018). For this study, in addition to the in-depth interviews (section 3.3.2), the other sources were documents (mostly photographs) and direct observations.

Field notes are one of the central methods in ethnographic work for participant observation and include a variety of writing produced in or near the field providing written accounts of an evolving array of experiences and observed events (Emerson, Fretz, \& Shaw, 2001). While some ethnographers treat the field notes as a primary data set grounding the subsequent analyses and preserving this material, others emphasise the richness of actual encounters and observations. These different approaches generate different concerns and sensitivities with regard to the field notes, such as writing styles, completed products and arguments to focus on and examine (Emerson et al., 2001). This thesis is not an ethnographic study and the focus was not on participant observation. Field notes were taken with regard to the physical changes in the landscape and of informal conversations with the residents, tourists and key informants. Some of the people I had informal conversations with were later interviewed or informal conversations followed the formal interviews.

The physical observations and informal conversations were helpful to refine and enrich the formal interviews. My field notes were useful to relate to and understand the changes that the residents talked about and enrich the conversation with the tourists. The next section presents the detailed explanation of the research process. 


\subsection{RESEARCH PROCESS}

As mentioned earlier, there are three key phases in this study: research design, data collection and data analysis (Table 3-1). Following the literature review and conceptual framework, phase 1 of this research process identified the research problem leading to the research questions and case studies selection. This section begins with detailed explanation of the preliminary field visit that leads to the main data collection (section 3.4.2). The physical constraints of the case studies and research technique adopted required an initial exploratory field work prior to the main interviews. This section concludes with the explanation of the analytical framework and process in the final phase of this research process (Section 3.4.3).

\subsubsection{Research design (Phase 1)}

\section{Preliminary field visit (October - November 2015)}

The preliminary field visit mainly focussed on assessing the visible changes and confirming the case study sites. This involved collecting available documents, including maps, past photographs and taking field notes. This phase also included meeting key informants in Kathmandu and Bandipur, visiting Bandipur and attending the conference in Korea. The key informants included community leaders, professionals and residents working in the fields of tourism and local development in Nepal and knowledgeable on the selected case study sites.

This preliminary field visit was important to connect with the informants and confirm the evidence of landscape change and select the case study sites. This became more significant in the aftermath of the April 2015 Nepal Earthquake that devastated large parts of the country, including Laprak that had been initially considered as a potential case study. Despite its proximity to the epicentre, Bandipur fortunately suffered only minor damage. The visit there confirmed the evidence of on-going landscape changes and the justification for the urgency of this research to study the interrelationship between landscape change and tourism. Ghandruk and Sauraha were also not affected by the earthquake. This preliminary field visit was limited to Bandipur due to the fuel crisis induced by the undeclared blockade imposed by India (September 2015 - February 2016) 
and the resulting scarcity of transportation options. However, I had several conversations in Kathmandu with key informants to confirm the suitability of the other two selected cases. These meetings augmented the literature review to refine the research questions and prepare the interview questions.

The international symposium, Rethinking lifescape: linking landscape to everyday life held in Jeju, Korea organised by ICOMOS-IFLA-ISCCL ${ }^{3}$ (November 2015) was an important platform to present the initial concept of the research and receive feedback from international experts. My presentation was on the relationship between changing landscapes and tourism in Bandipur. The symposium helped clarify the issue of the different aspects of landscape aesthetics and build a network with experts working and researching in the field of cultural landscapes and their associated values.

Photographic documentation, building records and plans are usually key sources for the measurement and detection of the visual changes in the settlement pattern, style, and spatial characteristics (Howley, 2011; Stephenson, 2008). Reliable sources for this type of research usually are building permits and land records; however, such records are scarce for rural settlements in Nepal and limited documents were found for the case study sites. The buildings in these villages were built by local craftsmen (masons and carpenters) relying on their experience rather than precise measurements and technology. This dependence on skilled labour and the lack of government mechanisms for record keeping has resulted in the scarcity of reliable data on the history of the buildings, including when or who built them. In addition, most of the buildings had been renovated over generations.

Nepal is also going through state restructuring as a newly established federal system and detailed updated maps are not available. The handful of available maps are general location maps that do not include the level of detail required for an analysis of landscape change. For example, the maps available for Ghandruk are mostly prepared for trekking purposes and indicate one village to the next on the trail. The maps do not include the geographical features, topography, settlements or vegetation cover that would indicate

\footnotetext{
${ }^{3}$ International Federation of Landscape Architects (IFLA)

International Scientific Committee on Cultural Landscapes (ISCCL)
} 
the aesthetic values of the landscape or the change. The topography of the settlements (Bandipur and Ghandruk) on high hills with steep terraces is also not ideal to be mapped on two-dimensional drawings. All three sites until recently were classified as villages and did not require building plans and permits. Bandipur was briefly upgraded to a municipality but has been recently re-categorised as a gaunpalika ${ }^{4}$ (rural municipality); five Village Development Committees (VDC), including Ghandruk have been merged to form Annapurna gaunpalika. Sauraha is within the boundaries of Ratnanagar Municipality and increasingly amalgamated into the urban fabric.

The existing architectural, settlement or landscape studies in Nepal are mostly on the mountain region or Kathmandu Valley and limited information is available for other parts of Nepal (section 2.6). The relevant documents found for the case studies include a brief planning document for Bandipur, basic building guidelines for Bandipur Preserved Cultural Zone, a management plan for Chitwan National Plan (CNP) that includes Sauraha in its buffer zone, management plans and annual reports for Annapurna Conservation Area Project (ACAP) that include Ghandruk.

One of the major tasks in this phase was the collection of past photographs to use in the in-depth interviews (Table 3-3). A range of photographs in different periods was collected, including images of festivals and pictures of everyday life. These could contain valuable information on the style, type of material of the built structures. Photo selection criteria was developed guided by the photographs collected in this phase. The criteria for selection included clarity and photographs that portrayed the different aspects of landscape aesthetics, including the type and style of houses, lifestyles, and local community activities as well as evidence of bygone commercial activities that could potentially depict changes in the present context. The selection criteria aimed to select a set of photographs for each site from the 1960s to the present day. This demonstrated the change (or not) over the period Nepal has opened to inbound tourists. The selection

\footnotetext{
4 Village Development Committee (VDC) was a lower administrative elected body similar to municipalities with smaller population under the Ministry of Federal Affairs and Local Development of the Government of Nepal. The VDC structure was dissolved on 10 March 2017 and replaced by Gaunpalika (rural municipality), which is now the lower administrative division. There are currently 481 rural municipalities in Nepal.
} 
criteria for the photographs varied with the site and the availability of the quality and quantity of the photographs.

The main sources for photographs were Bandipur Eco-Cultural Tourism Project 20052007 (BECTP) and the Peace Corps Nepal Photo Project 1962-1975 (PCNPP). After Nepal opened for tourism in the late 1950s, one of the first groups of visitors were the US. Peace Corps volunteers and their personal collection of photographs, now available online (Table 3-3). Necessary permission was received to use the photographs from this collection for the research.

\begin{tabular}{llllll}
\hline \hline CASE STUDY & PHOTOGRAPHS & PHOTOGRAPHS & SOURCE & & \\
\cline { 3 - 6 } & FOUND & SELECTED & PCNPP & BECTP & Informants \\
\hline \hline GHANDRUK & 29 & 5 & $\mathrm{~V}$ & $\mathrm{~V}$ & \\
BANDIPUR & 197 & 25 & $\mathrm{~V}$ & $\mathrm{~V}$ & $\mathrm{~V}$ \\
SAURAHA & 91 & 12 & $\mathrm{~V}$ & & $\mathrm{~V}$ \\
\hline \hline
\end{tabular}

Table 3-3: Sources and quantity of photographs used in the main interviews

BECTP Bandipur Eco Cultural Tourism Project

PCNPP Peace Corps Nepal Photo Project

The past photographs found for Ghandruk dated from 1968 to 1975 were taken by US Peace Corp volunteers Peter Von Mertens (1974), Michael Gill and Barbara Butterworth (1973). Five photographs out of twenty-nine were selected from this set, depicting the settlement, natural landscape, farmlands and life in the village. Additional photographs from 2005-2006 from the BECTP were included in this set. See Appendix C for a sample of photographs used in the interviews.

Twenty-five photographs out of more than a hundred photographs were selected for Bandipur. They included street views of different parts of the village and the surrounding landscapes depicting natural features such as hills and farmlands. The street views also included activities that provided an insight on the village lifestyle and people. Most of the selected photographs were from 1965 and taken by Bill Hanson (US Peace Corps volunteer). Additional photographs selected were from the period between 2005 and 2006 from BECTP.

Although more than ninety photographs from Sauraha and the surrounding areas were found dated 1967, few were useful because most of the photographs depicted farmlands that were difficult to identify. Additional photographs were collected from key 
informants; of which a few were relevant. The early research and development focus in Sauraha (and Chitwan) were on agriculture due to the location in the southern plains. Although tourism started in Sauraha in the early 1970s, it was focused on jungle excursions and the nearby Tharu settlements are primarily a group of thatched houses and comparatively simple in decorations and may not have been considered a tourist attraction, and hence not a subject of photographic interest. On the other hand, the architecture and settlement patterns in Bandipur and Ghandruk are relatively advanced with distinct character with the use of locally available materials and craftsmanship and caught the attention of early visitors.

\subsubsection{Data collection (Phase 2)}

This main data collection was carried out in two stages: exploratory fieldwork and the main interviews. I based myself in Bandipur and these two stages were spread over the length of my fieldwork between May and December 2016 with overlaps. The extended stay in Bandipur also provided an opportunity to observe the landscape in different seasons as well as conduct interviews with a wider selection of participants, both tourists and local community.

\section{Exploratory fieldwork (May - November 2016)}

An exploratory visit to all sites was carried out to take repeat photographs. Lack of proper photograph printing facilities at the case study sites made it necessary to conduct the exploratory fieldwork prior to conducting in-depth interviews. In all sites, I enlisted assistance from the local community to identify the exact location of the past photographs. There was considerable interest in the past photographs and field notes were taken to record the areas of their interest, which on a few occasions resulted in requests for a copy of the photographs. The insights and conversations during these visits were also useful to identify potential participants for the interviews.

While the past photographs were taken with the interest of the photographer to capture the best light and view, the repeat photographs were taken at the time of the exploratory visits and not necessarily in the same season. This has some impact on the aesthetics of the image in terms of colours, village activities and vegetation cover. For example, the 
past photographs for Ghandruk and Bandipur were mostly taken in October/November after harvest with barren farmlands, but the mountains are clearly seen. The repeat photographs were taken during or soon after the monsoon season (July-August), which shows a lot of green vegetation, but the mountains are not visible. The different seasons provided diverse views of the land rather than restricting the views, especially for the tourists who visit for a limited time in particular seasons.

Coincidentally, some of the past photographs had been exhibited in Bandipur in April 2016, just prior to the main interviews and most locals were familiar with the photographs. Although the location of most the photographs was easily identified, some views had been blocked due to later building additions. The exploratory visit to Ghandruk during the rainy season (July 2016) with mist and rain provided spectacular changes in the scenery, which was heightened by the momentary glimpses of the Annapurna range. On the other hand, the landscape of Sauraha had undergone drastic changes thus, despite consultations with a wide group of informants and residents, it was difficult to accurately identify the locations. However, the photographs taken during the exploratory field trip (October 2016) provided a range of images of the area for comparison with the past photographs, such as the typical cottages, newly constructed houses, the settlements, farmlands, farmers, the river, lakes and forests. The only set of past and repeat photographs were of the intersection of Gitanagar, a neighbouring village. The intersection still existed but had changed from a dirt road crossing amidst farmlands and cottages to a permanent market and bus stop (Plate 3-1). The memories of the residents became more valuable in this case study.

During these exploratory visits, in addition to taking repeat photographs and field notes, informal talks were held with guesthouse owners, shopkeepers, other residents as well as tourists. Although this was not high tourist season, there were a handful of domestic and international tourists in all sites. These visits were also an opportunity to conduct field observations to assess the landscape change and collect any available data. While Bandipur and Ghandruk were explored on foot, I visited the wider Chitwan National Park and its buffer zone on foot, bicycle and motorbike. Extensive field observation in Sauraha 
included nearby villages and the national park to assess the extent of change not only in Sauraha but also in the surrounding villages.

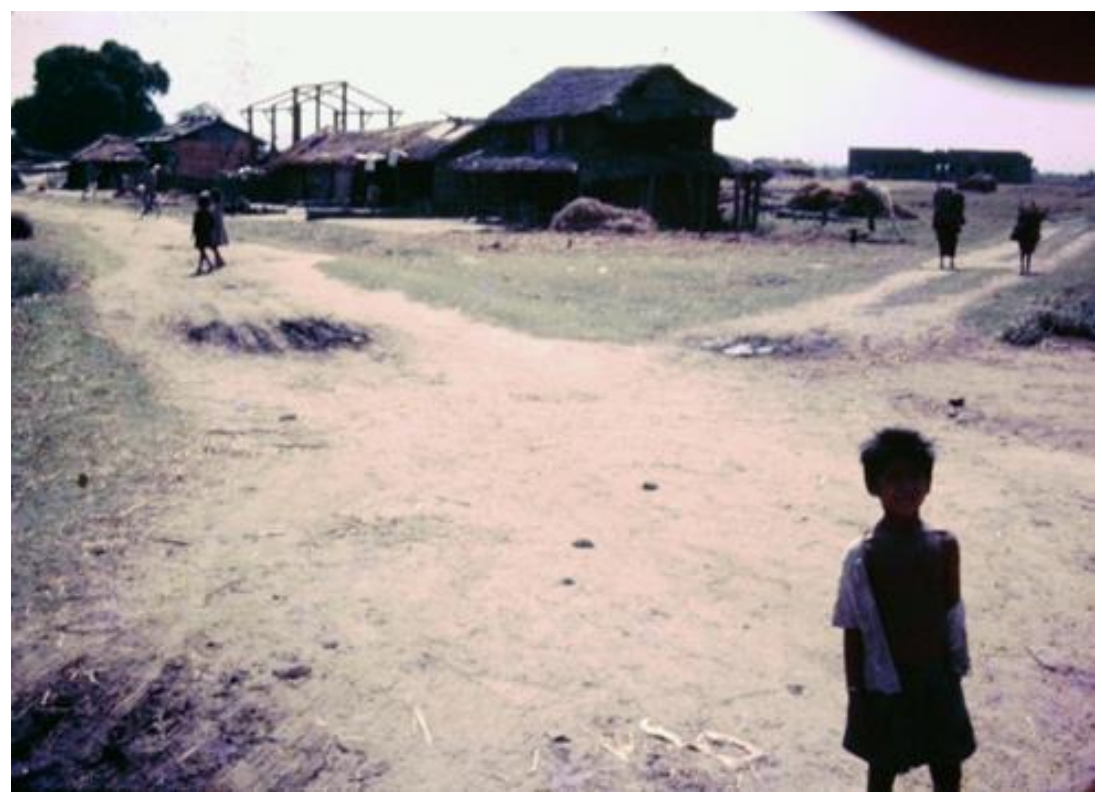

Photo:

Richard Pete Andrews (PCNPP), 1966

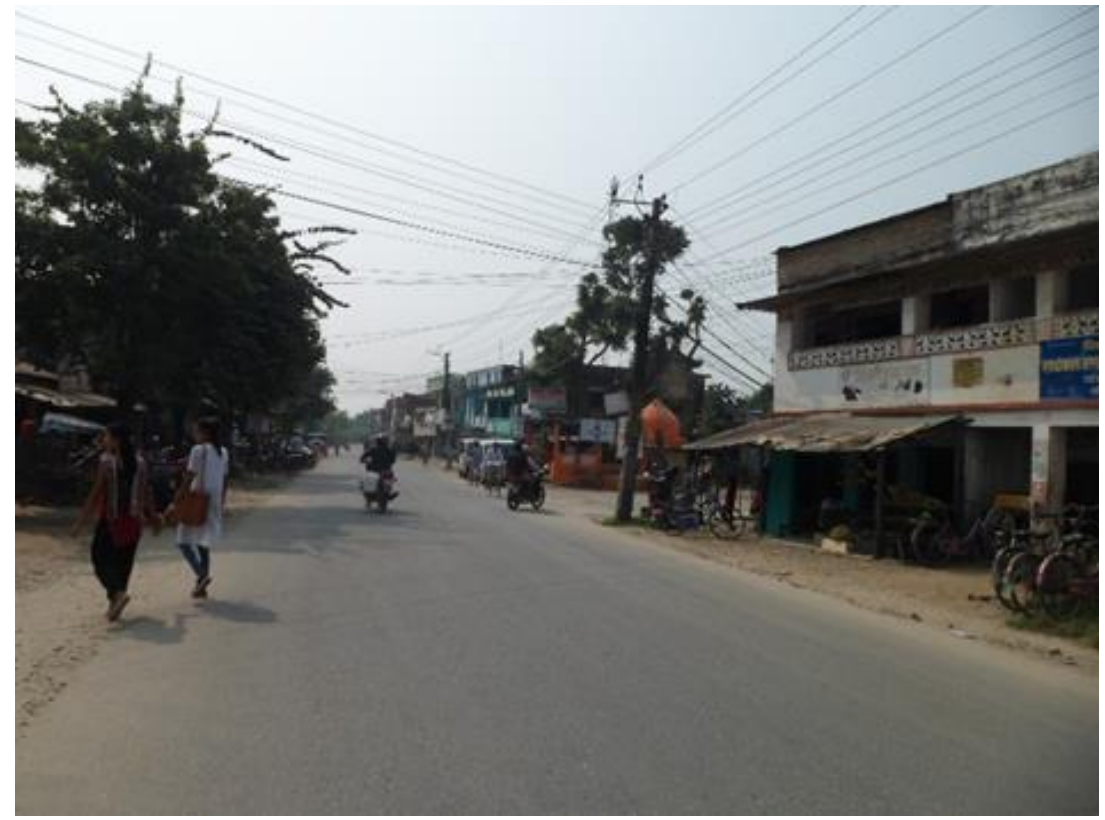

Photo: JJoshi, 2016

Plate 3-1: Past and repeat photographs of Gitanagar junction, Chitwan

These visits provided important groundwork for the follow-up data collection work in terms of resources and participants available. These visits also determined the appropriate season for the in-depth interviews since the initial fieldwork was conducted in the rainy season when tourism numbers are low, especially for Ghandruk, which is a hiking destination not a preferred destination when the chances of rain are high. Visiting 
multiple times also provided opportunity to observe the landscape, including the activities of the local community at different seasons.

Following the exploratory field visit, a preliminary analysis of documents and photographs available assisted in fine-tuning the interview questions. As expected, documentation such as maps and plans were scarce and not useful in detecting landscape changes for all three sites. Early analysis of data collection is useful to recognise any gaps in research methodology and allows for timely amendments of the process and the findings (Huberman \& Miles, 1994). This phase directed and highlighted the importance of the data collection from key informants, photographs and in-depth interviews.

\section{Main interviews (June - December 2016)}

In the second stage of data collection, in-depth interviews were conducted with the residents and tourists to collect their views on landscape aesthetics and changing landscapes. Bandipur was my base during the field work with trips to Kathmandu when necessary, especially to print good quality photographs. Bandipur was also the first site to begin the interviews, which were spread over the duration of the fieldwork from May to November 2016. This was particularly useful to select a diverse group of tourists; however, the length and season of the interview period did not affect the availability of the residents. The interviews in Ghandruk and Sauraha were conducted in October and November, which is the high tourist season in Nepal. A total of 51 participants were interviewed: 33 residents and 18 tourists (Table 3-4). An overview of the participants in the three cases is provided later in this section.

This research was granted approval (\#22662) from the Victoria University of Wellington Human Ethics Committee prior to the fieldwork. All the participants were given an information sheet and signed a consent form (Appendix A). A digital voice recorder was used in the interviews with the participants' permission. They were held at the participant's convenient location and time with an understanding that the interviewee could stop or withdraw at any time. Pseudonyms have been used and personal information such as occupation has been generalised, but it is recognised that given the small size of the case studies, the residents may be identifiable to those in the communities. 
The interview questions were broadly based on the themes of landscape aesthetics that included their views on the natural setting, the settlement, the architecture and the community activities as part of the everyday environment (Appendix B). The interview started with general questions on the participants' background and progressed to conversation on the physical aspects of the landscape. This was followed by specific questions to explore their perceptions on the evocative and cognitive aspects of landscape aesthetics. Their views on the community usually followed for a holistic perspective of landscape and associated values. Tourism and other general development were also discussed to assess the impact of tourism and identify other drivers of change followed by their familiarity with the other two case study sites. I usually took out the past and repeat photographs around this point to discuss the changes. At times, I also asked about their memories of the place to understand their worldviews and priorities with regard to landscape aesthetics. The interviews concluded by asking their opinion of the interview format and additional issues I had not addressed. At this point, some participants sometimes turned the questions back to me for my opinion on the changing landscapes.

\begin{tabular}{|c|c|c|c|c|c|c|c|c|c|c|c|}
\hline \multirow[b]{3}{*}{ CASE STUDY } & \multirow{3}{*}{$\begin{array}{l}\text { EXPLORATORY } \\
\text { VISIT }\end{array}$} & \multirow{3}{*}{$\begin{array}{l}\text { MAIN } \\
\text { INTERVIEW }\end{array}$} & \multicolumn{9}{|c|}{ "PARTICIPANT PROFILE } \\
\hline & & & \multicolumn{2}{|c|}{$\begin{array}{l}\text { Residents } \\
\text { non tourism }\end{array}$} & \multicolumn{2}{|c|}{$\begin{array}{l}\text { Residents } \\
\text { tourism }\end{array}$} & \multicolumn{2}{|c|}{$\begin{array}{l}\text { International } \\
\text { tourists }\end{array}$} & \multicolumn{2}{|c|}{$\begin{array}{l}\text { Domestic } \\
\text { tourists }\end{array}$} & \multirow[b]{2}{*}{ Total } \\
\hline & & & $M$ & $\mathrm{~F}$ & $M$ & $\mathrm{~F}$ & M & $\mathrm{F}$ & $M$ & $\mathrm{~F}$ & \\
\hline GHANDRUK & July 2016 & $\begin{array}{l}\text { October } \\
2016\end{array}$ & 1 & 3 & 4 & 4 & 1 & 2 & 3 & 1 & 19 \\
\hline BANDIPUR & May 2016 & $\begin{array}{l}\text { May - } \\
\text { November } \\
2016\end{array}$ & 4 & 1 & 4 & 2 & 4 & 2 & 2 & 2 & 21 \\
\hline SAURAHA & October 2016 & $\begin{array}{l}\text { November } \\
2016\end{array}$ & 3 & 3 & 3 & 1 & 0 & 1 & 0 & 0 & 11 \\
\hline \multicolumn{3}{|c|}{ TOTAL PARTICIPANTS } & 8 & 7 & 11 & 7 & 5 & 5 & 5 & 3 & 51 \\
\hline
\end{tabular}

Table 3-4: Profile summary of in-depth interview participants

The questions were a guide and conversation usually went back and forth around the key topics: landscapes (natural environment, built environment, people), tourism and change. The structure of the questioning also differed to draw deeper understanding of the perceptions on landscape. The responses of the participants were also cross thematic and at times, multiple questions were used for the same theme, especially to draw residents' perceptions and meanings of their landscape. Sample interview questions to collect experiential evocations, cognitive meanings and landscape attributes were:

How would you describe this place to someone who has never visited? 
What colours, smells and sound would you associate this place?

Comparing the present landscape with this photograph (from 1970s) what are your impressions on the differences?

What is your favourite memory of your hometown (local community)?

All participants were delighted to see the past photographs. This was an enriching process with the residents providing additional information usually through their memories, while I was able to explain the history to the tourists. I presented each set of past and present photographs and explained where it was taken then asked the participants whether they saw any differences and their preference. There were more past photographs for Bandipur than the other two sites, which elicited longer conversations and deeper insights. In addition to noting changes, these photographs showed a different aspect of the village that was not visible at the time of the interview and enriched the knowledge of the participant. Plate 3-2 presents an example of the comparative past and repeat photographs used to examine landscape changes and perceptions of landscape aesthetics.

The interviews lasted from half an hour to two hours. Interviews were conducted individually and in small groups, in Nepali and English, where appropriate. Most of the interviews with the residents were conducted at their residences, where they were most comfortable, while the interviews with the tourists were mainly in restaurants or guesthouses. The aim was to select tourists who had spent some time exploring the town. This was possible in Bandipur, as the majority visited to relax and explore the town and spent two nights or more. However, most visitors to Ghandruk rarely spent more than a night, as it is mainly a stopover on a trekking route rather than the destination. They arrive in the afternoon and are too tired after the hike to explore the village further. They also leave early the next morning after breakfast and head to the next stop on their itinerary. This limits their perceptions on many aspects of aesthetic values, such as the experiential evocations gained from interactions with the local community. Their interactions are limited to the employees of the hotel, their trekking guide and fellow trekkers. However, other trekkers contribute substantially to their expectations and decision to visit the particular village, as in the case of Bandipur, which is an emerging destination and requires the least amount of preparations prior to the visit. On the other hand, the attraction in Sauraha is the national park and the segregation of the host community from the commercial tourist areas restricted interactions between the visitors 
and the hosts. Field observations continued during these visits, especially notes on the changing landscapes and reading the landscape from my perspective. My viewing of the landscape is intended to delve deeper into the multiple layers of interpretations. The next section presents a brief overview of the participants.

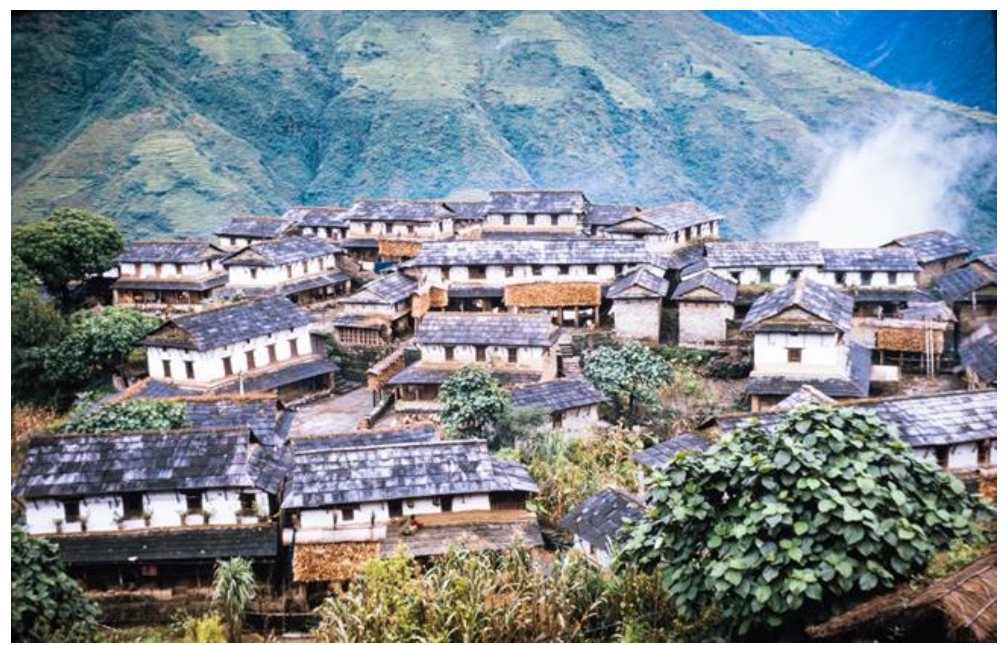

Photo: Mike Gill, Barbara Butterworth (PCNPP), 1973

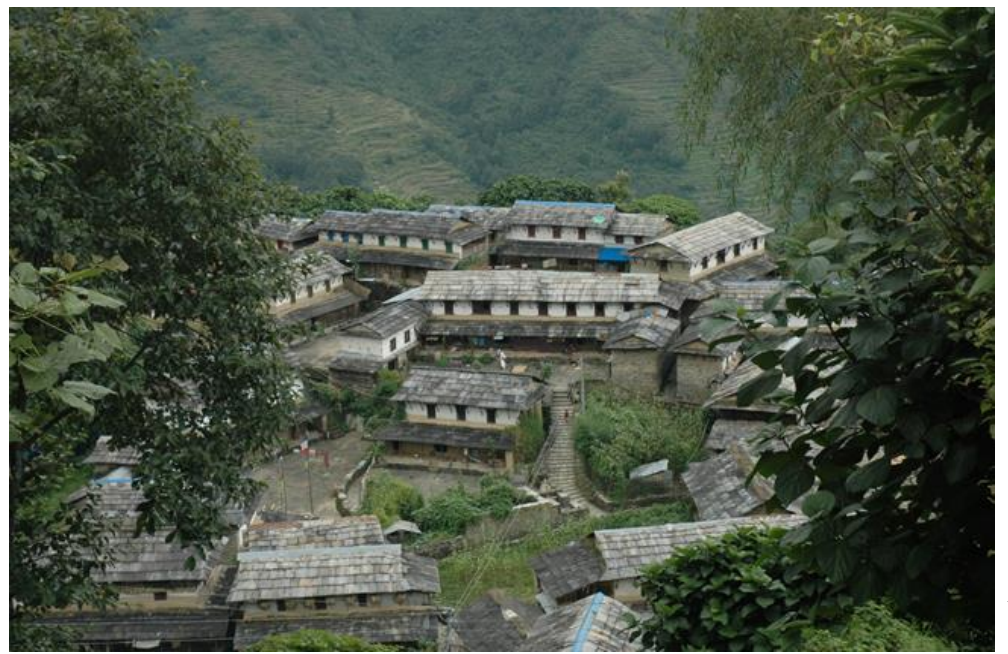

Photo: BECTP, 2006

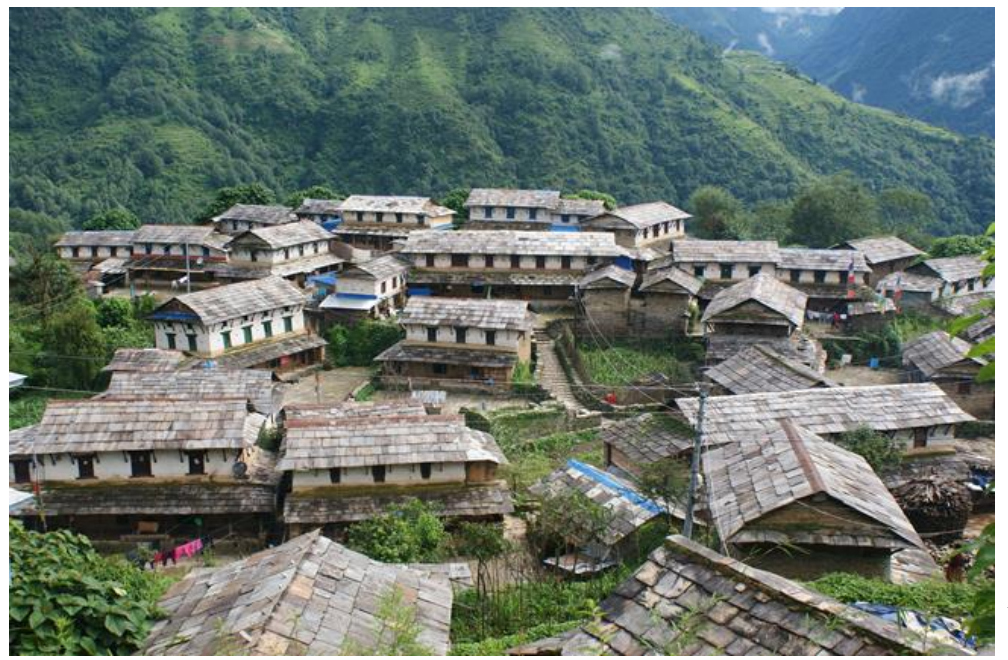

Photo: JJoshi, 2016

Plate 3-2: Example of past and repeat photograph set of Ghandruk village 


\section{The participants}

Out of the total 51 interviews, nineteen were conducted in Ghandruk (12 residents and 7 tourists), twenty-one in Bandipur (11 residents and 10 tourists) and eleven in Sauraha (10 residents and one tourist) (Tables 3-5, 3-6, 3-7). Participants included long-term residents and recent migrants attracted by the growth of tourism and residents who are not directly involved in the tourism sector. The residents were from the public and private sectors such as government and non-government organisations and businesses. The selection of the tourists (international and domestic) depended on their availability and seasonality. The tourists selected included high-end, budget travellers, short and long stay as well as repeat and first time visitors. The tourists were further sub-divided into domestic and international tourists. A gender balance was also sought as much as possible.

Resident participants were first selected from my existing contacts and networks in each site. Directed snowballing was used to select additional participants recommended by the key informants, contacts or participants. Participants were also selected during field observations to include a wider profile. Some of the interviews were pre-arranged while others occurred spontaneously. Family members, friends and neighbours sometimes joined in the conversation and were particularly interested in the photographs.

The non-tourism residents were concentrated in different areas of experience, work and age that included conservation experts, teachers, health workers and students. They were from age groups ranging from early twenties to elder residents, including the most senior person in Bandipur, 91 years old at the time of the interview. Although these participants were not working directly in the tourist industry, given that they live in a small community, their work supports the industry. For example, the mason and plumber may occasionally work for hotel owners to build or renovate their properties, or a teacher may help in running the family guesthouse when needed. Most non-tourism residents, especially in Ghandruk and Sauraha were involved in some form of farming regardless of their principal occupation. They were also involved in their communities in different capacities such as volunteering for community development work.

Most of the non-tourism sector participants lived with their families or extended families and were interviewed at their homes, hence family members were sometimes interviewed together (mother-in-law/daughter-in-law, husband/wife) as they continued with their 
household chores, minding children or making handicrafts. While Bandipur was the ancestral home for all non-tourism participants, some female participants in Ghandruk and Sauraha were born elsewhere and moved there after marrying residents. The residents were permanently based in Bandipur and Sauraha, while some residents in Ghandruk divided their time between the village and other towns. At the time of the interviews, some had recently returned to Ghandruk to celebrate Dashain, one of the major festivals in Nepal, with family and friends in their ancestral homes. Most of the interviews with the non-tourism sector residents in Sauraha took place in Bachhauli, an adjacent village that retains its traditional settlement form and indigenous Tharu population. As the indigenous population, the perceptions of the Tharu people are of particular interest, given their long history and traditional ties to the landscape and were sought for this study.

The tourism sector participants included long term residents as well as migrants, with families either living with them or in other towns in Nepal or abroad for studies or work. While only one participant in Ghandruk was a migrant (moved as a child for work), most of the participants in Sauraha were early migrants from the hill districts whose families had moved to Sauraha after malaria eradication either for agriculture, government employment, or more recently, tourism (section 6.1.1). There was a mix in Bandipur with one former resident returning to invest in tourism. This group included hotel owners, homestay owners, craft shop owners and tour guides; most owned their properties, while a few were renting. In addition to their business, most participants were active in their communities with the participants in Ghandruk also involved in some form of farming.

The tourists were chosen when striking up informal conversation and finding that their perspective would offer a wider dimension to the study. They were either guests at the guesthouses where I stayed or met at various restaurants and recommended by the guesthouse or restaurant owners and were interviewed in restaurants and cafés. Most tourists were first time visitors, with one international (Bandipur) and two domestic (Bandipur and Ghandruk) repeat visitors. The tourists were staying at different types of accommodations, ranging from family run homestays to local guesthouses and boutique hotels. 
The international tourists were from different countries (Canada, Israel, Netherlands, Spain, Switzerland, Taiwan, UK, and USA) and the domestic tourists were from Kathmandu. While most tourists interviewed were spending more than two nights in Bandipur, the tourists in Ghandruk were only spending a night. They were on longer trekking, such as the Annapurna Base Camp (ABC) $)^{5}$, arriving in the afternoon and leaving the next morning, except two domestic tourists travelling together who spent two nights while waiting for other members of their group. There were a variety of reasons for visiting Bandipur, but it was mostly to relax and experience village life. Except for the repeat visitor, the remaining participants had not pre-planned their trip to Bandipur prior to leaving their countries. They had either read about Bandipur or had been recommended by locals or other tourists met in their travels and mostly made spontaneous decisions to visit.

As Sauraha has transformed into an urban environment, the opportunities to interact with the tourists, both international and domestic were limited. Most of the tourists visiting Sauraha spent very little time exploring the nearby traditional villages and offered limited insights on the landscape and changes outside, which is the focus of this research. The primary reason to visit Sauraha was the Chitwan National Park; hence, there was limited interest among the tourists in the landscape beyond the boundaries of the park, where the main attractions were elephant rides, jungle walks and bird watching. Tourists have limited contact with the broader landscape of Sauraha and the informal conversations revealed that their input would have limited contribution to the research. This is mainly due to the stark change of the rural character of Sauraha to an urban main street development. Therefore, the only international tourist interviewed in Sauraha was a female from Canada, travelling with family friends in an extended visit of more than a month, mostly trekking in the Himalayas. Instead, the interviews focused on the perspectives of the local community living in the newly developed town as well as in the traditional village environment.

\footnotetext{
${ }^{5}$ Annapurna Base Camp trek, popularly known as ABC, is one of the most popular treks in Nepal. The setting of $\mathrm{ABC}$ at $4,130 \mathrm{~m}$ is unique with spectacular $360^{\circ}$ views of the Annapurna range and Machapuchhre.
} 


\begin{tabular}{|c|c|c|c|c|c|c|}
\hline & Pseudonym & Gender & $\begin{array}{l}\text { Residence or visit } \\
\text { length }\end{array}$ & Main occupation & Interview location & $\begin{array}{l}\text { Interview } \\
\text { date }\end{array}$ \\
\hline \multirow{4}{*}{ 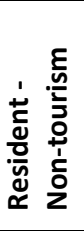 } & Sarita & $\mathrm{F}$ & Ancestral home & Homemaker & Home & 1-Oct-16 \\
\hline & Pratima & $\mathrm{F}$ & $\begin{array}{l}\text { Migrant } \\
\text { (marriage) }\end{array}$ & Homemaker & Home & 1-Oct-16 \\
\hline & Samjhana & $\mathrm{F}$ & $\begin{array}{l}\text { Migrant } \\
\text { (marriage) }\end{array}$ & Homemaker & Home & 1-Oct-16 \\
\hline & Rajesh & $\mathrm{M}$ & Ancestral home & Community worker & Home & 2-Oct-16 \\
\hline \multirow{8}{*}{ 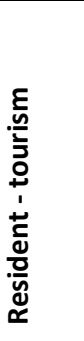 } & Bimal & $M$ & Ancestral home & Guesthouse owner & Guesthouse/ home & 1-Oct-16 \\
\hline & Hema & $\mathrm{F}$ & Ancestral home & Guesthouse owner & Guesthouse/ home & 1-Oct-16 \\
\hline & Srijana & $\mathrm{F}$ & Migrant (work) & Homestay owner & Guesthouse/ home & $2-O c t-16$ \\
\hline & Krishna & $M$ & Ancestral home & Guesthouse owner & Guesthouse/ home & 3-Oct-16 \\
\hline & Dibya & $\mathrm{F}$ & $\begin{array}{l}\text { Migrant } \\
\text { (marriage) }\end{array}$ & Homestay owner & Guesthouse/ home & $3-O c t-16$ \\
\hline & Himani & $\mathrm{F}$ & Ancestral home & Guesthouse owner & Guesthouse/ home & 3-Oct-16 \\
\hline & Anil & $M$ & Ancestral home & Guesthouse owner & Guesthouse/ home & 3-Oct-16 \\
\hline & Mahesh & $\mathrm{M}$ & Ancestral home & Teahouse owner & Teahouse/ home & 4-Oct-16 \\
\hline \multirow{3}{*}{ 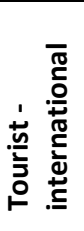 } & Penny & $\mathrm{F}$ & $\begin{array}{l}1 \text { night, } A B C \text { trek, } \\
\text { UK }\end{array}$ & Environment & Guesthouse & $1-O c t-16$ \\
\hline & Rob & $M$ & $\begin{array}{l}1 \text { night, Poon Hill } \\
\text { trek, Netherlands }\end{array}$ & Education & Guesthouse & $2-O c t-16$ \\
\hline & Lily & $\mathrm{F}$ & $\begin{array}{l}1 \text { night, } A B C \text { trek, } \\
\text { Israel }\end{array}$ & Engineer & Guesthouse & 3-Oct-16 \\
\hline \multirow{4}{*}{ 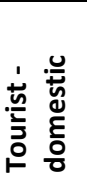 } & Hari & $M$ & 2 nights, $A B C$ trek & Public policies & Guesthouse & 1-Oct-16 \\
\hline & Himal & $M$ & 2 nights, $A B C$ trek & Public policies & Guesthouse & 1-Oct-16 \\
\hline & Sunil & $M$ & $\begin{array}{l}1 \text { night, Poon Hill } \\
\text { trek }\end{array}$ & Tourism & Guesthouse & 2-Oct-16 \\
\hline & Rashmi & $\mathrm{F}$ & 1 night, $A B C$ trek & Agriculture & Guesthouse & 3-Oct-16 \\
\hline
\end{tabular}

Table 3-5: Profile of participants in Ghandruk 


\begin{tabular}{|c|c|c|c|c|c|c|}
\hline & Pseudonym & Gender & Residence length & $\begin{array}{l}\text { Main } \\
\text { occupation }\end{array}$ & Interview location & $\begin{array}{l}\text { Interview } \\
\text { date }\end{array}$ \\
\hline \multirow{5}{*}{ 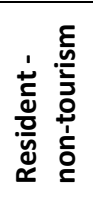 } & Prabin & 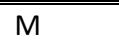 & "Ancestral home & "Tailor & "Home & 9-Jun-16 \\
\hline & Jivan & M & Ancestral home & Mason & Home & 9-Jun-16 \\
\hline & Binod & $M$ & Ancestral home & Teacher & Restaurant & 6-Oct-16 \\
\hline & Sunita & $\mathrm{F}$ & Ancestral home & Banker & Home & 2-Dec-16 \\
\hline & Jugal & $M$ & Ancestral home & Plumber & Home & 2-Dec-16 \\
\hline \multirow{6}{*}{ 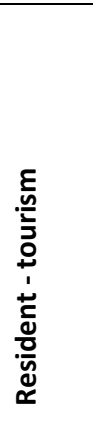 } & Binita & $\mathrm{F}$ & $\begin{array}{l}\text { Migrant } \\
\text { (marriage) }\end{array}$ & $\begin{array}{l}\text { Teahouse } \\
\text { owner }\end{array}$ & Home & 11-Jun-16 \\
\hline & Pankaj & M & Ancestral home & $\begin{array}{l}\text { Guesthouse } \\
\text { owner }\end{array}$ & Guesthouse/home & 11-Jun-16 \\
\hline & Harikala & $\mathrm{F}$ & Ancestral home & $\begin{array}{l}\text { Guesthouse } \\
\text { manager }\end{array}$ & Restaurant & 6-Oct-16 \\
\hline & Bipin & $M$ & Migrant (work) & Hotel owner & Hotel/home & 13-Nov-16 \\
\hline & Binay & M & Migrant (Investor) & $\begin{array}{l}\text { Guesthouse } \\
\text { owner }\end{array}$ & Guesthouse & 2-Dec-16 \\
\hline & Sushil & M & $\begin{array}{l}\text { Migrant } \\
\text { (Ancestral home) }\end{array}$ & Hotel owner & Hotel & 3-Dec-16 \\
\hline \multirow{6}{*}{ 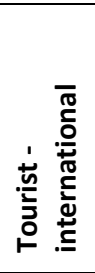 } & Angela & $\mathrm{F}$ & 2 nights, Spain & Therapist & Guesthouse & 9-Jun-16 \\
\hline & Maggie & $\mathrm{F}$ & 4 nights, USA & Artist & Hotel & 27-Jul-16 \\
\hline & Hanna & $\mathrm{F}$ & 7 nights, Taiwan & Writer & Restaurant & 30-Aug-16 \\
\hline & Becky & $\mathrm{F}$ & 5 nights, USA & Architect & Restaurant & 6-Oct-16 \\
\hline & Ray & $M$ & 5 nights, USA & Nurse & Restaurant & $6-O c t-16$ \\
\hline & Tim & M & $\begin{array}{l}4 \text { nights, } \\
\text { Switzerland }\end{array}$ & $\mathrm{IT}$ & Restaurant & 4-Dec-16 \\
\hline \multirow{4}{*}{ 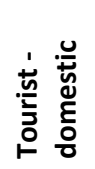 } & Paras & $M$ & 7 nights, & Auditor & Hotel & 13-Nov-16 \\
\hline & Mahesh & $M$ & 7 nights, & Auditor & Hotel & 13-Nov-16 \\
\hline & Bhavana & $\mathrm{F}$ & 2 nights, & Homemaker & Hotel & 3-Dec-16 \\
\hline & Bandana & $\mathrm{F}$ & 2 nights, & Homemaker & Hotel & 3-Dec-16 \\
\hline
\end{tabular}

Table 3-6: Profile of participants in Bandipur

\begin{tabular}{|c|c|c|c|c|c|c|}
\hline & Pseudonym & Gender & Residence length & $\begin{array}{l}\text { Main } \\
\text { occupation }\end{array}$ & Interview location & $\begin{array}{l}\text { Interview } \\
\text { date }\end{array}$ \\
\hline \multirow{6}{*}{ 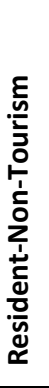 } & Bijay & $\mathrm{M}$ & Ancestral home & Museum & Tharu Cultural Museum & 15-Nov-16 \\
\hline & Debesh & $M$ & Ancestral home & Teacher & Home & 15-Nov-16 \\
\hline & Anju & $\mathrm{F}$ & Ancestral home & Student & Tharu Cultural Museum & $15-N o v-16$ \\
\hline & Laxman & M & Ancestral home & Farmer & Home & 17-Nov-16 \\
\hline & Poonam & $\mathrm{F}$ & Ancestral home & Student & Home & 17-Nov-16 \\
\hline & Lalita & $\mathrm{F}$ & Migrant (long term) & $\begin{array}{l}\text { Health } \\
\text { worker }\end{array}$ & Home & 17-Nov-16 \\
\hline \multirow{4}{*}{ 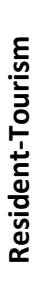 } & Govind & M & Migrant (long term) & Hotel owner & Hotel & 16-Nov-16 \\
\hline & Chenu & $\mathrm{F}$ & Migrant (recent) & Shop owner & Shop & 16-Nov-16 \\
\hline & Rakesh & M & Migrant (long term) & Hotel owner & Hotel & 15-Nov-16 \\
\hline & Bidur & M & Migrant (long term) & Guide & Restaurant & 17-Nov-16 \\
\hline 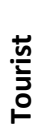 & Samantha & $\mathrm{F}$ & 2 nights, Canada & $\begin{array}{l}\text { Health } \\
\text { worker }\end{array}$ & Bus & 18-Nov-16 \\
\hline
\end{tabular}

Table 3-7: Profile of participants in Sauraha 


\subsubsection{Data analysis (Phase 3)}

Data analysis was conducted in two stages. First, a preliminary data analysis was carried out while transcribing the interviews. This provided the basis for developing coding and an appropriate analysis system for the final qualitative analysis that led to the findings and discussions (chapters four to seven) relating to the overarching research question and supplementary questions. In the second stage of analysis, the data was coded manually with additional use of the software NVivo. Coding occurred in multiple stages (open, axial and selective) based on descriptive, interpretive or patterns (Jennings, 2010). The interviews led to an inductive approach to analysing the data and extracting themes regarding the perceptions of the participants on landscape, changes, tourism and landscape aesthetics. The analysis consisted of repeated reading of the transcripts, the identification of an initial set of themes and then efforts to group themes, remaining cognizant of both clusters of similar themes and themes that are different or contradict each other. Attention was given to both the commonalities and contrasts as the themes that emerged were analysed and compared across the different groups (international, domestic tourists, residents who worked in the tourism industry and residents who were not directly involved in tourism) as well as across the three case studies. The photographs also illustrated the changes in landscapes and were included in the analysis.

This section first presents the analytical framework adopted followed by the process for analysing the data collected described in the previous section.

\section{Analytical framework}

Following the conceptual framework and the research questions, the focus of this analytical framework is on the landscape, landscape aesthetics and the drivers of change considering the perceptions of residents and tourists. As already established, this research adopts a holistic concept of landscape that is a dynamic social construct. In order to address the overarching research question on the perspectives of the residents and tourists on landscape aesthetics that is changing, it is important to first examine the drivers of change. Identifying the drivers of change lead to addressing the question why the changes are taking place. In this research, in addition to the other drivers of change, tourism is examined closely as the selected case studies are tourist destinations of different type, 
location and context. Tourism is used as a tool to improve the local economy and therefore, tourism development as a driver of change has already been established in other parts of the world (Tzanopoulos \& Vogiatzakis, 2011). Due to the importance of tourism in these case studies, it is critical to examine why as well as the process of how tourism is changing the landscape. In this analytical framework, the analysis of the drivers leads to the emerging themes that are central to the changing landscapes. The analysis of the perspectives of the residents and tourists on both the changing landscape and drivers of change lead to identifying the different aspects of landscape aesthetics.

As described in the previous section, following Pearce (1993), this analytical framework takes the comparative case study approach where the case studies are analysed and interpreted individually, and the subsequent findings are identified, compared and interrelated. As shown in the analytical framework (Figure 3-1), the analysis was conducted in three dimensions. First, the data are compared across the themes and the drivers of change. In addition to the significant role of tourism, the other key drivers examined are the local and national policies (and global trends), urbanisation, globalisation and migration (in and out migration). The components of landscape are also examined individually, initially by each case study. Secondly, the themes on the drivers of change and landscape aesthetics are examined across the cases. This comparison helps in examining the interrelationships between the themes and the case study context. This also reveals the impact of the drivers of change on the different components of landscape as well as overall landscape aesthetics. Third, the themes and case studies are examined from the perspectives of the residents and tourists. Finally, the perspective of the researcher overlaps the analysis of the case studies and the themes as well as the analysis of the documents and photographs to assess landscape change. Field notes and conversations with key informants were used to augment the findings, in particular the contextual background sections and the discussions in chapter seven.

This analytic framework (Figure 3-1) examines all the components of the landscape individually and holistically to compare and contrast across the cases for similarities and differences. The framework also examines the local and external factors and actors that are driving change. This helps to reveal the relationship between the drivers of change and the components of landscape. It also helps to reveal the intensity and impact of changes on the landscape. The comparisons across the case studies help to reveal the 
dependence and relationship between the drivers of change and landscape on the historical context, physical setting, the nature of tourism and other general and specific development issues.

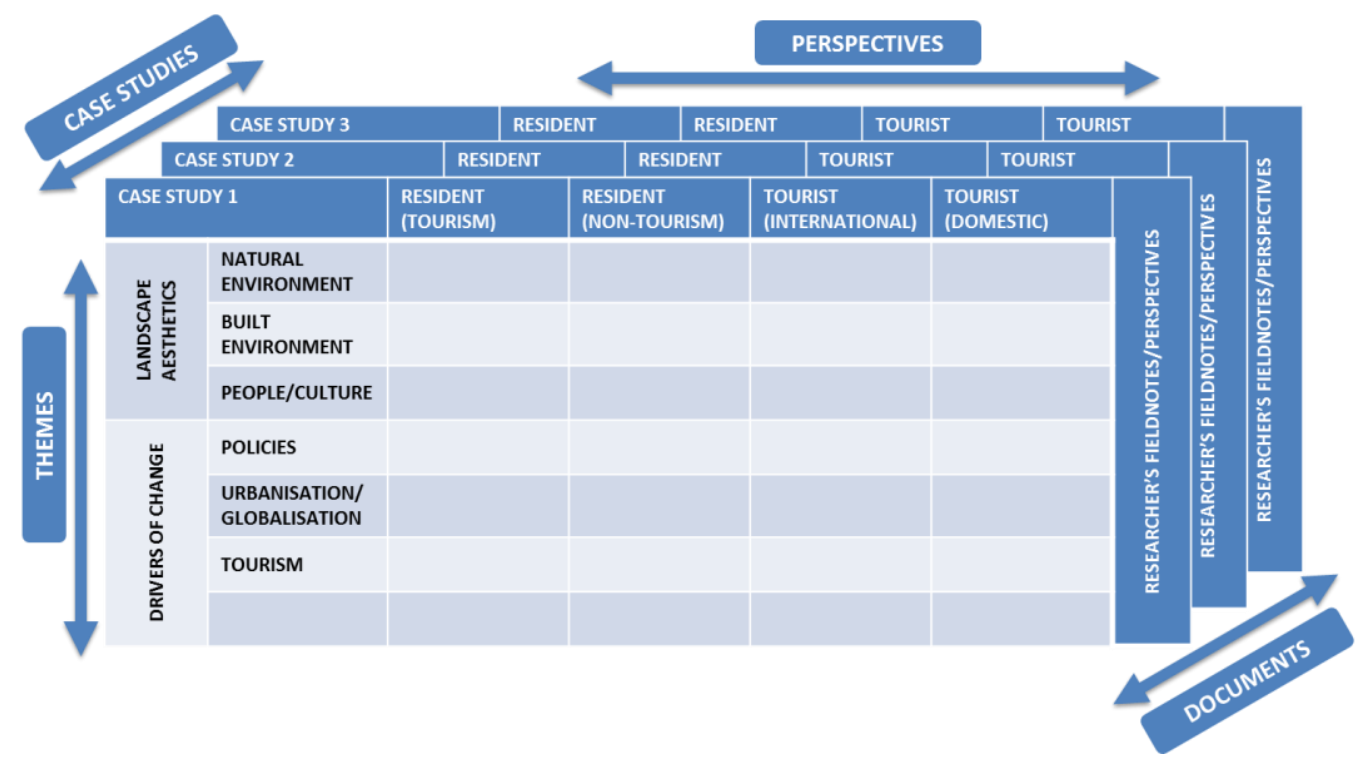

Figure 3-1: Analytical framework: Data analysis and comparison across themes and case studies

In addition to identifying why the changes are taking place, it is also important to understand how the transformation is occurring to assess their type and impact on the landscape. The analysis of the drivers of change reveals how the landscape is changing. In other words, it reveals the components of the landscape that are transforming and what the transformations are. Comparisons across the case studies help predict changes between places where a certain process is emerging and where impacts are visible. For example, urbanisation already has visible impacts in Sauraha, while Bandipur and Ghandruk are urbanising. Comparisons also help reveal the interrelations between the different components of the landscape and location, type and context of the case studies.

The second component of this analytical framework is the perspectives of the residents on the changing landscapes. Their perspectives are examined to explore the different dimensions of landscape aesthetics. Studies have demonstrated that residents and tourists view landscape aesthetics differently (Urry, 2002) and their background, motivations and histories influence their perspectives (Uusitalo, 2010). Therefore, the perspectives of the residents and tourists are sought to examine the extent of diversity of aesthetic values associated with the landscapes. This analysis leads to identifying and defining landscape 
aesthetics from the perspectives of the residents and tourists. Understanding the perspectives of different groups of people enables better information for management and planning strategies.

Drivers of change in landscapes are important to understand for management, conservation and development strategies at the landscape scale. Similarly, taking into account the perspectives of different groups that are involved directly and indirectly with the landscape enables successful implementation of plans and policies. Comparison across the case studies of the drivers of change helps reveal the temporal and spatial dimensions of landscape change. Comparisons across different perspectives reveals the impacts on change in different contexts. Overall this analytical framework helps identify the interrelationships between the landscape, drivers of change and the perspectives of different groups of people. This is a complex process with several overlaps. People are within the landscape as part of it and looking at the landscape with different perspectives that are products of their individual and social context, worldview and position. Similarly, tourism is part of the local economy and a driver of change, however it is also a component of the landscape and also a product of the changing landscape.

\section{Analytical process}

Data was analysed in Wellington after the fieldwork based on the verbatim transcriptions of the 51 interviews. The interviews in English were transcribed directly, while the interviews in Nepalese were translated and transcribed simultaneously. My knowledge and fluency in both languages enabled me to transcribe as I translated. This process of transcribing also helped me gain a sense of the whole body of data. Halfway through the transcriptions, I started manually coding the data.

Initially, data was coded by reading the transcripts several times while taking notes and sorting out by theme. A trial coding was also conducted using NVivo. The data was first sorted by the broad questions on landscape, tourism and change. Emerging themes were then identified and coded accordingly (see Table 3-8 for an example). This software proved useful in managing the volume of data. Once all data was transcribed, it was again first analysed using NVivo. This sorted the data by the themes identified in the earlier trial analysis. NVivo also proved useful to perform multiple searches using the themes 
and also get an overview of the entire data. However, in order to collect the nuanced interpretation, the final analysis was performed manually. As mentioned, the semistructured format of the interview allowed for free-flowing conversations that went back and forth between the topics. Furthermore, the topics often overlapped and thus, the final analysis was performed by reading the transcripts several times, colour-coding the emerging themes and sorting by broad themes. To reduce the likelihood of misinterpretation, a triangulation process was used, and transcripts were re-read to verify the validity of the themes.

As demonstrated, the complexities of the concepts of landscape, change and perspectives require a multi-phase research methodology. This qualitative research recognises this complexity and the contribution of the responses of humans (both the researcher and the participants) in this phenomenon and adopts an interpretivist paradigm. The next section presents in detail this research paradigm that guided the study. 


\begin{tabular}{|c|c|c|c|c|c|c|c|}
\hline 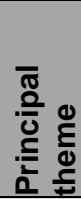 & 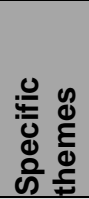 & 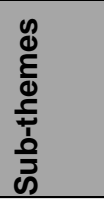 & Characteristics & $\begin{array}{l}\text { Residents } \\
\text { Non tourism }\end{array}$ & $\begin{array}{l}\text { Residents } \\
\text { Tourism }\end{array}$ & $\begin{array}{l}\text { Tourists } \\
\text { International }\end{array}$ & $\begin{array}{l}\text { Tourists } \\
\text { Domestic }\end{array}$ \\
\hline \multirow{29}{*}{ 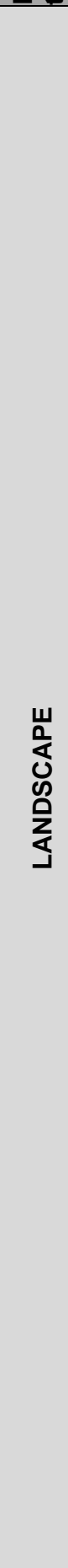 } & \multirow{10}{*}{ 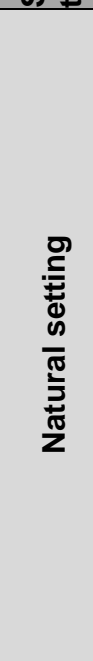 } & \multirow{4}{*}{ 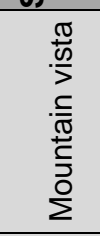 } & $\begin{array}{l}\text { Long range of the } \\
\text { Himalayas }\end{array}$ & & & & \\
\hline & & & $\begin{array}{l}\text { Marshyangdi valley } \\
\text { and the Himalayas }\end{array}$ & & & & \\
\hline & & & Above the clouds & & & & \\
\hline & & & Layers of mountains & & & & \\
\hline & & \multirow{4}{*}{ 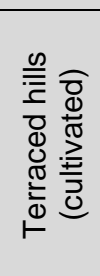 } & Southern view & & & & \\
\hline & & & $\begin{array}{l}\text { Changing colours in } \\
\text { a day }\end{array}$ & & & & \\
\hline & & & $\begin{array}{l}\text { Changing colours in } \\
\text { different season }\end{array}$ & & & & \\
\hline & & & $\begin{array}{l}\text { Farming seasons } \\
\text { and variety }\end{array}$ & & & & \\
\hline & & \multirow[b]{2}{*}{ 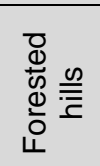 } & Greener & & & & \\
\hline & & & Community forests & & & & \\
\hline & \multirow{9}{*}{ 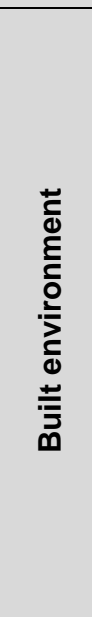 } & \multirow{6}{*}{ 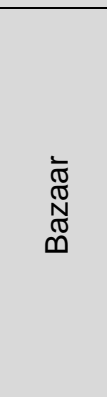 } & $\begin{array}{l}\text { Well preserved row } \\
\text { houses }\end{array}$ & & & & \\
\hline & & & $\begin{array}{l}\text { Wide stone paved } \\
\text { bazaar }\end{array}$ & & & & \\
\hline & & & $\begin{array}{l}\text { Spread out from the } \\
\text { main centre }\end{array}$ & & & & \\
\hline & & & $\begin{array}{l}\text { Covered walkway, } \\
\text { windows }\end{array}$ & & & & \\
\hline & & & Vehicle free & & & & \\
\hline & & & Restaurants, cafes & & & & \\
\hline & & \multirow{3}{*}{ 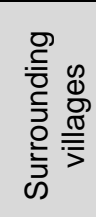 } & $\begin{array}{l}\text { Different } \\
\text { architectural style }\end{array}$ & & & & \\
\hline & & & $\begin{array}{ll}\text { Easy } & \text { walking } \\
\text { distance }\end{array}$ & & & & \\
\hline & & & Smaller villages & & & & \\
\hline & \multirow{10}{*}{$\begin{array}{l}\text { :े } \\
\text { हิ } \\
\text { है }\end{array}$} & \multirow{3}{*}{$\begin{array}{l}\overline{\tilde{J}} \\
\mathbb{N} \\
\mathbb{N} \\
\tilde{N}\end{array}$} & $\begin{array}{l}\text { Activities all day, } \\
\text { lively }\end{array}$ & & & & \\
\hline & & & Friendly & & & & \\
\hline & & & Festivals & & & & \\
\hline & & \multirow{3}{*}{ 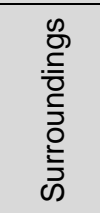 } & $\begin{array}{l}\text { Different } \\
\text { communities }\end{array}$ & & & & \\
\hline & & & Festivals & & & & \\
\hline & & & $\begin{array}{ll}\begin{array}{l}\text { Good } \\
\text { distance }\end{array} & \text { walking }\end{array}$ & & & & \\
\hline & & \multirow{4}{*}{$\vdash$} & Employment & & & & \\
\hline & & & Income rise & & & & \\
\hline & & & $\begin{array}{l}\text { In-migration, } \\
\text { returning locals }\end{array}$ & & & & \\
\hline & & & Revival of festivals & & & & \\
\hline
\end{tabular}

Table 3-8: Example of initial coding of interviews in Bandipur 


\subsection{RESEARCH PARADIGM}

This research applies an interpretivist paradigm with qualitative methods using interviews, field observations, and comparative study. With roots in philosophy and the human sciences, particularly in history, philosophy and anthropology, the interpretivist paradigm believes that understanding human experiences is as important as focusing on explanation, prediction and control (Phillimore \& Goodson, 2004). This approach is selected to examine landscape aesthetics from the participants' point of view that goes beyond visual observations to include their experience with the multiple aspects of the landscape. The approach to landscape taken in this research places people in the landscape and outside the landscape with the understanding that they are contributing to the change and transforming in the process. The experience of people is essentially context-bound and thus, complete objectivity, or neutrality was not sought, but encouraged, and along with the values of participants, my values also became integral parts of the research (Phillimore \& Goodson, 2004). Views of residents and tourists were collected to include diverse opinions on the aesthetic values of the landscape. The rationale for this approach was based upon the need to explore the context of the participants in order to ascertain the validity of their perspectives.

Hall (2004) regards personal reflexivity to be essential in qualitative research adding value to the research process and the way in which the researcher engages with the research subjects, particularly with regard to participant observation. In being reflective, I understand that research is an interactive process between myself and the participants that is influenced by different forces and constraints. Pink (2006) further adds that

\section{Reflexivity should be integrated fully into processes of fieldwork and visual or written representation in ways that do not simply explain the researcher's approach but reveal the very process by which the positionality of researcher and informant were constituted and through which knowledge was produced during the fieldwork. (p. 35)}

I acknowledge that my background in architecture with specialisation in historic preservation and cultural landscapes strongly determined my research interests and the overarching research question on the aesthetic values of changing landscapes. My reflections and dilemma as a researcher born and raised in the Asian culture yet trained in western educational values also becomes integral part of the fieldwork. For example, 
documentation and physical evidence is strongly emphasised in the west when evaluating heritage values and material authenticity and conservation gain precedence. On the other hand, intangible values such as rituals and practices are prioritised over authenticity of physical materials in the eastern value system.

My position as the researcher adheres to the interpretivist paradigm due to my previous work and familiarity in the selected sites and acquaintance with some of the participants from my previous visits. I have worked extensively in Bandipur and visited Ghandruk and Sauraha multiple times before embarking on this research and have contributed to the landscape change to some extent. I have worked in Bandipur and Sauraha in different capacities contributing to the preservation of the towns, change and tourism. As an architect, I have restored traditional buildings as well as designed new structures. As a consultant, I have advocated for the preservation of the landscape and promotion as an attractive tourist destination. As a domestic tourist, I have participated in activities, such as hiking in Bandipur and Ghandruk, elephant rides in Sauraha and tasted local food in all sites. As a researcher from Nepal, I have the advantage of being able to converse in the local language and my familiarity with the local culture enabled me to travel and approach participants for interviews with relative ease. My experience and familiarity with the case studies also permitted sustained engagement and facilitated an insider knowledge of the landscape and the socio-cultural dynamics of the sites. On the other hand, as a qualified architect, I was also able to input an external expert view. This is a definite advantage for the in-depth interviews with the participants, where I could provide information and elaborate on the discussions to probe deeper into the different aspects of landscape aesthetics

However, my disposition and life history are not the foreground of this research and the interpretivist approach goes beyond to actively interact with the participants using photographs as a tool to initiate and induce discussions on the multiple interpretations of landscape aesthetics. It is inevitable that my position and background shaped and directed my interpretation of the perceptions of others. My field observations also formed part of this research and enabled me to delve deeper into the multiple layers of interpretation of the landscape. My values also directed the selection of the photographs and the interview questions. 
In addition, my own perspectives have also evolved throughout the research process, interviewing the respondents and seeing the landscape through their eyes. I started this research project to examine the views of the residents and tourists regarding the changing natural and built landscapes. As explained in the earlier chapters, the majority of literature on the values of landscapes are from the perspectives of the experts and focused on environmental, social or cultural ecosystem services of landscapes. I was interested to engage the residents and tourists to explore the multiple aspects of the landscape, from the physical to symbolic aesthetic values to understand the significance and influence of context, background and values of the participants on their understanding and perspectives of the landscape. During the interviews and later while analysing the data, I realised that the people, both residents and tourists are part of the landscape, observe and experience the landscape and are observed as part of the landscape. Thus, people become the central value of both the landscape and landscape aesthetics.

Lastly, but most importantly, this research looks at landscape and the associated aesthetic values as a complex and unpredictable social construct. This research sought to inquire into the symbolic meanings people attach to landscapes. The aim was to explore the multiple and subjective dimensions of what people considered as aesthetic values for landscapes in different contexts, especially in the changing dynamics of tourism development. The mode of inquiry utilised in-situ observation of the landscape, past and repeat photographs and verbal descriptions through semi-structured interviews to delve deeper into viewing landscape beyond the traditional concept that considered landscape within the boundaries of physical and objective. This approach intends to increase the dynamic notion of text and enable the researcher to understand the meanings, interpretations and practices of the participants regarding the aesthetic values of landscapes (Bellentani, 2016).

\subsection{STRENGTHS AND LIMITATIONS OF METHODOLOGY AND DATA}

The main strength of this study lies in the comprehensive comparative case studies in three different geographic locations with distinct historic and cultural contexts. The use of multiple case studies broadened the scope of the overarching research question to produce credible results (Yin, 2012). The different context, type and location of the three 
case studies broadened the perceptions of landscape aesthetics and the drivers of change. The comparative study has proved to produce a rich content of the multiple dimensions of landscape and the associated aesthetic values. It also provides scope to explore the interrelationships between the drivers of change and the different case studies.

The strength of this study also lies in the multi-layered methodology adopted. The objective of this study, to explore the aesthetic values of the changing landscapes that includes both the tangible and intangible aspects of the landscapes from the perceptions of the residents and tourists, is complex. This required multiple visits to the case study sites and use of multiple data sources to prepare for the interviews that could capture the different cognitive and sensory aspects of landscape aesthetics. In addition, the concept of change is complex and has different meanings to different people. The multiple visits also allowed me to observe the sites in different seasons and assess a variety of landscape elements to fine-tune the interview questions. My extensive engagement in the sites also allowed for rich data collection with probing questions in the interviews and deep discussions on the complex issues of landscape aesthetics.

The in-depth interviews using the photo-elicitation technique proved to stimulate the respondents' memories and evoked responses that were rich in content. The use of past and repeat photographs provided the respondents with visual representations of the change that were easier to observe. This also provided the tourists with additional information on the context and history of the place enriching their experience and subsequently their perception of the changing landscapes and their aesthetic values. For some residents, the photographs evoked memories that are difficult to capture by simple verbal interviews. The photographs provided the participants with a better understanding of the landscape change.

In addition, the interviews were conducted in-situ, providing the respondents with a further layer of information to reflect upon. The small scale of the case study sites was advantageous as the participants had been to or were aware of the locations of the photographs and could compare the past and repeat photographs with what they viewed personally. Comparing the present landscape to the photographs of the past landscape and the repeat photographs taken in another season provided multi-dimension to the landscape perspectives. Thus, the participants were able to draw upon different 
perspectives of the landscape to reflect on their perception of landscape aesthetics. This is a novel approach that has proved to produce rich and good quality content on the cognitive and experiential aspects of landscape aesthetics.

The main limitation of this research is the scarcity of official documents such as maps and plans of the case study sites that would have been useful to assess the change, especially the style, size and scale of development. Although maps and mapping methodologies have evolved in the past decades, maps as a graphic reference remains a visual representation of the landscape (Cosgrove, 2008). However, maps are restricting when considering the personal and experiential values attached to landscapes and also reflect the dominating rational and scientific ways of reflecting the physical world (Cosgrove, 2008). Similarly, aerial photography has also been used to study landscapes and monitor the land cover changes and expansion of built-up areas (SK Nepal, 2005; Terkenli, 2001). Landscape change in urban areas has considered the built environment but only to the extent of built up areas and not the vernacular or distinctive architectural character (Antrop, 2004). Aerial photography has been used to measure the impact of climate change on land and sea; however, the scale of most available photographs limits their application to read the changes in rural settlement patterns that are largely small structures clustered among forested land or agricultural fields. Furthermore, in the cases of Ghandruk and Bandipur, the steep topography of the land distorts the image when captured two-dimensionally by photographs. The earliest clear aerial photographs available on Google Maps for Ghandruk date to 2012, for Bandipur 2008 and Sauraha 2005. Again, the two-dimensional images do not validate the steep topography of Ghandruk and Bandipur sufficiently to be able to appreciate the dramatic layering and aesthetic value of their landscape. The steep vicissitudes of the terrain that is characteristic of Ghandruk and the location of Bandipur on the ridge are lost in the aerial images. On the other hand, aerial photographs of the flat plains of Sauraha provide a useful perspective of the landscape, the lay of the land and the patterns of the farms, which would not be visible at eye level on the ground.

The lack of maps and record keeping has restricted the data collection to verbal accounts of events and the timescale of change. However, this lack of formal documentation stimulated me to explore other modes of data collection, such as the use of the past and repeat photographs and in-situ interviews. The ways of seeing and experiencing 
landscapes vary with individuals, cultures, genders and previous knowledge. Therefore, the photo-elicitation interviews were effective to explore the multi-faceted dimensions of landscape aesthetics. As visual methodologies advance and evolve across disciplines, use of photographs augments the types and layers of knowledge that derive from different viewers (Pink, 2012). Images are useful tools to initiate and expand interviews to include personal memories and reflections evoked by the images presented (Matteucci, 2013). Images also evoke more comprehensive and longer interviews as well as interaction between the researcher and the participant (Harper, 2002). The availability of photographic documentation from the 1960s when modern tourism was introduced in Nepal also mitigated the limitations of recorded documents. The photographs taken at different times also provided participants with a historic reference for comparison.

This research is also limited to the views of Nepalese and English speakers. On the other hand, the dual languages, especially the use of the local language, Nepalese, was useful to gain the trust of the local community and communicate openly. The three case study sites have different ethnic languages (Gurung in Ghandruk, Newari in Bandipur and Tharu in Sauraha) the commonly spoken official language of Nepal was used for the interviews with the residents and domestic tourists. Although English was the common language for interviews with the international tourists, not all were native English speakers, which has provided a range of international participants. The time limitations of the study also restricted the interviews, especially the tourists to those available at the time. However, the initial field trip was useful to identify and arrange interviews with the local community participants, which has greater importance compared to the brief experience of the tourists.

The in-depth nature of the interviews also limited the number of participants that could be included in the study; however, efforts were taken to include a wide selection, including a gender balance. This small sample size has implications for the findings in that it may not represent the views of a wider population. The focus was to include diverse perspectives such as long-term and short-term residents, tourism and non-tourism residents, residents living in the town centres and in the periphery, and long and short stay tourists staying at different types of accommodation and price range. Although policymakers and planners were not specifically selected for the interviews, given the small communities, some resident participants held multiple roles, such as guesthouse 
owners who also chaired the local tourism committee or were members in the local development committees. The focus of the current research is on the perceptions on landscape aesthetics and change and thus, participants were sought from the general residents rather than specifically seeking persons in authority. However, some of the key informants were policymakers and their views were incorporated in the discussions and the informed the contextual background of the case study sites.

In addition, my presence as a researcher in a small community may have had interviewer effects as there were possibilities of multiple encounters before and after the formal interviews. I knew some of the participants from my previous visits and this may have influenced their responses. The participants, especially the residents, are also known to each other and may influence their responses depending on when the interviews were conducted and who else was present. Efforts were taken to objectively conduct the interviews, however, given that my interests were the basis of this research and the interview questions, total objectivity was not sought.

\subsection{CONCLUSION}

The methodology used for this research drew from the conceptual framework that introduced the interrelationship between landscape, perceptions of landscape aesthetics and change. The multi-layered methodology adopted enabled the collection of data to address the overarching research question on the perceptions of landscape aesthetics in the changing landscapes in Nepal. In-depth interviews with the past and repeat photographs helped to explore landscape changes as well as the perceptions of landscape aesthetics.

The selection of the three case studies in the different geographic regions with distinct cultural contexts and different tourist development trajectories broadened the scope of comparative studies. The use of past and repeat photographs and in-situ interviews allowed for multiple interpretations of the cognitive and experiential dimensions of landscape aesthetics. Aesthetic values are also subjective, and the in-depth interviews was the appropriate method to draw the varying aspects of landscape and landscape aesthetics. The interpretivist paradigm used allowed me to explore the context of the participants as well as incorporate their values and worldviews. It also allowed me to 
acknowledge my values, background and previous knowledge that has shaped and directed this research.

This research is based on the 51 interviews in three case studies and includes perceptions of residents and tourists interviewed over a period of seven months. The semi-structured interview aimed to draw upon the participants' (especially the residents') memories to examine the perceptions of landscape aesthetics and landscape change. The diversity of the residents and tourists from different backgrounds has added richness and quality to the data collected. The analytical framework used to compare across the three dimensions of themes, case studies and perceptions was useful to explore the multiple interrelations between the key concepts of landscapes, change and perceptions of landscape aesthetics.

The next chapters (four to six) present the findings individually in the three case study sites: Ghandruk, Bandipur and Sauraha. In order to understand and address the overarching research question of how residents and tourists perceive the aesthetic values of changing landscape in Nepal, the three chapters present how the participants perceive landscape aesthetics and landscape change. Each chapter begins with an introduction to the site to provide a historical context prior to presenting the findings from the interviews. This contextual information is based on secondary sources, field notes and interviews with key informants and includes a brief outline of conservation policies and tourism development in each site. Next, the findings based on the interviews with the participants is presented, starting with the perceptions of landscape aesthetics. As stated in previous chapters, landscape aesthetics in this research encompasses the natural and the built landscape as well as the cultural landscape that includes the people. This is followed by their perspectives on the landscape change before conclusions are drawn. 


\section{GHANDRUK: CO-EXISTANCE BETWEEN CONSERVATION AND ROAD DEVELOPMENT}

In order to understand and address the overarching research question on how residents and tourists perceive the aesthetic values of changing landscape in Nepal, this chapter presents their perceptions on Ghandruk. Ghandruk is a relatively successful example of community-based conservation in Nepal and globally. Tourism in Ghandruk is mainly based on trekking and adventure tourism with the focus on nature and culture as an additional attraction.

First, this chapter presents a contextual background on Ghandruk, including its location, history, people and settlement This section also includes a brief outline of conservation policies and tourism development in Ghandruk. This is based on field notes, interviews with key informants and secondary sources that include literature, documents, maps, photographs and interviews. This section also includes my observations and reflections from my previous visits for work and recreation as well as notes from formal and informal conversations with the residents and tourists. Next, in section 4.2 , the findings from the main interviews are presented; first, residents and tourists' perceptions on the landscape, followed by their perspectives of landscape changes, mainly focused on tourism, before conclusions are drawn. As stated in chapter three, 19 participants (12 residents and 7 tourists) were interviewed in Ghandruk (Table 3-5).

\subsection{CONTEXTUAL BACKGROUND}

Ghandruk lies in Kaski district in the southern part of the Annapurna Conservation Area and is a substantial village. It is situated $55 \mathrm{~km}$ northwest of Pokhara, the second most visited destination in Nepal after the capital, Kathmandu. Located at 1,975 metres above sea level, the topography of the village is moderately steep and incorporates several smaller villages or settlements. In the 2011 census, Ghandruk had a total population of 6,158 people in 1,102 households with 2,054 male and 2,211 female members (CBS, 2012). The majority are Gurung with other ethnic groups intermingled at the periphery of the main village. The local economy depends on tourism and the forest and their management is a key priority in this region (Adhikari \& Fischer, 2011). 
The landscape of Ghandruk and the views from the village contain some of the most spectacular natural areas in the world. The lowlands of Ghandruk Besi, where the climate is hot in the summer is mostly cultivated. Most of the settlements are located in the upper parts where the temperature is moderate with heavy rainfall during the monsoon season. This region is also densely covered by forest of mixed type with a variety of rhododendron trees that bloom in the spring adding to the attraction. The higher areas of Ghandruk extends to the foothills of Annapurna South and are extremely cold all year around. The mixture of green forested hills and cultivated terraces that change colours with the different seasonal crops with the high snow-capped mountains, especially the Annapurna range and the Machhapuchhre with its unique fish-tail shaped peak (the name in Nepali translates to fish tail as the mountain is colloquially referred to) creates perfect photo opportunities in Ghandruk (Plate 4-1).

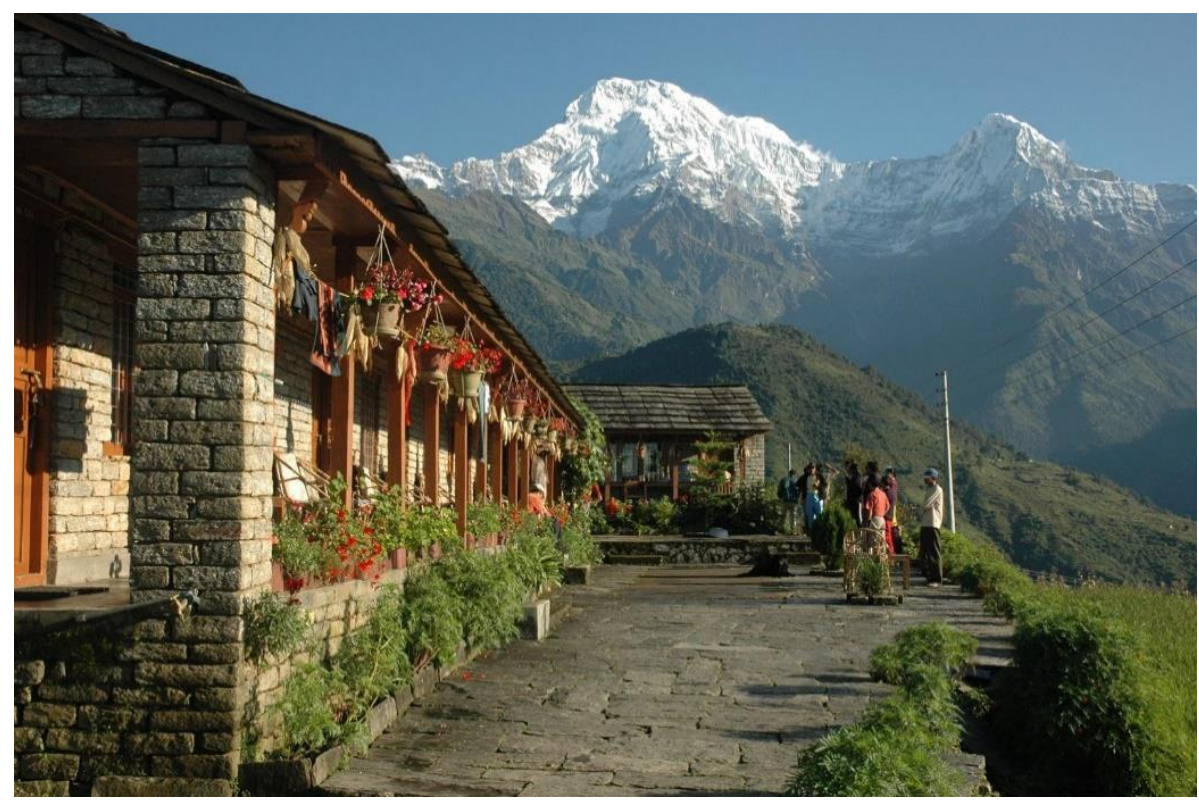

Plate 4-1: Ghandruk with Annapurna range in the background

Photo: BECTP, 2006 
Ghandruk village is accessed from Birethanti, on the Prithvi Highway that connects to Pokhara (Plate 4-2). It was only accessible by a foot trail (about 5-6 hours' uphill hike from Birethanti ${ }^{6}$ to main Ghandruk village) until the construction of a fair-weather road which opened in 2016. This new gravel road connects Birethanti to Kimchi at the base of the village with regular bus/jeep services from Pokhara, reducing the trek to the main village to a couple of hours.

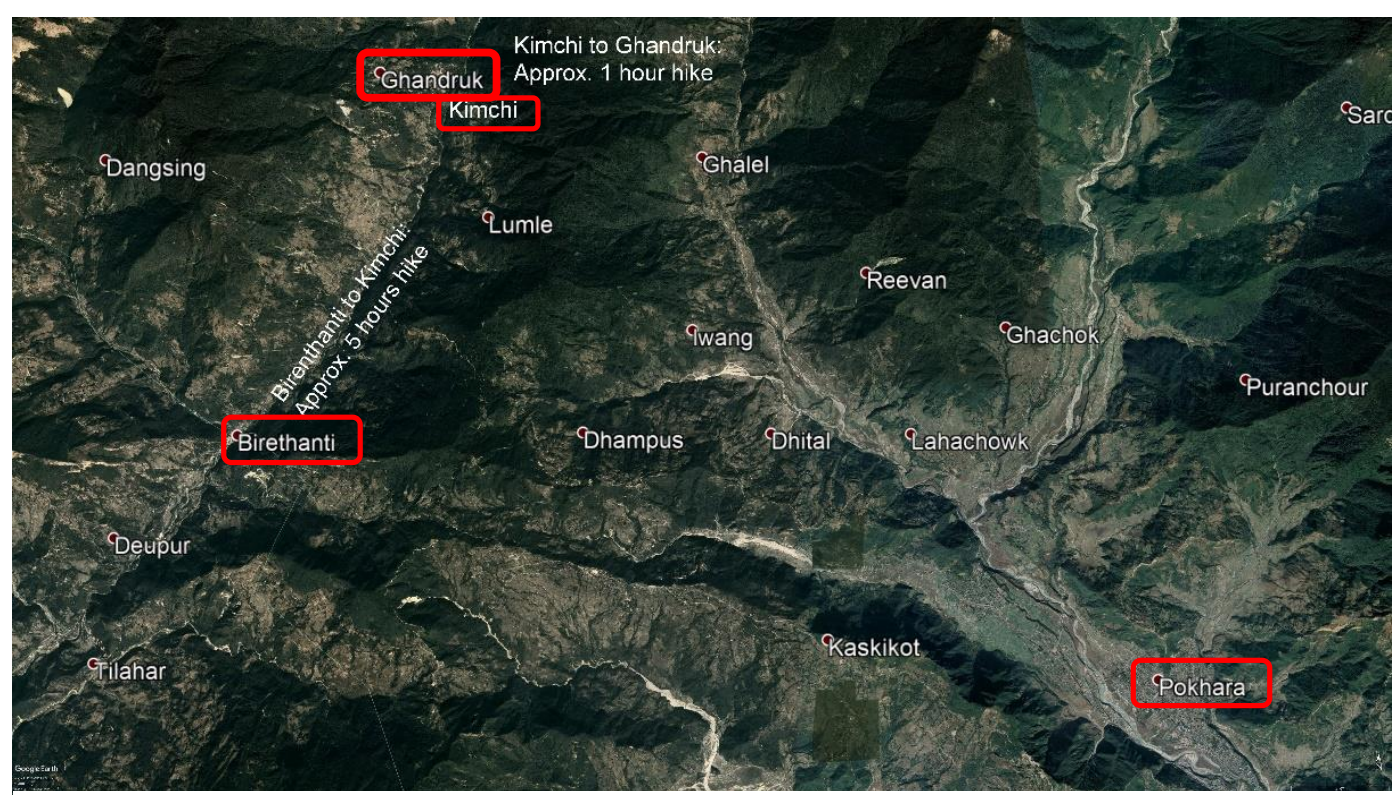

Plate 4-2: Location of Ghandruk in relation to Kimchi, Birethanti and Pokhara

Source: Google Earth, 2018

\subsubsection{History and the people}

Very little written documentation is available on the origins and history of Ghandruk, however, legends, oral history and evidence of settlements dates the present location of the village to more than 200 years. The ancestors of this predominately Gurung community of Ghandruk were nomadic herdsmen whose primary occupation was raising livestock, especially sheep. The abundance of forests, trees, grassland and water sources for their livestock were most likely the attractions for selecting the present location to build more permanent structures. Bhrej Meshrong is the ancestral god revered as a

\footnotetext{
${ }^{6}$ Birethanti is the drop off point on the highway and one of the starting points for the ACA treks with a checkpoint where entry fees are collected. The new vehicular road goes from Birethanti up to Kimchi with an extension planned to reach the main Ghandruk village where the local government offices are based.
} 
protector and any auspicious event such as joining the lahure or Gurkha regiments, is initiated with a visit to this temple.

The tradition of enlisting as lahure or Gurkha deserves an explanation here. They were instrumental in bringing the first tourists to the village and to date influence the politics and development, hence change in Ghandruk. The term lahure is derived from Lahore (in present day Pakistan) and generally denotes anyone going abroad to join the army, while the Gurkha is a special regiment in the British army. The history of the British Gurkha dates to the early $19^{\text {th }}$ century when the British started recruiting men from Nepal in its Indian forces. This was due to the history and reputation of the army from a small village, Gorkha in mid-western Nepal that conquered other principalities creating modern-day Nepal in 1768. The term changed from Gorkha to Gurkha in adaption to the British tongue. Today, Gorkha is generally used to denote the town, while Gurkha refers to the army men.

The Gurkha soldiers were selected from specific ethnic groups (Gurung, Magar, Rai and Limbu) and a few hill districts that include Kaski, where Ghandruk is located (Pariyar, 2016). The change in the settlement rights of the Gurkha soldiers in the U.K. following the change of Gurkha Immigration Policies in 2004 and 2009, has resulted in the migration of the retired soldiers and their families. This has direct implications in Ghandruk with diminishing populations, vacant properties and decreasing investments. Prior to the change in the settlement rights, the retired Gurkhas were known to invest in properties in Nepal and were active in their communities. Although the settlement right is a noteworthy victory for of the Gurkhas, Nepal has lost out in investment potential.

\subsubsection{The settlement and the architecture}

The settlement of Ghandruk developed in response to the topology and the demands of the agricultural and livestock lifestyles. The most striking built characteristics of Ghandruk are the stone buildings and the network of stone trails and stairs that weave around the village and connect the villages. These stone trails and stairs date back more than a hundred years and can be considered a national heritage. The local people built 
the trails through jhara $^{7}$, a unique system of voluntary work where each household contributes in time to a community project. These high-quality trails were used extensively for local travel and trade, and today have become a major tourist trail. The stones have become smooth with use over the years and shine reflecting the sun and even the moon. The locals claim that the moon reflects on the stone trails and lights your way eliminating need for artificial lighting even at night.

Huge boulders were sourced locally (from the Modi River) and hand-cut for the trails with larger stones used for steps wide enough to allow human and cattle to pass (Plate 43). The trails follow the natural contours of the land and at some places are quite steep; however, most are at an incline relatively easy to climb. Resting places are located at clearings near trees and watering places and found approximately every kilometre. The unique type of resting place along this trail is the double level stone seats, the lower step to sit and the upper step to rest the load (Plate 4-4). The traditional method of carrying goods was on the back of people or mules. The double steps are placed perfectly to take the load off the back of the carrier, yet close enough to the body so that it can be carried again with minimal effort.

The settlement form is compact along moderately steep hills facing south and consists of groups or clusters of dwellings that belong to one family. The present settlement pattern and building type is relatively recent (100 to 200 years) with little evidence of the earlier round shaped building form. The clusters are formed with a main building and outbuildings for the extended families and livestock. The main one to two storeyed dwellings are arranged horizontally; the length depending on the wealth and position of the family with a porch extending the length of the house opening to the courtyard in front (Plate 4-5). The interior is usually a single space and the attic space under the roofs is used for fodder storage. The larger dwellings have intricately carved windows and doors. The principal building material is stone with mud mortar and timber doors and windows, with some earlier building made of mud walls. Stone tiles are used for roofing on timber frames and rafters.

\footnotetext{
${ }^{7}$ Free contribution of labour in Gurung dialect.
} 
The courtyards in front of the dwelling or in the middle of a cluster of buildings are also paved in stone and serve as an extension of the house, where various household chores are carried out, such as drying harvests, washing clothes and social gatherings. Most of my interviews took place in these courtyards with some of the participants continuing

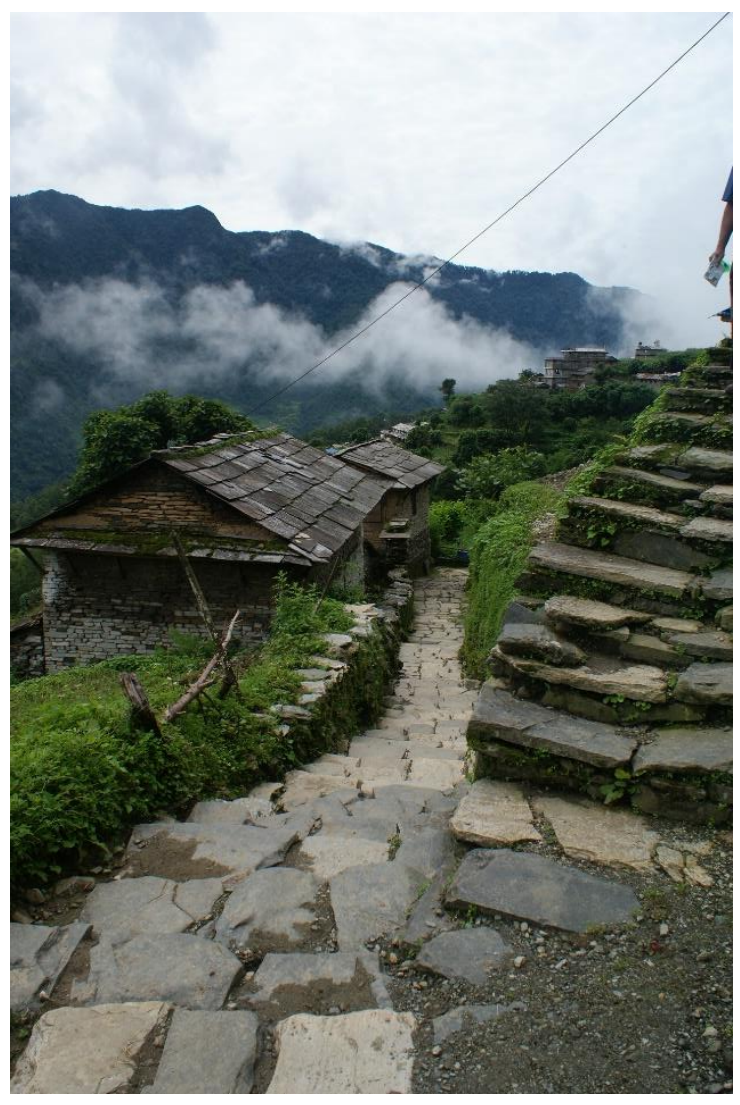

Plate 4-3: The historic stone trail in Ghandruk

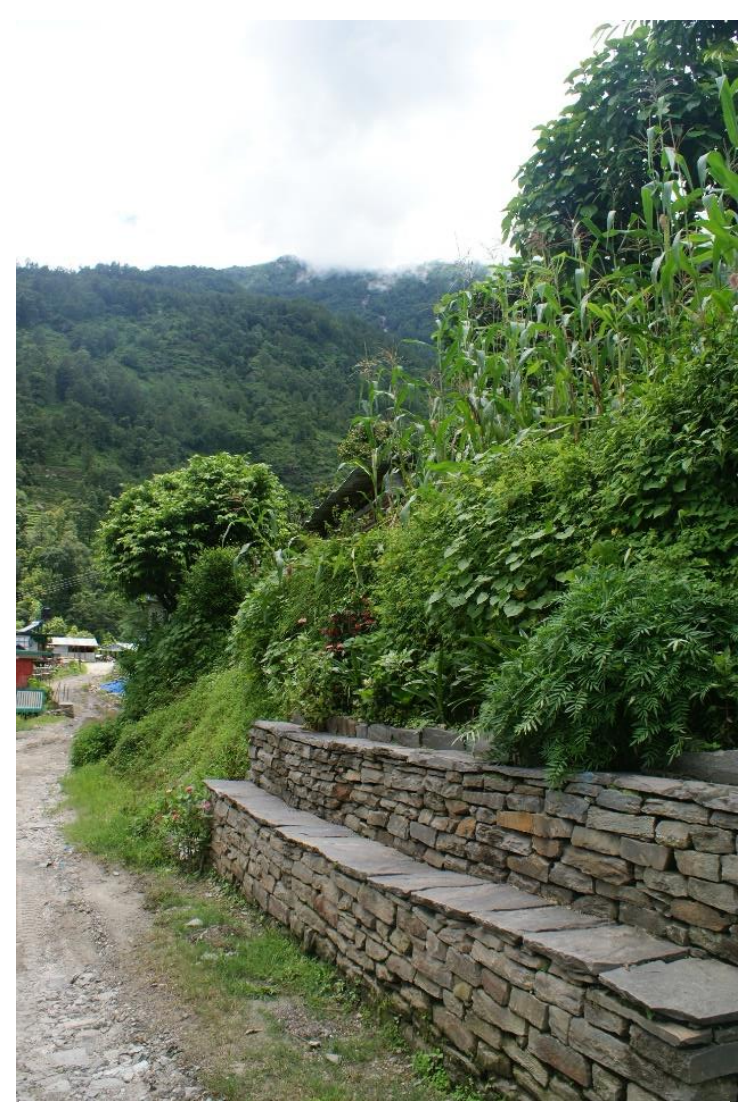

Plate 4-4: Seating along the trail

Photos: JJoshi, 2016

with their various chores while we talked. Although these courtyards are private, they are also part of the network of paths that weave around the village and are used publicly. As the houses are built on terraces, they are generally detached, and small farming plots or kitchen gardens are found adjacent to the houses.

The low-rise buildings in clusters and the array of stone trails, courtyards and small farms within the settlement form an interesting open pattern that is pleasing and coherent. There is a good balance of building materials (stone) and vegetation (green) in terms of the small farms and flowers planted along the walls and courtyards. Larger farms are located 
away from the settlements surrounding the village and in the low-lying areas of the village, where the access to water sources is more convenient.

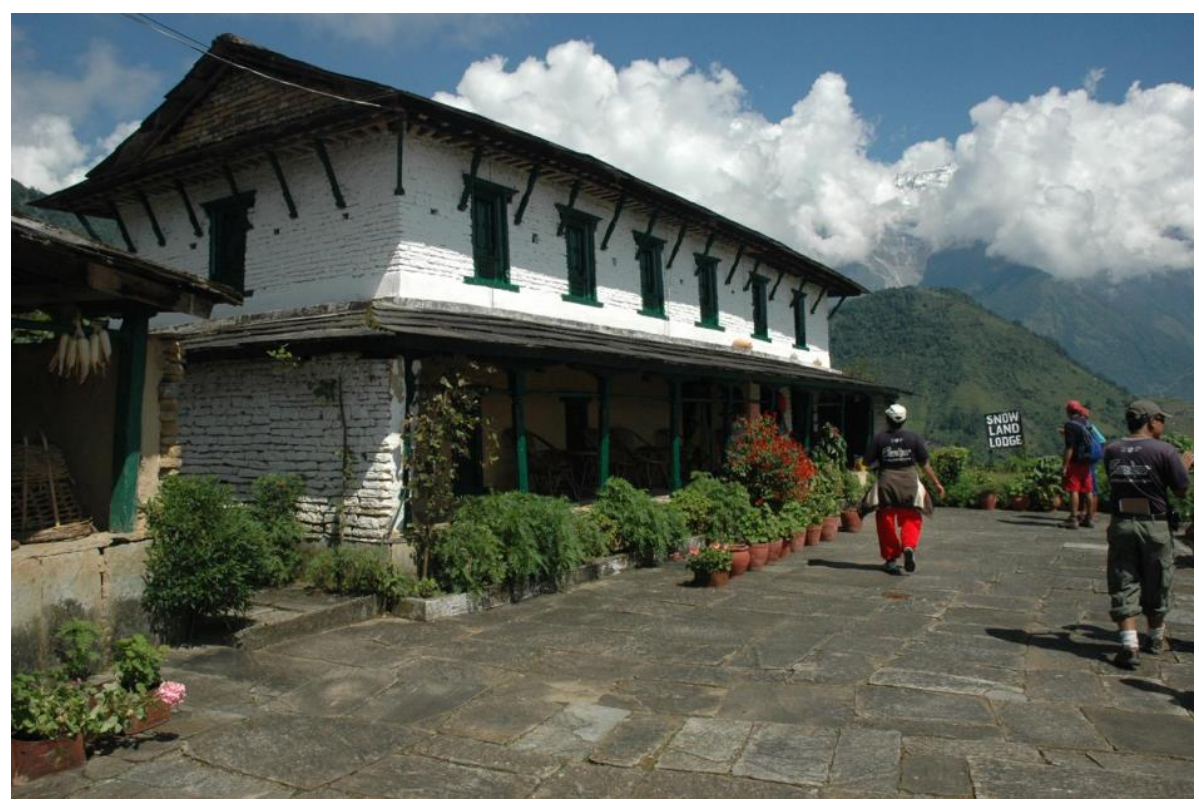

Plate 4-5: Typical Gurung dwelling in Ghandruk with paved front courtyard

Photo: BECTP, 2006

\subsubsection{Conservation area and tourism}

Annapurna Conservation Area (ACA) is the largest conservation area in the country covering 7,629 sq.km. The ACA region is rugged and heavily mountainous, most of the region is above 1,000 metres extending to 8000 metres with settled farming communities scattered within the conservation area. This variation in altitude has endowed the region with some of the most spectacular natural sites and exceptional biodiversity, making this the most popular trekking destination in Nepal, receiving more than $50 \%$ of the total number of trekkers to visit the country (Table 1-3). The Annapurna Conservation Area Project (ACAP) was initiated in Ghandruk in 1986 to address the multifaceted problems of the growing tourism industry in the region through an integrated, community-based conservation and development approach. It was an experimental model that promoted the concepts of conservation area through an "Integrated Conservation and Development Programme" and in 1992, the entire area was officially gazetted as a "Conservation Area" (NTNC, n.d.). 
Tourism in Ghandruk and the region began without government support or planning as local residents started providing for the early western trekkers who visited the region for its natural and cultural diversity with lodging and food (Gurung et al., n.d.). The entrepreneurship skills and lahure culture of the local Gurung community further developed the tourism industry constructing lodges and maintaining trails. The residents with the help from the retired Gurkha soldiers collected funds and cleared the trails at the beginning of the tourist season through the traditional jhara system.

However, the construction of the new tourism infrastructure resulted in clearing of forests leading to the loss of biodiversity and environmental degradation in the major trekking routes. The growth of tourism with the additional burden on scarce resources also created tension between the lodge owners and the villagers. The ACA was created partly to alleviate the environmental degradation with sustainable development of tourism as one of its principal management goals. ACA is the first conservation area in Nepal where the local communities lived inside the boundaries of a conserved area. Integrating natural resource management with alternative energy, ecotourism, gender development, and other community development programmes, ACAP involved the local communities in all stages from planning to implementation to monitoring of project activities. In terms of tourism management, the ACAP is involved in building tourism facilities, destination promotion and development, tourism trails and alternative trekking routes construction/repair, and capacity development and training (NTNC, 2015).

ACAP is considered globally a good example of a successful conservation project involving the local community that promotes sustainable tourism winning international awards including the Global Winner of the British Airways Tourism for Tomorrow Award in 1991. Revenue from tourism covers $85 \%$ of the annual budget of ACAP, clearly demonstrating that tourism revenue is a major driving force in the overall conservation and development policy of ACAP (Bajracharya, 2011). Conversely, if tourism is weakened in the ACA, the conservation of the natural and cultural environment will bear direct adverse consequences.

In summary, while the ACAP has been key in reforestation and tourism promotion, the recent migration for work and the tradition of the lahure culture has increased the number of abandoned terraces and houses in the villages. The traditional settlement of Ghandruk 
is changing with the signs of urbanisation such as a new vehicular road bringing new building materials. The next sections present the interview findings on the perceptions of the residents and tourists on the landscape and landscape changes.

\subsection{MOUNTAIN VISTAS, THE VILLAGE AND GURUNG CULTURE}

The residents have a deep attachment to the landscape due to their long and intimate association with the land and relationships with the people. Their perception of landscape aesthetics is closely connected to their everyday life in the village. The tourists interviewed were on a multi-day trek stopping overnight in Ghandruk and spent limited time exploring the villages. As mention, it takes about five hours' trek to reach the main Ghandruk village from Birethanti (highway town), which passes through small settlements and terraced farms. While the international tourists interviewed started their trek from Birethanti, the domestic tourists interviewed took local buses to Kimchi, from where the main village is about an hour's hike.

This section presents the residents and tourists' perceptions on the landscape. The main landscape features in Ghandruk include the mountain vistas, the village and Gurung culture. The perceptions of the residents are presented prior to the tourists with comparisons drawn in the conclusion.

\subsubsection{The Himalayan vista and the village}

There were mixed responses from the residents regarding the scenic landscapes. Most felt blessed to be surrounded by the lush natural environment and enjoyed the visual landscape. Although the landscape is always present in their everyday lives, the sublimity of the natural landscape affects the residents. However, there were differences in how the residents who were in the tourism related businesses and those who had fewer opportunities to interact with tourists described the landscapes. For example, a guesthouse owner described his feeling as:

I am never tired of this view. Even when I see it every day, I am amazed by it. For those who see it for the first time, it must be incredible. (Bimal, resident-tourism, guesthouse owner) 
This sentiment was echoed by another resident who was not involved in the tourism industry but lived in the main village, had relatives and neighbours running guesthouses and was involved in community activities through the Mother's Group:

\begin{abstract}
I was born here, and I hope I will never have to leave this village because as soon as we wake up, we see this view. Tourists have limited number of days to see it. People plan so long to come here and sometimes the mountains are covered. For us, if we don't see it today or tomorrow, we will see it soon as we are here. (Samjhana, residentnon tourism, homemaker)
\end{abstract}

The above response indicates that the non-tourism resident is aware of the tourism potential and the benefits to the village due to her indirect associations with the tourism industry. On the other hand, the residents living in the fringes of the village who had little contact with the tourists were ambivalent towards the scenic beauty of the natural landscape. For example, when asked to describe their village, a resident who lived in the fringes and was not from the majority Gurung community responded,

I don't know what to say. We are from this village. What can we say? (Sarita, resident-non tourism, homemaker)

This response indicates that the presence of the view in their everyday life made it ordinary. Their everyday presence in the landscape and familiarity with the scenic views present in their daily lives makes the scenery ordinary. Landscape aesthetics are derived more from the social interactions and communal activities and the village holds prominence over the scenery. The landscape for the residents is their home that provides them their identity. They place themselves in the landscape and as an insider describe their surroundings for the benefit of others, such as the tourists. They cited having family and friends nearby for preferring to live in the village, which reflects their sense of belonging and attachments formed from social relationships become part of landscape aesthetics. Their concept of heaven or the perfect place was often associated with their families and friends being nearby, weather and the cultural activities. A response from a resident who had migrated to Ghandruk as a child from Chitwan and had just started operating a homestay illustrates this attachment:

I like it here very much. Even if I was not born here, I grew up here. I visit Chitwan (where I was born) but not for long. I return as soon as I can. Maybe because I grew up here, I like it here. All my friends are 
here. I am used to this place. (Srijana, resident-tourism, homestay owner)

Pride and love for their home were evident in their descriptions. They preferred their hometown as opposed to migrating elsewhere and the biggest appeal was family and the social network they had built over generations. Although most of her family had migrated to bigger cities or abroad, one resident responded:

This is our ancestral village. We do not want to leave this village and go anywhere else. I was born here. I grew up here. I like this village the most, the water here is the best, the air here is the sweetest. That is why, the food here, the vegetables and other crops as well, are the best. We do not like the produce from anywhere else. We have been here for generations. (Himani, resident-non tourism, guesthouse owner)

This indicates that the attachment to the land becomes integrated into the concept of landscape. The landscape in totality, with the everyday aspects of life, its products and social relationships contributes to the perception of landscape aesthetics. The social connections and familial ties add value to the land and the landscape. Similarly, a guesthouse owner who had studied and worked abroad and returned to take advantage of the tourism potential remarked:

\section{I was born here and have seen the mountains all my life. But I still enjoy looking at the mountains early in the morning when I wake up. I like looking at where the snow line is, where the range is. I look at them every day. I enjoy it. No one tells me to do that, I do it from my heart. I have been abroad and there are many things that amazed me. But ultimately, they are made by humans and I lose interest. But here, it is different. (Krishna, resident-tourism, guesthouse owner)}

This response indicates the close relationship between the residents and nature. The detailed observation of the snowline indicates their deep knowledge of the landscape. Although they were not able to provide me with any myths or legends regarding the mountains, one female participant remembered her grandparents predicting that rice would grow at the base of the mountain in the modern period. She was unsure if the elders were predicting climate change or advance in technologies, but rice is now grown at a much higher altitude where it was not traditionally consumed or produced.

The second prominent feature in Ghandruk is the network of stone trails and stone buildings that provides a unique settlement pattern. The traditional buildings were 
identified by the tourism sector residents as an essential character of Ghandruk to be preserved, while the non-tourism residents were more concerned with the high maintenance requirements. Some acknowledged the benefits of traditional buildings, while others opined the environment created by traditional settlements is favourable to attracting tourists. However, the traditional houses signified work, especially for the women. The following statements illustrate the two opinions:

I am more comfortable in this mud building. I prefer our ancestral house because it is made with stone, mud and timber. These natural materials are better for health. You get ill easily in the new concrete houses, knee pains, heart problems. (Dibya, resident-tourism, homestay owner)

It is better in a concrete house. You don't have to plaster it often; you just have to paint it once. In the traditional houses you have to plaster often. It is difficult. Once you build a concrete house, it is forever. That is why I think concrete houses are easier. (Sarita, resident-non tourism, homemaker)

The above two statements also indicate the dichotomy between the new and the traditional. While the inherent values of the natural material used in traditional buildings are acknowledged, the changing lifestyles and less time for household chores makes the new materials attractive. The convenience of the new material adds value to it and thus becomes aesthetically pleasing.

The stone trails are regularly maintained by the community through the traditional jhara volunteering system, however, the residents had differing views on the trails (Plate 4-6). The Mother's Group led the maintenance works mostly through the funds collected by performing cultural shows for tourist groups. Some residents, especially those involved in the tourism industry, value the historic stone trails as an essential part of the heritage of Ghandruk. They expressed concern that the new vehicular road was destroying parts of the trails. For others, the vehicular road indicated development and was more convenient than the stone trails that held no significant value other than a transport route. This creates conflicts between the tourism sector and non-tourism residents with two guesthouse owners making the following remarks:

We built the trails for ourselves not for tourism, hundreds of years ago. That is our identity, our heritage. We have to conserve it. That has been 
affected by the new road. (Krishna, resident-tourism, guesthouse owner)

We need the road for the transportation. That is good, but I requested not to damage the old trail. This old trail shows our culture, our traditions. When tourists walk in this trail, they have a good experience. (Dibya, resident-tourism, homestay owner)

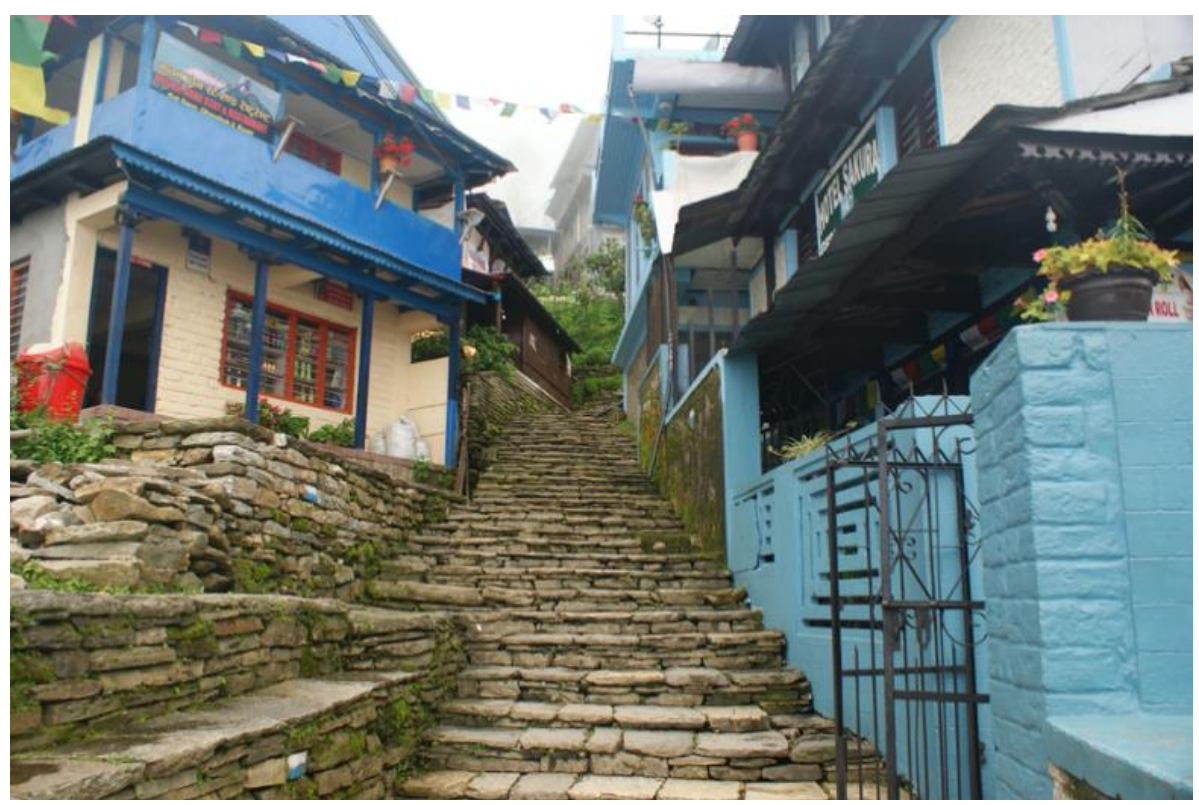

Plate 4-6: The historic stone steps in the village

Photo: JJoshi, 2016

Residents not involved in tourism were mostly ambivalent towards the historic trails and supported the new road that was more convenient to access bigger markets. Some held the local tourism industry responsible for stalling development in Ghandruk for the profit of a handful of businesses. The following remark illustrates the resentment towards the local tourism businesses:

If there was a road, it would be good for the farmers. They can send the vegetables, milk to town. It would be easier to make a living. Without the road, it is very difficult. The hotels are stopping the road fearing that the foreign tourists will not stay here and return to Pokhara if there was a road. For us, it is a problem. They say if there is a road, tourists will not stay here and so they don't want the road. (Pratima, resident-non tourism, homemaker)

The above contrasting statements regarding the trails and the new road illustrate the paradoxical tensions that exists between conservation and development. On the one hand, 
the trails are part of the landscape and heritage of Ghandruk, while on the other they are viewed as an impediment to development. The perspectives on the potential landscape change due to the new road is presented in section 4.3.2.

Not surprisingly, the view of the high mountains was the highlight for the tourists in Ghandruk. Even when weather limited the vista of the snow-capped mountains, the fleeting views as the clouds shift and the green forests in the lower mountains was still mesmerising. The mist and clouds provided spectacular changes in the scenery, which was heightened by the momentary glimpses of the Annapurna range. Moreover, there was excitement of anticipation of clear skies and mountain vistas as they continued on their journeys. The following responses from the tourists when asked to describe their feelings of the landscape illustrates the dominance of the natural vista:

Oh, just magical. Really magical. (Penny, tourist, UK)

When you see the mountains, it is amazing. (Hari, tourist, Nepal)

What strikes me is the white mountains that are on top of all. On top of the green forests, mountains. That is what I like the most. Those gigantic mountains. (Rob, tourist, Netherlands)

This suggests, for all tourists, landscape aesthetics are related to the physical qualities of the landscapes and their preferences to view and experience it. In Ghandruk, this included surrounding mountains and hills, the trail, terraced farms and the villages along the way. The hiking trail mostly passes through terraced farmlands with scattered settlements. The vista changes as the trail starts along the riverbed and climbs up with many photo opportunities. One participant remarked, "We were not hurrying though. We stopped and rested taking photographs" (Rashmi, tourist, Nepal). The experience of being in the landscape, walking through and engaging with the different aspects of landscapes as they trekked provided time for contemplation in addition to the scenery. The following example illustrates the multiple opportunities present in experiencing landscapes:

I have been around people now for 3-4 weeks very intensively and I think I really needed to do some healing and just some thinking. So, I have been here for a week and already feeling quite peaceful. (Penny, tourist, $U K$ ) 
This response indicates that the non-material values of landscapes and manifold opportunities of engaging with it is linked with human well-being (Bieling, Plieninger, Pirker, \& Vogl, 2014). This response also indicates that tourists' motivation for landscape experience is individual and influences the expectations of the visit. For Penny, the long walk provided her time to reflect and heal. It was an opportunity to be on her own, away from her everyday urban life and people, which the trek and the landscape provided. This suggests that people create individual meanings and values out of the physical landscape addressing intangible aesthetic values embedded in the landscape.

Despite the overwhelming presence of the mountain vista, the tourists also observed other aspects of the landscape that reflected their backgrounds, interests and experiences. For example, for some tourists, the villages were equally important and represented the image of Ghandruk. They noticed the local stone used profusely in buildings, courtyards and paths creating a harmonious setting with the natural landscape and giving the village a distinctive character. The following responses illustrate this:

There are these trails, paths, houses, they are all constructed in a similar way. We can see it clearly as we walk by. That is distinctly Ghandruk. This is what you see in the photographs of Ghandruk too. These houses and the community represent Ghandruk. (Hari, tourist, Nepal)

My first impression of walking through were how varied the buildings were. I think because of just finishing the workshop ${ }^{8}$ my mind is focused on the façade of buildings and sort of structurally looking at them. Some of the bottom guesthouses looked quite modern and I saw a few that were traditional, a few that were very run down. So, I saw some variations in the buildings as I was walking up. The agriculture. I am very interested in agriculture, so I was walking very slowly and sitting down to watch women work. (Penny, tourist, UK)

These responses confirm that previous knowledge and experience of tourists play a role in their experience of the landscapes. Hari was delighted to see the village being true to the image he was familiar with and that had been promoted. On the other hand, recent experience working with buildings such as the post-earthquake reconstruction workshop, trained Penny's eyes to notice details that are not usual parts of the tourist landscapes.

\footnotetext{
${ }^{8}$ Volunteered 2.5 weeks at the post-earthquake reconstruction workshop in Bungamati, Kathmandu conducted by Architects Sans Frontiers.
} 
She also noticed the difference between the traditional and new buildings. Furthermore, the farming activities were also part of her landscape experience. These responses also suggest that the tourists value the processes in the landscape, such as the farming activities that suggested human presence and life. This also confirms that human presence is also valued by tourists as an integral part of the landscape.

In line with the tourism-sector residents, the trails were categorically part of the landscape for the tourists, especially for the international tourists who started their trek at Birethanti and used the historic trail. Most tourist participants remarked on the steep steps that leads to Ghandruk; some participants were surprised by the steepness with one expressing discontent. However, most agreed that the stone steps were a distinct part of the landscape.

\section{I like how it is kind of quite winding, almost like it meanders at different places. For example, when I was coming here I was not expecting such a sharp staircase. It was almost quite like mystical how you had to turn at different corners. The trails are in quite good condition. I find it easy to walk around. I just think it is very beautiful the way it looks onto the side of the hill. (Penny, tourist, UK)}

One observation that all tourists noted was that Ghandruk was a clean village, especially compared to other parts of Nepal, for example:

You can immediately see the difference from other towns or villages I have been to or walked through. It looks clean. Looks more organised. Looks more like Europe, in a way. (Rob, tourist, Netherlands)

This response confirms that tourists look for familiarity and cleanliness indicate the living condition of the local community. A clean environment suggests prosperity and provides a sense of security adding to the landscape aesthetics. In addition, some tourists appreciated the clean environment for a break from busy city lives. The sound, or the absence of traffic, suggest tranquillity and peace that is increasingly being lost in the cities and was observed by the tourists as well. For example, the domestic tourists observed:

Another aspect is that this village is very clean. The landscape is very beautiful, the mountains, the view. Once you are here, this is a relaxing and peaceful place. For example, we live in cities that are crowded and 
polluted. This village is pollution free. It is worth coming as you can get here in an hour's walk if you want. (Rashmi, tourist, Nepal)

Coming from an urban setting, the way we are racing every day, trying to go ahead of time, where there is pollution, crowd, noise. Ghandruk is perfect. (Hari, tourist, Nepal)

In summary, the two physical landscape characteristics in Ghandruk all participants identified were the mountains and the village. The climatic conditions, the fresh air, tranquillity and way of life of Ghandruk were also attractions identified by both residents and tourists. However, there were distinct differences in their experience of the multiple aspects of landscape aesthetics that were largely based on their personal circumstances and situational context. The residents placed more value on the intangible aspects such as social ties but were appreciative of their natural surrounding landscape that has shaped their settlement, culture, traditions and identity. Their home and relationship with the land and people were included in the landscape. Their landscapes intertwined with everyday lives with attachments and relations created and contributed to their perceptions of landscape aesthetics. For, the tourists, the natural landscape was the foremost attraction, however, the experience of being in the landscape was equally important and was individual.

\subsubsection{The Gurung culture}

For the residents, Gurung culture was the principal characteristic of Ghandruk and represented their identity. Although Gurung people reside in other parts of Nepal, the residents of Ghandruk differentiated their culture and language as unique to the region. Their opinions differed on the importance of the views of the Himalayan range as unique, but all agreed that the Gurung culture, language and traditions were unique to the region. Their relationship with the landscape was associated with their long ancestral history in Ghandruk. They were emphatic that their Gurung culture was distinct from other parts of Nepal and keen to point out their uniqueness compared to other Gurung communities. A resident was quick to inform me, "you can see similar structures in Sikles ${ }^{9}$ as well. But,

\footnotetext{
${ }^{9}$ A Gurung village east of Ghandruk, also within ACA.
} 
the Gurung language here is different. We can differentiate the Gurung language of Ghandruk easily" (Bimal, resident-tourism, guesthouse owner).

One of the leading characteristics of Gurung culture is their hospitality and welcoming nature. The following response illustrates this character as well as pride and concern for their heritage:

Ghandruk is a unique village with different culture and traditions. It is not only blessed with natural beauty; the culture and traditions are different as well. It is mainly a Gurung community with indigenous costumes, culture, traditions. We are still continuing the traditions established by our ancestors many centuries ago and we cannot remove ourselves from that identity. We strongly believe that we have to continue our culture. This place is blessed. As soon as you arrive here, you will experience this. When you first arrive, after the steep climb up, maybe you complain that it is difficult to get here, but once you are here and you have experienced our hospitality and culture, you will want to stay on an extra day or two. (Anil, resident-tourism, guesthouse owner)

This response indicates a strong Gurung community presence in Ghandruk that has shaped their culture and identity with a multi-sensory experience of the landscape. In additional to the gazing at the natural vista, the invitation to the tourists to experience the culture and traditions suggest the locals include their culture, food and music as part of their landscape. Culture becomes ingrained in the landscape and contributes to landscape aesthetics.

In addition, the history of the place and the recent developments also become part of the landscape for the residents. They integrated the history with the on-going local development works in the description of their landscape. For example, the tradition of recruitment of Gurkha soldiers for the British, Indian or Singapore army is part of the local history (section 4.1.1).

There is a lahure in almost every household. They used to join the British army, the Singapore army and had connection with foreigners. That was also a reason why foreigners came here. They came with the lahure. That made me believe there was a lot of potential in tourism in Ghandruk. That is why I left everything and came back to my village. (Krishna, resident-tourism, guesthouse owner) 
The above remark illustrates the influence of the lahure culture in Ghandruk. This social group continues to drive development issues of the village, including the state of the youth, vacant buildings and local economy.

While the tourists had high regard for the natural landscape and enjoyed the views, they had peripheral views on the settlement and the built landscape and limited experience with the local community. After a tiring day of trekking, international tourists in Ghandruk had fleeting interaction with the local community with a few casual exchanges on the route and any other communications limited to the staff at their guesthouses or the guides. Ghandruk is well known within Nepal as a typical Gurung village and is gaining popularity in the domestic tourism market. This was evident with the domestic tourists with insight on the culture and ethnic groups of Nepal. The following response illustrates this:

\section{I would recommend people to come to Ghandruk to see not only to see the beauty of the mountains but also the place, how the community is living, how active they are in strengthening their communities, especially the Gurung community here. (Hari, tourist, Nepal)}

The domestic tourists also had more interactions with the locals due to their common language and familiarity with the culture. They were able to communicate with the locals and gain better understanding of the landscape, enhancing their experience. For example, one domestic tourist participant talked about the recent community meeting regarding the electricity tariff ${ }^{10}$. This knowledge helped him understand the workings of the community based micro-hydro projects, which are popular in the hilly regions of Nepal that are otherwise difficult to connect to the national electricity grid. However, the international tourist agreed that knowledge of the local community and interactions would enhance their experience.

In summary, for the residents, the Gurung culture was the defining character of Ghandruk. The Gurung participants were proud of their heritage and keen to point out

\footnotetext{
${ }^{10}$ Ghandruk has two community owned micro-hydro stations that generate $100 \mathrm{~kW}$ of electricity in total. The residents pay for the amount they use per watt and the meeting held that day was to discuss alternative payment systems such as paying by a metering system. The jhara system contributed to the construction of these micro-hydro stations. Each house contributed labour that included digging, laying pipes and carrying the pipes to the project site. The projects preceded the road, hence the villagers had to carry the materials from the highway.
} 
their uniqueness compared to other Gurung communities. The domestic tourists were also familiar with this history and their observations sometimes reflected that of the residents (Gurung culture defines Ghandruk). The Mother's Group often performs local dances for tourists for a fee that goes towards community work. None of the tourists interviewed had viewed the cultural programme. However, one of the tourists (Penny, UK) was interested in farming and had asked her guesthouse owner about the local food products. She was pleased to know that all vegetables are grown locally using natural fertilisers. This indicates that interaction with locals has the potential to enhance tourists' experience, however, the dominance of the natural landscape (visual and trekking) neglects the cultural aspects.

\subsection{LANDSCAPE CHANGES: CONSERVATION AND DEVELOPMENT}

While the establishment of ACAP with its conservation policies has restored vegetation and wildlife enhancing tourism and improving living conditions, it has also increased demand for accessibility and infrastructure. This section presents findings on the perspectives of the participants on the changes brought by conservation policies and the new vehicular road. As described in the methodology chapter, the past and repeat photographs were used to draw out the perspectives on change while viewing the live landscape. The residents were witness to the change and the set of past and repeat photographs brought memories. On the other hand, most tourists depended on the photographs to assess the change and were delighted to be able to see the past photographs.

\subsubsection{Conservation policies and tourism}

In general, the residents agreed that the ACAP conservation policies were key in shaping development and subsequent landscape. ACAP had different priorities for the fifty-seven villages under its jurisdiction and integrating nature conservation with community-based tourism was the focus in Ghandruk. Most residents pointed out the contribution of ACAP in increasing the forested areas, developing tourism and promoting Ghandruk in the international markets. Reforestation is one of the most noticeable visual impacts of ACAP on the landscape. The following statement illustrates this: 
The hills became green after ACAP came here. The forest has grown. Before ACAP it was not like this, there was very little forested areas. There were a lot of cultivated land. There were a lot of farming. Look here [pointing at the earlier photograph, Plate 4-7], there are no forests. Positive things have happened after ACAP. It used to take us three, four hours to collect firewood. After ACAP came, many plants were planted. If you need to have cattle, they grew grass, planted trees. (Samjhana, resident-non tourism, homemaker)

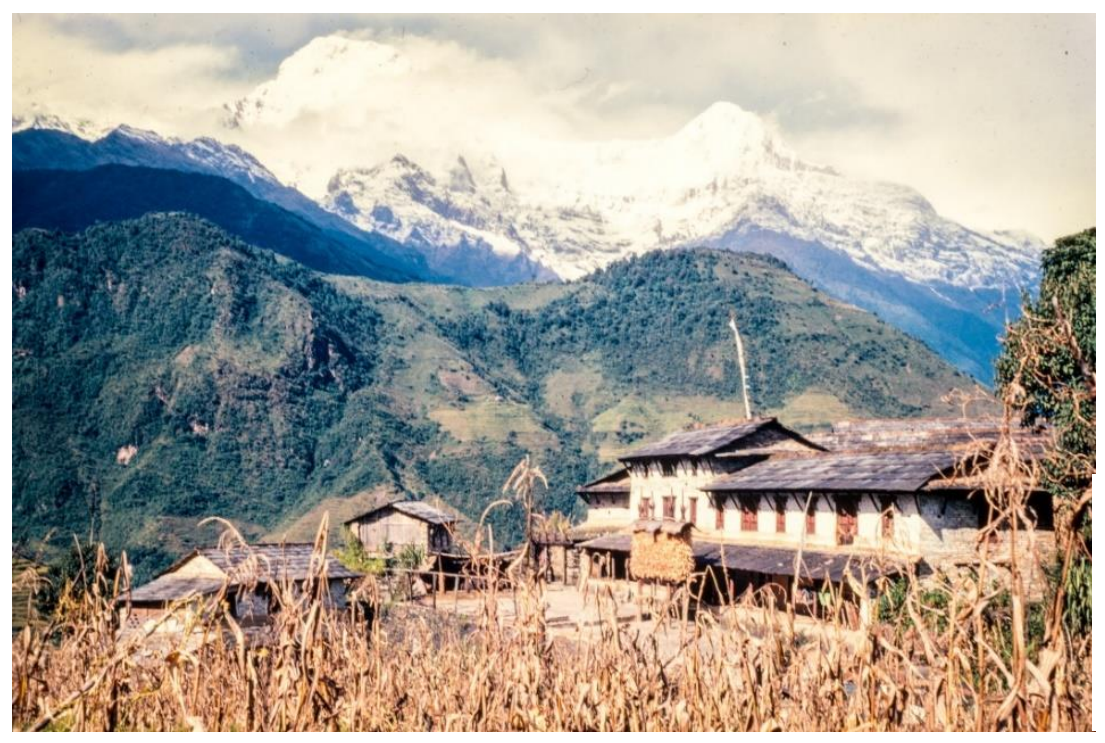

Photo:

Mike Gill and Barbara Butterworth (PCNPP)

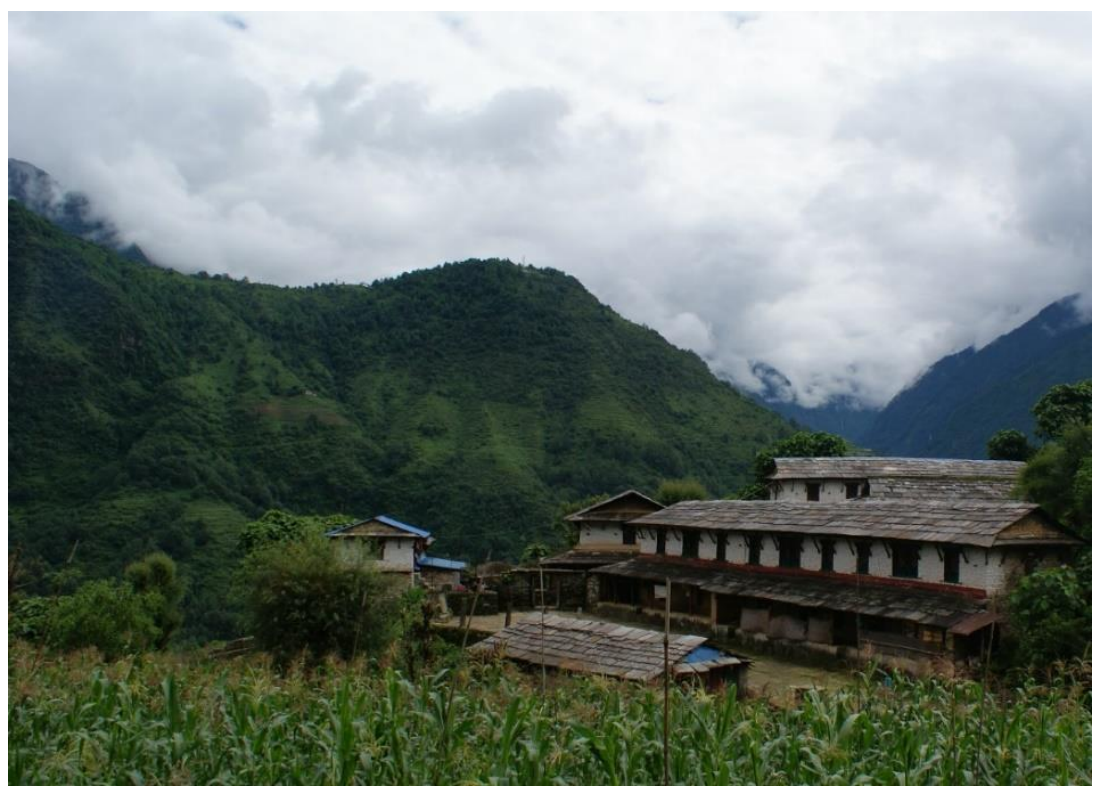
1973

Photo:

JJoshi, 2016

Plate 4-7: Past and repeat photographs showing increase in forests and decrease in cultivated terraces

The above response also indicates the dichotomy in the residents' views regarding reforestation. On one hand, there were benefits of the increased forests for collecting essential firewood and fodder. On the other hand, the increased forested land is a 
reminder of a lifestyle that is diminishing. Although farming in high mountains is arduous, the memories attached, especially when it is disappearing makes it desirable. Some residents also pointed out increase in the number of wild animals was harmful for their farms destroying precious crops, especially the monkeys and the deer. One resident added that the reforestation and increase of wildlife was forcing people to abandon farming.

The accompanying ban on hunting and controlling felling of trees has contributed to the change in the landscape. While some residents were positive about the ban placed on forest-related activities, others considered the ban added to the difficulties in procuring timber for construction compelling them to seek alternative materials. They held ACAP responsible for changing the built landscape because of the restrictions placed on collecting timber for construction. Residents have to apply for permits at the ACAP offices to fell selected trees for timber and carry them to the construction sites. According to the residents, this extends the timeframe of construction and adds costs. The following remark by a resident who was building a large new guesthouse using traditional materials and style illustrates the difficulties in acquiring the materials that tends to discourage residents concerned about their investments:
I like old buildings but there are problems. I spent one year just collecting stone and timber. The next year, I started the foundation and then there was a huge landslide on the way. It took four months to clear that and when I re-started it was monsoon and the road gets blocked with the rain. Then there was the earthquake and the blockade. The earthquake did not affect much but the blockade had a huge impact. Work totally stopped. With the fuel crisis there was no transportation. It was difficult to get the material as well as the workers. So the cost went up a bit. I am in debt now. (Anil, resident-tourism, guesthouse owner)

The above statement indicates that residents value the traditional built landscape and are willing to invest in maintaining it. However, the restrictive conservation policies could discourage potential investors. In addition, the above statement also demonstrates the complexities of importing non-local materials and the impact of urbanisation and national-level events and policies in remote areas. It indicates the potential influence of external drivers in shaping landscapes. At a local level, the absence of elected local government during the Maoists conflict (1996-2006) also exacerbated the change when 
the Maoists forcefully closed the ACAP office in Ghandruk. Prior to the conflict, ACAP had been able to control and monitor the building activities to some extent through dialogue. A resident not involved in the tourism industry remarked:

The rules of ACAP were not like this. You could not build concrete houses. The ones who are building concrete houses are building to show off. But now, it has to change. We have to all get together to stop it. Foreign tourists do not come here to see the concrete buildings. They want to see one or two storeyed traditional buildings here. People do not think of the consequences and they have destroyed the harmonious character of the village. (Samjhana, resident-non tourist, homemaker)

The above response indicates that Ghandruk is not immune to urbanisation or globalisation despite its remoteness. The prevailing building style in the rest of the country and region is infiltrating due to the changing societal aspirations, demands and perceptions of development. New building materials and styles are associated with modern lifestyle and wealth and hence a way to show off. This response demonstrates the dichotomy in the local perceptions regarding the built heritage with one group supporting heritage conservation, while the other eager to move with the changing times (Plate 4-8).

The community-based participatory approach promoted by ACAP has resulted in tourism generally being viewed positively by the residents. This may be because tourism is still seasonal and mass tourism has not swamped Nepal compared to other destinations, where tourists are facing the backlash from the residents. The remoteness and limited accessibility may have contributed contribute partially to this perspective. In addition, the settlements of Ghandruk cover a large area in a moderately steep topography with relatively small structures and that helps to spread the tourists avoiding concentration and crowding. For example, I did not notice or hear the large group of army officers stopping overnight during the field visit for the interviews until one of the participants pointed them out.

If you look down in that row of houses, there are about a hundred army officers there today. You do not notice it. We can accommodate 200300 people, may be even $300-400$ in the entire village. There are 


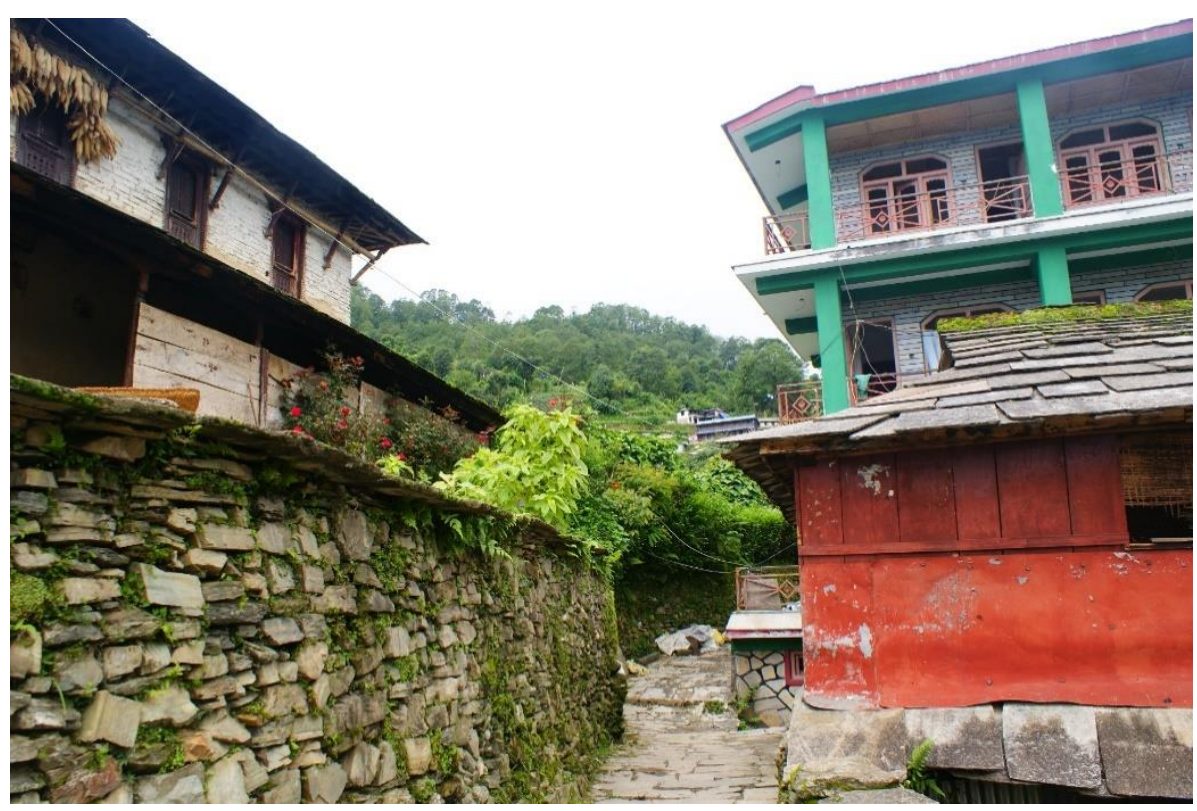

Plate 4-8: The new (right) in contrast to the old (left) building

Photo: JJoshi, 2016

As explained earlier, tourism in Ghandruk started as a camping destination and with the general increase in tourists visiting Nepal, the nature of tourism in Ghandruk is also changing. The tented camps have been largely replaced by guesthouses that are increasing in size and volume. While some residents were already experiencing the impact with the increase in domestic tourists, others had not benefitted from it. The perceived demand of tourists for amenities and home comforts have pushed residents to build facilities such as attached bathrooms. The general perception of upgrading to include modern facilities is building completely in new materials and styles. The concept of renovating traditional houses to accommodate modern facilities is not practiced in Ghandruk as in Bandipur (chapter five). The growth of the Asian market and their travelling culture is partly influencing this change (section 2.2.3). However, some residents expressed concerns on the potential impact of this change on future tourism prospects of Ghandruk (above statement by Samjhana). The following statement by a tourist echoes the concern: 
three. Even if it is two, it just seems quite imposing. Different style. It is just the size, it takes away from this idea of a teahouse or a guesthouse, which invokes cosiness and smaller. So that seems more just more like a mainstream hotel, which I think is a bit out of place here. (Penny, tourist, UK)

The above statement shows that the growth of the tourism industry is one of the potential drivers of the change in the built landscape of Ghandruk. The tourists were also concerned that the new structures that were not conforming to the traditional architectural styles would have adverse effects on the future of tourism in Ghandruk (Plate 4-9). However, some were willing to accept the change if it benefitted the larger community. The following illustrates this:

I think that Nepal needs tourism. Chatting to people in Pokhara, they said first it was the earthquake and second there was this blockade with India. Tourism is a big part of the drive in the economy here. So, I am almost spilt with this kind of tourism I see. For me it is not beautiful, not necessarily but the kind of tourist that want that are seeking the authentic but maybe sometimes wants the home comforts like a hot shower or whatever. It is not for me, but if it is good for the people here, then I support it. (Penny, tourist, UK)

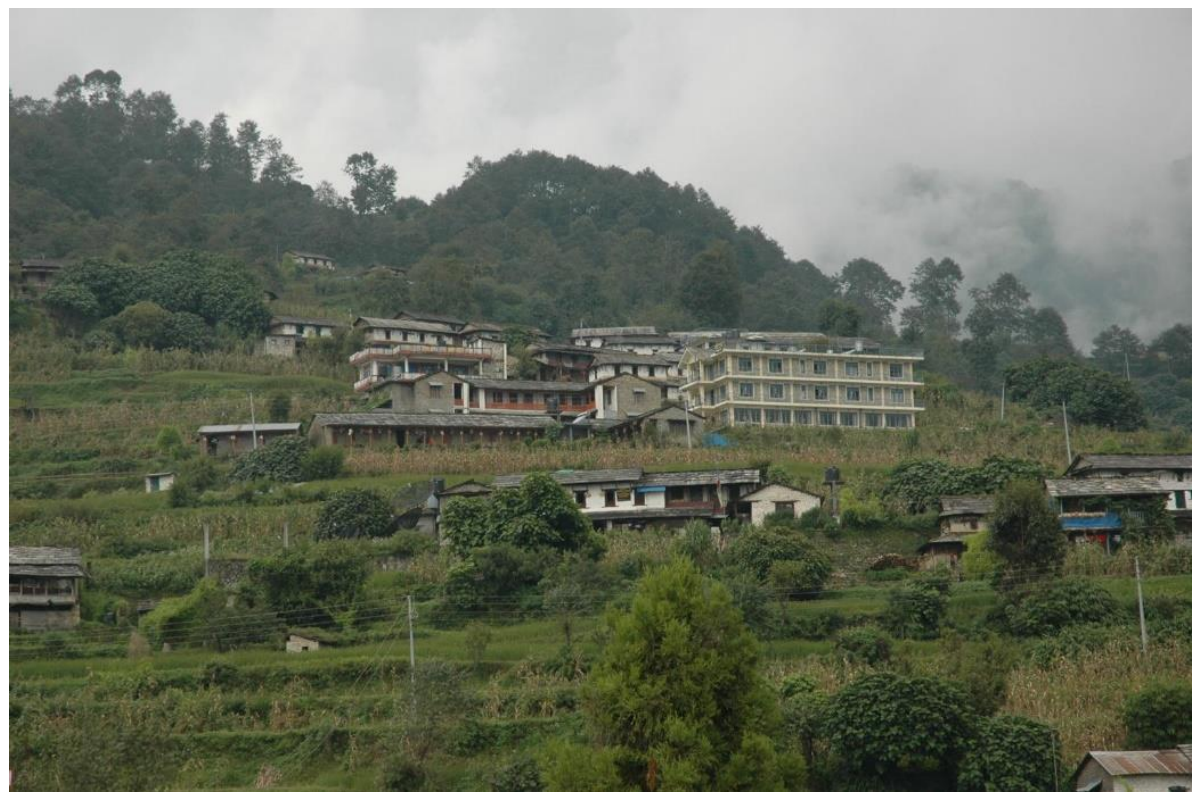

Plate 4-9: New larger buildings dominating the traditional buildings

Photo: JJoshi, 2016

One benefit of tourism for the community that most residents agreed upon was the establishment of Ama Samuha or the Mothers' Group in every ward by the ACAP and 
the involvement of them in various community works. These groups are formed in every ward, the lowest local administrative zone in Nepal, and include women of all ages. One of their successful work is the maintenance of the historic network of stone trails. The material costs and specialized labour costs are paid by the Ama Samuha, with funds raised from the cultural performances for the tourists, while the regular cleaning and clearing of grass and weed is done through the jhara system.

In summary, there was duality in the responses of the residents with regard to the impact of the conservation policies on the landscape. While most were generally satisfied with the increase in forested areas and the ban on hunting that had reinstated the biodiversity, there were some grievances, especially in procuring traditional building materials. The increase in forest areas also indicated loss of farming traditions and way of life for the residents who regularly engaged with the land and had insightful knowledge not only of the landscape and processes of farming but also the nuanced understanding of the changes through history. With no knowledge of the policies and history, while acknowledging the hard work involved in the cultivating the steep high hills of Ghandruk, the tourists appreciated the presence of the large areas of the lush green forests.

\subsubsection{The road and the society}

The newly constructed road has played a key role in bringing new materials and change in Ghandruk. While some agreed that Ghandruk should maintain its unique architectural character, others alleged they should accept and move with time. All building materials, except local stones and timber have to be carried by labourers at extra cost. There were different reasons for the preference of new building materials over traditional stone and timber structures (Plate 4-10). In addition to the lack of proper building byelaws, a key concern was the unavailability and long wait for local timber due to the above stated ACAP conservation policies. The proper timber used for building construction was only available in higher regions and that added to transportation costs. One resident who had opted to build in the new style remarked:

It is very difficult to get the good timber these days. Getting someone to haul it over is difficult, cutting the wood is difficult. You cannot use any old wood. For example, utish is not good enough. It has to be the 
red wood Padke and it is only found in the higher parts of the hills.

(Himani, resident-tourism, guesthouse owner)

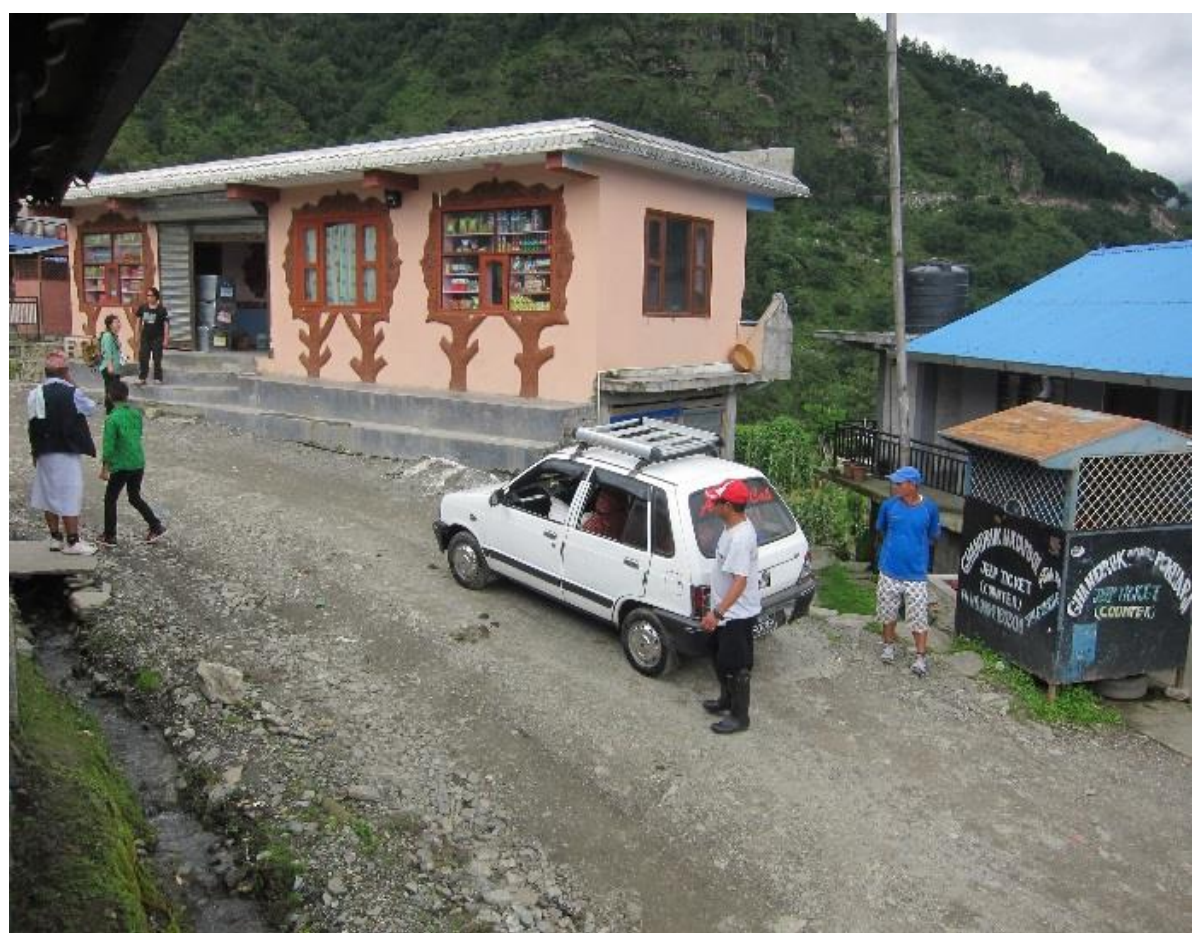

Plate 4-10: New building in non-conforming architectural styles in Kimchi, the last stop for vehicles

Photo: JJoshi, 2016

On the other hand, a phone call to the supplier in Pokhara delivers the materials such as cement and rebar, at least up to Kimchi. In addition, there is a misunderstanding/belief that traditional houses with mud mortar are not as permanent or strong as the ones with cement mortar. The Government of Nepal also lists mud mortar buildings as kachhi or temporary houses. Since the earthquake in 2015, this concern has intensified due to a significant loss of traditional buildings. There is an on-going discussion between conservationists and engineers regarding the use of mud mortar ${ }^{11}$. The following remark illustrates that the residents perceive new materials as more reliable and their availability as important factors for the decreasing interest in traditional materials and building styles:

There used to be all stone houses before. Now with the road people want to build with concrete. It is also convenient to bring materials easily with the transportation services here. To bring timber from the hills above and build with it is troublesome. The vehicles will bring it

\footnotetext{
${ }^{11}$ Society of Nepalese Architects (SONA Annual Symposium 2017: Designing and Planning Challenges in the Post Earthquake Built Environment, 3 - 5 November 2017
} 
for you right to your doorsteps. You build your house once in a lifetime and want to build something permanent, a 'pakki' (permanent) house. That is why people are attracted with the concrete buildings. It is the convenience of transportation. (Mahesh, resident-teahouse owner)

There was also nostalgia accompanying the loss of traditional buildings, especially from the tourism-sector residents. They understood the significance of retaining a distinctive architectural style and image for tourism marketing purposes. The traditional architecture and settlement pattern is a distinct landscape characteristic of Ghandruk and one of the major attractions. They also acknowledged the need to accommodate changing demands, which could be incorporated within the traditional style. For example, a resident who operated a newly constructed guesthouse in a traditional style remarked:

They are building a house right there that looks completely modern. If that could just be modified and given a traditional flavour, that would be attractive to people. It is also a kind of marketing strategy. Otherwise in a village like this you are building a conventional modern house, what is the use? Why would I want to stay in such a house? (Hari, resident-tourism, guesthouse owner.

There was also hesitation among the residents to take firm actions against those changing the architectural landscape because of their substantial investments. Most of the guest accommodations in Ghandruk are either homestays in traditional buildings or new constructions built in the land that was previously used for farming. To date, very few traditional buildings have been demolished to build new guesthouses. The new constructions, hence, are substantial investments that are attracting the residents to return to their hometowns and generating employment opportunities. The earlier new buildings mostly used local stone and timber and followed the traditional architectural styles, while some of the new ones are not conforming to it. The following remark by a guesthouse owner who has maintained the traditional style in his new guesthouse using local stone and timber while providing attached baths illustrates his dilemma between being optimistic that residents are returning to invest and the negative impact of the investments.

When the process of people moving to Kathmandu and Pokhara is increasing, at least some are returning to invest in the village. That is the reason I have not opposed them too much. But slowly I will try. It is a very difficult situation. We also feel that they are ugly, but we cannot say that they are ugly. They are returning to the village and 
investing huge amounts of money. But there is a growing awareness of that now. It is slowly growing. (Krishna, resident-tourism, guesthouse owner)

As evident from the above statements, there is a slow but growing concern for the potential drastic change in the traditional architectural character and settlement pattern of the village. One of the reasons that the change has been controlled and slow and control is the informal agreement that binds the villagers not the sell their properties to outsiders. The outsiders include people of Nepal or foreigners who are not from Ghandruk. This ban was placed to restrict big investments or star hotels from entering the market and competing with the residents ${ }^{12}$. Although this restriction has controlled the growth of large properties and unfair competition, the growth of tourism in the region has also been limited.

One of the striking changes that the residents were drawn towards in the earlier photographs were the images of the "makkai ko suli" or the corn stacks (Plate 4-11). Corn in their husks are stacked to dry and raised above the ground to protect from animals and rodents. This tradition had almost disappeared but was still fresh in the memories of the residents. The migration of the local population to the cities during the Maoist conflict and political instability resulting in the youth seeking work abroad and the lahure traditions were primary causes for the decrease in farming and the subsequent absence of the makkai ko suli. The residents expressed concern about the decrease in population and the increasing number of abandoned houses. Another recurring reason the residents mentioned for families migrating to nearby towns was the lack of quality education. Ghandruk has a public high school but the students are compelled to take their final school leaving examination in Pokhara due to the lack of proper facilities. This social phenomenon or out-migration has the potential to influence the development of Ghandruk and the subsequent landscape changes with increasing abandoned houses and shortage of labour.

\footnotetext{
${ }^{12}$ Not all residents agree to this restriction, however, this informal ban is followed for now.
} 


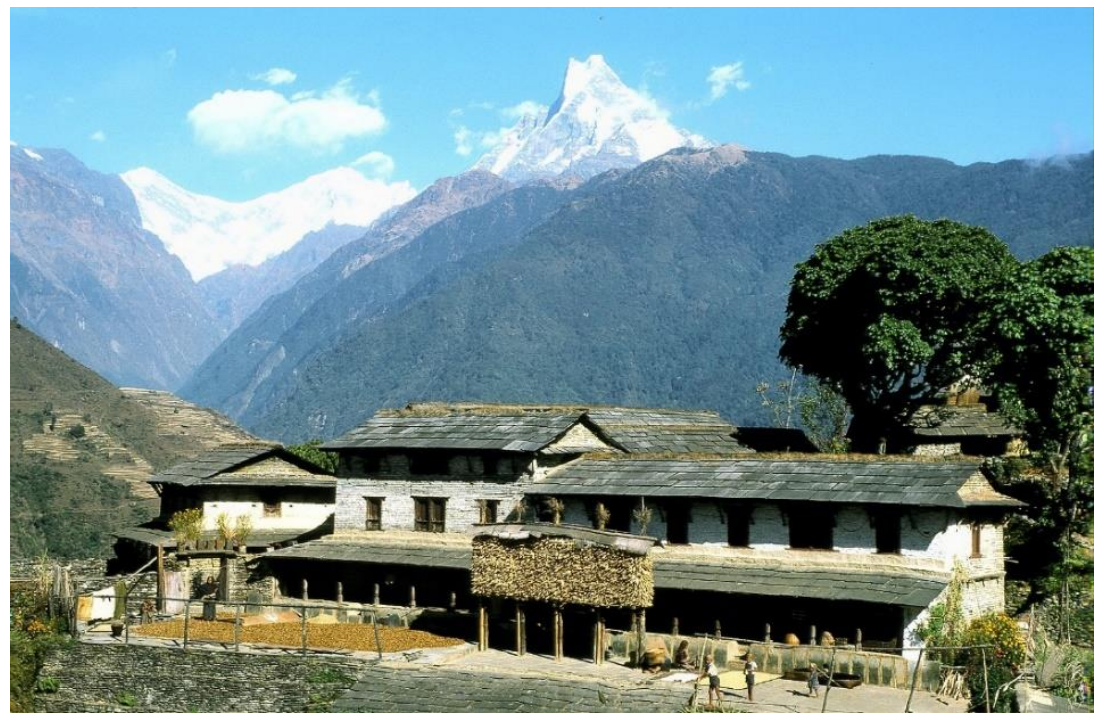

Photo:

Peter Von Mertens $(P C N P P), 1974$

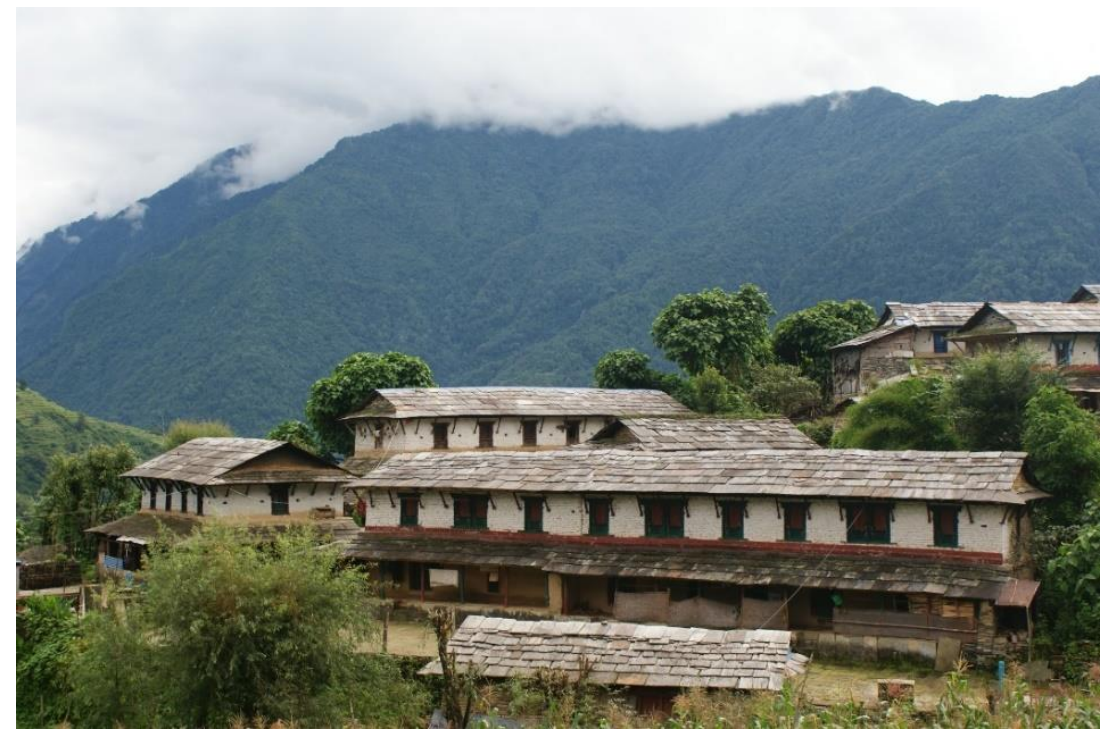

Photo:

JJoshi, 2016

Plate 4-11: Past and repeat photographs showing the corn stack in 1974

With no prior knowledge of the village, the tourists interviewed were not able to discern major changes in Ghandruk even in the past and repeat photographs, except one Nepali participant who had been to the region on several occasions due to the nature of his profession as a tour guide. The change he observed related mostly to the improvements in the available amenities for the tourists and the types of tourists visiting the region. This change is reflecting on the built landscape. For example, a guesthouse owner remarked:

The difference between the traditional mud houses and the new concrete houses is that once you build it you do not have to paint/plaster it often. You have to paint/plaster the mud house every year. You have to repair the mud floor daily. When the tourists come in, their big [hiking] shoes will destroy the mud floor in a minute. You have to repair/paint it every day. But the traditional houses are better 
to look at. In terms of cleanliness, the concrete houses are better.

(Srijana, resident-tourism, guesthouse owner

The above statement indicates the indirect role or behaviour of the tourists in the change in the building material. The traditional houses with mud floors are not meant for heavy hiking shoes and the tourists are unaware of the efforts required to maintain them. As mentioned earlier, tourism in Ghandruk started with western explorers and mountaineers camping along the trails carrying their own tents. Slowly, the villagers started opening a room or two in their homes for trekkers to sleep and eat, and this later progressed to guesthouses with shared or attached bathrooms. Therefore, through their subtle demands, the tourists have been changing the character of Ghandruk. In order to gain more revenues from the tourists, the local residents were accommodating the demands of the tourists with structures that can drastically change the character of a place. Some tourists noticed the new bigger structures being constructed, especially the ones that were in styles that were not compatible with the earlier one and two storeyed traditional stone buildings.

While the residents were able to spot the details such as the abandoned terraces and makkai ko suli, the tourists had difficulties differentiating the past and repeat photographs, although some were able to notice small changes on careful examination of the details. The tourists travelling through had limited knowledge and intricacies of the processes and the history of the village landscape. One of the reasons the tourists were confused with the earlier and later photographs was also because with the abandoned houses with their windows and doors shut, the later photograph looked older than the earlier pictures with a more active population.

In line with the residents' mixed responses to the new road, the responses of the tourists were ambivalent. While some remarked that the road disturbed their trek with noise and dust, others were not disturbed. This may be due to the difference in hiking hours, bus schedules and where the road was crossed. The following demonstrate the two opinions:

It was disturbing, and we talked about it on our way. It was not nice. With the dust, the motor pollution. (Lily, tourist, Israel)

I definitely noticed it. I thought the stairs were nicer, but the road would be easier for my knees. But Ram [guide] kept walking on the steps and I thought that was the way we were supposed to go. And as 
we were walking up, a bus came up and I heard the beep. I noticed it. I mean it wasn't a disturbance. (Penny, tourist, UK)

On the other hand, the domestic tourists were happy with the option to take the available vehicles to the nearest point and decrease the hiking distance. However, they also expressed concern about the potential impact on tourism. They suggested that the road should not extend further:

I think the road up to that point [Kimchi] is fine. Walking from there on is fine. At least the transportation costs will be lower for things like food they don't have to be carried all the way up. Otherwise the cost to carry them from the highway would be higher. Walking from that point is good. It would be good if the road does not extend from there. The slope of the road is quite dangerous. That is why it should not extend up. But up to that point is useful. If there is no transportation access at all, the people here will not have access to the market either for their agricultural produce. It would be beneficial for the villagers; they need it but it should not extend any further. It will benefit the village if people hike up from that point. (Rashmi, tourist, Nepal)

The above statement expresses concern for both the residents and the tourists. The residents need the road for transportation of goods, while the tourists should be able to experience hiking. This indicates the importance of both the road and tourism and the need for a balance between the two for the local economy.

All tourists agreed on the popularity and potential of Ghandruk as a tourist destination. However, their opinions varied with their situational contexts. While the international tourists were mainly interested in the experience of trekking in the Annapurna region, they were highly impressed by the quality of the trek and the views of the Himalayan range and the landscape. Their principal motive was to trek and enjoy the views in a relaxing environment. However, the domestic tourist expressed concerns about the need to include other activities in addition to viewing the mountains. The mountains are visible from most parts of Nepal and are familiar to most people. In addition, physical activities such as hiking, trekking or cycling as recreational activities are still at the early stages of development in the domestic market with a desire for new and different experiences from their daily lives. This also indicates the change in tourist types and its potential impacts on the landscapes. The following remark suggests potential impact on the landscape as domestic and non-trekking based tourism increases in Ghandruk: 
There should be more activities to engage people. I have already decided to bring my wife here with my son, even if we have to get help to carry him. My son and my wife will want to do something to engage themselves. I hope there are more activities. We will stay at hotels but that is not enough. There is the mountain to view but there should be more than that. I will be motivated to bring them for 2-3 days or a weekend. They will enjoy the visit and the stay, and it will be memorable. They cannot walk a lot. (Hari, tourist, Nepal)

Overall, the participants viewed the landscape changes both positively and negatively. The beneficial changes for the tourists included the lush green forests and the amenities in the accommodations. On the other hand, there were mixed responses to the change in the built landscape and the new vehicular road. The residents also expressed varied opinions on the construction and impact of the road, especially regarding the destruction of the historic stone trails. However, they also appreciated that the road cut their travelling time to Pokhara considerably and made transporting goods easier and cheaper. There was also a concern that the older buildings were left vacant and not being preserved and that newer ones did not reflect Ghandruk architectural character. Concerns were also raised over the decreased population and that the benefits of tourism had not reached more remote settlements of Ghandruk, which still lacks electricity. Ghandruk is a unique and popular destination with diverse natural, built and cultural landscapes and most of the participants expressed strong positive feelings about this.

\subsection{CONCLUSION}

The residents associated the landscape with the social relationships, history and cultural aspects in addition to pride in living in a highly visited natural landscape. The local culture and social networks played an important part in the landscape for the residents. They also tended to compare the present landscape to the past and associate the general local situation, such as the lack of higher education, health facilities and the new vehicular road. This indicates that, for the residents in addition to the physical and cultural aspects, the landscape comprises their everyday lives. These components in totality encompass their perception of landscape aesthetics.

The biodiversity centred conservation policies of ACAP have shaped the current landscape of Ghandruk. Urbanisation that had been comparatively slow in the course of 
the last century mainly due to the lack of vehicular roads, has the potential to change with the new road. The tradition of leaving home as a lahure, rural depopulation and aging population has continued with the outflow of the younger and better educated age cohorts to the larger urban centres or abroad for work. This is a common contemporary phenomenon in most of Nepal's villages, particularly since the 12-year long Maoist conflict (1996-2006) and subsequent political uncertainty. However, tourism is increasing along with infrastructure development such as road construction and that has potential to increase the pace of change. The residents had mixed responses to changes in the landscape, such as the loss of traditional built heritage, emergence of new building styles and the increased forested areas. Although the loss has been controlled in Ghandruk due to its remoteness and lack of vehicular road, the newly constructed road is showing signs of change at a more rapid pace with implications on the future of tourism. There was also acknowledgement that while traditional architecture was more suitable for the local climate, traditional materials and technologies are regarded as high maintenance and expensive, while new materials are easily available and cost effective. There was also acceptance of modern conveniences generally associated with the changing lifestyles as well as the demands of the new types of tourism developing in Ghandruk, especially the rising popularity in the domestic and Asian markets. Although the traditional buildings were not demolished for new structures, the new buildings were built on land that was previously farmed. The size and construction materials of the buildings have changed from 1-2 storey to larger 3-4 storeys and stone and timber structures have been replaced by concrete, cement and corrugated metal roofs.

The primary purpose of all the tourists interviewed in Ghandruk was to experience trekking in the Annapurna region, which included both the natural and cultural experiences. The main attraction, not surprisingly, was the spectacular mountain landscape enhanced by the typical villages along the trail. The Himalayan vista captivated the tourists, but the villages and the settlements they encountered along their treks added value to their experience of the natural scenery. Their principal focus and excitement were the anticipation of their journey and the destination of which, Ghandruk was merely a stopover. None of the international tourists had selected to stop in Ghandruk and had depended on their trekking agents to make all arrangements, including the route and accommodation. The domestic tourists, however, selected the route to visit 
Ghandruk. They had also chosen the lodges they were staying based on reviews on the internet or from friends. This suggests the domestic tourists had insider knowledge and information, while international tourists depended on secondary sources. This also indicates the level of interaction and engagement different groups of tourists have in the landscape. The domestic tourists are more comfortable in the surroundings due to their familiarity with the local language, which allows them to engage with the residents and gain insights on their life. The acceptance of the changes brought on by tourism was found to be related to the perceived benefits shared by the local community.

Today, Ghandruk is considered to be greener and cleaner with a huge potential for nature and culture-based tourism. Reforestation, increase in wildlife, employment opportunities, lahure culture, migration of youth for work were among the changes associated with Ghandruk, in addition to the larger buildings that were of strikingly different styles. Most of the changes attributed to tourism were considered to be good, though there were concerns for the modern construction changing the landscape and the road discouraging the tourists. Increasing number of vacant houses due to the lahure tradition and recent economic migrants would have an impact on the overall landscape of Ghandruk. 


\section{BANDIPUR: PRESERVED HISTORIC BAZAAR AND THE DEVELOPING PERIPHERY}

Following the format of the previous chapter, this chapter presents the perceptions of the participants on landscape aesthetics, landscape change and tourism in Bandipur. First, this chapter presents the contextual background of Bandipur based on secondary sources, field notes and interviews with key informants. Next, the findings on how the residents and tourists perceive the landscape and landscape aesthetics are presented, followed by their perceptions on the landscape changes before conclusions are drawn. Twenty-one participants (11 residents and 10 tourists) were interviewed in Bandipur (Table 3-6).

\subsection{CONTEXTUAL BACKGROUND}

Bandipur is located in Tanahu district (Kaski Zone) in Province No. 4 and is a Gaunpalika or rural municipality. Bandipur generally refers to the main bazaar and Bandipur Gaunpalika indicates the larger area with all the wards. For this study, Bandipur denotes the bazaar and the surroundings wards. It is located in west-central Nepal at an elevation of 1030 metres.

Bandipur is situated to the south of the Prithvi Highway that connects Kathmandu to Pokhara covering an area of 102 sq. km (Plate 5-1). The main supply and bus stop town on the highway is Dumre. From Dumre, an $8 \mathrm{~km}$ black topped road winds up the hill to the top of the ridge that slopes gently on two sides (north and south) forming a saddle. At the end of the black topped road, the road enters onto a long stone-paved bazaar lined with brick houses on two sides. This is the main Bandipur Bazaar and the headquarters of the rural municipality. The road continues as an unpaved dirt road and connects to the rural parts of Bandipur. Vehicular access is completely restricted within Bandipur Bazaar which has been declared as a Protected Cultural Subzone, which includes the main bazaar and the surrounding 500 metres. 


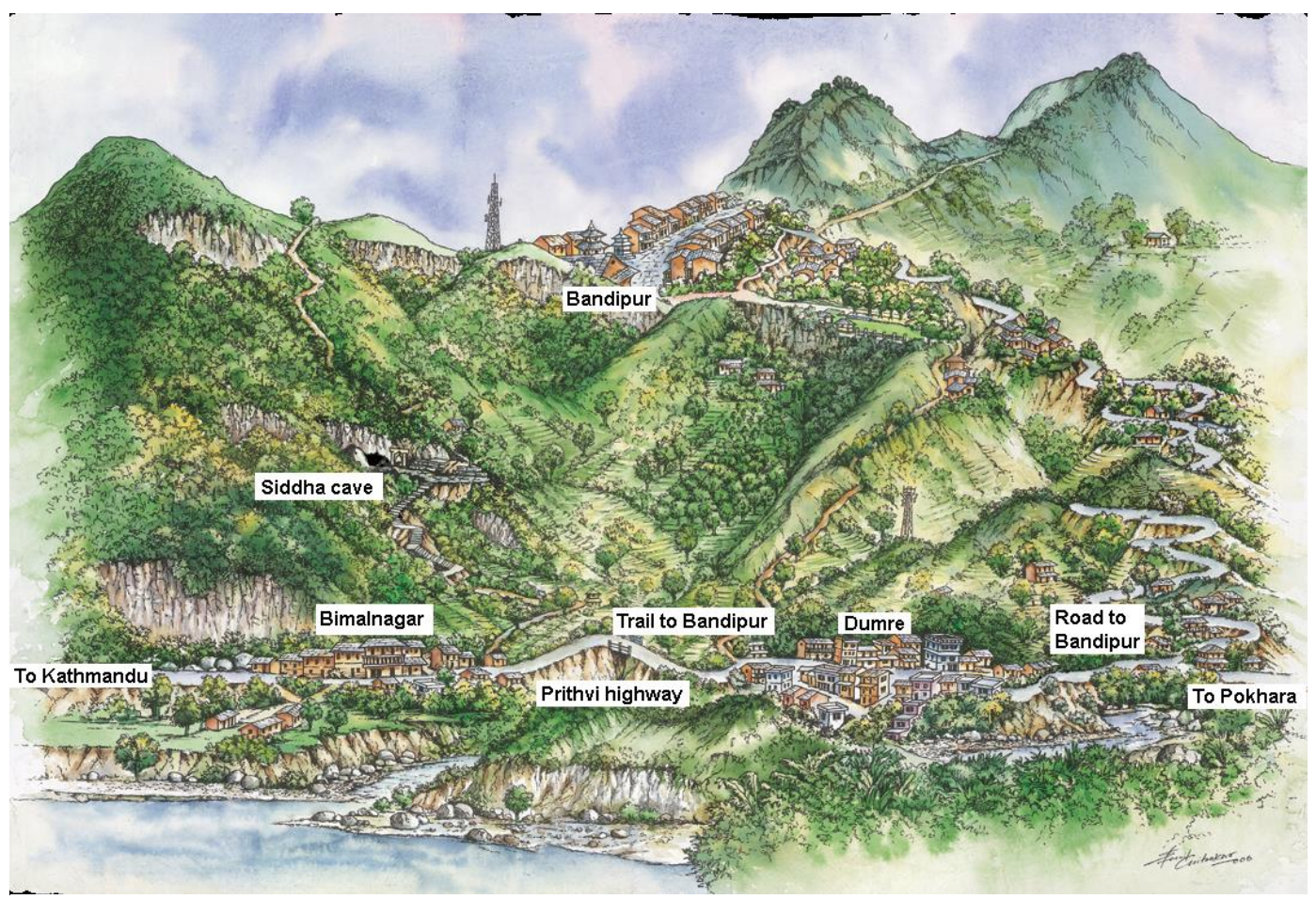

Plate 5-1: Location of Bandipur and access routes from Dumre and Bimalnagar

Source: BECTP, 2006

The landscape of Bandipur includes forests, valleys, cultivated lands and settlements within an altitude between 300 and 2000 metres. This variation in the altitude situates Bandipur in both the Tropical and Sub-Tropical Zones, resulting in a diverse array of ecosystems, cultivation seasons and biodiversity (Barnekow Lillesø, Shrestha, Dhakal, Nayaju, \& Shrestha, 2005). The forests are mostly located in the hilly parts. The lowlands and the valleys are heavily cultivated, and the main crops include rice, maize, wheat, barley, potato, fruits, vegetables, off season vegetables and hill cash crops. Parts of the hills near the settlements are also cultivated on terraces, mainly corn, though less intensively because of the limited water sources. In 2011, the population of Bandipur was 20,013 from diverse ethnic groups (Gurung, Magar, Brahmin, Kshetri, Kami, Damai and Sarki and Newar) with the Newars residing in the main bazaar.

Bandipur Bazaar is elongated east-west with the two ends rising up to form hillocks on each end, providing excellent vantage points overlooking the bazaar and the surrounding landscapes. The northern and southern parts of the ridge slope gently with cultivated terraces, especially on the southern slopes, where there is good sunlight and water sources. Although the Himalayan Range can be seen from most parts of Nepal, the view 
from Bandipur is unique; the length of the Himalayan Range visible from Bandipur is extensive. On a clear day (usually in November or December) the views extend in the west from the Dhaulagiri range to Annapurna, Manaslu, Langtang and Gaurishanker to the east. Most interesting is the view of the Marshyangdi Valley at 300 metres and Mt. Annapurna over 8000 metres in one frame, which is possible because of the location of Bandipur on a hill overlooking the valley (Plate 5-2).

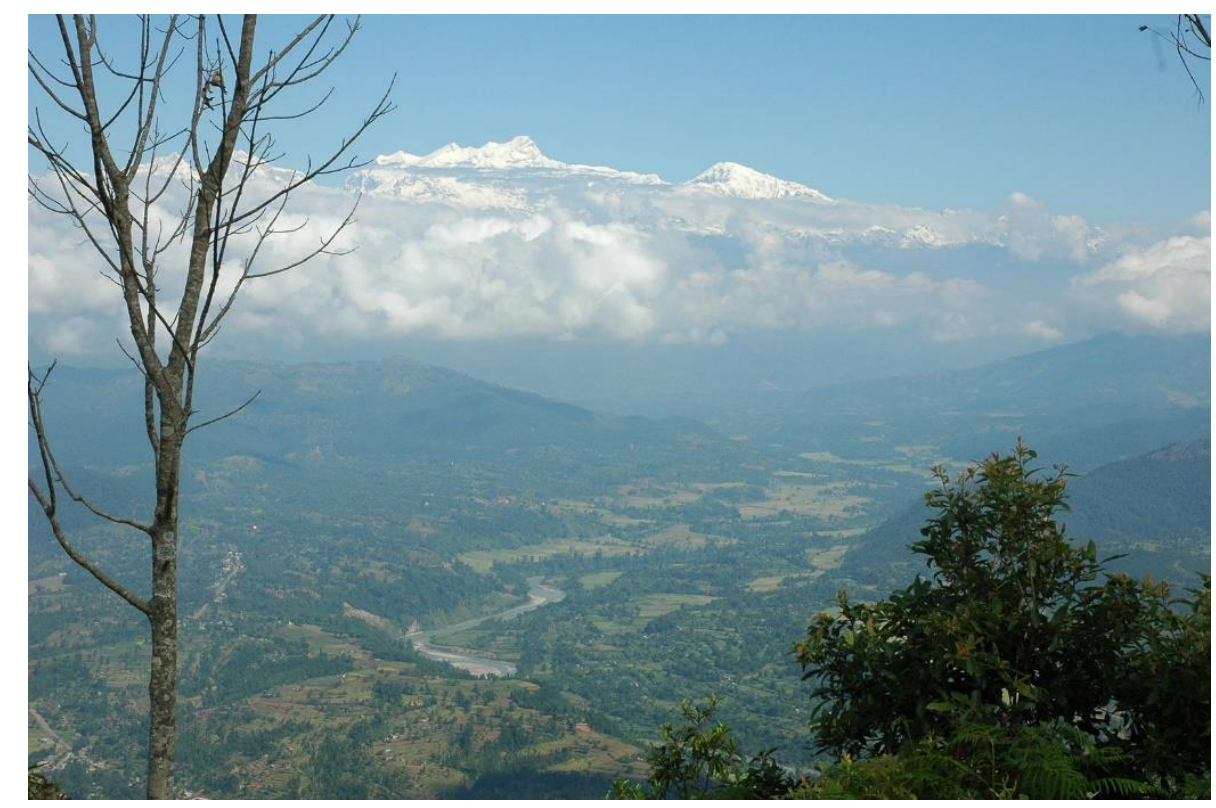

Plate 5-2: View of Marshyangdi valley (300m) and Annapurna range (8000m) from Bandipur

Photo: BECPT, 2005

\subsubsection{History and the people}

Although limited written documentation exists regarding the origins and history of Bandipur, the extant physical evidence supports the local legends, oral history and written accounts by early western travellers (Iltis, 1980). Legends associate Bandipur to Mukunda Sen, the Magar king of Tanahun in the $16^{\text {th }}$ century. A sword he left behind when he meditated in the hills of Bandipur is believed to be enshrined in the Khadga Devi temple. The temple still exists (rebuilt in later years) with a sacred sword wrapped in many layers of cloth and believed to be a representation of Goddess Durga. 
The early settlers of Bandipur, the Magars, were mainly farmers and relatively selfsufficient in a climate that provided at least two crops a year and abundant fruit trees (Iltis, 1980). Around the beginning of the $19^{\text {th }}$ century, an influx of a new population, Newars from Bhaktapur, in the Kathmandu Valley (Iltis, 1980) who were mainly merchants marked the beginning of transformation from subsistence farming to a thriving trading town (Plate 5.3). Bandipur, the district headquarters, became an important centre in the north-south trading route connecting Tibet and India as well as internal trade with surrounding districts, such as Gorkha and Lumjung. In the 1950s, the merchants from Bandipur took advantage of the eradication of malaria in the Terai to settle in new towns and expand their trade in India (also see section 6.1.1). This increased the accessibility to Indian goods, including machinery and mechanised mills were installed in Bandipur. This further strengthened Bandipur as a trading centre providing a basis for development in other sectors such as education and health.

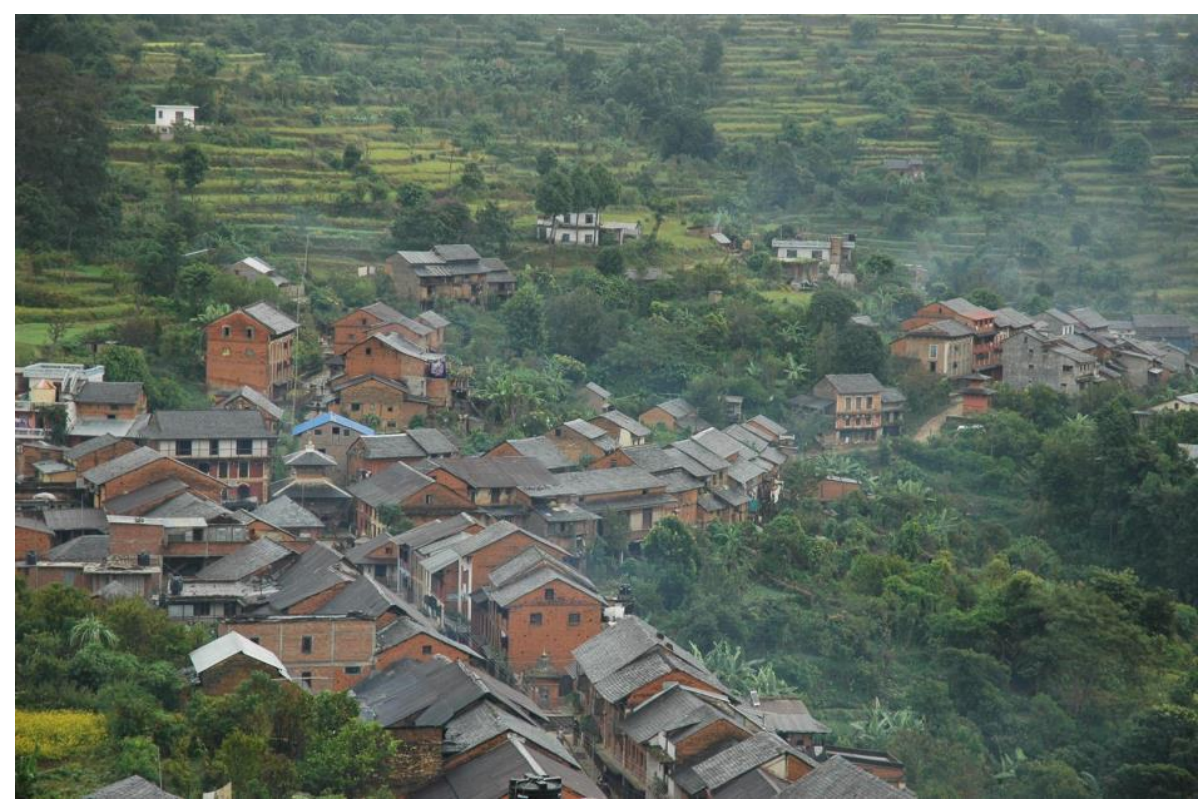

Plate 5-3: Bandipur settlement against the terraced farms

Photo: BECTP, 2005

However, this period also started the decline of Bandipur along with major reorganisation of administrative systems of Nepal. The district structures were realigned and the new borders of Tanahun district did not position Bandipur favourably. Despite protests from the residents, the new headquarters shifted to a geographically accessible Damauli on the lowlands along with all administrative work traffic. Next, the plans for the construction 
of the Prithvi Highway, linking Kathmandu to Pokhara, also bypassed Bandipur extending along the river and the new headquarters. Again, despite aggressive protests, the original plan remained, however, Bandipur managed to secure funds for a new vehicular access road from the highway. Although the district school and hospital remained, the access road was not effective to stop people and trade moving down to the highway or drawing trade up to Bandipur.

The above mentioned two incidents had devastating effects with trade declining to small scale local transactions (Iltis, 1980). To save their businesses, merchants moved to the highway setting up new gateway settlements such as Dumre. Despite the decline in trading and the political turmoil in the country, Bandipur retained a core population sufficient to maintain basic infrastructure, including the district school and hospital. The Newar merchants who migrated to other places continued to maintain their cultural and familial ties, retaining their houses and land holdings and returning for major festivals and family events. Thus, although the settlement diminished in size, population and importance, the fine architecture of the bazaar survived and Bandipur has been able to adapt and take advantage of its tourism potential.

\subsubsection{The settlement and the architecture}

The extant settlement pattern of Bandipur evolved from the scattered clusters of dwellings that were spread in and around the hill. The early settlers, the Magars, preferred to construct their houses in small clusters and traces of two of the original five are still discernible with their names, the inhabitants and building types (Iltis, 1980). The original Magar dwellings were constructed with un-planed, roughly-sawn wood, poles and small stones with mud mortars and plastered with clay, dung and straw. They were one to two storeyed with thick thatch roofs and a covered porch in front of the houses where household chores were carried out as well as providing a shaded area for weaving cloth or bamboo baskets. Since most of the household chores take place in the entrance porch, the openings are usually small-latticed windows and a low door. Cattle were kept next to the house under shade, a small structure with poles covered with thatch roof. Historically, the Magars depended entirely on agriculture and animal husbandry and their dwellings reflected their occupation and way of life. 
The most obvious evidence of the Newar influence in Bandipur today is reflected in the architecture and settlement pattern of the main bazaar. In the period of prosperity, the settlement also extended beyond the current boundaries. A distinct characteristic of a Newar settlement is the compact row housing on two sides of a street, three to four stories with brick face, carved wooden windows and doors and pitched roofs. The architectural style of the Bandipur follows this pattern with some local variations. The row houses efficiently utilise the level ground of the ridge with the row houses built at the edge of the slope with three to four storeyed on the main street but extending below a level or two following the slope of the ridge. The houses extend beyond the bazaar branching out along the ridge and following the natural curves without excavating or levelling the land. The bazaar is the widest and relatively aligned, whereas the branches are narrower and gently rise or slope. This creates interesting spaces at the nodes, where temples or pati (small public resting houses) are placed. These public spaces are extensively used for religious, cultural and social events as well as play areas for the children. The two hillocks on each end of the bazaar are perfectly placed to view the meandering pattern of the settlement.

The entrance to the bazaar is the terminus for vehicles and start of the pedestrianised Bazaar. The street slopes down gently at the entrance to provide a striking view of the Bazaar with the row houses and stone paved street (Plate 5-4). With the recent economic upturn, the bazaar is usually busy with various activities. In the mornings and afternoons, schoolchildren in different uniforms fill the bazaar on their way to and from their school at either end, while the tourists relax in the many restaurants that line the bazaar, especially in the evenings.

At the eastern end, the street that bends north ends at Tundikhel, a former parade ground that is now used for a variety of activities. A row of five Peepal trees line one side of the ground while the other side drops down sharply towards Bimalnagar and the Marshyangi valley, providing a spectacular view of the majestic Annapurnas and the lush green valley with the meandering Marshyandi River (Plate 5-2). This is one of the best locations to view the long range of the Himalayas from Bandipur and in winter mornings the valley below is usually covered with mist giving the impression of being above the clouds with the mountains rising from a white sea. In the mornings this ground is filled with residents out for a brisk walk, while the tourists enjoy the scenic panorama. Later in the afternoon, 
this space turns into a football ground with tourists joining in the friendly matches with the local schoolchildren.

The architecture built by the Newars was strikingly different from the modest Magars dwellings. The Newars brought masons, carpenters and artisans from Bhaktapur and built three-four storey houses with bricks that they manufactured nearby from local clay (Plate 5-4). While the Magar interior was a single undivided space, the Newar houses had partitions and separate rooms for different activities. A typical house in Bandipur has a shop on the ground floor with sleeping rooms in the upper floors and the kitchen in the attic. The ground floor facing the bazaar can be fully opened with shuttered doors, creating a true bazaar like atmosphere, as displayed goods can be seen from the streets. The shop fronts on the south facing façade of the street have a covered passageway with a continuous balcony extending the length of the bazaar (Plate 5-5). The covered passageway shields residents and visitors from the summer sun and the rain cooling the interior of the house. This covered passageway lines only the northern side of the bazaar (south facing) to catch the sun in the winter and provide shade in summer.

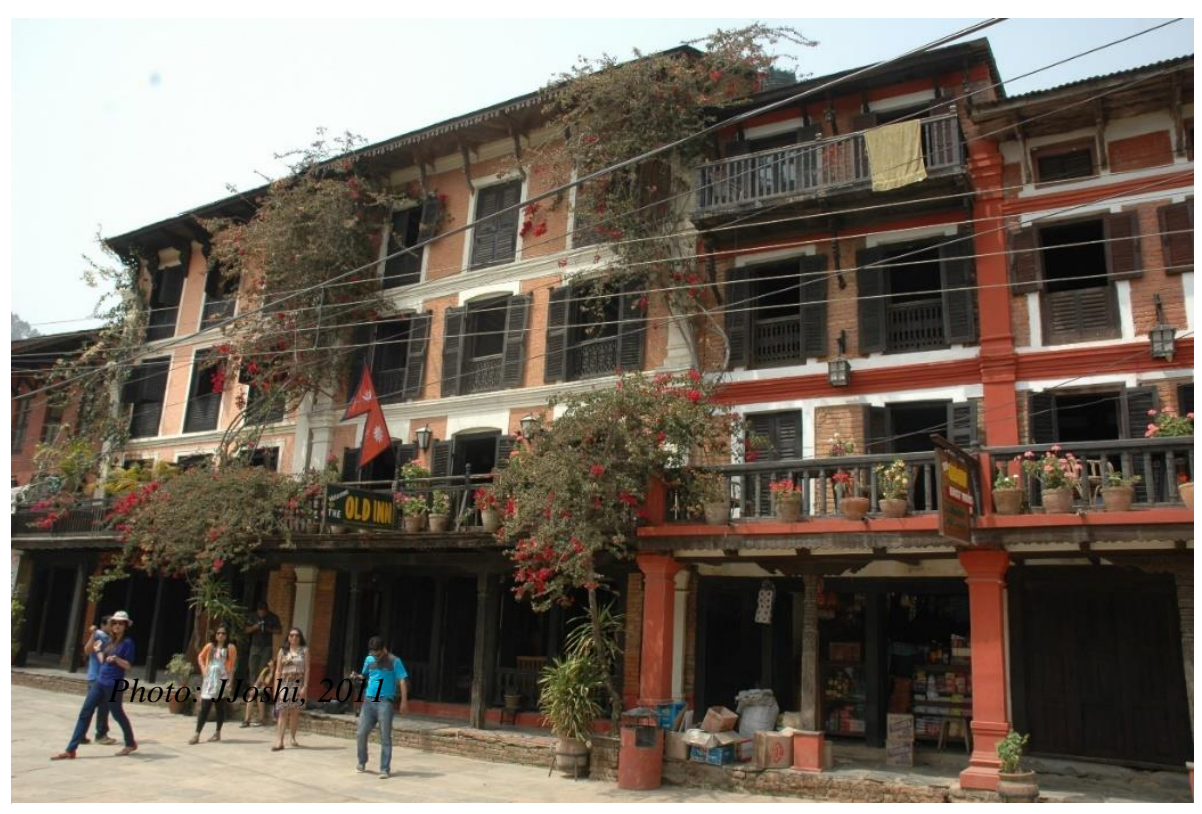

Plate 5-4: Typical buildings in Bandipur bazaar

Photo: JJoshi, 2012 


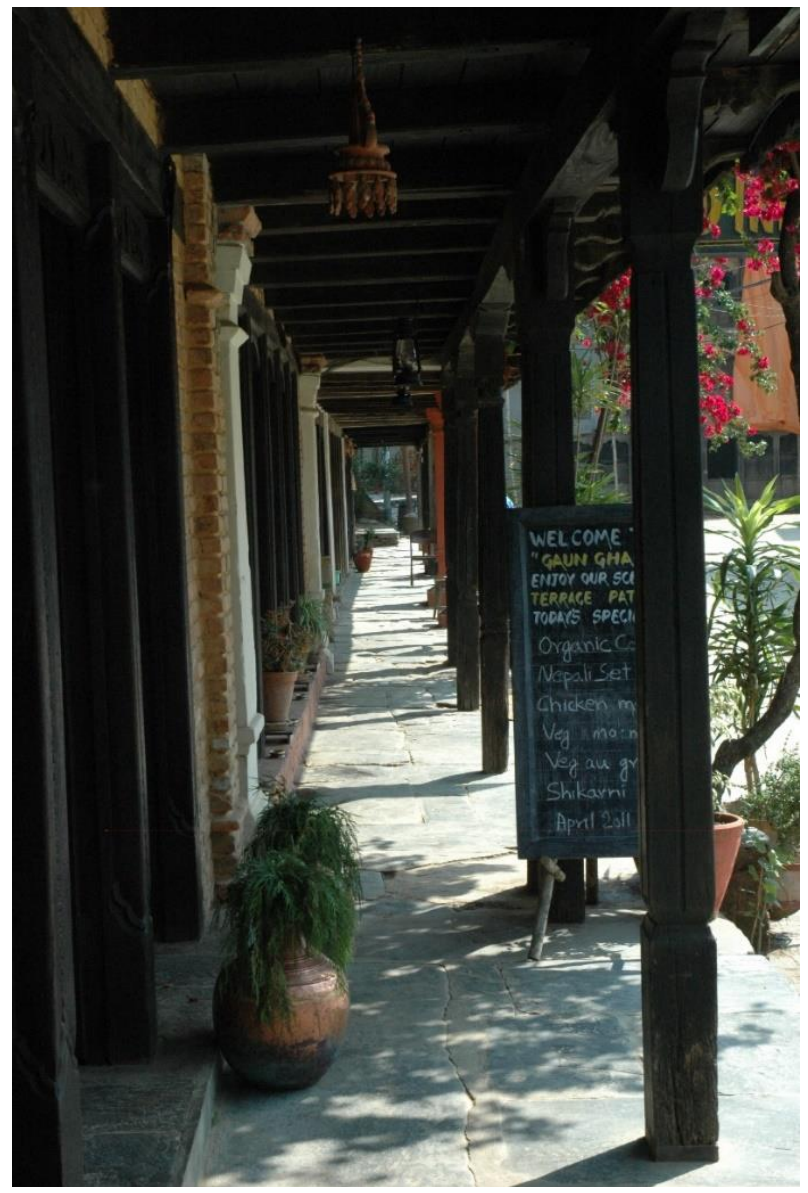

Plate 5-5: Covered passage with balconies on the first level

Photo: JJoshi, 2011

\subsubsection{Preserved zone and tourism}

The core area of Bandipur and the surrounding 500 metres was declared Samrachit Upachetra or Preserved Cultural Subzone in 2016 by the municipal board. The aim of the designation is to preserve the traditional buildings of Bandipur. The potential of the bazaar with its unique architecture and settlement pattern as a tourist destination and subsequent economic benefits were the motivations for the designation. The declaration is accompanied by basic guidelines and regulations on restoration and reconstruction of buildings within the protected zone. This document is based on earlier guidelines for Kathmandu Valley and uses examples from the architecture of Kathmandu Valley (Government of Nepal, 2016). The requirements are basic and specify height restrictions, roof and architectural style including types of windows and door. It also requires a demolition permit to be approved from the local authority and restrictions on any "modern or western" styles. The conservation policies address the built heritage but there 
are no provisions to conserve other aspects of the landscape, such as the natural environment or the intangible heritage.

Tourism development is relatively new in Bandipur, although there were visitors as early as the 1960s and 1970s including the U.S. Peace Corps volunteers, and this is the main source of the past photographs used for this research. Tourists started arriving steadily after the different promotional activities by a wide range of agencies such as the Bandipur Eco Tourism Project (BECPT) in 2005-7, Nepal Tourism Board (NTB) and Bandipur Social Development Committee (BSDC). In 2007, there were a handful of hotels and guesthouses, including a few that catered to international tourist groups, however, most mainly targeted domestic tourists and individual international travellers. Today, Bandipur has more than 50 hotels, guesthouses and homestays of different capacities and facilities catering to a wide range of tourists. Although there is no official data, the figure provided by the Bandipur Tourism Development Committee for 2012 was 10,000 international and 80,000 domestic visitors (including day visitors). Bandipur receives substantial number of picnickers ${ }^{13}$ and day visitors from the surrounding towns, especially in the months of October and November.

\subsection{PERCEPTIONS: THE BAZAAR AND THE VISTA}

This section presents the participants' perceptions of the landscape in Bandipur. As described above, the main centre of Bandipur, the main bazaar is a preserved zone with distinctive architecture and settlement pattern attracting international and domestic tourists as a cultural tourism destination. It is located on a ridge providing unrestricted views of the multiple layers of hills and mountains, capped with the Himalayas in the north and the terraced farming in the south. This location creates a vantage point for the vistas as well as for the settlement that meanders along the ridge. These two factors: the village and the vistas, were the main landscape aspects noted by both the residents and tourists. However, there were differences on the attributes that the two groups associated with landscape aesthetics and further differences within the groups. This section first

\footnotetext{
${ }^{13}$ Picnickers in Nepal generally cook food on-site.
} 
presents the perceptions of the residents and tourists with regard to bazaar, followed by the natural landscape.

\subsubsection{Bandipur bazaar: the heart of Bandipur}

In Nepal, Bandipur is known as the "Queen of the hills" due to its location on the ridge with its mild temperature and quaint bazaar. The residents interviewed were proud of this reputation that went beyond the visual aesthetics to include the historical context of a prosperous economy (section 5.1.1). Although the type of commerce has changed, from a regional trading post to a touristic town, the main bazaar has retained its importance, and this is reflected in the residents' responses. However, the importance of the settlement pattern and the traditional architecture held varying degrees of significance for the residents. The tourism-sector residents were particularly focused on its contribution to the Bandipur landscape. The following remark illustrates this:

The settlement is the most unique about Bandipur. The way this settlement is laid out. On top of a hill, on a ridge. There are temples spread around the settlement. This is unique about this town. You cannot find this in other places. (Harikala, resident-tourism, guesthouse manager)

There is an implicit link between the increase in tourism and associated economic consequences and the significance of the bazaar. For example, another guesthouse owner stated:

Bandipur is known as the 'Queen of the hills'. But the main street here is the heart of Bandipur. If this is gone, the uniqueness and identity of Bandipur will be gone and it will lose everything. (Binay, residenttourism, guesthouse owner)

The above statement indicates the importance of the architectural heritage for the tourism industry. The recent restoration and maintenance work in the bazaar is also related to the increasing tourism activities. According to some residents, without the economic returns, there would be no reason to restore the traditional houses. For most residents, houses are to be lived in and it does not matter how it looks from the outside. A teahouse owner simply stated: 
Why would they do it [restore, paint]? Houses are just to spend the night. (Binita, resident-tourism, teahouse owner)

The above responses indicate that tourism has influenced the perceptions of landscapes in Bandipur. The importance of the bazaar has increased, not only in terms of property value but has also instilled a sense of pride and raised awareness for its preservation. The following two responses illustrate the influence of the tourists' perceptions and tourism influence on the residents:

For travel connoisseurs, the bazaar with its traditional Newari style buildings is very attractive. My house is on the way to Tundikhel from the bazaar and I hear tourists making comments as they walk through the bazaar. I hear them praising the bazaar and it makes me proud this is my hometown. (Binod, resident-non tourism, teacher)

The bazaar is the most important attraction. The style of architecture and the houses built more than 200 years ago. There are such towns in other countries too and they preserve them. Even if they are renovated or changed inside, they maintain the façade; if it is weak, it would be reinforced from the inside. When we visit European cities, they have information written how old the building is. From this we learn that mostly the Europeans and the American like this kind of towns. (Sushil, resident-tourism, hotel owner)

For the residents, in addition to the architectural heritage, the cultural diversity, history and ethnic groups were key characteristics that defined Bandipur. This was more important for the residents for whom Bandipur was their ancestral home. They were witnesses to the heydays as a trading post and had experienced the highs and lows. They reminisced about when Bandipur was livelier with traditional festivals and activities that have decreased with the downfall and subsequent migration described above.

The cultural events are not like before. It used to be unique and creative. There used to be singing. Nowadays people use recordings. In the past, the festivals used to go on all day and night. People from all the surrounding villages and hills used to come here and the bazaar would be crowded and lively. (Prabin, resident-non tourism, tailor)

During my childhood here, the main thing I remember are the Newar community festivals and the way they were celebrated. I don't see the kind of celebration of my childhood anymore. That makes me unhappy. During Phulpati, we used to wake up early in the morning and sleep the next morning. There were programmes all day. My parents had a teahouse and they worked all night with people coming from all over. They came for the Dashain festival shopping and mainly for the 
Khadgadevi festival. The businesses would be open all night and it used to be crowded. There used to be many programmes as well, Gurungs would be dancing to 'chutka', playing cards, praying [puja] and people moving about all night. (Harikala, resident-tourism, guesthouse manager)

The above statements illustrate the diverse culture of Bandipur and the importance of culture in the everyday lives of the residents. The festivals, commerce and other activities become part of the landscape, without which the significance is diminished. These statements also demonstrate the importance of the historical context that defines the identity of the residents. For the residents of Bandipur, the past history as a key trading post with its cultural diversity is ingrained in the landscape and their identities. This is reflected in the physical settlement pattern of the bazaar as well as the cultural landscape.

In addition to history and culture, the convenient location with road links to nearby towns as well as the regional hospital and schools were important components of the village landscape. For the residents, the convenience of these everyday necessities added value and quality of life. The following statements illustrate this:

In a place like this you have a district hospital. If you wanted to send your children to school, we have the Notre Dame School, which is a missionary school, and until recently had students from all over Nepal. For ordinary people like us, we do not have to send our children away for high school studies. Parents have to think of their children's future and we have good quality education for a reasonable price. That is one of the attractions of Bandipur for people from the surrounding areas. (Binod, resident-non tourism, teacher)

There is a good school here and the children have a place to get good education. They leave their villages and come here to live and educate their children. The education here is good. Simple people can live well. There is no fear of thieves and stealing. (Jivan, resident-tourism, mason)

The above statements indicate the importance of everyday lives in the concept of landscapes for the residents. As the landscapes are home for the residents the infrastructure such as transportation, education and health facilities indicate the quality of life and the available economic opportunities. These conveniences are components of their home or the landscape. The totality of the landscape with its natural, cultural and everyday aspects contribute towards their sense of place and identity that is integrated into their perception of landscape aesthetics. 
The main characteristic and attraction of Bandipur for the international tourists was undoubtedly the main bazaar, its architecture and settlement pattern. The foremost description of the international tourists was, "a classical Newar town” (Maggie, tourist, USA) or, "a small village in the mountain" (Angela, tourist, Spain) adding in her language, "pueblo con encanto" meaning a charming small village. The following remarks further illustrate the charm of the bazaar for the international tourists:

What I think is interesting is the way it is laid out in the hillside on the crest of the hills. It is really cool to be able to walk above it and see the layout from above, how it winds and see all the different trails along the mountains. It is just like a nice little oasis between peaks. It is really nice. (Becky, tourist, USA)

Especially I enjoy the views. There is the temple at the top of the mountain from where you can see the small village. You can see this main street. And you can see this small and compact village. (Angela, tourist, Spain)

These statements indicate that the settlement with its row houses has become part of the overall natural landscape. The hilltop location provides an excellent vantage point to view not only the extended Himalayan range, the multiple layers of hills and cultivated farms and valleys, but also the bazaar. The village profile along the crest of the hill and the settlement pattern that flows with the topography was a surprising delight for the visitors. The purpose for the tourists was mostly relaxation before or after a trek spending two or more days, giving them sufficient time to explore the village and the surroundings. Their days were spent exploring the town and they described the town as a perfect destination for those who liked to walk, especially after their experience in the chaotic Kathmandu city with limited footpaths and constant honking of cars and motorbikes. The following response illustrates the richness of the everyday vernacular architecture for the tourists:

I would say, if you like walking through old quarters, alleys and like seeing old traditional houses, this is the place to be. This is a nice place for easy walking, without suffering through the noises and the traffic. Not like in Kathmandu, when you walk through the alleys, there is a lot of noise and cars honking. Here it is quiet walking through the old quarter, through the old bazaar. This is a perfect place to do that. The first impression walking in, you would think that this main bazaar is the end. But then, when you are walking through these side alleys then they will continue. And there are actually more houses and alleys. So, 
for me, I really enjoy that. There is so much more to see! (Hanna, tourist, Taiwan)

The extended length of time spent in Bandipur also allows the tourists to be familiar with the landscape. The above tourist related her interaction with another international tourist visiting for a day and inquiring about the "tourist attractions" in Bandipur,

Just earlier today, I met another traveller in a café. She had just arrived last night, and she asked me what is there to see here. And I said, a lot. I said, you could see these old houses. No, not the old houses, she was saying, any other attractions. Well, I said, everywhere is an attraction. You know if you look behind the old houses, there is the mountain. And if you walk beyond the bazaar you will see more old houses. And she said, I want to see if there is any 'tourist attraction.' I said anywhere could be a tourist attraction depending on how you see it. So, but that is quite normal, you know, for a lot of people who are here for a short time. She just said she is here just for today and tomorrow morning she is leaving. So she wants to know what she can do today, within today. But I told her, everywhere you can see it, the old houses are an attraction. (Hanna, tourist, Taiwan)

For the international tourists, the bazaar with its winding streets and beautifully lined row houses presented "a great place to relax" and "sounded like a great walking city, something we both love to do" (Ray, tourist, USA). The above response also shows that the international tourists are a complex group with different motivation, which impact the expectations as well. For the participants of this research, the view of the snowcapped mountains became secondary to the experience in town, as expressed by "even without the mountains, I think the landscape of this town is beautiful" (Angela, tourist, Spain). However, the opinions of the domestic tourists were divided with the mature travellers more appreciative, while the younger visitors were not particularly interested in exploring the settlement.

I find nothing distinct here because the main thing is the bazaar. There are many places like this in Nepal. That is why I do not find this place any different. The way they have lighted the hills, I found that attractive. (Mahesh, tourist, Nepal)

For this set of domestic tourists, the attractiveness of a place is associated with activities and new products (lights on the hill) and walking around town "would not be interesting" and "we were bored because there was nothing to do" (Mahesh, tourist, Nepal). This contrasted with the international participant's comment, "It's a small town but it is very 
hard to be bored in a little town like this" (Maggie, tourist, USA). Another participant also remarked,

There are enough restaurants to keep you entertained. There is enough to keep you going. Beautiful walks to take, short ones and long one. It is just a nice quiet place. There are no cars! Beautiful views. (Becky, tourist, USA)

Domestic tourism in Nepal is still new and evolving with social media assisting its growth. When asked to describe the landscape that they see around Bandipur, the young domestic travellers find the landscape beautiful, but their interest is often fleeting. However, the repeat and mature domestic tourists agree that the traditional architecture of the bazaar adds value to Bandipur. The following response by a repeat domestic tourist resonates with the views of the international tourists:

This is a good place to enjoy your holidays with your children. Because Bandipur is an old town. I have visited many places/districts in Nepal but the uniqueness of this place is the way the village is situated on the top of the hills with row of houses on the two sides and the wide road in the middle. I like that very much. It looks very beautiful. If you go to the bazaar that is what you will see. If you go to the temple you can see it clearly, you see the road with houses on two sides. This is different than other places. Most places have houses on one side. But the way the houses are placed here is different. There are high hills here and most other places such as Chapagaun ${ }^{14}$ are flat, whereas Bandipur sits on a hill. (Bhavana, tourist, Nepal)

As the tourists a spent generous amount of time in Bandipur, exploring the town and the surrounding villages, they were able to experience the town beyond the visual and physical and interact with the local community. Although the language barrier limited their interactions, the tourists enjoyed the relaxed atmosphere and interactions in the shops and cafes. For example, when a participant entered a shop, the shopkeeper was across the street chatting with neighbours and took his time serving him with some "chitchat" that he enjoyed (Tim, tourist, Switzerland). The tourists mostly commented on the lively atmosphere of the town, especially with the children playing in the bazaar and locals getting together. For them, the local activities accentuated the village like charm,

\footnotetext{
${ }^{14}$ A village in the southern part of Kathmandu valley, in Lalitpur district
} 
And I don't know if there are less tourists now, but I like the local people in the streets. I don't know if it is because it is summer or there is life in the winter too. The local people in the streets, the children when they finish school and run in the street. (Angela, tourist, USA)

The above statement demonstrates that everyday activities of the community such as children going to school enlivens the place for the tourists. These activities are also reflections of the quality of life. Similar to Ghandruk, clean was another reflection of the community that the tourists noted, often in context of the overall condition of the country as well as South Asia.

One of the things I really love, after visiting some parts of India and some parts of Nepal too, is here, it is clean. I can see some advices writings, paintings in the walls saying, please take care of your rubbish. I can see where rubbish is put, and I think that is important. That is something that is good here. But for me, I came from India, this is clean and really important. (Angela, tourist, Spain)

What I like about this place is that it is clean. It is very clean, the bazaar. There is a good feeling of community, it is clean and very warm. People are hospitable, and the scenery is so beautiful. It is also well-kept. I hope these picnic people do not spoil it. (Bandana, tourist, Nepal)

The cleanliness was also a reflection of the participation and care by the community. This provided a sense of safely that is important for the tourists. For example, a repeat tourist remarked:

This is the only place that I have travelled that I can feel safe moving through even in the night. The last trip here, I went to Ramkot [a village about 2 hours hike] by myself for hours on the trail and I saw very few people, felt perfectly safe. I have seen other female travellers coming here alone and of various advanced ages feeling safe. That is a tremendous compliment. Because I don't think I would have the same experience even in India. So, that is a real feather on the cap of the nation in general and this town specifically. So, I have to say that as a woman this is as close as to feeling like what it is to be a man and being able to travel freely without what men take for granted. (Maggie, tourist, USA)

With ample time to explore the town, the tourists noticed the sounds and colours around the town that the residents may have been habituated to and failed to mention. While no specific smell was associated with town, the loudness of the crickets and two colours (red and green) were frequently mentioned. Green was mainly used to describe the 
surrounding landscape, while red defined the village. The following response illustrates that the built landscape plays an important role in the tourists' perceptions of landscape aesthetics:

Bandipur, I would say the most obvious colour for me would be, it is red, because when the sun shines on the architecture, from far away it looks like the houses are bright red. That is a very nice feeling, a very comfortable feeling. Those bright red houses. Because when there is sunshine shining on this architecture, even though these are not actually red, they are more like brown. But from faraway it looks like red or orange colour. I like that type of colour and that type of feeling. When I went for a walk today in the other direction, I could see the bazaar, so when there was sun shining the whole bazaar was red. Shiny and red. So, at least for me, it is important that when you build a house, you are not just comfortable living inside the house, it is also comfortable looking at it. (Hanna, tourist, Taiwan)

In summary, the bazaar as the centre of the town holds multiple meanings for the residents and tourists. While history, culture and economic activities are important to the residents, the visual aesthetics are prominent for the tourists. In addition to the natural, built and cultural components, the convenience and necessities of everyday life are integrated into the landscape of the residents. Everyday lives and quality of life are important components of the landscapes for both groups and contribute to their perceptions of landscape aesthetics. While the residents are nostalgic for past glory, the tourists, with exploring and experiencing village life as their main motivation, notice details that are regular parts of the everyday landscape for the residents.

\subsubsection{Mountain vistas}

The location of Bandipur forms a natural viewpoint providing a panorama of the Himalayan range as well as multiple layers of hills and valleys. For the residents, the view of the mountains was unique to Bandipur compared to other parts of the country. They were quick to point out this uniqueness:

You can also see the mountains from other places, but the range you see from here is different. You can see from the top of the mountain peaks to the rivers in the valley below. That is different. (Pankaj, resident-tourism, guesthouse owner) 
Even if you can see mountains from many places in Nepal, from here you can see a long range of the Himalayas. That is one of the attractions. If you go to Tundikhel and see the long range of the Himalayas, it mesmerises all the visitors. Especially, those people who come in the evenings from Dumre. They get fascinated as they come up the winding road. They start stopping the vehicle and take out their cameras and take pictures on the way and when they get up to the Tundikhel, they are awe-struck. You can also see the valley and the peaks from one spot. Another thing is if you walk about three hours to a village near here you can see the Terai and see the mountains from the same place. (Binod, resident-non tourism, teacher)

The above remarks indicate the importance of the vista not only as a tourist attraction but also for local identity, to stand out from the rest of the country. In addition to the views, the location also provides a mild climate making it a pleasant place to live. The fresh air and cool climate were often mentioned. For example:

The air is fresh and cool all year round, we use only a thin blanket. That is also special about this place because if we go to Dumre [8 kilometres down] it is hot and unbearable. But here, it is always cool. (Harikala, resident-tourism, guesthouse manager)

Even though this town is small in size it is beautiful. The environment is quiet. There are not many disturbances. The air and the environment here is fresh and clean. I tell my friends and others who have never been here to come and enjoy this beautiful village. Especially to the people of Kathmandu, which is much polluted, air pollution, noise pollution. (Sunita, resident-non tourism, banker)

This indicates that the general quality of the environment is an important aspect of the landscape that influences the preference and landscape aesthetics. For the residents of Bandipur, it has an added market value to attract tourists.

The common statement of the tourist regarding their general description of Bandipur was the views of the surrounding landscape and the situation of the hilltop town, that facilitated the views of the surroundings. For most international tourists, the views of the snow-capped mountains were "a good surprise" as most were travelling without any expectations recommended by fellow travellers or friends. A tourist who had only heard that it was a Newar town remarked,

I did not even know that you could get such a good view of the snowcapped mountains here. I know you could get mountain views but not like that. So that was a good surprise for me. (Hanna, tourist, Taiwan) 
The hilltop location provides an excellent vantage point to view not only the extended Himalayan range but also the multiple layers of hills and cultivated farms in the south and the valleys, illustrated by the following remark:

I was on the top of the hill today looking out and you can see a little bit of the mountain peeking through. It was amazing because I was already up there for so long on the tops all along and the valley is so far down below. So far away revealing itself and eventually it was like the mountains show up and they are still so far away and so huge. And when you are facing it, you just see so many different things, a very spectacular view for sure. I just kept looking at it and it is like there is so much to look at. You see these mountains and then those mountains and there are still more mountains. Then eventually this peak out there but there is this valley with the winding rivers and in-between villages. (Becky, tourist, USA)

As described earlier, the orientation of the houses on either side of the ridge provided excellent views from the windows, which became part of the experience of the tourists. When asked what they liked best about the town, they were quick to respond,

The best is the view from the room. (Angela, tourist, Spain)

Just from my homestay, I can get a very nice view from the window or the balcony. (Hanna, tourist, Taiwan)

While the above remarks indicate the sublimity of the Himalayan vista, they are also part of regular everyday life that can be viewed for the comforts of one's bedroom or guesthouse. This integrates the vista into the landscape of Bandipur. This observation was shared by those visiting during the monsoon season (June-August) as well as in autumn (October-November). Although, the rainy monsoon season is seen as off season for the tourism industry in Nepal, the participants interviewed were not deterred but appreciated the fleeting glimpses of the mountains and play of weather strengthening the residents' statement that Bandipur is a perennial destination.

We have had a lot of clouds but when we do have the breaks in the clouds, sitting on the rooftop, the scenery is just perfect. We had pretty rainy weather but honestly, I like it when the clouds come through and go away. You kind of forget what is out there but when they go away, you get that same exciting feeling like when you saw it first time again. It is so cool. (Ray, tourist, USA) 
Never-endingly beautiful to apprehend. And because of its situation, the seasons roll very gently and aesthetically over the town. Even in monsoon. This is the first time I have been here in monsoon. Even if it has been a very brief period of time, I had a very good sampling. Right now, I am looking at the mist coming down. We've experienced everything from the torrential rain, with a bit of lightening, a very dramatic cloudscape, clouds laying low on the streets, bursts of sun and we are happy and fortunate enough to auspiciously have the clouds lift and the view the Himalayas last night and so I could say I have seen again. Very happy. A blessing. (Maggie, tourist, USA)

Despite their familiarity, the panoramic view of the mountain range was also an important part of the landscape for the domestic tourists. The location provided unique perspectives to the familiar views:

Bandipur sits on a ridge. In the mornings, the valley is covered with clouds. That view is also very attractive. When I put that photograph on Facebook, everyone was interested in that photographs and the view, everyone asking where that was. The morning view is very beautiful and that is something to do in the mornings. We saw the sunset from the hilltop. The sunset view was also beautiful. It was red and colourful. I also shared that in social media. We can promote a lot through the social media. When I was here the last time, I took some pictures for the Siddha cave with the view of the valley and the mountains with the caption 'little more than what we say about heaven.' I also placed photographs with caption, 'breath-taking view of the Himalayas resting above the sea of clouds.' A lot of people were amazed that such places existed. That is also our small contribution to promote Bandipur. (Paras, tourist, Nepal)

The other thing I like is because this is high up, you are above the clouds. Sometimes the valley will be covered with clouds and looks like a sea of clouds. My children used to describe it as 'sea of clouds' and it made the children very happy to see it. Then you see the top of the mountains above those clouds. There will be clouds and mountains rising from the sea of clouds. When the sun shines on this, it is even more beautiful. The view is only seen from Bandipur. (Bhavana, tourist, Nepal)

The above remarks indicate that landscapes lend to national identity. For the domestic tourists, travelling is also a form of promoting the country and encouraging others to travel.

In summary, although the Himalayan range can be viewed from most parts of Nepal, the location of Bandipur provides a unique view. This provides favourable climatic 
conditions with fresh, clean air and was appreciated by both tourists and residents alike, making it a perennial place to live and visit. It also blends into the everyday landscape as it is situated on one of the hills that form the overall landscape. For the residents, the history of the built landscape, the everyday convenience and the mild climatic conditions provided by the natural landscape are significant to their perceptions of landscape aesthetics. The visual aesthetics of the built and natural landscape along with the opportunities to observe the everyday activities of the local community integrate into the landscape and contribute to the tourists' perceptions of landscape aesthetics.

\subsection{CHANGING LANDSCAPES: RESTORATION AND TOURISM}

This section presents the findings to address the supplemental research question on the perspectives of the participants on the changing landscapes. The recent growth in tourism is revitalising the local economy, resulting in declaring the Bazaar, the main attraction, a preserved zone limiting growth and change. However, this policy is accelerating building activities in other parts of the town and that is changing the overall landscape. This section first presents the perspectives of the participants on the impact of the preservation policies and tourism followed by the changes in the Bazaar before conclusions are drawn.

\subsubsection{Conservation policies, tourism and the society}

In the last decade, tourism has been the key driver to revitalise the local economy with increase in employment opportunities and population growth. This growth highlighted the significance of the main Bazaar and raised concerns for its future, resulting in a set of special bylaws for the preservation of its architectural heritage. This policy has preserved the traditional buildings, but its limited boundary with the Bazaar and surrounding 500 metres has pushed rapid growth in the periphery. The following remark illustrates the impact of the conservation policies in the protected zone:

In the bazaar, people have understood the importance of preserving the traditional buildings. You see people taking care of their buildings now. It is in the surroundings that change is rapid. Most houses are built with concrete pillars and metal shutters. They are also different colours, red, blue, green and yellow houses. (Binay, resident-tourism, guesthouse owner) 
To attract more tourists, the unique bazaar with its authentic houses, that should be the main focus. International and domestic tourists visit Bandipur for the authentic bazaar. All the traditional building that exist should be preserved and if we can build the new structures in a similar model, this town can be exemplary. Old settlement but a model with its unique identity. (Bipin, resident-tourism, hotel owner)

The above responses indicate that the conservation policies have been successful in raising awareness of the significance of the vernacular architecture. However, outside of the preserved zone, new buildings are built in different styles suggesting a lack of appreciation of vernacular styles and preference for global trends (Plate 5-6). The remarks also suggest that the awareness of the built heritage is built on its tourism potential as the restored buildings are also attractive investments. The number of buildings restored for guest accommodations and restaurants is increasing. It is attracting external investors, especially returning migrants from Kathmandu and Narayanghat, such as Sushil, one of the residents interviewed. This has raised concerns "so that this does not become another Sauraha ${ }^{15 "}$ (Binay, resident-tourism, guesthouse owner).

The concentration of the business interests and policies in the Bazaar has neglected development control in the periphery (Plate 5-6). This has resulted in rapid building activities in these areas where land price is cheaper compared with the bazaar. This growth is noticeable with one resident expressing the following concern:

\section{The vehicles are banned in the bazaar and it is well maintained. However, the best thing is, if they can continue in the surroundings as well. Even if people build cemented concrete houses in the surrounding, my personal hope is that they will not destroy the bazaar. I hope that they will not demolish the old houses and build in new styles. Preserve what is already there, that reflects the time at the town was established. (Sushil, resident-tourism, hotel owner)}

While the residents involved in the tourism industry stressed the need to preserve the traditional settlement, this concern was not shared by the non-tourism residents. They pointed out societal changes and other concerns such as cheaper materials and labour took priority.

\footnotetext{
${ }^{15}$ Sauraha case study findings is presented in chapter six.
} 


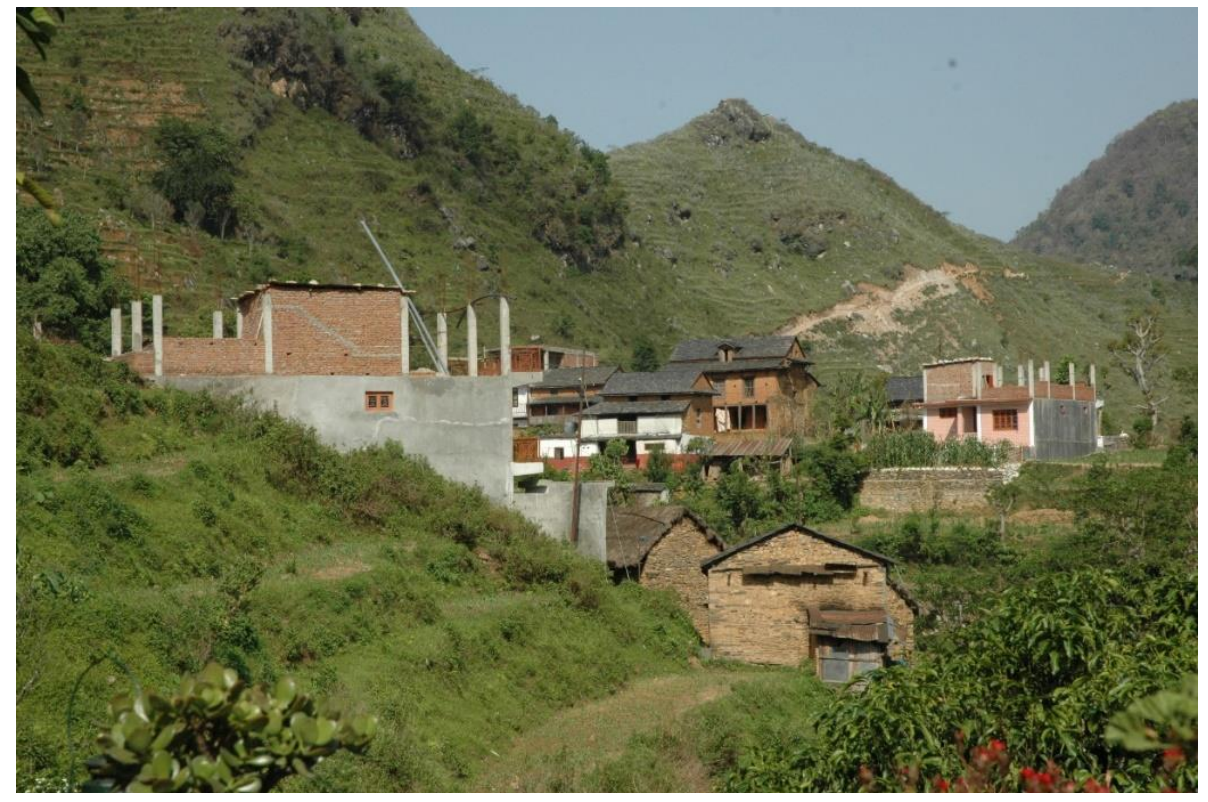

Plate 5-6: Increasing building activities in non-conforming style in the periphery

Photo: JJoshi, 2013

The houses are different now. Those days' wood and timber were cheap. Now wood is expensive, so people bring in cement, rods and build. There were plenty of wood back then, so you could make everything like the joists, rafters. Now it is difficult to get wood and the rods are cheaper. The new houses are built according to the present time and is good for that. The houses today are good but if you have to demolish them, it is not reusable. The old houses are reusable; you can use everything again. (Jivan, resident-non tourism, mason)

The above statement indicates that for non-tourism residents, the cost and durability of new buildings is more important than maintaining the traditional landscape. Although the resident understands the benefits of traditional materials and technology, when the motive for new building is not for tourism, the preference is for new materials. This indicates that the significance of built heritage relies on tourism and not because of increased awareness of architectural heritage. This also implies that the built settlement will be preserved as long as it is economically viable for the tourism industry. It also indicates that the tourism industry may direct the future of Bandipur in its preservation or development. Conversely, if tourism declines, there is the risk of loss of the traditional landscape. 
Given that the economic revival and tourism development in Bandipur is relatively recent, most residents viewed tourism positively. A participant who had returned to invest in Bandipur remarked,

When I see the changes, I am very happy. When I first started returning, Bandipur was a dead city, it was quiet, neglected. Even up to ten years after I started returning there were no activities, no life here. But later when the number of hotels started increasing, people became interested in tourism, the people who had left are returning and investing in tourism, starting hotels. Others have also started hotel businesses. They are also doing well. The changes here started from zero, from nothing, and now every year more buildings are coming up, more buildings are being built. The reason is tourism, the people who left and went to Chitwan are returning, searching for their ancestral properties, renovating them. (Sushil, resident-tourism, hotel owner)

The series of historical events explained in section 5.1.1 decreased the importance of Bandipur that resulted in out-migration and loss of its commerce. In this context, the recent growth in tourism activities with increased building and economic activities is perceived positively. The return of the Bandipur residents who had left to seek better futures elsewhere is taken as an indicator of the recent economic success. Another nontourism sector participant who also remembered the historical migration expressed similar views:

And slowly, this is becoming a place where there are economic opportunities. We still talk about 1969, when the district headquarters moved from Bandipur and many people were displaced. Many people left for work and business to nearby towns. They are also starting to return. Because commerce and money are important in life and earning is important. Most people had not even imagined Bandipur would change so much. If people want to invest in tourism and open hotels or restaurants, there are many opportunities, and this is an appropriate time for that. (Binod, resident-non tourism, teacher)

The above remark illustrates the contribution of tourism to the local economy. It also indicates that the downfall is in recent memory and tourism is a fledgling industry awaiting increased investment. While the location has provided Bandipur with spectacular views of the surrounding landscape, it has also limited industrial opportunities. With limited flat land and a hilltop location, regular industrial development possibilities are limited. This has increased the local economy dependence on tourism. The following remark illustrates the concern of a teahouse owner: 
We are very happy with both foreign and Nepalese tourists. Our business will increase; we will get some income. If the foreign or the Nepalese visitors don't come to Bandipur, what will we do? We will have to move to a bigger city to find some work to survive. That will be a huge problem for us. (Binita, resident-tourism, teahouse owner)

The above response clearly indicates the influence of tourism in generating employment opportunities. However, the benefits of tourism are limited to the Bazaar and the residents in the periphery are not convinced of the tourism potential. A non-tourism resident who lived away from the Bazaar remarked:

No, there is no impact of that here outside of the Bazaar. There are 910 hotels in the bazaar, a few homestays. That is too in the bazaar and on the other side of the bazaar, there is nothing here. (Prabin, residentnon tourism, tailor)

The international tourists also noticed the conservation, remarking that they would be willing to pay higher prices to stay in restored buildings. There was some concern with the new building activities but was viewed as acceptable for the present time.

Even though it is undergoing quite a bit of increased building of late, it is at least as of this date, the level of building and development is very appealing. I almost feel like this is kind of the perfect level. Maybe a little bit more could be tolerated. (Maureen, tourist, USA).

They were ambivalent on the impact of tourism with some remarking that it has become "touristy" while others observed that it still retained village like character:

This village reminds me of a small village where I live in the mountain. That is a small village too. I don't know why it kind of remind me. Maybe it is the style of life, the people, and small village. (Angela, tourist, Spain)

However, the increasing number of guesthouses and restaurants with menus catering for international tourists was noted by most tourists. One international tourist who put Bandipur on his list of recommended places warned, "Places like this, I hate to see turned into Hoi An in Vietnam" (Ray, tourist, USA). Another domestic tourism expressed concern that that the facilities for tourists were displacing the traditional activities:

It is not like before. There used to be local people sitting in the sun. Some women oiling themselves and their babies. We used to play with the children, talk to the elders. (Bhavana, tourist, Nepal) 
Overall, most participants agreed that tourism development is still in its nascent stage in Bandipur and there was space for growth as well as the need to preserve its traditional character. Limited land and the geography restrict large infrastructure in Bandipur, but tourism can instigate multiple potential. Although the new preservation policies protect the bazaar, there were concerns for the surrounding areas affecting the overall landscape aesthetics of Bandipur. The preservation of the built heritage is heavily dependent on tourism that has not benefitted residents beyond the bazaar. In addition, there are no provisions for the conservation of the natural and intangible heritage. This is despite most residents stating the diverse culture of Bandipur as part of the landscape.

\subsubsection{The Bazaar: past and present}

The Bazaar, no doubt has been the centre of Bandipur throughout its history. However, it has also changed with the highs and lows in relatively recent history. The past photographs brought back memories for the residents, which they claimed to be good times, yet they were also proud of the present state of the bazaar. Most found no drastic changes in the bazaar, sometimes reconfirming the past and repeat photographs, and looking for details that were different. The following examples from residents who were born and grew up in Bandipur illustrate that externally, the Bazaar has remained mostly unchanged:

The houses are almost the same. No one has demolished the façade. Whatever has been changed is inside. The façade looks the same, maybe some have painted a different colour. (Sushil, resident-tourism, hotel owner)

The changes are not very evident. They don't stand out. There are these doko $^{16}$ so you know it is not recent. In those days, this was the way to Chitwan, so they used to carry goods in doko like this. Here they would rest. (Binod, resident-non tourism, teacher)

Although the physical changes were not distinct, lifestyles had changed as illustrated by the above example of the presence of doko to distinguish the difference. However, some

\footnotetext{
${ }^{16}$ Traditional bamboo basket used to carry good on backs of people
} 
residents preferred the present bazaar to the past that mostly reflected the present economic revival as demonstrated by the following response:

The colours have changed. It is more colourful now. It was not coloured before. I prefer the one with colours. Now. Before it was abandoned, and the wood was rotting. But now people are repairing, and colouring/painting and it looks beautiful. Look at the old buildings, it was not repaired and looks ugly. Now it is used and plastered, painted and looks good. I like it very much. (Binita, residenttourism, teahouse owner)

The above response reflects the findings that tourism has revived businesses in the Bazaar with renewed interests in restoring traditional buildings (Plate 5-7). This has provided a positive atmosphere that is reflected in the attitudes of residents' who had lived through the downfall of the Bazaar.

One of the recent changes in the Bazaar is the stone paving, one of the unique features that defines Bandipur. The original paving was destroyed when vehicles started arriving in the 1970s. Since the Bandipur Eco-Tourism Project restored the paving in 2007, the community has restricted all vehicles and is responsible for its maintenance. The restriction of vehicles, a first in Nepal, has supported businesses such as restaurants in addition to providing safe space for children to play and for residents and tourists to wander around:

When I come here to the bazaar in the evenings, I am very happy. I enjoy it after a long day's work. During the day, I work and have other things to do. I come here in the evenings and walk around meeting friends. This is a place where vehicles are banned, and it is very enjoyable. Just now, two tourists were at a café using the internet and commenting how quiet this place was. Quiet and peaceful. (Binod, resident-non tourism, teacher) 
The above response demonstrates the importance of open spaces for tourists and residents alike. The vehicle ban has also contributed to the tourism potential of Bandipur and increased economic activities.

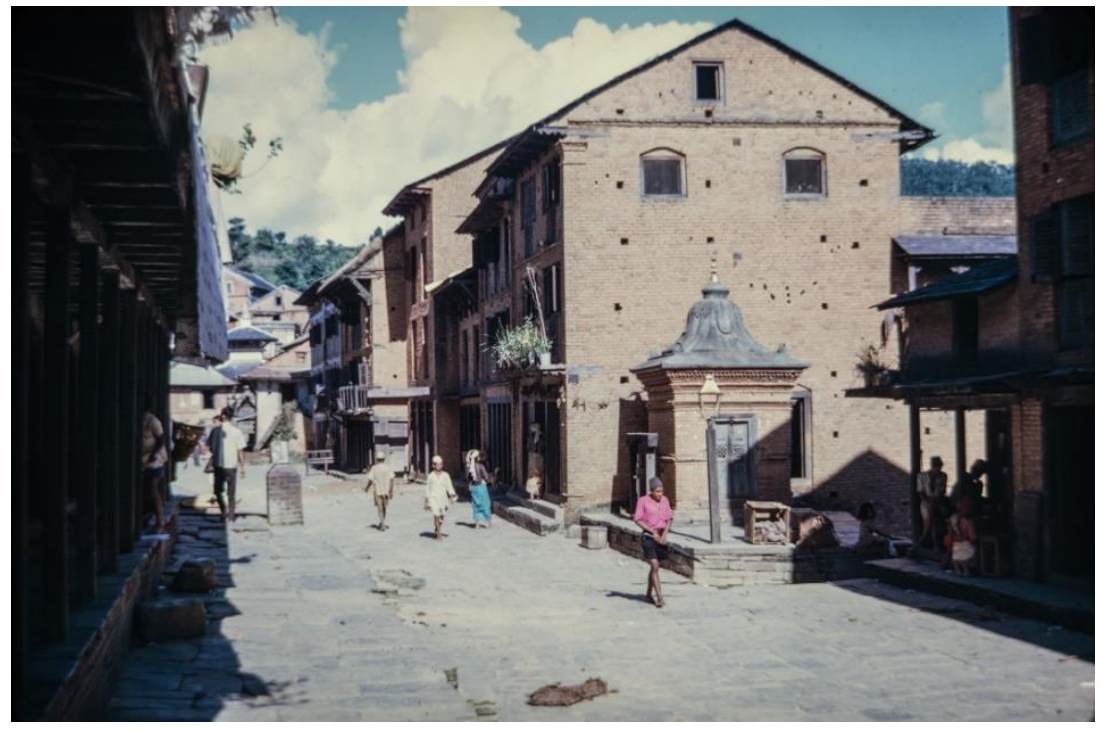

Photo:

Bill Hanson (PCNPP), 1965

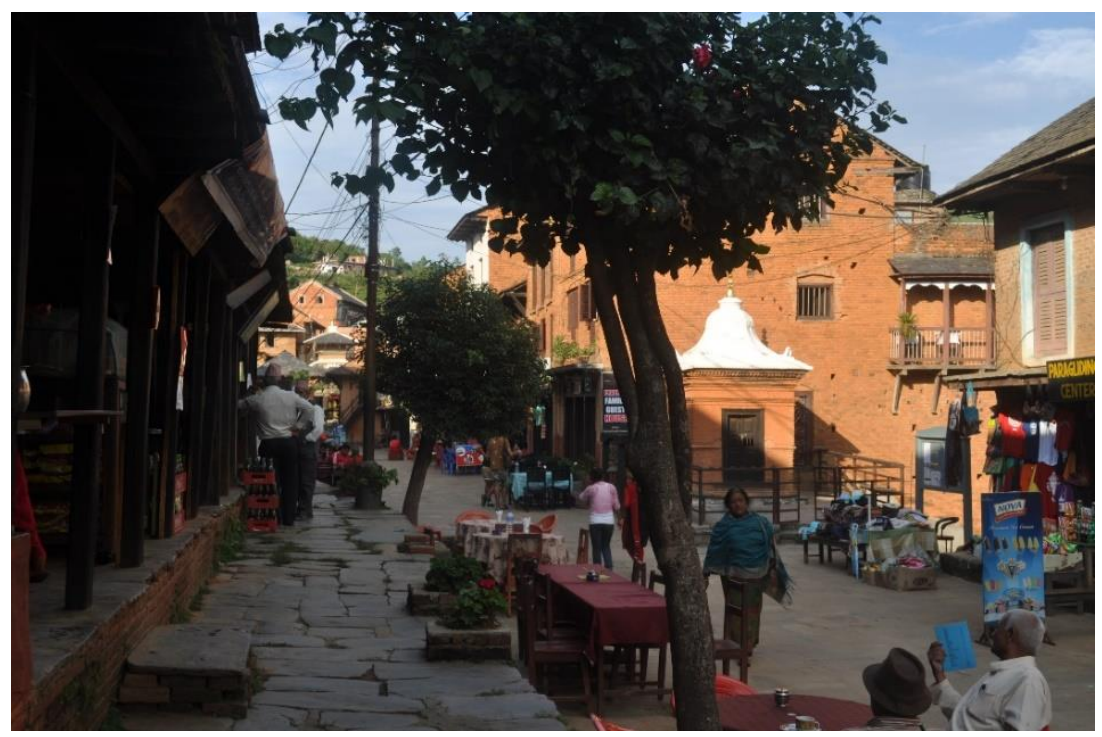

Photo:

JJoshi, 2016

Plate 5-7: Past and repeat photographs showing more cafes and painted houses

The past photographs of the Bazaar also evoked memories and the residents shared stories of their childhood in Bandipur. Most residents remembered the festivals but their memories of everyday activities such as fetching water was also strong. ${ }^{17}$

\footnotetext{
${ }^{17}$ Water has to be pumped up from the valley to Bandipur and there is acute shortage in the dry seasons. The growth in the number of guesthouses has increased the demand as well.
} 
There used to be public taps here. We used to fetch water and there used to be arguments in the mornings when everyone went to fetch water. We don't have to do that anymore and have piped water in our homes and kitchens now. Life is more comfortable now. It looks cleaner now, which it wasn't before. I also remember people drying grains and we used to run on them and the old women used to shout at us. They dried rice, millet, corn. (Harikala, resident-tourism, guesthouse manager).

The above statement indicates that although the experience of fetching water and associated social interactions were nostalgic, from the residents' perspectives changes that improve everyday life are important. The residents in general accepted the changes positively, however some were concerned more changes would be detrimental to the future of Bandipur, especially if the changes occurred in the Bazaar.

A common remark across all participants was that the present landscape is much greener than in the past (Plate 5-8). The principal reason for the increase in greenery was the community forestry programme that was started in Nepal in 1980s and the subsequent reduction in the use of firewood for fuel.

The hills are greener now. When the community forestry programme started, it started getting greener. Otherwise they just cut down everything. We used to get a brunch of firewood for 5 rupees. The income source of the people of Lungeli was to sell firewood. We did not have gas like now. Everyone used firewood to cook food. That was one reason the forests were destroyed. When the forests were handed over to the community, then preservation started, and the progress is very good now. (Binod, resident-non tourism, teacher)

While the residents were pleased that the forests were preserved they also pointed out that reforestation had replaced cultivated terraces, which were less productive. For example, the above quote demonstrates the residents' approval of the community forests but in the following statement indicates preference for the landscape that evokes memories:

This is quite different. In this, you see the green [repeat photograph] and this one you see the terraces clearly [past photograph] (Plate 58). The old one is good, you can see the terraces and the houses. You can tell it is a rural location. This must be winter, harvesting season that is why it is not green. You see the hay too, which is gathered like this in December after being beaten and would be soft. The rice 
harvested in July will not have this. (Binod, resident-non tourism, teacher)

This remark demonstrates the deeper understanding of the processes in the landscape.

This indicates that for the residents, the landscape holds multiple meanings such as work.

The following remark further illustrates this:

People do not like farming anymore. It is difficult. And they can find some other work and earn a little. You can buy most things now so why work hard? You have to pay for the labour, work hard, the produce is not enough for the year. So, it is easier to buy stuff. So, people are abandoning farming and buying food. (Harikala, resident-tourism, guesthouse manager)

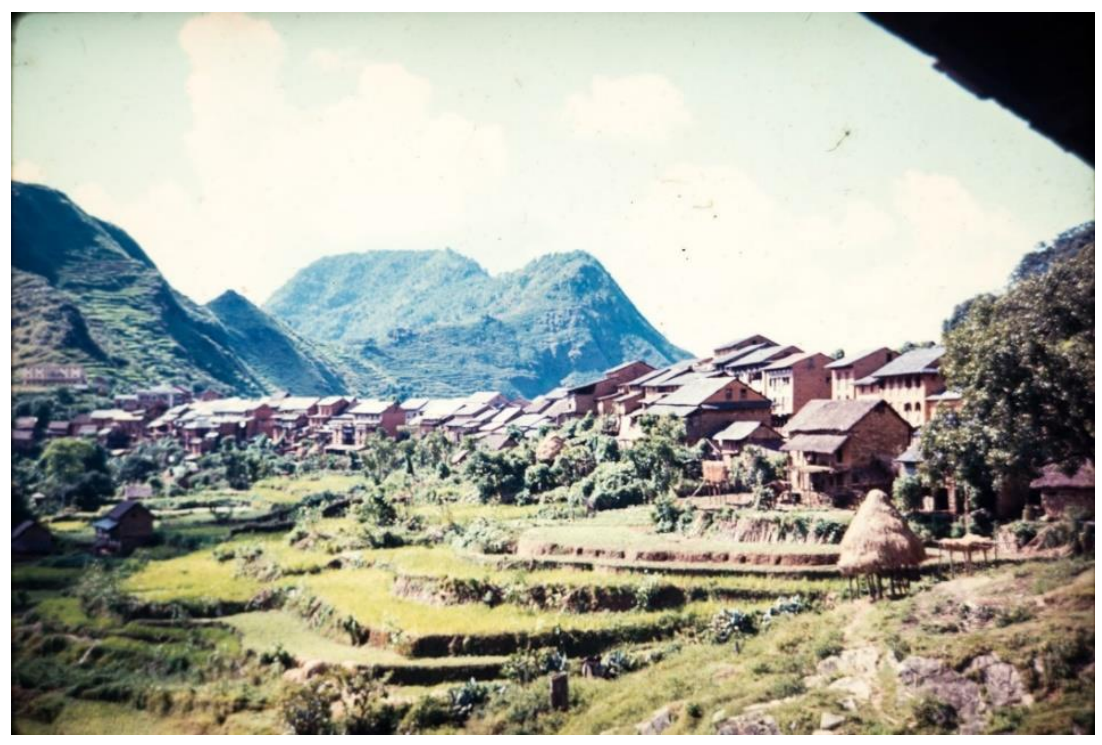

Photo:

Bill Hanson (PCNPP), 1965

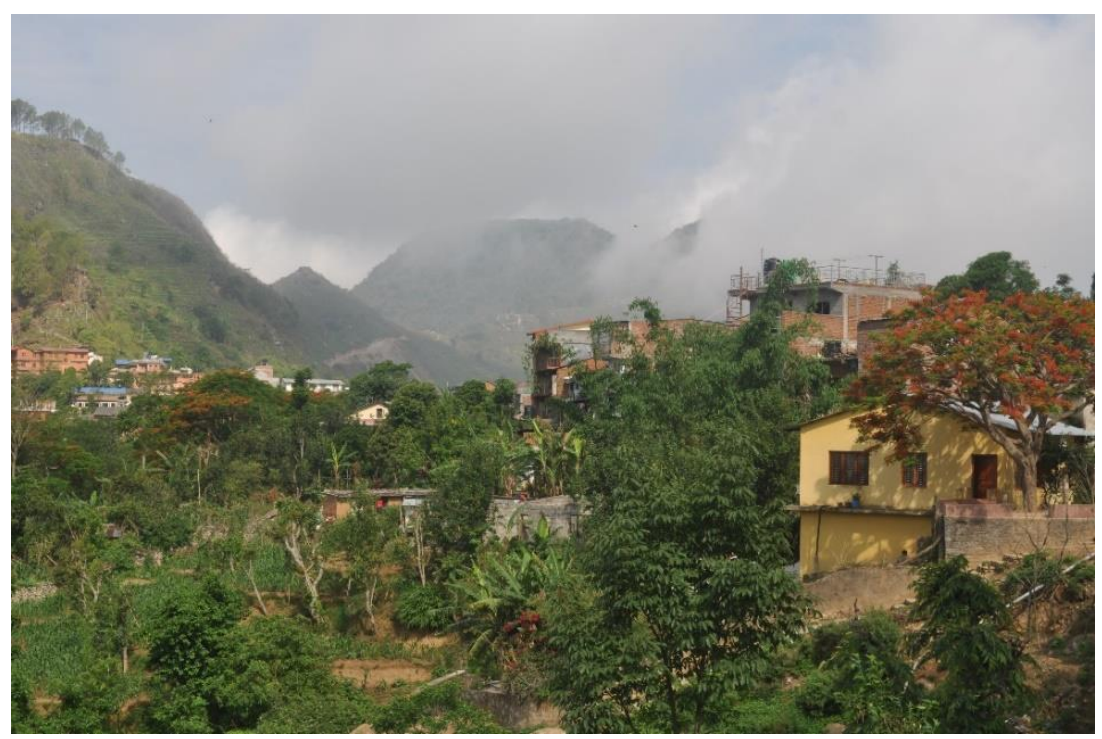

Photo:

JJoshi, 2016

Plate 5-8: Past and repeat photographs showing cultivated terraces and increased greenery 
The above statement also indicates the changing society and their needs. Urbanisation and globalisation are making life convenient at the same time are changing practices and traditions. The changes are reflected in their decision to restore or build new structures.

Unfamiliar with the history, the tourists were mostly satisfied with the present state of Bandipur. They assumed what they were seeing was unchanged and reflected their concept of a village life. When asked what they would like to see in Bandipur if they returned in twenty years, most responded "not too much change" (Maggie, tourist, USA). However, the repeat domestic visitor lamented on the change from the traditional local community centred village activities to the town catering for the tourists:

\section{I was a little disappointed with the bazaar. It was quiet and there were not many people around. It is all hotels now, you look at the houses and the decorations. That is nice but there is no life there. There is no local life anymore. It used to be lively before. They would be people sitting out in the sun, others doing some household chores. (Bhavana, tourist, Nepal)}

On the other hand, the tourists clearly preferred the recent green landscape. Their preference was augmented by their own personal experience of the present landscape.

\section{I prefer the recent photograph with the vegetation. I think it is important with the green. I think it is nice the buildings are renovated because it is maintained. It has the same structure but just with colours, vegetation too. Wow. This has changed a lot. I thought it was like this all the time, but it is not true. Because I thought one of the things that I like here is the green. I saw this tree and I thought it was there all the time. So, it was agricultural land changed to green. I really love this green and the temple. I think it is new, but I really like it. (Angela, tourist, Spain)}

This response confirms that for the tourists, the present landscape is most important, but the historical narrative adds to their understanding. One of the changes most participants immediately noticed were the electrical poles and power lines. Although the power lines were obstructing the views of the Bazaar, most accepted them as part of modern life and a necessity, with one international participant stating that they become "part of the landscape too" (Angela, tourist, Spain). This demonstrates modern facilities are accepted as basic requirements by both residents and tourists as part of everyday lives. 
Overall, the residents' response to the changing landscape was a mixture of positive and negative; optimistic about the changes brought by the recent economic revival at the same time nostalgic for the past landscape and life. There were also mixed responses from the tourists, most preferring the present landscape, however at times failing to find differences. For the residents, the downfall of Bandipur is still in recent memory and they are taking the new developments with caution. Unfamiliar with the history, the tourists assume the present state of Bandipur is what it was in the past. Without knowing how much it has changed, they prefer Bandipur to remain unchanged in the future.

\subsection{CONCLUSION}

The bazaar is the most important component of the landscape with regard to the current tourism and economy in Bandipur. The location on a ridge provides a vantage point for a spectacular view of the Himalayan range as well as other hills and valleys. These two elements combined with the cultural diversity are identified by the residents as key landscape components. However, they added that other conveniences and requirements such as education, transportation and health were equally important in their everyday landscapes. Historical context is equally important in defining their identity as well as the landscape, which in turn contributes to the perception of landscape aesthetics.

The economy of Bandipur has seen changes in a relatively short span of time, from a thriving trading post to a deserted town, revived recently with the rise in tourism. For the residents, Bandipur still has room to grow, thus continued change is inevitable. The location and limited land restrict large industries; thus, the current economy depends tourism. Tourism in Bandipur has the potential to instigate and support local development in the sectors that are necessary for a sustainable society such as education, health and transportation that the residents have identified as integral to their everyday landscape. While Bandipur may not be able to control the mountain vistas, they can manage the viewing of the vista. The limitation of the designated preserved zone with basic conservation policies that only consider one aspect of the overall landscape is accelerating development in the periphery and this brings concerns that this development may adversely impact the bazaar and the fledgling tourism industry. 
For the tourists, Bandipur bazaar is at its optimal in terms of retaining a "village like" character with spectacular mountain views, at the same time convenient with a good selection of cafes and restaurants. It is conveniently located for relaxation between strenuous hiking in the mountains and the busy cities. Unaware of the historical context and the changes that were central to the residents, for the tourists, the present landscape in Bandipur is a balanced mix of the natural, built and cultural components. In other words, it is the landscape in totality, natural vistas, built settlement, cultural diversity and indirectly, the modern conveniences that contributed to the landscape aesthetics. 


\section{SAURAHA: CONTESTED LANDSCAPE BETWEEN THE PARK AND THE CITY}

This chapter presents the findings on the perceptions of the participants on the landscape, landscape aesthetics and landscape change, including the state of tourism in the final case study, Sauraha. This chapter follows the format of the previous two chapters starting with a contextual background, followed by the findings drawn from the interviews. Eleven participants (ten residents and one international tourist) were interviewed in Sauraha (Table 3-7).

\subsection{CONTEXTUAL BACKGROUND}

Sauraha is located in Ratnanagar municipality in the district of Chitwan, Province No. 3 in the Inner Terai ${ }^{18}$ region in southern Nepal (Plate 6-1). The district name is derived from the Chitwan valley that lies between the Mahabharat and Siwalik and Churia ranges. Chitwan is used to denote both the district and the valley, with the residents referring to their hometown as Chitwan in general and specifically naming their town or village to differentiate themselves within Chitwan. The small village of Sauraha, formerly part of Bachhauli VDC, was incorporated into Ratnanagar Municipality in 2014.

Sauraha is located at the eastern entrance of Chitwan National Park (CNP), a UNESCO World Heritage Site (natural) since 1984. This was the first national park in Nepal. Located at the junction of two rivers, Rapti and Narayani, Sauraha is prone to regular flooding, naturally changing the landscape. Situated at 300 metres above sea level, the landscape of Sauraha is flat. It lies in the subtropical climate zone and is hot and humid most of the year with mild winters. Several clusters of houses along the river bank make up Sauraha, with the main centre at the entrance to the national park.

\footnotetext{
18 The Terai is a narrow belt of flat and fertile land in the southernmost part of the country and extends from the east to the west of Nepal. The Terai includes Inner Terai, Bhabar and Terai Plain.
} 
As shown Plate 6.1, Sauraha is mainly accessed from Tandi, a rapidly expanding highway town and a transportation hub. This is the main bus stop that links Sauraha not only to the district headquarters but to the rest of the country by the East-West highway. The bridge across Budhi Rapti (200x) is an important linkage for Sauraha that was until recently accessed only by a seasonal road and a pedestrian bridge. Tourists were transported across the river by jeeps or elephants, with the river usually flooding during the monsoon (July-August). The locals used either tanga (horse-driven cart), rickshaws or bicycles. Today, there are regular bus services from Sauraha to Tandi as well as Ratnanagar and beyond.

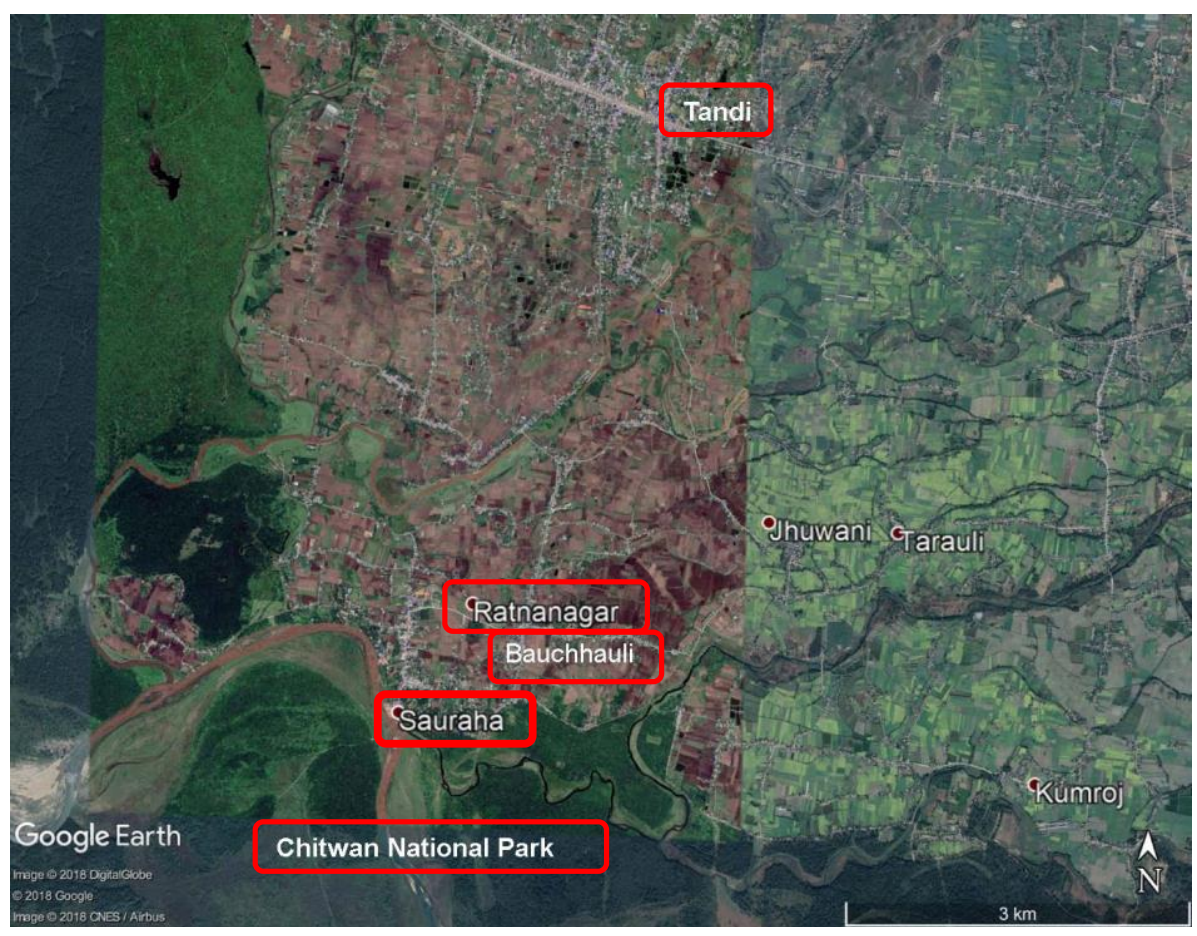

Plate 6-1: Past and repeat photographs showing cultivated terraces and increased greenery

Source: Google Earth, 2018

\subsubsection{History and the people}

Chitwan was sparsely populated with the Tharu people practising traditional shifting cultivation and moving locations every few years. The cultivated land bordered the dense forests and swamps which created a natural barrier to the south. The hot and humid climate was the perfect breeding ground for malaria mosquitoes limited population 
growth despite the abundant fertile land. Chitwan was assimilated into modern day Nepal in the $18^{\text {th }}$ century, however, it remained peripheral to central government. The strategic location of Chitwan along the Nepal-India border with its thick forests and swamps formed a natural barrier to the south and was closed off during the rule and expansion of the East India Company in India. The indigenous Tharu people, known to be immune to malaria, were the only inhabitants until the campaign to eradicate malaria in the Terai began in the 1950s.

A major turning point in the recent history of Chitwan was the control of malaria in the 1950s. This was followed by the government's major resettlement policy (Rapti Valley Development Programme, 1956-61) that started after the heavy flooding and landslides in 1953/54 in the hill districts. A motorway was built, and land was made available by clearing forests and grassland to settle migrants from the neighbouring hill districts ${ }^{19}$. Uncontrolled forest clearing continued after the planned resettlement programme came to a close and Chitwan continued to grow with a mixed population. Tharu villages in the forests were cleared and the people deprived of their traditional access to land and way of life. In addition, chemical fertilisers and mechanised machines replaced the traditional farming methods with the loss of traditional knowledge and shifting cultivation practices. Nevertheless, Chitwan continued its farming traditions, supplying produce to the rest of the country and is known as the "granary of Nepal".

Although the origins of the Tharus of Chitwan are unconfirmed with different legends, they describe themselves as the "forest people" living in the region for generations. This is validated by the ties to the land and the forests reflected in their festivals and rituals (Müller-Böker, 1999; Pyakuryal, 1982). The Tharu oral traditions and religious rituals refer to the Sen kings $\left(16^{\text {th }}\right.$ c.), revered as local tutelary deities confirming their long association with Chitwan (Müller-Böker, 1999). They identify themselves as Hindus but have distinctive rituals and festivals that are associated with the land and their life as farmers. For example, during the Jitiya festival women fast, worship and bathe in the river. During Pittri ausi, they remember their ancestors after bathing in the river. Another big festival Maghe Sankranti, is also celebrated with a ritual bath in the "holy river" and

\footnotetext{
${ }^{19}$ The merchants from Bandipur also took advantage of the eradication of malaria to settle in Narayanghat (section 5.1.1).
} 
special dishes are made of the indigenous variety of rice $(\text { anandi })^{20}$. The life cycle or the three stages of life, birth, marriage and death are important for the Tharus and are marked with specific rituals and celebrations ${ }^{21}$.

Tharus generally live in large families in a cluster of houses sharing meals, work and festivals. Some enclaves consist entirely of one Tharu family, which includes the grandfather and his brothers and their families in one settlement. This extended family structure is beneficial for farming practices that require manual labour. Both men and women work in the fields, with men doing the labour-intensive work such as ploughing, cutting wood, while the women transplant rice and take care of the animals.

Prior to the eradication of malaria, the other ethnic groups were seasonal visitors to Chitwan in the dry winter months, especially the merchants who crossed the region on their way to India and also sold their wares in the local markets. After the influx of hill communities such as Brahmins, Chhetris, Gurungs and Newars, today the Tharus are the minority in Chitwan.

\subsubsection{The settlement and the architecture}

The current centre of Sauraha is the main street that connects the national park to the highway. There are mainly two types of buildings in this main street, the 4-5 storey row houses that line the street and bungalow type one to two storeys that are set away from the road and usually shielded by trees (Plate 6-2). Both types of buildings mainly cater for tourists, with guest accommodations, restaurants, shops and tourism service businesses. The side lanes retain clusters of traditional Tharu houses, however, new development is expanding rapidly.

\footnotetext{
${ }^{20}$ According to my participants, this variety is almost extinct with a small batch grown especially for the festival.

${ }^{21}$ The central exhibit at the Tharu Cultural Museum in Bachhauli is wall paintings and sculptures depicting the Tharu life cycle.
} 
The clusters of Tharu houses usually belong to a single family with other houses around it. Some clusters have two rows of houses with paths, roads or irrigation channels cutting across, while others are formed around a courtyard. Usually, houses are added as the family size increases with sons getting married and starting their own families.

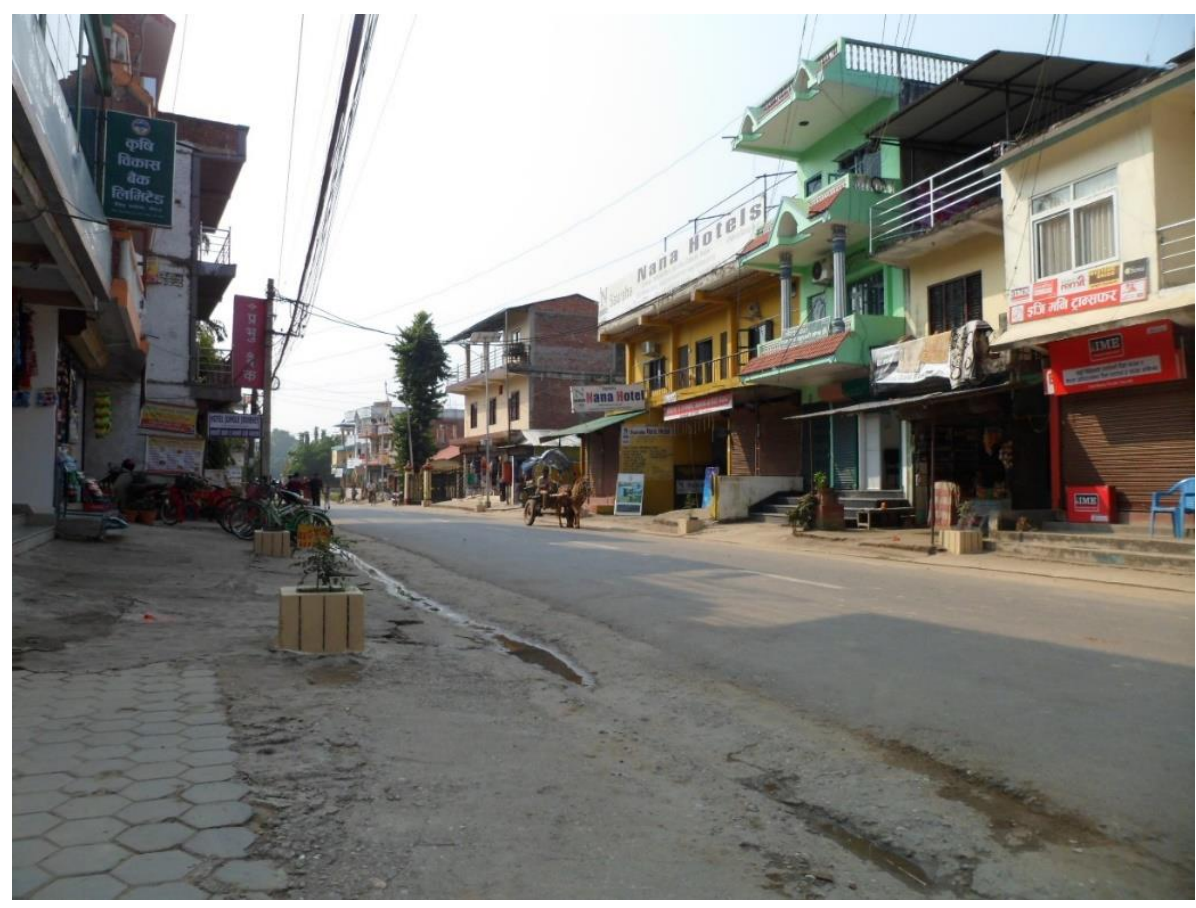

Plate 6-2: Main centre of Sauraha with non-descript buildings

Photo: JJoshi, 2016

The traditional Tharu house is a simple, single storeyed structure oriented north-south with doors on each side (Plate 6-3). They are built exclusively with natural materials, collected from the nearby forests (presently the CNP) or made locally. The openings are usually small, keeping the interior dark and cool. The walls are light and made of wattle and daub, consisting of a meshwork of canes, kharahi or jhaksi tied together with ropes of sabai or patuha known as batti and plastered with layers of a mixture of earth, water and cow dung. This mixture is also used for the floor and has to be applied daily for the floors and at least once a year for the walls, usually after the monsoon. The pitched roof was originally thatch, later replaced by locally made khapada, ceramic tiles. The animal shelters are separated from the main house and are open sheds with thatched roofs. Birdhouses are also found in each of the clusters. 
The pitched roof extends out to form a veranda and provides a shaded place to work and rest or sleep. Depending on the time of the day, women are usually seen doing household chores such as cleaning and cutting vegetables or making craft in these spaces. Babies are placed in homemade hammocks while the women work, and older children play around.

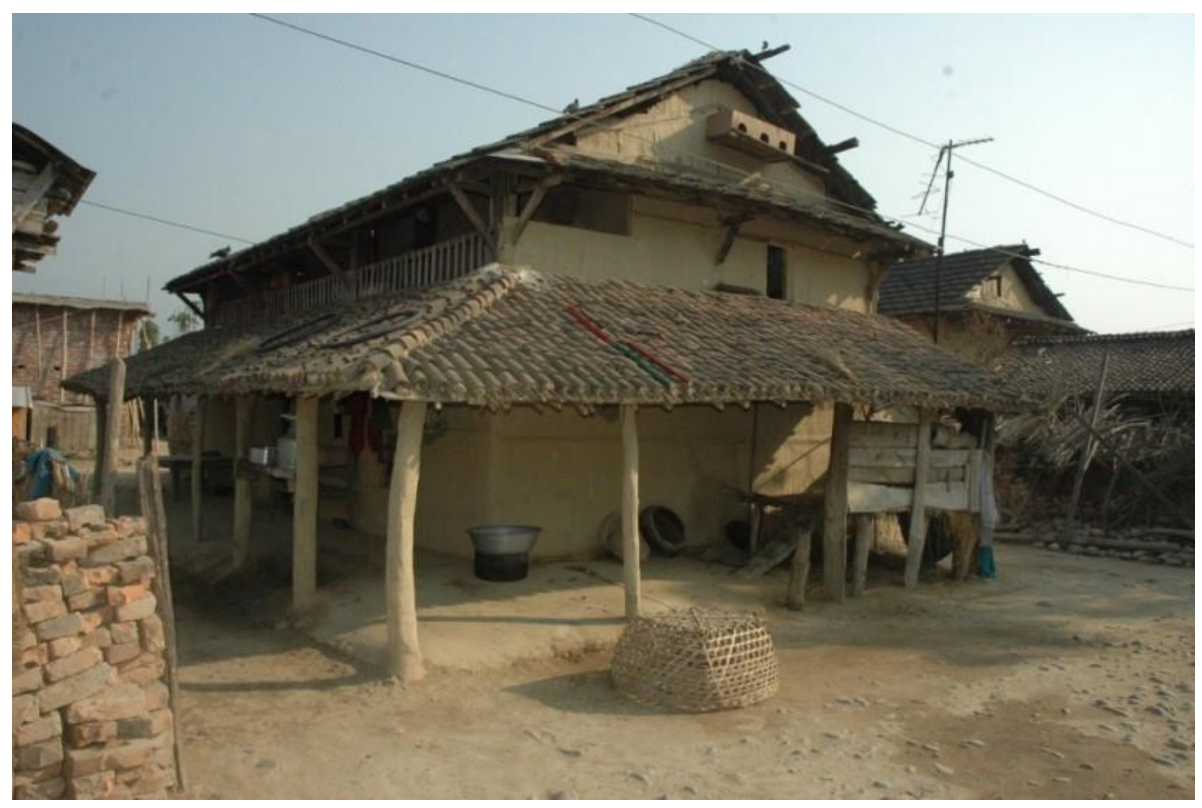

Plate 6-3: Traditional Tharu house with pitched tile roof and veranda

Photo: JJoshi, 2016

The early hill migrants also used the readily available timber to construct their houses but were usually two storeyed in the style of their former residences. The ground floor was open and used as a shelter for the cattle, while the upper floor was used for living. The houses are also double plastered with a final coating of red coloured mud, in contrast to the natural mud colour of the Tharu houses. For the later settlers, timber was not available, banned after CNP was established (discussed further in section 6.1.3). Thus, bricks and other factory-made materials replaced the traditional natural materials of the Tharu houses.

The earlier hotels continued the traditional Tharu construction techniques and were mostly one or two simple rooms with or without attached bathrooms. After the establishment of the national park, access to the forests became restricted, changing building materials and styles. The newer buildings today use brick, concrete and cement 
plaster and are mostly box-like structures without any distinctive style that are found all over the world.

\subsubsection{National park and tourism}

The conservation programmes in Nepal began in response to the degradation of the forests that started when the ruling elite used the resources as a source of income and for recreation. Increasing population and uncontrolled clearance of forested areas for cultivation and migration further intensified the loss. As a result, the first National Parks and Wildlife Conservation Act in 1973 established government institutions to create and manage Protected Areas. CNP was the first park (in 1973), spreading over 932 sq. km. with an additional $750 \mathrm{sq}$. $\mathrm{km}$. of buffer zone. Prior to the national park, a rhino sanctuary had been established to protect the flagship species, which later became part of CNP. The initial park policies followed contemporary global trends and adopted a strict conservation approach, restricting access and controlling with armed forces. This approach enabled CNP to successfully save its flagship species, the one-horned rhinoceros and the Bengal tiger, but created human-wildlife conflicts excluding the local people. The people were deprived of their traditional rights and dependence on the forest resources, with some villages forcefully relocated disrupting livelihoods and sociocultural associations.

Nevertheless, the conservation efforts in Nepal have evolved, shifting from central government control to active community participation creating buffer zones and Conservation Areas, such as the Annapurna Conservation Area (Gurung, 2008). The later approaches integrated nature conservation with community development attracting international and domestic tourists. The revenue collected from tourists visiting national parks and conservation areas has protected the biodiversity, managed the natural resources and contributed to local communities through infrastructure improvement and socio-economic development.

CNP and its buffer zone are managed the National Trust for Nature Conservation (formerly King Mahendra Trust for Nature Conservation), an autonomous not-for-profit organisation established in 1982. The management goal of the CNP is "to protect wildlife species through an appropriate protection strategy and manage their habitat applying 
science-based measures to maintain the world heritage value of the park and mainstream the conservation for people's well-being" (Chitwan National Park, 2015). It is evident that the primary objective is the conservation of biodiversity. The buffer zone was the outcome of the Park and People programme that sought to minimise the human-wildlife conflict due to the rise in population and pressure on the park resources. One of the key reasons for the provision of the buffer zone was to compensate for the human casualties, crop damage and livestock loss due to the wild animals straying from the park boundaries.

The buffer zone is further divided into Conservation Zone, Sustainable Use Zone and Intensive Use Zone. Sauraha lies in the Intensive Use Zone, which includes all the settlements and private land (Plate 6-4). This zone was established to reduce the dependency of the people on the forest resources through "environment friendly development activities" and conservation awareness (Chitwan National Park, 2015). There are no specific guidelines or regulations prescribed for the "environment friendly development activities" with the activities for the five-year period (2012-16) mostly focused on awareness raising through publications, eco clubs and income generation and skill development programmes.

In terms of sustainable tourism promotion and the buffer zones, the management objectives are to minimise access to the national park and encourage activities in the buffer zones that includes the community forests. The park envisions collaborations with local people in the community forests to contribute towards improving their livelihood, at the same time protecting the core national park. Tourism for the park is a means to raise awareness of the benefits of conservation of the natural and cultural heritage, while generating revenue for conservation and enhancing the livelihood of the local communities.

Tourism in Chitwan predates the national park with the establishment of the Tiger Tops Jungle Lodge in 1964, a pioneer in wildlife safari in Nepal. It also pioneered the concept of tourism within protected areas to benefit conservation, operating with minimal impact on the environment using local building materials and employing local people as well as setting an example for other hotels within the protected area and the early hotels built outside the park. There were seven hotels within the park before they were forced to close 
in 2012. Today, there are more than 70 hotels of different qualities and capacities in Sauraha and around CNP.

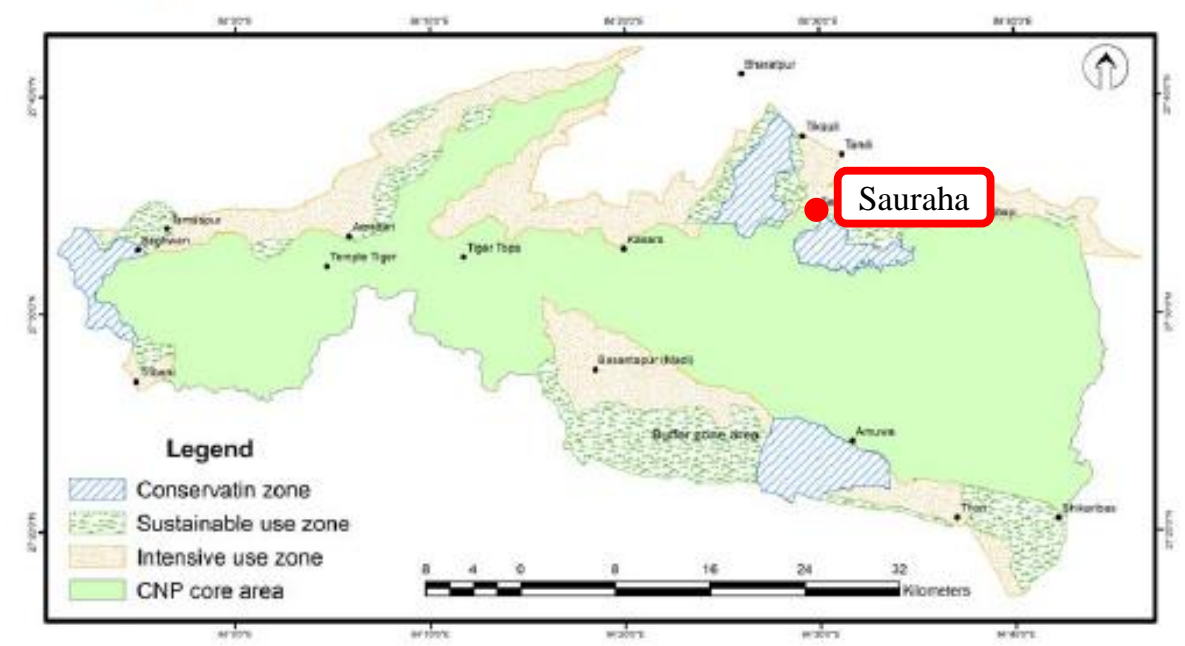

Plate 6-4: Map showing land use in the buffer zones

Source: Chitwan National Park

In summary, Chitwan valley, once malaria-infested and thinly inhabited by the indigenous Tharu people has developed substantially in the last half a century into a mixed community. Sauraha has also evolved from a small farming village to a bustling town. Surrounded by the lush forests and fertile agricultural land, it is a mix of typical Tharu settlements and new brick and cement plastered houses. Sauraha continues to attract in-migration due to its fertile land and more recently, its location at the entrance to CNP. The national park, no doubt has significant influence on the development of Sauraha and subsequent landscape changes, especially through its biodiversity conservation centred policies and subsequent tourism development.

The next sections present the main findings drawn from the in-depth interviews using past and repeat photographs. First, the perceptions of the participants with regard to the landscape and landscape aesthetics are presented, followed by landscape changes.

\subsection{PERCEPTIONS: THE PARK, THE LAND AND THE PEOPLE}

Eleven participants were interviewed in Sauraha including five non-tourism residents, five tourism sector residents and one international tourist (Table 3-7). As explained in section 3.4.2, the tourists had limited interactions with the overall landscape of Sauraha, 
hence the focus was on interviewing the residents. This section presents the findings on the landscape components identified by the participants that comprise their perceptions of landscape aesthetics. This section first presents their perceptions on the natural setting, which in the case of Sauraha, includes both the national park and the farmlands, followed by the built settlement and the community.

\subsubsection{The national park and the farmlands}

The location of Sauraha, as a gateway to Chitwan National Park, a WHS, receives more than $75 \%$ of the total visitors to the park (Chitwan National Park, 2015). The image of the park with the one-horned rhino, Bengal tiger and elephants as a wildlife tourism destination has been widely promoted by the state and the tourism industry. These images of the wildlife imply experiencing nature (Mackay \& Fesenmaier, 1997), which is reflected in the responses of all residents interviewed. For example, Rakesh, a hotel owner who migrated to Sauraha as a child said,

Sauraha is especially known for wildlife tourism. It is a destination for wildlife tourism. (Rakesh, resident-tourism, hotel owner)

Not surprisingly, the prized flagship species, one-horned rhinoceros, was often cited as the principle attraction.

The jungle, the national park is well known and the identity of Chitwan is attached to it. The wildlife, especially the one-horned rhinoceros of Chitwan has made Nepal known in the world. (Debesh, resident-non tourism, teacher).

The presence of the "exotic" animals and potential to encounter wildlife in their natural habitat made Sauraha an attractive and unique place. The idea of aesthetics was not only in the presence of the animals (visually pleasing) but also in the opportunity to experience nature (recreational, experiential value), through different activities such as jungle walks, elephant rides, canoe rides and jeep rides. One Tharu resident, born and raised in Sauraha but who had not been inside the national park remarked:

My village is beautiful. It is a tourist destination and there are many places to visit. Many people visit our village. It is a beautiful place and there are many places to see here. (Anju, resident-non tourism, student) 
These responses suggest the overall image of the national park as promoted by the state and the tourism industry has become linked to local identities. It has generated a sense of pride to be associated with its reputation attracting tourists and contributing to the national economy. The national park dominates the landscape of Sauraha, both physically and conceptually. Not surprisingly, the national park was the first and foremost aspect of Sauraha that most participants identified as their prized landscape and key attraction.

Despite the dominance of the national park in Sauraha, for the indigenous Tharu community, the agricultural land, their farming traditions and culture retain high significance. As explained above, the Terai is known as the "granary of Nepal" and the traditional farming occupation of the Tharu people is still continuing to various extent. The flat landscape on the confluence of Rapti and Nayayani Rivers with good irrigation has made Chitwan very fertile and productive. One Tharu participant remarked,

\section{Irrigation is good here. The Tharu people have always settled where there is good irrigation. Tharu people never settled where the irrigation is not good. That is the tradition. (Bijay, resident-non tourism, museum).}

The above statement indicates the deep knowledge of the Tharu people of their land. Their traditional shifting cultivation also indicates knowledge of farming techniques that are suitable for the climatic conditions. The sparse population of the time also allowed for this practice of shifting cultivation. Although farming practices have changed, the buffer zone adjacent to the national park is mainly a cultivated landscape. All the Tharu participants had some land and either worked in the fields or hired people to till their land. For example, an elderly resident remarked,

This land has been in our family for generations. We are farmers. We have always been farmers. There was nothing else to do here. We farmed and lived here. (Laxman, resident-non tourism, farmer).

Another young student participant who also produced local crafts added,

During the farming season, I work in the farms, mainly transplanting rice and I enjoy it. (Poonam, resident-non tourism, student)

The dominance of farming culture in the landscape of Sauraha is evident from the number of planting seasons despite the loss of the traditional practice of shifting cultivation and 
land fragmentation since migration started in the 1950s. The fertile land is never left barren and the landscape changes colour with the seasons. Although the residents did not explicitly describe the farms in terms of aesthetics, their knowledge and experience of the land revealed the meanings and values that they attached to the landscape. The following example illustrates this knowledge:

\section{If you look around, it is time for mustard seeds to be planted. Only recently it was rice, now it is the season for mustard. If you return in a few months in Chaitra [March], it will be something else. In Asadh [June], we will plant rice again. The land is always green and productive. (Debesh, resident-non tourism, teacher)}

The dichotomy of the residents' responses regarding their attachments to their landscape reflects the complex and multi-layered relationship with the land. While the image of the park promoted by the state provides a sense of pride and belonging in the wider international community, their traditional ties lie in the land that they have tilled for generations providing sustenance and unique identity. This duality also reflects the local concept of landscape that encompasses the natural (park) and the cultural (farmlands and farming).

While the Tharu participants were directly connected to and identified the farmlands as part of their landscapes and identities, the non-Tharu residents focused on the tourism activities in and around the national park. Although some of the non-Tharu residents were early migrants, their ties to the land and the culture of farming were less prominent. Only one tourism sector participant (Rakesh) talked about personal experience in farming. He reminisced about his childhood growing up in Sauraha:

The history of Chitwan is such that we were all farmers before the national park was established. There was a lot of farming and many buffaloes and cows. We used to take the cattle out to the forests in the mornings to graze before school. On the way back from school, we would find our cattle by the river in the afternoon and brought them back. That was our basic occupation, raise cattle and farm. We used the manure as fertilisers and got milk from them. (Rakesh, residenttourism, hotel owner)

The above statement indicates the traditional dependence of the people on the landscape, such as the river and the forests. It also indicates sustainable traditional practices that were connected to the land, farming and raising cattle using the manure as fertiliser. This 
response also suggests the continuation of local traditions and landscape to some level after non-Tharu started settling in the region. However, since the non-Tharu participants interviewed were in the tourism industry, it was natural that their perception of the landscape of Sauraha focused on the national park. Although their perception of the landscape was linked to its tourism potential, their knowledge of and connections to the landscape was evident. For example, a non-Tharu tourism entrepreneur described his landscape in the following manner:

The landscape here is beautiful. From the Churia hills to the Mahabharat range, they are all in Chitwan. The landscape is diverse here. The birds and mammals found in Mahabharat range are not found here in Sauraha. There are grassland and riverine forests here. You will also find Sal forests, alpines forests, pine forests right here. The mammals and birds you see in different forests are different. (Bidur, resident-tourism, guide)

The above statement suggests, for some residents the landscape extends beyond the immediate surroundings of CNP, incorporating the wider Chitwan region. This is also an indication of the increasing dominance of tourism as an economic driver. The wider landscape of Sauraha extends beyond the national park and includes the Mahabharat Range and the Churia hills that bisect the park add to the biodiversity of the park increasing its tourism potential. However, these ranges are not associated with the people of the Terai, and linkages have not been established.

The informal conversations with tourists, both international and domestic, provided limited insight into the overall landscape of Sauraha. Their interest and experience were mainly focused on the activities that they participated in the national park, as the international tourist interviewed observed,

\section{I honestly would only recommend going there [Sauraha] if you are going for some activities in Chitwan. In the jungle. Small. I don't know how else I would describe it. (Samantha, tourist, Canada).}

In summary, the Chitwan National Park dominates the landscape of Sauraha, however, the agricultural landscape holds high significance to the indigenous Tharu population. Their attachments with the land through their traditional farming tradition add value to their landscape that is integrated into their perception of landscape aesthetics. The international image of the park and success in biodiversity conservation and tourism also 
hold significance. This dichotomy reflects their traditional ties with the land and the future as global citizens through their association with the park. The non-indigenous population who migrated in various periods also associate both the national park and the farmlands as defining components of their landscape. However, there are some differences in the level of attachment to the land between the two groups of participants. While farming and associated lifestyles are still ingrained in the lives of the Tharu community, the non Tharu population have shifted to the service sector. For the tourists, the primary interest remains the national park. The image of the park as a haven for wildlife with a variety of activities and opportunities to be close to nature, is the attraction, with limited exploration of the wider landscape of Sauraha that includes the farmlands, villages and the people. The flat landscape of Sauraha also limits the vision to eye level and does not provide a sense of the magnitude or variety of the landscape with landscape experience limited to activities such as canoeing in the river or walking in the forest. The adjacent Churia and Mahabharat ranges provide some perspective of the vast forested land covered by the national park, however, neither the residents nor the tourists venture to these parts.

\subsubsection{The village and the community}

The Tharu settlements consists of clusters of houses around open courtyards, usually belonging to one extended family and adding houses as the family grows. This tradition was expressed by one participant stating, "We like to live close to each other in a compact settlement" (Debesh, resident-non tourism, teacher). This clustering pattern is favourable for their farming lifestyles as well as the hot and arid climatic conditions. The traditional natural materials from the nearby forests, khar and khapada, provide ventilation that most participants observed "it doesn't get hot in the summer or cold in the winter" and "healthier". The khar and khapada do not retain heat making the cottages cool in the summer evenings. The small windows also reduce direct sunlight entering the cottages keeping them "cool and comfortable" in the summer. The one storey structures clustered around provide good sun in the winter months, which is short and mild.

In addition to the materials, the cottages also represent their traditions and are suited for their lifestyles, with one elderly resident continuing to live in the one remaining 
traditional house in a cluster, where his sons had built newer structures. When asked why he was living alone, he laughingly remarked,

This is my house and I like this house. My sons say they have room for me in the new house. I don't go there, and I sleep here. I have always lived here and for me this is the best. (Laxman, resident-non tourism, farmer)

The clusters are also well suited for community-style living where all family members contribute to household work, the farming related activities, such as basket weaving and festivals that are celebrated together. While the participants were interviewed outside their homes, they continued with the work or kept an eye on young children playing in the yard. The housing pattern allowed them to continue with their traditional lifestyle, which contributed to their preference for and attraction of the traditional cottages.

As the history of the national park is relatively recent, the older residents still retain their memories of Sauraha prior to the park. Most participants described Sauraha as a "typical Tharu village with small huts." The Tharu residents interviewed were either still living in the typical houses or had only recently moved to a newer structure, however, they were still living in the same neighbourhood and as one elder participant lovingly remarked, "let us just say, this neighbourhood is just one family" (Laxman, resident-non tourism, farmer). This response suggests the role of the community in the creation of the settlement. Although not explicitly expressed, this response indicates that the concept of landscape aesthetics includes the sense of belonging in a community. The neighbourhood as part of a family suggests familiarity that binds the community together, creating a safe place that adds meanings and values to the landscape.

Tharu people and their culture was the prominent feature described by the participants in the landscape of Sauraha, which was historically an exclusively Tharu settlement and stated in the statement of significance as a significant characteristic when inscribed in the World Heritage List. The Tharu participants were proud of their culture with most asserting at the beginning of the interviews,

Our birth place is Chitwan. We are the indigenous people of Chitwan. The Tharu community is the principal indigenous community of Chitwan. (Debesh, resident-non tourism, teacher) 
The Tharu participants emphasised that they were in the region generations before the national park was established with some stating their people and culture as the primary attraction of the region.

Chitwan is Tharu community's region. The Tharu people have been living here for generations. So, this region represents the Tharu culture and traditions. We have our own culture, traditions and arts that we still practice. It is near the national park and the forest, so it is green and rich in biodiversity. (Poonam, resident-non tourism, student)

All participants considered Tharu traditional culture and practices as important to the landscape of Sauraha, especially their agricultural heritage, festivals, costumes, ornaments and lifestyles. They emphasised the importance and contribution of the Tharu community to the identity of Chitwan. When asked what meaning the place had, a Tharu participant responded,

Chitwan is known and has been promoted because of the Tharu people. Because the lifecycle of the Tharu traditions, the indigenous people and culture is multi-lingual and multi-cultural. We celebrate many different festivals, the costumes and ornaments/jewellery of the Tharu people are so rich that it is known in the world. Now all the tourists who visit Chitwan do the Tharu village walks. Hotels have also organised tours and have a schedule for village walks. (Debesh, resident-non tourism, teacher)

The above response indicates that the importance of the local culture is not only for the benefit of the tourists but equally significant to the people as part of their lifecycle. One young participant remarked proudly, "Even if the tourists were not around we should continue our traditions and culture" (Poonam, resident-non tourism, student). The local culture, traditions and festivals are intrinsic parts of the life of the Tharu people, their place attachment and identity. Poonam also stated, "It is my community and I love living here and the culture here", continuing,

My favourite is the Jitiya festival. It is a special festival for the women. It is fun. We keep fast on the day and there are various programmes for entertainment. We all wear our traditional dresses and it is beautiful. It represents our culture. (Poonam, resident-non tourism, student)

The Tharu traditions and culture are connected with and dependent on their surrounding forests and rivers. For example, one of the main Tharu festival is Tittre ausi when they 
remember their ancestors and perform rituals that connect them to their land. The river and the grass from the forest are important to their rituals and would be at risk with access restrictions. One participant explained this connection as follows:

We remember our ancestors on Titre Ausi and go to the river, purify ourselves with a dip in the river. We remember our ancestors and offer holy water. We collect the "elephant grass" from the forests and make a bunch to establish our deity. We offer all the food that our ancestors like, such as tobacco, cloves, cardamoms, beetle nuts, alcohol, milk and water. We offer all these and worship our ancestors and celebrate Titre Ausi. (Debesh, resident-non tourism, teacher)

The above response indicates that the culture and festivals are derived from the landscape and tie the Tharu people to the land. This in turn becomes integrated into their perception of landscape aesthetics. The concept of landscape aesthetics further expands beyond the scenery and the physical environment, the historic and cultural values to include the present day and everyday lives. For example, the new road, accessibility to town centres, hospitals and schools all added to the attractiveness of the town and were regarded as "a good thing" (Laxman, resident-non tourism, farmer). The elderly residents tended to draw comparisons with their childhood and were pleased with the present development of their hometown.

What is like the best is this land, this settlement, this cluster of houses. Compared to other villages, we have everything here. We have a hospital, a dental hospital, an eye hospital, the tourist bus park. We can go everywhere very conveniently from here. We do not have to rush to the city hospital in Bharatpur for some illnesses. All the facilities are here. It is a tourist destination, the beauty of this place is the national park, and our village is adjacent to the national park. This is a world famous place and is a favourite place for all. (Debesh, resident-non tourism, teacher)

This response illustrates that the concept of landscape for the local residents incorporates the traditional and the modern. It expands beyond the traditional concepts of landscape as natural, cultural or traditional and includes the present-day lives and necessities such as health, education and transportation. The convenience of modern facilities adds value to the landscape and is included in their perception of landscape aesthetics.

The non-Tharu residents who call Sauraha their home also agree that the Tharu culture is the identity of the region and should be preserved. Their value of Tharu culture also 
goes beyond the benefits of tourism and most recognise it as the identity of the region. For example,

Chitwan is known as a place of the Tharu people. It is known for the wildlife and Tharu culture. (Chenu, resident-tourism, handicraft shop owner).

The tourists have fleeting contact with the Tharu community while on the village tour, which usually includes a visit inside a typical cottage. Their interactions are limited to any purchase of local handicraft or with mahouts who are usually from the Tharu community. Tharu dances have also been part of the tourist attractions in Sauraha. The dances were included in the package tours for the hotel guests in their hotels and resorts. There are now private and community-run Tharu Cultural Centres in Sauraha with daily Tharu dance performances. In addition, the Tharu Cultural Museum provides an adequate insight into the cultural lifecycle of a Tharu from birth to death and the historical development of the region, including the stories of migration during the establishment of the national park. The national park information centre also provides brief information on the Tharu people, which is limited to their ethnic description. CNP has failed to include the rich agricultural history of the region into their narratives. This is mainly due to its focus on "conservation first" that has also removed the traditional rights of the local people from the park along with the history of the landscape that had been worked by the people for generations.

On the other hand, the town centre of Sauraha was inconsequential with the common box-type houses that are found in most parts of the country. The expanding centre with hotels, restaurants and shops lining the main street has turned it into "Thamel ${ }^{22}$ of Chitwan" (Bijay, resident-non tourism, museum). Most of the non-Tharu tourism entrepreneurs interviewed agreed that the traditional cottages added value remarking that,

\section{"I will only build cottages, but comfortable cottages. That time will come. Environment friendly. The exterior would look like a cottage but inside you will find all the comforts. I will provide all the modern facilities but use all traditional features" (Rakesh).}

\footnotetext{
${ }^{22}$ Thamel is an area in Kathmandu known for tourism services such as budget hotels, trekking and travel agents, trekking and mountaineering equipment, shops, cafes, bars and restaurants.
} 
This response also demonstrates the duality of the expectations of the tourists and service providers with regards to the "traditional" houses. The "exotic" Tharu cottage is a marketable product, however, the addition of modern amenities enhances its marketability. Overall, the dichotomy between the traditional settlement and the emerging Sauraha bazaar is the result of its unique location. This dichotomy also reflects the changing societal values and is presented in the next section.

In summary, the traditional settlement and the architecture of Sauraha reflect the farming traditions, culture and the lifestyles of the indigenous Tharu community that was also the result of the geographical setting and climatic condition. However, in the present context, it is located in the buffer zone of the Chitwan National Park, which has substantial impact on its overall development, including the built landscape. For the indigenous residents for whom Sauraha or Chitwan has been home for generations, the aesthetic value of the landscape is related to the land and their traditional occupation as farmers. The non-Tharu residents who have spent significant number of years in the region, call it their home and are dependent on the recent tourism development also agree that the Tharu settlements identify Sauraha. For both groups, the concept of landscape aesthetics includes the traditional settlements (visual aesthetics) and the Tharu culture (cultural aesthetics) as well as economic value through tourism. For the tourists, their experience of the built landscape is typically limited to the "Tharu village tour" that involves an hour long walk through the settlements. Some of the tourists I had informal conversations with had visited the newly established Tharu Cultural Museum in Bachhauli village and remarked that they found the village "interesting" and "quite similar to a lot of families we had already seen from being here in Nepal. But this definitely seemed a lot more remote and not as modern" (Samantha, tourist, Canada). It is interesting to note that although Chitwan is accessible by air and road and Bachhauli is only a short walk from Sauraha town centre, the small cluster of Khar cottages were perceived as "remote."

\subsection{PERCEPTIONS: THE CHANGING LANDSCAPE}

Both the historical chain of events and the current state of affairs has had a significant impact on the landscape of Sauraha that has evolved from a malaria infested land of shifting cultivation and small cottages to the present-day bustling town with the world- 
renowned national park and a growing tourism industry. There are three main aspects of Sauraha that are the drivers as well as the constituents of change: the national park, the indigenous Tharu community, and the tourism industry. Although the participants agreed that all three components are vital for Sauraha, there were different views on the perceptions of landscape change.

First, this section presents the finding on the participants' perceptions of landscape change following the conservation polices of CNP. The second part presents their perceptions on the recent changes due to internal and external drivers including tourism.

\subsubsection{Conservation policies and Tharu culture}

The establishment of Chitwan National Park in 1973 is undoubtedly one of the turning points in the Sauraha landscape. The small farming village with mostly one storey cottages transformed to a bustling town with multi-storeyed structures that are mushrooming in most parts of the country due to the success of the national park. Sauraha lost much of its traditional built environment, however, there are pockets of traditional settlements scattered in the peripheral areas, such as Bachhauli, where most of the interviews were conducted. These settlements retain the Tharu population and culture that were prevalent in the region prior to the establishment of the national park, as one Tharu resident stated, "The Tharu people have been here for generations. The park was only established in 1973" (Bijay, resident-non tourism, museum).

The Tharu participants pointed out the restrictions of access to the forests and rivers as the key hindrance and driver of change, especially to continue their culture, traditional professions and construction techniques. The following statements illustrate this point,

When we were children, our fathers and grandfathers went to the National park forests to collect wood and other materials for a month or a month and half. They used to bring back materials to build or repair the houses. Collect from the National Park and repair once a year, that was the tradition. The National Park has closed that. Now you cannot get the material from the forests when you want or need. (Bijay, resident-non tourism, museum)

The materials for the traditional houses, the khar, the khapada tiles were all collected from the forest. It is prohibited to collect them from the national park now. Before, people were able to go to the forest for 
about a month to collect khadayi, khar -they were all collected from the forests. We made the walls of the khadayi and put the khar roof on for our houses. That was our tradition. We cannot go to collect them in the national park now. Only limited access for 3-5 days is allowed. Those 3-5 days is not enough to collect sufficient materials for a house. The most you can collect in that timeframe may be 20 bundles of khadayi and 20 bundles of khar. That is not enough to build a house. (Debesh, resident-non tourism, teacher)

The restriction placed by the national park on the number of days means the time is insufficient to collect the amount needed for building or repairing the traditional cottages. The short opening also did not guarantee the most favourable ripening period and the availability of labour. The original thatch khar roofing was replaced by the roofing tiles khapada, however, these too require wood and cow dung to bake. The recently built Tharu Cultural Museum imported the tiles from Birgunj, about $130 \mathrm{~km}$ south east of Chitwan. The following response indicates the difficulties in maintaining traditional architecture:

The tiles we have here, if they are damaged and we have to replace them, we cannot find them here. The tiles for the museum were brought from Birgunj. These one I have here are old ones that were made here locally. You need cow dung to make these tiles, then you need wood. You cannot get either the wood or the dried cow dung now. Without the two, you will not be able to bake these tiles. That is a reason why the traditional buildings are slowly being lost. (Debesh, resident-non tourism, teacher)

Despite the difficulties in procuring the materials, the Tharu residents preferred traditional buildings. One of the reasons cited was that traditional materials performed better in the hot and humid climate. For example,

Yes, if the materials were available people would prefer that. Even in the hottest month, Jestha [May] if we stayed in the traditional hut, you will not be hot" (Debesh, resident-non tourism, teacher).

In contrast, the buildings in the new Sauraha centre are mainly 4-5 storey row houses that are different from the Tharu architecture in materials, size and styles. All the tourism sector participants expressed discontent for "all these big concrete buildings" that were "not good for Sauraha." Most preferred buildings that were "smaller and in a typical traditional style, suitable for this place, that blend in the environment and the village" (Chenu, resident-tourism, handicraft shop owner). 
The above-mentioned concern regarding the larger and incompatible style of constructions and the loss of Tharu houses was widespread. According to the participants, an additional reason for the change in architectural style was the inability of the national park and the municipality to enforce building byelaws that promote traditional styles. A participant noted,

According to the rules and regulations of the national park, you are not allowed to build more than two-storeys within the buffer zones. But people are building as they please. People are encroaching and disregarding the rules even when they know about these rules. They know you are not supposed to go higher than two storeys. The rules say, you can build up to two floors, paint your exterior with colours that are appropriate with the natural environment, be environment friendly and the building has to be finished and end at two storeys. (Govind, resident-tourism, hotel owner)

The exterior appearance of the building is specified to be appropriate with the surrounding natural environment such as mud colour. It was found that all the participants were aware of the guidelines and pointed to the weakness of the local government and the national park to enforce the guidelines. One of the participants regarded this issue beyond the local context and attributed the recent transformation to the period of Maoists' conflict when the state structure, including the national park had weakened ${ }^{23}$. The participant put it as:

\begin{abstract}
We also have some weaknesses. It is more our country's problem than something we are solely responsible for. We could not control during the internal conflict. That is when we have failed. We were not part of the municipality, but you could not build without the permission from the national park. During the conflict when the permissions were being granted the management of the national park became weak. They did not look closely at the designs and gave the permits easily. This is after the mid-term elections around 1996-97, when the Maoists conflict was at its climax. We have not been able to recover from that time. New areas that will be developed in the future should seriously consider this. (Rakesh, resident-tourism, hotel owner)
\end{abstract}

This response indicates that despite strong conservation and management systems, implementing policies is also dependent on larger political conditions. It also reflects the

\footnotetext{
${ }^{23}$ This was also observed in Ghandruk with some participants pointing out that the new style buildings were first built when the Annapurna Conservation Area Project office in Ghandruk closed due to the threats from the Maoist insurgents (section 4.3.1).
} 
juxtaposition of Sauraha in the buffer zone of the national park and within Ratnanagar municipality with two sets of opposing regulations. The park management document categorises Sauraha in the "Intensive Use Zone" of the buffer zone, described as:

This is the area in the buffer zone, including all the settlements and private lands, where environment-friendly development activities will be carried out to enhance the livelihood of the people living in the area through various developmental inputs. The basic objective of this zone is to reduce the dependency of these people on forest resources and garner their support in conservation through conservation awareness. The area under this zone will be again prioritized based on severity of the interface problem, dependency of people on forest resources and wellbeing status of people. Based on this priority, the developmental inputs will be provided. The total area under Intensive use zone is 381.86 sq. km. (Chitwan National Park, 2015)

No further explanation is provided regarding the "environment-friendly" development activities that are allowed in this zone. The objective to reduce the dependency on forest resources suggests development that minimises the access to the park. The omission of the types of building and planning guidelines also suggests an overlap of jurisdiction. Ratnanagar municipality has adopted the general "Housing development, urban planning and building guidelines" set by the Ministry of Federal Affairs and Local Development in 2015 (Government of Nepal, 2016). This document is based on the guidelines prepared for Kathmandu Valley and provides basic controls such as Ground Coverage Ratio, Floor Area Ratio and Setback for building construction without any specifications on land use, zoning or accompanying maps ${ }^{24}$. In other words, at present, the municipality has no specific objective to preserve the traditional settlements. This allows large structures to be constructed in the agricultural lands that dominate the one-storeyed traditional built landscape.

In addition to the building materials, restrictions on access to the forests and rivers has impacted on the occupations of the communities that depended on the resources, such as the fishermen. "They used to fish as a group and divide the day's fishing between the group. That is not practiced anymore" (Bidur, resident-tourism, guide). Those who have land and means have been able to adopt new occupations and benefit from the rising land

${ }^{24}$ Also used for Bandipur (section 5.1.3) 
prices or the tourism industry, however, the disadvantaged and marginalised population have been left behind.

On the other hand, while acknowledging the restrictions as hindrance to the continuation of Tharu culture and tradition, the tourism entrepreneurs generally observed the positive impact of the national park, especially with biodiversity conservation and the resulting growth in tourism. For example,

\section{Basically, we have seen a lot of changes. The good changes are; the forest is in much better condition than before. For example, now in Bandabar forest, there are 7-8 tigers but in the 1960s and early 1970s, there were only 15-20 tigers in the entire Chitwan National Park. There were no tigers in Bandabar forest. Now there are more than 120 tigers in the Chitwan National Park and more than 600 rhinoceros. (Rakesh, resident-tourism, hotel owner)}

The tourism entrepreneurs also claimed, "the relationship between the national park and the hotel sector is excellent" (Govind, resident-tourism, hotel owner). The tourism sector depends on the success of the national park and supports the park policies of "conservation first and then tourism", however tourism operators also argue that "there has been sufficient efforts put into conservation and more should be done towards promoting tourism" (Govind, resident-tourism, hotel owner). On the other hand, the Tharu participants had reservations regarding their relationship with the park and the tourism industry. To gain greater local support for biodiversity conservation, the park enacted a byelaw in 1996 that allocated 50\% of the park entry fees and a portion of concessionaire tax to local communities affected by the park policies. However, a Tharu participant disagreed and remarked that,

The policies of the park are not favourable to the Tharu people. The buffer zone was established because the local people suffered from the wild animals and they had to be compensated for it. But the decisionmaking is in the hands of the outsiders. So, the policies and decisions made are not beneficial to the Tharu people. Fifty percent of the earning from the national park is supposed to go towards local development. There are no good programmes for it. There are other programmes and projects as well, but they are never Tharu-friendly. (Bijay, resident-non tourism, museum)

This response indicates the discontent with the park policies, which also suggests that the Tharu people do not share in the benefits of tourism. The "Tharu village tour" is one of 
the activities that take the tourists to the villages for a local experience and this has been seen as a tool to improve their livelihood. However, this activity is limited to walking around the village with no direct benefits to the local community. A Tharu participant observed:

\section{Tourists come here to look at the mud houses. They do not come to look at the new houses. They want to look inside the traditional houses and are not interested to go inside the new ones. They like the Tharu houses. (Lalita, resident-non tourism, health)}

There is a hint of resentment of the intrusion of the tourists and being put on show in this response. This response also reflects the dichotomy between the traditional cottages and the societal changes reflected in the new houses. While most preferred the traditional cottages, some preferred the low maintenance required in the new "easier" buildings. However, most participants remarked that the restriction imposed by the national park was the key deterrent to maintain the traditional buildings. This change in the built environment is explored further in the next section.

In summary, the national park with its biodiversity centred conservation policies is a key driver of landscape change in Sauraha. The restrictions on the traditional rights of the Tharu people to the natural resources has not only transformed the built environment but also affected their traditional livelihood patterns and culture. The indigenous Tharu community perceive the benefits from the park to be minimal despite the park polices of re-investing half of the profits from its entrance fee into the community. The conservation efforts of the park are appreciated by the tourism sector, however benefit from tourism growth is not strongly observed by the Tharu community. The location of Sauraha in the buffer zone of the national park and within Ratnanagar municipality has also created conflicts in conserving the traditional built landscape.

\subsubsection{Tourism and society}

The most noticeable change the majority of participants agreed upon was that Sauraha had changed beyond recognition from "just a bagar (riverside) of the big Rapti river" and "there was nothing there" (Lalita, resident-non tourism, health) to a "becoming like Thamel and changed to another destination" (Govind, resident-tourism, hotel owner). 
Although most participants agreed that the changes indicated economic development, they were also concerned with the loss of the unique identity of Sauraha as an exclusively Tharu village to a town with "big concrete buildings" (Chenu, resident-tourism, handicraft shop owner) of universal culture. The comment below illustrates this concern,

When you come to Sauraha you come to see a village. Sauraha has changed a lot from what it looked like. There used to be bullock carts before. People went to the forest, took boat rides. Now it is mostly elephants and jeeps. And all these big concrete buildings. They should not have been allowed. It is not good for tourism in Sauraha. If they were smaller and in a typical traditional style, suitable for this place, that blend in the environment and the village. Chitwan is known as a place of the Tharu people. It is known for the wildlife and Tharu culture. But now that has changed. This much change is not good for Sauraha. (Chenu, resident-tourism, handicraft shop owner)

This response indicates that changes have been rapid and go beyond the physical to lifestyles and activities of both residents and tourists. The current use of vehicles and elephants indicates the growth of tourism that resulted in "big concrete buildings." There is a hint of nostalgia with the loss of bullock carts, traditional cottages and unique Tharu identity. While the conservation policies were key in changing the built landscape for the Tharu non-tourism residents, the tourism entrepreneurs suggested the change in the building styles was partially driven by the tourists' demands. The early tourists to Sauraha were mostly Europeans who came to explore the jungle for the wildlife and biodiversity and, travelling with their own "sleeping bags and mosquito repellents" were satisfied with basic amenities provided in the typical cottage that were the prevalent type of accommodation. The more exclusive resorts inside the boundaries of the national park also had similar accommodation. The early tourists were described as:

They used to just throw their bags in the room and without even entering the room ask where the national park is and just head straight to it. They did not care about where they were sleeping. You just had to provide them with a bed, they brought their own sleeping bags. (Bidur, resident-tourism, guide)

However, the tourists were now asking for "Wi-Fi first, then bathtub, television, air conditioning, then the variety of food" and "even swimming pools" (Govind, residenttourism, hotel owner). The recent rise in Asian and domestic tourists, especially the school tours from other cities in Nepal, are demanding different accommodation types to 
the earlier typical cottages. According to the participant, this trend is driving new investors to accommodate the new group of tourists and "they feel that if they do not have these facilities, they will be left behind" (Bidur, resident-tourism, guide).

One of the recurrent themes concerning the benefits of tourism was the increase in employment opportunities in the tourism industry and associated industries. With the increase in the number of hotels from three hotels before 1980 (Dinerstein, 2003a) to more than 70 today, this clearly indicates that there is a demand for labour with further indications of growth in the coming years with the general growth of tourism in the country. New areas around the park are also opening up, such as Kasara and Meghauli, with larger star hotels and international chains. The nearby city centres, Bharatpur and Ratnanagar are rapidly expanding, increasing opportunities of growth through MICE and domestic tourism. A participant stated that although Sauraha was "hot and rains a lot in summer" it offered "fresh and good environment" in the winter and is located at a convenient distance for businesses in Narayanghat that is "dusty and polluted" (Govind). It is also situated at a convenient distance from the East-West highway and easily accessible from Birjung ${ }^{25}$ and India. This places Sauraha in a juxtaposition to continue as an exemplary national park with its bio-diversity centred conservation policies or develop as a hub for the region.

Although the Tharu participants agreed about the increase in employment opportunities, opinions differed on the extent of benefit. Some pointed out that the majority of businesses were owned by the non-Tharu population and increasing external investors indicate the validity of their concerns. They also stated that the jobs available for the Tharus were mainly low-paying, such as mahouts, kitchen hands or guides. A Tharu resident stated,

There are many employment opportunities, which is one benefit of tourism. The sources of income have also increased. The benefits of tourism to the Tharu community is another issue. All the land in Sauraha used to be owned by the Tharu people. There are almost a hundred hotels in Sauraha, the ones owned by a Tharu are less than five. In such a large area, there are maybe just one or two restaurants. The local people have not been able to benefit much from tourism, not

\footnotetext{
${ }^{25}$ Birgunj is an important border town next to Raxual in India with railway and highway connections to the rest of India.
} 
as much as they could have. That is very unfortunate for the Tharu people. (Bijay, resident-non tourism, museum)

This response suggests that the benefit of tourism has not been fairly distributed, especially with regard to the Tharu people. The tourism entrepreneurs, not surprisingly are happy with the contribution of tourism to the local economy and the conservation of biodiversity in the park. The contribution of tourism extends beyond Sauraha to the neighbouring villages and the municipality. Tourism is also supporting the community forests in the buffer zone of the park, where $75 \%$ of the park's jungle activities take place. ${ }^{26}$ Equally, the community forests have protected the wildlife, preserved the forests and contributed to the social and social development of the communities. Community forests are learning from the park and organise boat rides, elephant rides and collect fees, which employs the locals and funds community development projects.

A common view among the tourism entrepreneurs regarding the recent transformation was also the growth of tourism attracting larger investors where previously development had been largely limited to the local people ${ }^{27}$. Since the new investors were "coming from outside this region and investing huge sums of money and building hotels with all sorts of facilities" the earlier established hotels were under pressure to expand and "in a bit of a dilemma" (Govind, resident-tourism, hotel owner). The issue of the negative impact of the growing tourism industry on the built environment of Sauraha was also raised by another participant:

The negative aspects of the change, with the success, people from outside are coming to do business here. They are investing in huge properties. Tourism is booming. They [the outsiders] do not understand the values and the norms here, with respect to tourism, the forest, the landscape. Where water freely flowed, they have buried it and built huge hotels. They should not have changed the geographical character. If water flowed, they could have raised the building [on stilts] and let the water flow. One day the water will return and cause them damage. But they have damaged the landscape. Those investors

\footnotetext{
${ }^{26}$ The entrance fee to the park and the community forests in the buffer zone is the same, NPR 1765 (NZD 23).

${ }^{27}$ The earlier resorts inside the national park were mostly developed by external investors from Kathmandu and Narayanghat.
} 
from the outside have not understood the value of Sauraha. (Rakesh, resident-tourism, hotel owner)

The above response indicates the inner knowledge of the residents regarding the fragile landscape with regular flooding every few years. However, the local Tharu people regarded both the earlier and later migrants as "outsiders" and voiced a different view. Concerns were expressed that the indigenous Tharu population was being displaced and "the population of the hill people is increasing, and it is getting difficult for us to live here." (Lalita, resident-non tourism, health). In addition, one participant raised concerns about the loss of fertile and productive agricultural land to rapidly expanding urban sprawl, "If people were not turning the productive land into housing areas it would have been good for Chitwan to continue with its reputation as the food/grain storage like Punjab in India. Chitwan would have a good reputation as the grain/food store in Nepal" (Debesh, resident-non tourism, teacher).

The in-migration and external investments have increased the value of the land and converted this to cash, which according to some Tharu participants, "was not valuable for the Tharu people. The Tharu people did not know or use money. They were only used to working in the land and that was the only thing of value for them" (Bijay, resident-non tourism, museum). Another participant also stated, "Tharu people do not know any other occupation. So, they are selling the land to live. The hill people are coming and offering money and pressuring people to sell. People get greedy or they have needs and are compelled to sell" (Lalita, resident-non tourism, health). This response indicates that recent developments are changing the traditional occupation of the Tharu people resulting not only in the loss of farming culture but also changing landscapes.

Although tourism has been the driving factor of the change in the built environment in Sauraha, other issues were also identified. Some commented that it was reflection of the current trend with the improvement in the economic status of the people. When asked if the building styles reflect the changing economic and social needs, the response was,

More than building a beautiful building, it is more the question of what the neighbour or others are doing. If he feels that the other person has built a better building, he would want something similar too. The society brings this change. (Govind, resident-tourism, hotel owner) 
This indicates social pressure and conformity driving neighbours to compete and sell off ancestral land in order to build a new house (Plate 6-5). It is also augmented by the common concept that the traditional Tharu house is temporary compared to the brick and cement edifices that are permanent. Thus, as most would build a "permanent" house once in their lifetime, the new materials are preferred ${ }^{28}$. As one participant put it:

They just think that they are building a house once a lifetime. If they build once, they have it for 50-60 years. They do not have to regularly repair them, re-invest in them anymore. Another thing is the competition as well. Your neighbours are going abroad, your neighbours on the right and the left and building new houses. They are all building permanent houses. The others in the village see that and want the same. So they build new houses even if they have to sell land in order to be able to afford a new house. (Bijay, resident-non tourism, museum)

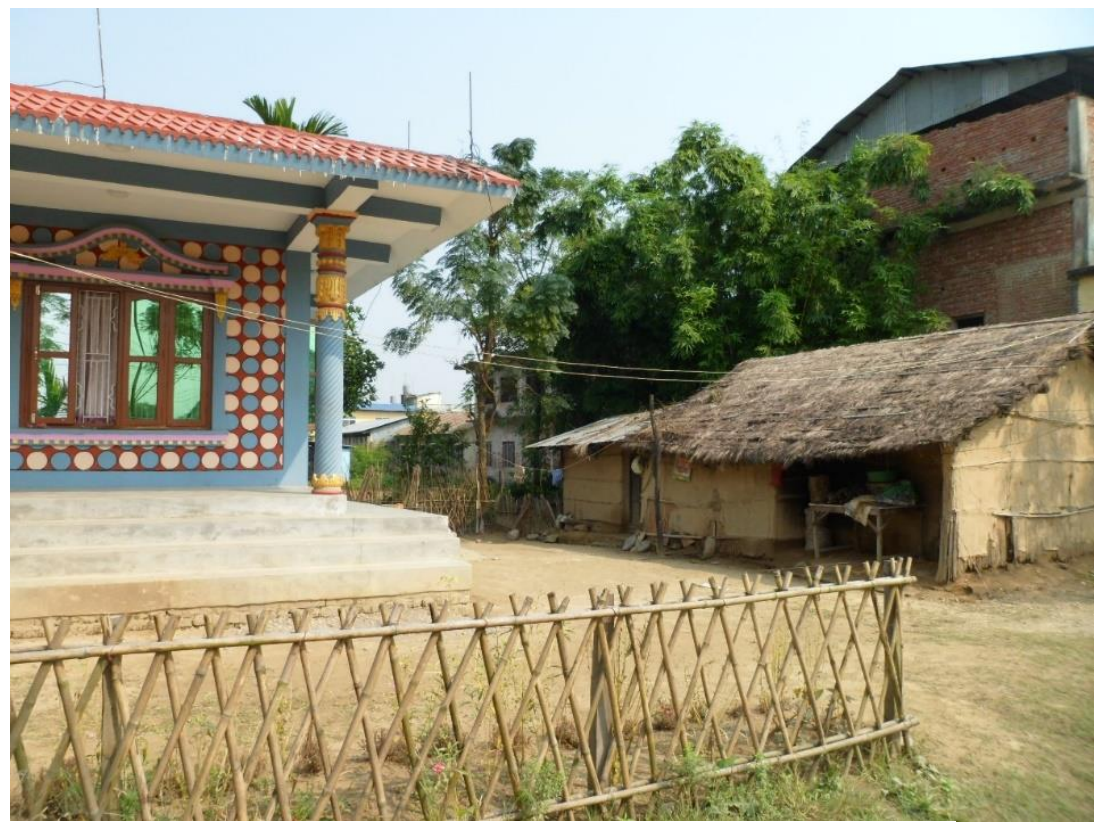

Plate 6-5: New colourful building alongside a traditional cottage

Photo: JJoshi, 2016

The continuous need to repair the traditional houses is a recurrent theme, especially for the female participants as it is mostly their chore to take care of the daily cleaning and maintaining of the mud floor. A female participant quickly corrected me when I asked if they painted the house once a year saying, "We have to paint more than once. The floor

\footnotetext{
28 The new buildings being regarded as more "permanent" to traditional houses was also observed in
} Ghandruk section (4.3.2). 
has to be maintained almost daily. The walls are painted once a year in Tihar" (Poonam). In addition to the materials collected from the forest, cow dung is also a key building ingredient. The loss of traditional farming method has reduced the cattle size and there is not sufficient dung required for the regular maintenance of the Tharu houses.

Tharu settlements and their lifestyles are intrinsically linked with their land and the farming culture, the remnants are still visible with the cattle sheds, grain storage, bird houses and chickens running around. However, the dichotomy between the traditional and new societal changes is reflected in the physical environment with new houses alongside the traditional cottages and the household chores that were mostly performed in the common courtyards are finding space inside the new houses. The newer houses are mainly brick and concrete structures that also reflect the transition from traditional farming to other professions and the current national trend of migration abroad for work. The Maoist conflict $(1996$ - 2006) displaced families and forced the young to find employment overseas. This migration has impacted on the local landscape in several ways, from shortage of labour to work in the fields to fewer people celebrating festivals and returning migrants' preference of non-Tharu style houses. One of the common investments after their return, is to build a new house. This trend is prevalent among both the Tharu and the non-Tharu as expressed by one participant:

The locals are going abroad, like Dubai or Qatar and when they return, their first priority is to build a house. When they return from working abroad, you can be sure that the first thing they do is to build a house. (Bidur, resident-tourism, guide)

This response indicates a change in building aesthetics that is driven by societal change and globalisation. The expanding opportunity of working abroad has exposed the locals to international influences that are reflected in the choices of building styles and materials as well as their changing lifestyles. There is concern for the impact of this change on tourism,

Slowly, Tharu villages are disappearing. We can hardly find a Tharu village to show to tourists. Because new buildings are coming up everywhere. The traditional houses are gone. (Bidur, resident-tourism, guide) 
This response recognises the value of traditional settlements as part of a tourist attraction. It also indicates that the local population do not share the benefits of tourism, hence are not preserving the traditional settlements to gain from tourism. Although the impact of the loss of the traditional built environment on tourism is not clear from this case, examples in other parts of the world suggest a positive influence of tourism in preserved traditional settlements (Giannakopoulou \& Kaliampakos, 2016). This response also suggests the importance of understanding landscape values in a community context (land to farm) and their participation and benefit sharing in the development process by managers and decision makers. For example, the present building construction trends in Sauraha followed the globalised, homogeneous architecture found all over the subcontinent. There was no particular character to distinguish Sauraha, as one participant observed, "I know this is Sauraha bazaar, but it could be anywhere. Even in the middle of the fields the new buildings are the same" (Bijay, resident-non tourism, museum).

There are some resorts and restaurants using traditional materials and styles. Some participants noted that the success of these hotels may encourage local residents to find a compromise with the new and traditional materials, preserving the exterior while modernising the interior. There were already some examples where one of the participants had recently built a brick house but used the traditional mud colour on the exterior plaster and maintained the low single storey scale of the traditional enclave. However, one Tharu participant preferred the changing building styles saying, "Sauraha was a small village. Now it is a city and colourful" (Laxman, resident-non tourism. farmer). This was echoed by one tourist who observed that although the traditional houses would be the preferred choice for many, the colourful new houses were also attractive as it offered a contrast from her hometown.

\section{I did love seeing these homes. I really like them. I think they are pretty. And it seems funny the difference from Canada. I mean, there would be no way there could be a house like this in Canada. Just the colours. I like that. I think that is fun. (Samantha, tourist, Canada)}

Overall, the common view regarding the recent changes in the landscape of Sauraha was a sense of loss of the traditional settlement and transformation into a ubiquitous urban sprawl of universal cement plastered brick edifices. A participant summarises, 
We have lost our unique Sauraha identity. This buffer zone in Sauraha has been completely destroyed with buildings. The park is still unspoiled. But in the buffer zone, these buildings have made this place ugly. The buildings have destroyed the beauty of this place. (Bidur, resident-tourism, guide).

Overall participants agreed that tourism had contributed to the economy of Sauraha. However, it had also transformed the built environment from the typical Tharu village that it was known for to a non-descript town. This raised some questions about the conservation and management policies of the national park and the on-going in-migration of other communities. As the tourism industry in Nepal was still in a recovery stage at the time of this research, their concern was augmented by the uncertain future, especially with regard to the road construction that was already behind schedule. The participants' responses to the changing landscape was a mixture of positive and negative, optimistic on the changes brought by the recent developments and tourism, at the same time a sense of loss for the past landscape and life.

\subsection{CONCLUSION}

The findings in Sauraha have identified CNP, the farmlands, the Tharu settlements and culture, and the everyday lives as key landscape components of landscape aesthetics, especially for the residents. Tharu culture and the people are an integral part of the landscape of Sauraha and the greater Chitwan region. Although farming methods have evolved, the agricultural fields and the farming culture are still essential in retaining the identity of the Tharu people. The Tharu people and their culture are tied to the land that is presently within CNP, which is also recognised in the UNESCO WHS inscription. The unique location of Sauraha as a buffer zone to CNP and assimilated within the rapidly urbanising municipality of Ratnanagar places the residents of Sauraha in an interesting juxtaposition between the traditional and the modern. The ties to the land reflect their strong attachments to the traditional lifestyle, at the same time, they are embracing the change and adapting themselves as urban citizens. This dichotomy is also present in their relationship with the national park. There is pride from being associated with a successful world-renowned park, but the costs for the indigenous population with regard to their loss of traditional rights and cultural patterns are high. Sauraha and the residents are not immune to societal changes and the modern amenities become part of their landscape. 
For the residents, Sauraha is an everyday landscape, where they work and live with contemporary necessities. This creates a multi-layered relationship between the land and the people that is reflected in their perception of landscape aesthetics that includes the natural (national park), cultural (farmland, village, traditions) as well as the everyday lives. For the residents, their day-to-day life was part of their landscapes and influenced the aesthetic values they placed on their landscapes. At the same time, their history, culture and associated worldview also played a role in their perceptions of landscape aesthetics.

This chapter has identified three key drivers of change in Sauraha: the conservation policies of CNP, urbanisation/globalisation and tourism. The ambivalence and contradictions in the participants' responses with regard to landscape changes reflects the unique location of Sauraha. The conservation policies of CNP have influenced the landscape as well as the indigenous culture. It has also attracted tourism, generating employment, driving local development and improving living conditions. The rapid urbanisation of nearby towns and globalisation are also driving changes in the local culture and society, which is reflected in the standardized architecture in the expanding Sauraha. 


\section{PERCEPTIONS OF LANDSCAPE CHANGE AND LANDSCAPE AESTHETICS}

The preceding three chapters analysed each of the three case study sites and presented the perceptions of the participants on landscape aesthetics and landscape change. This chapter discusses the findings across the three cases to address the overarching research question on how the residents and tourists perceive landscape aesthetics in the changing landscapes of Nepal. The conceptual framework (Figure 2-2) guided the methodological approach and the analytical framework (Figure 3-1) served as a foundation for data analysis and the presentation of findings. The conceptual framework presented the complexities of the dynamic relationship between landscape, change and perception of landscape aesthetics, however, it lacked the specifics of landscape or change (section 2.5). This chapter first revisits the conceptual framework to incorporate the new-found knowledge from the findings and present a more detailed conceptualisation of the interrelationship between landscape, change and perceptions of landscape aesthetics. This chapter then discusses the key themes that have emerged in relation to the drivers of landscape change across the three cases. Next, the key themes are incorporated into the concept of landscape to discuss the values residents and tourists attach to landscape aesthetics before conclusions are drawn.

\subsection{FRAMEWORK FOR LANDSCAPE, CHANGE AND LANDSCAPE AESTHETICS}

The relationship between landscape, change and perceptions of landscape aesthetics is reflected in the conceptual framework (Figure 2-1). Due to the dynamic nature of landscape and the different concepts and approaches to landscape in landscape-tourism studies, it presents an overview of the relationship but lacks details such as the drivers of change, constituents of landscape, and nature of perceptions. The framework provided sufficient structure and information to develop the multi-layered research approach that allowed for a comprehensive investigation of the dynamic relationships. It provided a framework to examine the drivers of change that are transforming the landscapes and landscape aesthetics, from the perspectives of the residents and tourists. It also allowed to examine the role of tourism in transforming landscapes. Based on the empirical 
research and analysis, the original framework has been revisited to incorporate the findings of this study.

Figure 7-1 is based on a revision of the conceptual framework (Figure 2.1) in which landscape, change and tourism were interrelated but separate components. Figure 7.1 now brings these components together and incorporates them within the concept of landscape and landscape aesthetics. In addition to the natural, built and cultural aspects, this framework accommodates the residents and their everyday lives in the landscape, emphasising the role of people in shaping and changing landscapes. The key drivers of change that have emerged in this study (conservation policies, urbanisation/globalisation, and tourism), act upon the landscape both internally and externally. Change is, thus, part of the landscape as well as an external driver that is transforming landscapes. Landscape in totality incorporating the natural, built, cultural and everyday lives as well as change, contributes to the perceptions of landscape aesthetics.

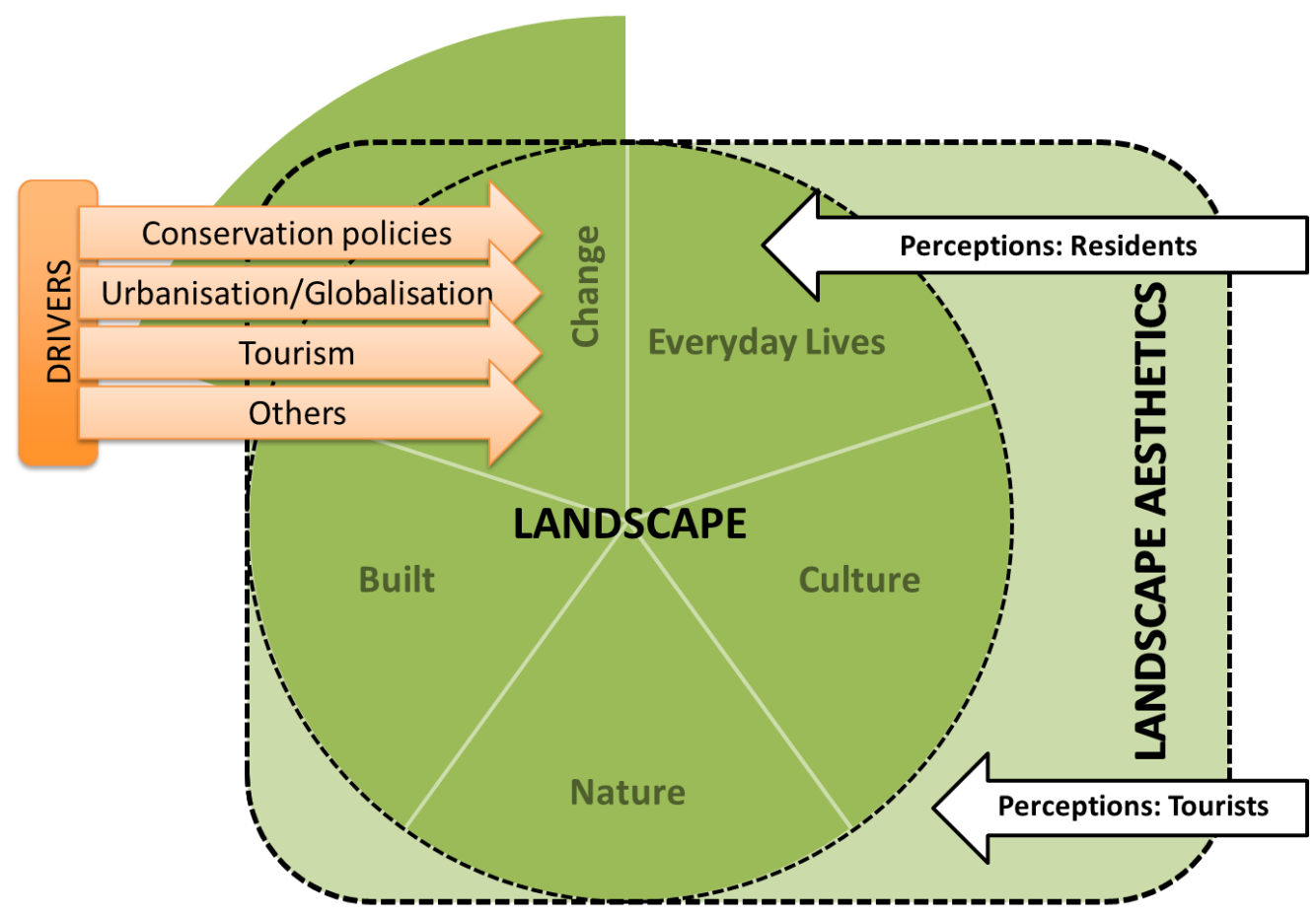

Figure 7-1: Framework for landscape, change and landscape aesthetics

In Figure 7.1, the two main components of the conceptual framework, landscape and change are merged. Landscapes are constantly evolving, hence change becomes a component of the landscape. Change is integrated as a component of landscape yet 
extends beyond to include the external drivers. The three key drivers identified in this research are conservation policies, urbanisation/globalisation and tourism. However, other drivers can be added to the framework, depending on the context. Drivers of change are influenced by external forces such as regional and national politics, international trends as well as internal natural and cultural processes, thus positions within the landscape and extends beyond the landscape. The dotted line incorporating landscape components indicates the dynamic characteristics of nature, culture, built, everyday lives and change as well as the interrelationships and overlaps between them.

The landscape in totality, incorporating change, contributes to perceptions of landscape aesthetics. The residents who live and work in the landscape with their everyday lives, form an important constituent of the overall landscape and landscape aesthetics, and thus, their perceptions incorporate and extend into the landscape. This perception of landscape aesthetics expands Berleant's (2005) concept of emphasising the role of people and Saito's (2007) concept of everyday aesthetics by incorporating change in the landscape and landscape aesthetics (section 2.3). The tourists, on the other hand, are mostly temporary observers and perceive landscape aesthetics externally. However, they are also partly within the landscape as a component of the tourism industry, one of the principal drivers of change. Landscape aesthetics take into consideration the different roles of the residents and tourists as well as the dynamic characteristic of landscape, changing perceptions within the landscape, as represented by the dotted lines in the revised framework.

In considering the wider application of the framework, it is worth noting that it has been developed in relation to small communities and it may not reflect the complexities of larger settings such as cities. The drivers of change could be more complex, both internal and external as well as imbedded as processes rather than components. Nevertheless, the framework attempts to allow for these complexities within the holistic approach to landscape with change extending beyond landscape and landscape aesthetics and incorporating internal and external drivers. In addition to the dotted lines depicting the dynamic nature of landscape and landscape aesthetics, they also indicate that the perceptions of landscape and landscape aesthetics overlap. 
The following sections examine the overall landscape based on the additional aspects that have emerged in the findings. First, the three key drivers of change that are an integral part of the landscape: conservation policies, urbanisation/globalisation, and tourism, are examined. This is followed by the perspectives on the overall landscape that includes the natural, built, and cultural aspects along with the everyday lives and change that contribute to landscape aesthetics. These discussions thus address the overarching research question on the perceptions of residents and tourists regarding the aesthetic values of the changing landscapes in Nepal.

\subsection{DRIVERS OF LANDSCAPE CHANGE}

Change, an essential characteristic of landscape, as explained in the above framework, contributes to the perception of landscape aesthetics. In order to understand the perception of landscape aesthetics, it is essential to understand the underlying drivers of change. Three key drivers of change (conservation policies, urbanisation/globalisation and tourism) that have emerged have been discussed in the broader landscape and tourism literature (Antrop, 2004; Hersperger \& Bürgi, 2009). The finding that landscape, incorporating change and everyday lives, has to be considered holistically to understand landscape aesthetics provides a major contribution to the literature. While previous studies focused on either natural or cultural aspects of change in landscape (Palmer, 2014; A. J. Scott, 2010; Vinge \& Flø, 2015), this study explores the impact of change holistically, with an emphasis on the people living and working in the landscape. This section discusses the three key drivers of change across the three cases and in a wider perspective.

\subsubsection{Conservation policies}

Conservation policies are formulated to preserve and protect natural and cultural resources for the purpose of maintaining their intrinsic values, providing for the wellbeing of the people and safeguarding the options of the future generations. The three case study sites clearly demonstrate that conservation policies have played a key role in shaping landscapes. The physical, cultural and social changes brought by conservation policies have contributed to landscape change. While conservation policies have been in 
effect for a longer period in Ghandruk and Sauraha with varying impact on the landscape, the recent 2016 building guidelines to conserve the architectural heritage in Bandipur are yet to be fully implemented and will be discussed further.

The key factor in the conservation policies that are changing landscapes is their focus on either natural or cultural components of the landscape that have consequences on the other. Recent planning approaches have attempted to address this nature-culture divide with an emphasis on local participation in decision making process and benefit distribution (Frost \& Hall, 2012; Spiteri \& SK Nepal, 2008). While there have been attempts by site managers and researchers to integrate the components, the focus tends to be on the philosophy of the lead agency (Han, 2006; Thing et al., 2017). For example, in the case of Sauraha, the conservation policies of Chitwan National Park (CNP) are focussed on biodiversity conservation. Conservation of built and intangible cultural heritage is limited to maintenance of the few temples and religious sites, providing some financial support for cultural activities such as festivals, training, and supporting the museum activities (section 6.3.1). There is a lack of deeper understanding of the built landscape, cultural aspects and the needs of the local communities. The focus of the conservation policies on biodiversity overshadows other aspects of the landscape and the policies are developed through the lens of nature conservation. This reflects international trends and conservation practices that focus on the conservation of the ecosystem and biodiversity and overlook the cultural conventions of the people living within the area and their historic dependence on the forest resources (Guha, 1997). In addition to creating conflicts between the park management and the residents, such policies change traditional landscapes that depend on natural resources breaking the continuity with the land (Cochrane, 2012; Eagles \& McCool, 2002; K. B. B. Ghimire \& Pimbert, 2009).

The traditional architecture of Sauraha and Ghandruk is heavily dependent on natural resources such as timber and stone. The conservation policies that restrict access to forest resources, such as timber and stone, that are crucial to maintaining the traditional houses have undermined the built landscape, resulting in the loss of their distinct character. These restrictions require residents to seek alternative building materials, thus changing the settlement style and pattern as well as lifestyles. The Tharu houses in Sauraha are constructed of plants that need to be harvested in specific seasons. The CNP conservation policies restrict the local community to collecting the materials within a specified week, 
which is insufficient to gather the amount needed for repairs or new construction. In addition, the collection time may not be ideal for harvesting for building purposes. This discourages the construction of traditional houses and is a hindrance to maintaining them. This thesis is not arguing for complete access and continuation of traditional practices to conserve the built landscape, rather it is highlighting that current conservation policies have costs that go beyond the visual aesthetics of conserving the built landscape. Traditional architecture and settlements evolved from layers of historic development, local culture and traditions and are important aspects of local identity, as demonstrated in all three cases. The natural materials sourced from the land strengthen the attachment with the land, while the settlement pattern evolved from the farming culture and adapted to the traditional community lifestyles. The change in traditional buildings and settlement patterns undermines the identity of local communities, weakening their links to the landscape. Existing literature has not adequately addressed the linkage between the natural landscape, built environment and the cultural ties that this current research has highlighted.

Natural landscapes or national parks with human settlements are rare in the western context and the prevailing policies and models fail to consider the complexities of local communities' dependence on forest resources. European rural or agricultural landscapes are the closest comparison, where the natural landscape is mostly farmlands with villages or scattered farmhouses with clear separations from the forested areas and strong connections between the farmlands and villages (farmers) with the management mainly in the hands of the landowners (Swanwick, 2009). Unlike the protected areas that are created to conserve biodiversity, the farms are mainly cultivated and planning decisions mainly concern the extension of natural (woodland) boundaries and environment or agricultural plans (Swanwick, 2002). In contrast, the policies in Sauraha were formulated specifically to protect the natural environment for biodiversity conservation with little consideration or capability of incorporating the complex cultural aspects of landscapes. This has relegated the built, cultural and everyday aspects of the landscape with a potential displacement of the original community as evident in Sauraha with the decrease in traditional settlements. Unlike in the west, the implementing institutions and mechanisms are also weak and that further exacerbates the situation, as evidenced in 
Sauraha during the Maoist conflicts (1996-2006) when building guidelines were flouted (section 6.3).

Another factor in conservation policies that changes landscapes is the prevailing zoning systems. Zoning is a widely used tool in land use and city planning as well as resource management and wilderness recreation, such as Recreational Opportunity Spectrum and Tourism Opportunity Spectrum (Butler \& Waldbrook, 2003). However, these frameworks are mainly used for recreational experiences that assume a homogeneous community and fail to capture the complexities of the interrelations and overlaps in traditional landscapes and the range of values held by the residents of that landscape. In traditional landscapes, the distinctions between the natural, built and cultural components are seldom clear with interdependence and overlaps (Berleant, 2005a). This creates tensions between management and local communities, as demonstrated in all three cases.

In Sauraha, CNP implements strict conservation criteria within the core with allowances for change and development in the buffer zones. The buffer zone was the outcome of the shift in policies to include the people in park management (section 6.1.3). However, the biodiversity-focused conservation policies have failed to adequately address the issues of the built and cultural components of the landscape, especially regarding the adjoining villages such as Sauraha that is demarcated as an Intensive Use Zone. The cultural and vernacular characteristics of Sauraha are not taken into consideration in the concept and guidelines for the Intensive Use Zone that allow high density built-up and land uses that are detrimental to the local distinctive character. This undermines the importance of vernacular architecture in landscapes that are predominately natural. It is also a reflection of the problematic concept of buffer zones. Sauraha is part of a complex and dynamic spatial, social and temporal landscape where people live and work. The delineation perpetuates a piecemeal approach to conservation and management ignoring the organic linkages between the different components of landscape. A parallel can be drawn with the Hoi An case study where extensive development in the buffer zone is overshadowing the historic core (Avieli, 2015). The indigenous Tharu community in Sauraha has been pushed further from the core with external investors and in-migrate population dominating the Tharu people. In addition, Ratnanagar municipality (that Sauraha is part of), is also in its infancy and focussed on infrastructure, agriculture, trade, industrial and economic development. Although tourism is the driving economic force in Sauraha, the 
proximity to the highway, flat terrain and well-developed transportation links make it attractive to alternative industries. The potential of Chitwan as an industrial and agricultural region overshadows the cultural aspects of Sauraha with the migrant population increasingly dominating and homogenising the indigenous Tharu population and culture. The intensive use also allows for mass tourism and related infrastructure such as larger bars and casinos that may further transform the landscape of Sauraha.

The community-based conservation policies of the Annapurna Conservation Area Project (ACAP) in Ghandruk have conserved biodiversity and raised awareness of its importance, and at the same time provided economic opportunities through tourism promotion. However, this has also increased land abandonment and decreased interest in farming (section 4.3). The conservation policies have increased forested land and the aesthetic appeal, boosting tourism. However, the residents are concerned about the loss of farming and increase of wild animals destroying crops due to the increase in forested areas. The conservation policies emphasising the natural landscape and biodiversity have resulted in the loss of the cultural landscape of terraced farming. Again, attention to the built landscape is lacking and there are no specific guidelines with the conservation policies restricting the collection of local timber needed for traditional construction. In contrast to Sauraha, the high level of local participation in the conservation process adopted by ACAP has slowed outside investments limiting building activities and drastic landscape change. This is also due to the strong presence and history of the Gurung community and the lack of road connection until recently. The impact of the new road is discussed in the next section.

In contrast to Ghandruk and Sauraha, the designation of the bazaar as a preserved zone has highlighted the significance of the built landscape in Bandipur. However, the conservation policies are limited in scope (general adoption of national building and town planning guidelines) and capabilities (technical and financial) for implementation. The preserved zone includes the 500 metres of land surrounding the main bazaar independent of the characteristics of the surrounding landscape. This delineation has neglected the importance of the surrounding landscape (terraced farming, forests) and focuses solely on the built landscape. The location of the bazaar on the ridge of the hill is one of the defining features with the surrounding landscape giving the bazaar its distinct characteristic. The location, settlement pattern and architecture reflect the traditional 
Newar town planning of Kathmandu Valley that has been adapted to the local context (use of slate for roofing, covered passage). The settlement is a testimony to the land use patterns of the Newars with compact settlements on high ground and intensive farming in lower fertile lands (section 5.1.2). The surrounding farmlands reflect the history and the culture of the people of Bandipur. The separation and focus on the built landscape risk the loss of the terraced farms and farming culture.

With limited guidelines, there is also a risk of extensive building activities in the surrounding areas that would have implications in the preserved zone that depends on tourism. The focus on limited built characteristics of the bazaar disregarding the social dimensions create conflicts between the local authority and the residents. The uncontrolled growth without due consideration to the historical, natural, and cultural aspects of the landscape will decrease the potential of tourism in Bandipur as a cultural destination. This follows the example of Hoi An WHS, where the transformation was more rapid in the buffer zone with extensive growth that was allowed in order to divert development from the core and accommodate the increasing number of tourists (Avieli, 2015). Generally, the buffer zones immediately bordering the core often share features and linkages that the rapid rate and scale of growth severs, subsequently changing the overall landscape. The lack of an overall perspective of landscapes and prioritisation of selected features undermines their holistic character and distinctiveness. The significance of the surrounding landscape and the impact of development on the periphery affecting heritage sites is acknowledged by transnational agencies such as UNESCO. For example, Dresden was delisted as a WHS because of the potential visual impact of a new bridge on the heritage site, a development that was supported by the residents (Albert \& Gaillard, 2014). This indicates the importance of the residents' perception of the landscape that includes their everyday lives and is discussed further in the next section.

In most cases, conservation policies treat natural, built and cultural landscape separately, which have consequences on the other. For example, conservation policies designed to protect the natural environment may have consequences for the built and cultural landscape that depends on the natural resources. The conservation of nature developed from the concepts of preserving the wilderness for recreational purposes and has recently expanded to include the social aspects of people and culture (Frost \& Hall, 2012). Similarly, the conservation of built heritage evolved mainly to conserve art objects and 
immovable heritage as monuments and heritage sites and has recently started to include the intangible culture. The inclusion of intangible culture within the broad concept of landscape is still in its early developmental stages and not much understood. This research has demonstrated the role of conservation policies in changing landscapes and the need to consider landscape in totality incorporating its multiple aspects while developing such policies.

\subsubsection{Urbanisation and globalisation}

Urbanisation, with the development of infrastructure, is the second key driver of landscape change, especially with the construction of roads in formerly remote areas, as demonstrated in Ghandruk. The needs and rights of the people living in remote areas to proper access to transportation-related infrastructure are undeniable. The fundamental rights of people to health, education and economic opportunities are also valid. However, this creates tensions and conflicts in remote communities or conserved areas between the residents and the authorities with regard to development and conservation, as in the case of Ghandruk. In Bandipur and Sauraha, ease of accessibility is increasing land value and development pressure, with risks of rapid urbanisation and loss of distinct characteristics. In addition, globalisation has provided opportunities with the youth migrating abroad for work and returning home influenced by global trends. This phenomenon is present in all cases and will be further discussed.

Convenient transportation is essential to development and road connection is taken as a primary requirement. Roads are seen as the connector between the urban (developed) and rural (undeveloped) divides. The rural communities look at roads as a vehicle to reach the infrastructure (health, education, employment, market) that is not readily available in rural areas. For the urban communities, roads to the rural locations open up possibilities of economic and recreational opportunities. This exchange becomes a driver of change in both directions, however, the impact is magnified in rural communities due to its smaller scale. The urban areas would be able to absorb small changes, whereas small changes would be more visible in rural communities. This generally results in rural areas urbanising and absorbing urban characteristics. Existing literature has demonstrated the 
impact of the rural-to-urban change on local communities (Gkoltsiou \& Terkenli, 2012; Gkoltsiou et al., 2013; Hussain et al., 2017; SK Nepal \& Jamal, 2011).

The pace and scale of change in Ghandruk compared to Sauraha and Bandipur illustrates the impact of landscape change driven by road connection. The remote location of Ghandruk and its accessibility limited to foot trails and manual transportation added higher costs to the import of external materials. The mountainous terrain also limits largescale production of construction materials. Building the road that links Ghandruk to the national highway has opened its reach and network that was previously limited to walking distances to a wider region. The opening of roads makes transportation of industrialised materials to remote locations expedient and increases the pace of change. When this is compounded by the scarcity of materials due to conservation policies discussed above (section 7.2.1), the attraction of the newer materials increases. The road to Ghandruk is still incomplete (unpaved), however visible changes are observed in the landscape (section 4.3).

In Ghandruk, the road is facilitating the import of new building materials such as cement, rods, tin roofs and aluminium windows. These materials are easily available, while the procurement of stones and timber for traditional houses is a lengthy process with permission required from ACAP. After permission is granted, it is up to the owner to arrange for the felling of trees, mining for stones and transporting the materials. The forest areas where it is allowed to cut trees are generally further up the hills and the stone mines are also away from the villages. This increases the costs of preparation and transportation of the traditional materials, a deterrent for the residents. The out-migration and decrease in population has resulted in labour scarcity, compounding the deterrents to build with traditional materials. In addition, the construction of the road has caused landslides degrading the forest cover and making the hills barren. The unpaved road in the hilly terrain will continue to be subjected to landslides and landscape degradation with annual monsoon rains (Plate 7-1). 


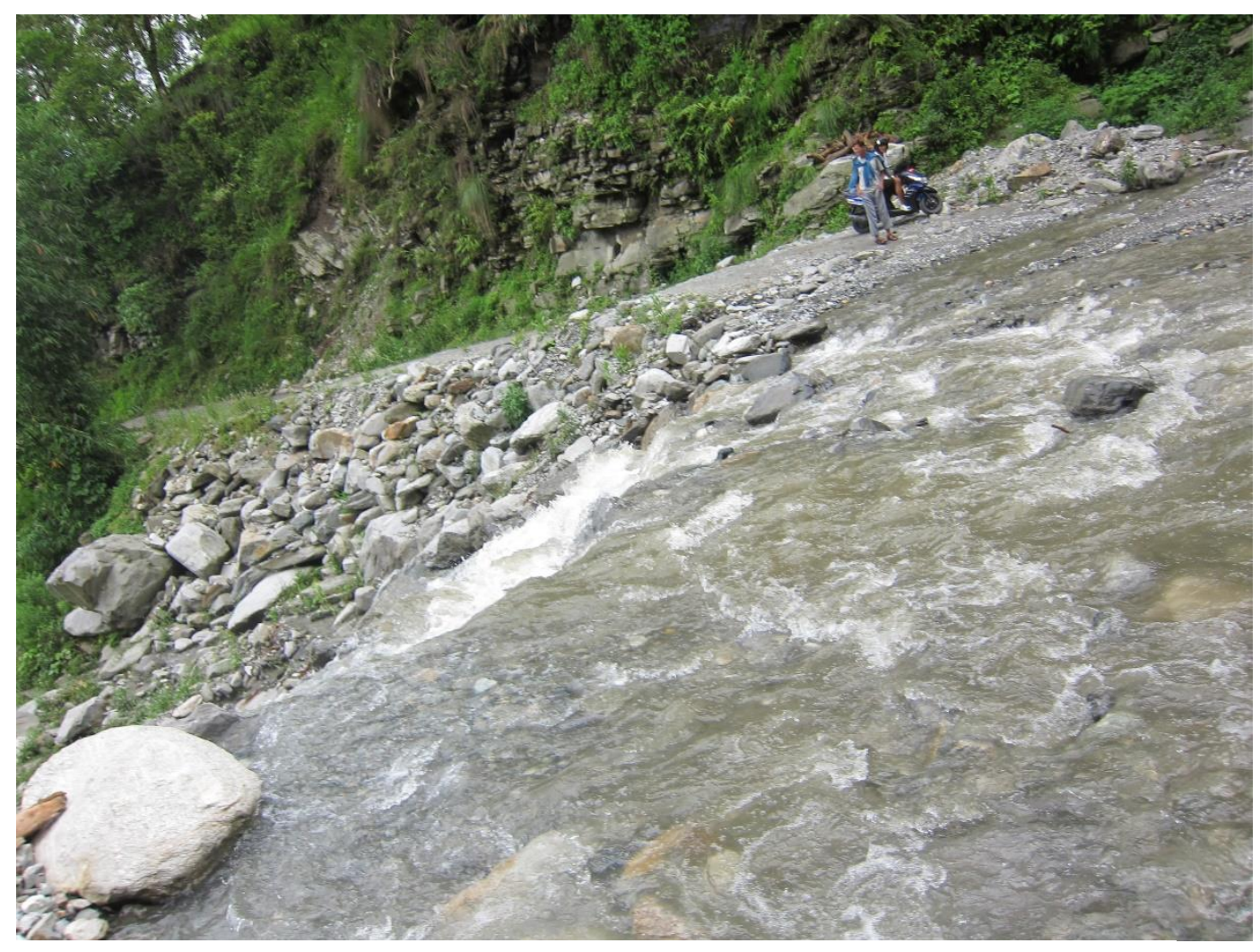

Plate 7-1: Unpaved new road near Kimchi that is flooded in the monsoon seasons

Photo: JJoshi, 2016

Change in the built landscape of Sauraha, with its flat terrain and convenient road network, has been drastic (section 6.3), while Bandipur located in the low hills but well connected to the national highway is seeing moderate changes (section 5.3). In the cases of Ghandruk and Bandipur, where the potential for alternative industries is limited due to their location, the change in the distinctive built landscape could have severe consequences. Local vernacular architecture evolved from locally made or available materials and is adapted to accommodate the climatic conditions producing a distinct character. Locally made and sourced materials are also produced manually, which increases costs and time for preparation, but provides a unique vernacular landscape. In contrast, industrially produced materials are economical and can be transported in larger quantities. In Ghandruk and Bandipur, the distinct settlement pattern, built landscape and culture are important components of the landscape and valuable resources for the community. With limited alternative development potential, tourism plays a significant role in the local economy. 
One of the major changes in the Ghandruk landscape as the result of the road is the growth of settlement clusters at the major bus stops. This phenomenon was also evident in previous studies in Nepal, where road construction opened up new settlements or gateway communities (H. Gurung, 2004; Messerschmidt, 1980). The current terminus at Kimchi, which originally had a few scattered houses among the farmed terraces, is growing with hastily constructed huts to take advantage of arriving and departing tourists and residents. The road to reach the main centre of Ghandruk, where the local government offices, hospital and schools are located, is under construction. The difficult terrain with constant landslides that threaten the villages below is slowing the progress. However, the road to Kimchi has already reduced the travel time between the highway and the main centre of Ghandruk to an hour. In addition to the physical travel time, the perceived distance to the highway and towns beyond has also been reduced with the advance of telecommunication technologies. A telephone call is sufficient to order materials that will be delivered at the door on the next available transport. For a community that has been struggling and transporting goods manually, this simple tool is revolutionary. This cuts time and labour of transportation that can be applied to other activities. The connection to the wider region also increases the options of materials beyond the traditional local materials such as stone and timber. These multiple options become an attraction adding prestige and attraction to the new materials.

Roads are two-directional, and the importation of goods should theoretically also mean the export of local materials. However, there was no evidence of an increase in the export of local produce or materials with access to a wider market, in the case of Bandipur. The national highway that linked Kathmandu to Pokhara decreased the importance of trade in Bandipur that resulted in its downfall (section 5.1.1). Although Bandipur was linked to the highway, the road was one-directional bringing goods to Bandipur without any export from Bandipur. The road link only served as a transportation link and did not contribute to the local economy. The road, however, facilitated the out-migration of the residents to establish new highway towns, similar to the recent growth of Kimchi in Ghandruk. The migration decreased the population and investment in Bandipur, accelerating the abandonment process resulting in declining property value. The convenience of the road linkage facilitated the decline of Bandipur as a trading town rather than contributing to its development. This desertion and reduced property value 
due to the lack of economic opportunities, however, prevented the demolition of the traditional houses that have been revived through recent tourism potential (section 5.3).

The present scenario in Ghandruk, where the road is importing goods and changing the landscape also has the potential to deter economic development and to impact on tourism. Apart from subsistence farming, the economy of Ghandruk depends heavily on tourism. Most international tourists are trekkers stopping for a night on their way to or from Annapurna Base Camp or the Annapurna trek. Ghandruk, one of the starting points of the Annapurna trek was a day's hike from the highway town, Birethanti. The new road has shortened the trek to an hour. Apart from the reduction in time, most parts of the new road were built by widening the original foot trail. This is unpleasant for the tourists who still prefer to hike and may discourage them further when traffic on this road increases. Tourists taking motor transport to Ghandruk have the option to move on to the next village with just a short lunch break in Ghandruk. The smaller villages on the trail between Birethanti and Ghandruk have already experienced a decrease in tourists with few businesses remaining.

On the other hand, the road and a shorter hike to reach Ghandruk is now attracting domestic and Asian tourists. The destination for the domestic market is usually Ghandruk without further hiking and they are interested in the local culture, especially food. The natural landscape becomes a setting to experience Gurung culture. The domestic tourists have opportunities to view the Himalayas in daily life and thus culture becomes more important than the natural landscape. As the motivation of this new group of tourists is relaxation and recreation rather than trekking, the expectations with regard to accommodation and activities during the stay are different. The traditional international trekkers are only concerned about the bed for a night, dinner on arrival and breakfast before departure. However, those who make Ghandruk their sole destination may spend more nights and expect a more comfortable stay with additional activities in the village. This trend is driving change in the building type that is comprised of simple and basic rooms (mostly with separate bathroom but increasingly with attached bathrooms) and a common dining area to more spacious rooms with comfortable beds and ensuite bathrooms. The growth of domestic and Asian tourists is also increasing the demand for larger structures to accommodate the growing numbers, where traditional houses are one to two-storeyed family homes. Studies have shown the cross-cultural differences in travel 
culture and preferences with urban dwellers and Asian countries seeking relaxation and comfort (Burch, 1969; Han, 2006). This difference and its potential implications for the landscape is vital for the future direction of tourism development.

Globalisation and technological advances have made communication and movement easier and within reach of a wider population. One of its impacts on the economy of Nepal is the migration of youth abroad for work. While this trend is bringing remittances into the national and local economy, it is also decreasing labour in the local markets. The other impact of this economic migration on the landscape is the trend of updating or building new houses on their return from work abroad. This is a trend that has transformed landscapes around the country, including Sauraha, Bandipur and Ghandruk. The returning work migrants are influenced by their experience of a different country and lifestyle, which is manifested in their investments at home in the form of new houses. As most work migrants are low-skilled workers with limited education, their options for alternative investments are limited. In addition, this trend is also guided by cultural conventions that have been set by earlier returning migrants. New buildings become a symbol of the change in status, adding more decorations or storeys to compete with their neighbours. This follows existing literature on the attitudes of residents towards landscape aesthetics as depending on several factors such as age, social groups, social and economic status and ethnic origins (Kaltenborn \& Bjerke, 2002; Swanwick, 2009). For this group, the traditional styles become irrelevant or even an image that should be rejected in order to demonstrate their new standing in the society. Migration is driving change in the social structure, which in turn is transforming the built landscape. In Ghandruk, the original investments in tourism were initiated by returning Gurkha soldiers. With lifetime pensions and early retirement, the former soldiers were in advantageous positions within the village with experience and knowledge of foreigners. However, the recent change in British policy allowing Gurkha soldiers to remain in the U.K. may decrease the number of returnees and their investments. With the current restrictions on external investments, this decrease in Gurkha investment may result in Ghandruk lagging behind similar destinations offering more facilities. 


\subsubsection{Tourism and the local economy}

All three case studies depend to some extent on tourism and the findings in the three cases clearly demonstrate the importance of employment opportunities generated from it for the local economy. Economic and employment opportunities are vital for the sustained growth of a place. Employment opportunities facilitate the growth of the town and hence change becomes inevitable. The increase in employment and economic opportunities attracts investors and potential migrants as demonstrated in the cases of Bandipur and Sauraha. This increase may put demands on the limited resources of the village, such as water resources. Without proper planning and monitoring the potential economic growth causes strain in the local infrastructure and may transform the village arbitrarily as in the case of Sauraha.

For Ghandruk and Sauraha, the conservation area and the national park are tourist attractions and hence, have economic potential. As an emerging cultural destination, Bandipur is also gaining popularity in the domestic and international markets. Sauraha and Bandipur are attracting external investors, while Ghandruk has unofficially restricted external investors. This has restricted big investments or star hotels from entering the market and compete with the residents, controlling the growth of large properties and unfair competition, however, limiting the growth of tourism (section 4.3). In Nepal, economic growth that had declined during the Maoist conflicts has revitalized since the peace agreement in 2006 and the recent political stability. This has accelerated the need for development and employment opportunities, with tourism identified as a major industry, which in turn is transforming the landscape. In Bandipur and Sauraha, external investors are building larger structures that are not conforming to the traditional built landscape. The external investments are guided by the markets as they are investing substantially in having to purchase land, which increases investment and risks. They are also guided by the universal trends in building styles and technologies independent of the vernacular styles. When there is a lack of strict enforcement of building regulations, the change tends to be drastic as in the case of Sauraha, with concerns in Bandipur with the limited scope of the preserved zone. Weak legislature in conservation of landscapes combined with the pressing demands of health, education and budget restrictions, 
compounded by policies targeted at promoting tourism, are widespread in developing countries (Avieli, 2015; Harrison \& Hitchcock, 2005; Joshi, 2014; Orbasli, 2000).

The preserved zone in Bandipur, focussed on the bazaar, is the result of the economic potential in preserving the built landscape to attract tourism. The residents of the bazaar are fully aware of this potential and are profiting from tourism growth. The houses that were abandoned for lack of economic potential have increased substantially in value, especially in and around the bazaar. There is a growing interest in building restoration following several successful projects that are attracting high-end tourists. This economic potential will ensure the restoration and maintenance of the bazaar as long as tourism growth continues. Unlike Ghandruk and Sauraha, where the national park and conservation area are gazetted and protected by national laws, the preserved zone in Bandipur is a local declaration with limited authority and regulations (section 5.1.3). Tourism growth has been organic, mostly helped by individual or external organisations. With an increasing number of hotels, homestays and lodges and lack of monitoring and scientific research, patterns and directions of tourism are unknown. As demonstrated in Ghandruk and Sauraha, changes intensified during the Maoists conflict when the management and implementation mechanics had weakened (sections 4.3 and 6.3). This reinforces the importance of planning and conservation policies that take into consideration the multiple aspects of landscapes, especially the relationship between the landscape and the people (Berleant, 2005a).

In Bandipur, the success is attracting residents, returning residents and external investors to capitalize on the present trend and build bigger structures in the periphery of the protected zone. This has two main impacts. The first is the visual impact of the settlement. The view of the bazaar from the surrounding hilltops is one of the highlights of visiting Bandipur. This view is changing with the new structures becoming increasingly more visible and dominating the bazaar and surroundings that once were predominantly agricultural terraces. Currently the change is visible only to the returning visitors, however, the continued change would make the view from the hilltops redundant.

The second impact is the economic consequence of the first (visible changes) with the potential loss of tourism. There is already some tension between the businesses in the bazaar where growth is restricted and the periphery where the limitations of the protected 
zone do not apply. With growing domestic and Asian markets, as discussed in the above section, there is a need to accommodate increasing numbers of tourists in Bandipur. With limited scope for expansion in the bazaar, investors are building bigger structures in the periphery where the restrictions of the conservation policies do not apply. The continued and uncontrolled growth would urbanise and transform Bandipur putting its attraction as a cultural destination in danger.

In Bandipur, the preservation of the bazaar is built on the premise of its attraction as a tourist destination and driven by the economic gains. There is low awareness of the historical, cultural and aesthetic value of the bazaar among the local communities. This is reflected in the new buildings adopting non-vernacular styles that are in contrast to the traditional buildings. There is also low awareness of the visual impact of the larger setting looking at the entire village as one entity with tourism potential beyond the bazaar. This low awareness of the historical, cultural, architectural and aesthetic values drives new construction to adopt new materials and styles. The new constructions follow current trends, becoming cultural conventions that give rise to a newness value disregarding the local context as also demonstrated in new houses built by returning migrant workers in Sauraha (section 6.3). In other words, new materials and styles reflecting the social conventions and change in economic status add a newness value to landscape aesthetics. This confirms earlier studies on preference and attitudes towards landscape aesthetics that depend on a wide range of factors such as age, social and economic status, familiarity and place of upbringing and residence (Kaltenborn \& Bjerke, 2002; Swanwick, 2009).

This trend is also a reflection of the reach and perceptions of benefit sharing from tourism. There are wider benefits with increasing investments in the infrastructure due to the gain in economic activities induced by tourism and tourism levies as in the cases of Ghandruk and Sauraha. Tourism also supports wider economic growth through employment and demand for supporting products and services, such as food production. While the community-based ACAP management in Ghandruk has local support, lack of community involvement in the decision-making process has resulted in low appreciation and knowledge of the wider implication of tourism growth in Bandipur and Sauraha. The residents on the periphery generally perceive the businesses in the centre as profiting directly from tourism and fail to understand the indirect gains to the overall development. However, tourism benefit has not been perceived as equitable and fair, especially in the 
peripheral and marginalised communities that follow previous study on ecotourism in Sauraha (Bookbinder, Dinerstein, Rijal, Cauley, \& Rajouria, 1998) and benefits of integrated conservation and development project in Ghandruk (Schuett et al., 2016). Studies on the impact of privately owned ecotourism enterprises in Chitwan have also shown minimal benefits to the local economy to the point of being exploitive (Bookbinder et al., 1998; Dinerstein, 2003a).

The restriction on external investment in Ghandruk has managed to control building growth. As discussed above, the remote location and transportation limitations have also restricted economic opportunities in Ghandruk. In addition, unlike Bandipur and Sauraha that have good basic education facilities in the village and easy access to additional facilities nearby, Ghandruk lacks such facilities and this reduces investors' interest. This is also detrimental to the residents who have to migrate to provide quality education for their children, and also deters retaining local youth or returning residents. Although the potential of tourism is good with a well-established reputation, the growth in Ghandruk is limited by the lack of supporting infrastructure.

The potential consequences of tourism on landscapes could extend beyond the physical degradation to a loss in tourism revenue affecting the natural resources that tourism depends on. The uncontrolled noise and lighting could drive the wildlife away toward less inhabited areas shifting tourism to parts where there is the higher potential of wildlife viewing, the main activity of tourists in Sauraha. Intensive urbanisation would also bring social and cultural change that would put the local Tharu culture of Sauraha in danger. A population shift with increasing migrant population and decreasing Tharu population would diminish the other (cultural) aspects and attractions of the national park (section $6.3)$.

Cultures are defined by the people, however, there is a risk of tourism turning people into products. In a narrow definition and promotion of culture, tourism expects the locals to "perform" for the tourists. The locals become part of the product, such as village tours and cultural programmes in Sauraha. While the tour company profits from the tours, the benefit for the villagers is limited to voluntary gratuity or purchasing small souvenirs. The cultural shows performed for the tourists are usually traditional and folk dances and songs that are performed during celebrations and festivals. When performed outside of 
their specified days, they lose their significance and authenticity and are reduced to mere songs and dances, as evident in the earlier study in Bali, Indonesia (Wall, 1998). In more conservative cultures the people, especially the women, are at the risk of exploitation by the industry and ostracised by their community.

There are economic gains for both the industry and the people from this activity and these could be beneficial both for the individuals and the community. Cultural performance and events are indications of a vibrant place and community. Event tourism is growing worldwide, and annual cultural events are effective tools to boost tourism in the off-peak seasons. It is attracting professionals and entrepreneurs to what was previously mainly the realm of individual and community initiatives (Getz \& Page, 2016). These events can showcase the local culture and opportunities for cultural exchanges. Cultural performances can also be a tool for local empowerment. The focus on the local perspective to preserve and promote culture serves the dual purpose of preserving the culture and promoting it to the next generation. The Tharu Cultural Museum and Research Centre is a platform to showcase Tharu culture to the world as well as preserve it for the coming generations.

The Mothers' Group in Ghandruk is a good example of using cultural performances to empower women and contribute to local development. The Mothers' Groups utilise the funds raised by performing for the tourists on various community works, such as maintaining the stone trails. This programme is an extension of the traditional Gurung culture of women getting together to perform for different celebrations when the hosts invite them to perform and pay in kind (usually food) or cash. This practice has been extended to perform for the tourists to showcase their culture. These exclusive women groups organise themselves, providing training and managing the funds. This direct involvement ensures their active participation and investment in the planning process of local development. Culture becomes an integral part of local development and is not limited to performing for the tourists, which may have negative insinuations. Social benefits and tourism revenue sharing have been seen as incentives for conservation (Spiteri \& SK Nepal, 2008). 


\subsubsection{Changing landscapes}

In summary, the three key drivers identified that are changing landscapes reflect global trends. Firstly, recreation and ecology-based conservation policies are evolving to take into consideration built and cultural landscapes as well as the people. This change is transforming landscapes in different ways. While the community-based conservation policies have raised awareness and contributed to landscape conservation, economic gain-driven policies have hastened urbanisation and landscape change.

Secondly, urbanisation and globalisation, especially through road and transportation development are also changing the landscape. Road development is importing new building materials and styles and changing landscape. On the other hand, it is also facilitating out-migration with returning economic migrants preferring new building styles that reflect their changed status. Thirdly, the economic potential due to tourism development is undeniable in all three sites. However, the possibilities also have the potential to drive business competition to build bigger to accommodate new types of tourists. In addition to employment, availability of health and education facilities is also required to sustain a population and place. Economic potential without the availability of accompanying health and education facilities will not be able to sustain growth. To attract a wider range of investors and employees, support that includes health and educational facilities become important.

Three key drivers have been identified in this research, however, there may be additional drivers in other landscapes (Figure 7.1). Identifying the drivers of change will assist in the policies and strategies to manage or direct change. It would also help in defining aesthetic values of the landscape that is acceptable and satisfy the criteria of the different components of landscape; the natural setting, the built environment and social aesthetics of the people. The balance achieved by addressing the multiple components of aesthetic values will ensure the sustainability of the natural, cultural and local economy.

\subsection{DEFINING LANDSCAPE AESTHETICS}

This section follows the discussions on the key drivers of change to work towards defining landscape aesthetics from the perceptions of the residents and tourists. 
Perception of landscape aesthetics is bound by cultural, historical and social context. It goes beyond art and beauty and is inherently connected to life experiences. This section discusses the different aspects of the landscape in order to address the research question on residents and tourists' perception of landscape aesthetics.

Three key topics emerged that were important in how residents and tourists perceived landscape aesthetics: attachments to the land that connects to the past (natural, built, cultural), everyday lives in the present, and change that directs the future. Various studies have established that the world views of people influence their perceptions, including the perceptions of the landscape. Hence, how people view their landscape becomes important for landscape change. This section discusses landscape and landscape aesthetics from the perspectives of the residents and the tourists.

\subsubsection{Attachments with the land (natural, built and cultural)}

For the residents, the findings across the three case study sites clearly demonstrated that the land as their home was most significant in defining their perception of both the landscape and landscape aesthetics. For them, landscape is inseparable from the home and the land, signifying that both physical and cultural aspects of the landscape are interconnected. Their relationship with the land as well as with other people defines their landscape. The distinctions between the natural and the built components are not always clear, but attachments transcend the physical features that become parts of their socially charged landscapes. It is both the physical features (natural and built) and a sense of being at home with the various relationships and attachments (cultural) that define the landscape (Relph, 1976; Tuan, 1974).

The place as home with stories and memories to share evoke a sense of belonging. The memories are attached to both the physical features and social connections. Familial ties and social networks are foremost among these memories. Attachments are also tied with physical spaces and events that reflect intimate personal connection, for example, time spent with friends and families at temples or squares where festivals are held, or times spent in forests and rivers with friends. The festivals and rituals are often tied to the land, such as the Tharu festivals in Sauraha. The festivals celebrate the harvests with rituals and feasts linked to the harvest. The festivals evoke images of the land and the harvests 
evoke images of the celebrations. These strong cultural ties to the landscape confirm other studies where landscape aesthetics are linked to the utilitarian aspects of the landscape along with spirituality, recreation, social space, myths and legends, religious spaces and places for celebration (Jackson, 1995; Tekken et al., 2017).

The memories and the relationship with the people converge with the landscape. Places that one has memorable experiences of childhood or life spent bring nostalgic memories and make a landscape aesthetically pleasing. Nostalgia tends to be associated with childhood friends, activities and festivals. Familiarity with the place and the people also evokes a sense of safety and security. Hence, the distinction between place and landscape is blurred for the residents with landscape aesthetics encompassing a range of relationships such as sense of place, sense of ownership, cultural ties, family ties, memories and nostalgia along with the physical spaces (Jackson, 1995).

History and culture have profound significance in the perceptions of the landscape, especially for the indigenous communities with strong ties to the land. It defines them and their land converging their identities with the landscape. In this, they are part of the landscape and this is evident in all cases. The assertion that Gurung culture is unique and defines the village (section 4.2), the built heritage in Bandipur reflects their culture (section 5.2) and that Tharu culture defines the region in Sauraha (section 6.2) indicate the importance of landscapes in shaping cultures. Their identities derive from the place and even when they migrate to another town their relationships and strong attachments remain. This is evident in Bandipur, where those who left after the town lost its prominence as a trading centre still retained their cultural ties and properties, hence preserving the built landscape. This tie has also led to the former residents returning to invest in Bandipur. Similarly, in Ghandruk, residents continue to maintain their roots, returning to celebrate major festivals with family and invest in tourism businesses. This confirms the role of historical context in the perception of landscape aesthetics.

The cultural convention of scenic landscape that includes the natural and built is present in all three sites investigated. It is especially present in Ghandruk and Bandipur, where the main motivation of tourists is to enjoy the scenic views. For the residents, the scenic views also become elements of landscape aesthetics. The scenic view provides them with a sense of pride and ownership. The fact that tourists from all over the world place value 
on the beauty of the natural surroundings increases its importance and aesthetic values. They may not pay great attention to the visual aesthetics of the landscape as, living in the landscape, they place themselves as part of it. The appreciation of the landscape by the outsiders raises awareness of the visual impact and its significance. This demonstrates the importance of tourists' perspectives in shaping the residents' perceptions of landscape aesthetics. Their perspectives become more important where the local economy is heavily dependent on tourism, especially when the landscape is the major attraction.

Unaware of the history of the land, the tourists view the landscape in the present-day context. In the cases of Ghandruk and Bandipur, the visual aesthetic of the natural landscape in high mountains are often dominating in scale and visual impact, which according to Urry (2002), is the fundamental tourist gaze. The abandoned terraces naturally overgrown become visually pleasing, providing a sense of pristine nature and higher aesthetic appeal. The evolution of travelling for recreation in exotic places has focused on the scenic values of the landscape to promote the destination. Thus, a cultural convention has been ingrained, especially in the western worldview to define the aesthetics in terms of the picturesque. The quest for the picturesque may incline managers of the landscapes to constantly improve the landscape removing any growth that is deemed not to fit in with the general concept of aesthetics. This improvement also becomes targeted towards the tourists who are generally not aware of the intricacies of the landscape that may not be indigenous or healthy. The key qualities and characteristics of scenic become clean and regularly maintained landscapes, which was evident in the tourists' responses in Ghandruk and Bandipur. This applies in relation to the built environment as well. Increasing numbers of picturesque and quaint villages, mostly in Europe, that contain clusters of houses surrounded by well-maintained agricultural land are catering for the tourists, at least seasonally (Berleant \& Carlson, 2007). This puts pressure on the local community to maintain the villages and farms for the tourists irrespective of the seasons and authenticity.

The significance of the landscape extends beyond the scenic aspects and the benefits of nature to human well-being is well documented (Parsons, 1991). Engagement in the landscape through activities such as trekking provides time for contemplation reducing stress, as observed by tourists in Ghandruk. Although tourists generally have limited interactions and lack social connection with the locals, Caletrío's (2011) study showed 
tourists returning develop ties with the destination and fellow travellers. This was also observed in Bandipur with the repeat visitors observing changes and forming a relationship with the local community (section 5.3). This indicates that, for the tourists, people and unique culture also play a role in their perceptions of landscape aesthetics. The "attractiveness" of places includes the opportunity to experience the uniqueness of the place and hence the people and their cultures become an important component of the landscape.

\subsubsection{Everyday life and everyday aesthetics}

For the residents, the landscapes are their everyday life, taskspaces, a place of work. The land incorporates a range of everyday activities, which in turn influences perception of landscape aesthetics. This is more significant to the communities that are directly involved with the land, such as the farmers. Their involvement and dependence imbed the land in their everyday lives and embodies the landscape. Farming and the farmlands hold a cultural significance that is tied to their traditions and identity. This is demonstrated in Sauraha, where the indigenous Tharu people accept farming culture as their identity (section 6.2). The Terai region, where Sauraha is located in the Greater Chitwan, is known as the granary of Nepal. This recognition provides a sense of ownership of the land, which in turn adds value to the landscape. Their attachment to the land and dependence form a unique bond that transposes the landscape to a sense of place that induces a sense of ownership and pride. This close bond to land extends beyond the visual aesthetics to a higher level of landscape aesthetics. The land is a taskscape, a place of work, their livelihood, ingrained as part of their history, culture and identity that is valued beyond what is visual, contributing to their perception of landscape aesthetics. The residents, especially those with long ancestral ties to the land view the present landscape through the complex lenses of their everyday lives and past experiences that may not be shared by residents with recent histories, mainly driven by economic opportunities. This was demonstrated in Sauraha, where the non-Tharu residents did not have similar ties with the farming culture or the associated rich traditions and festivals.

The attachment to the land includes deeper knowledge and understanding of the nuances such as the changes in the land that may not be visible to those who are not closely 
connected to the land. The farmers see the land in different climatic and planting seasons. This was most prominent in Sauraha, where more varieties of crops are possible due to the location and climate. However, the residents in Ghandruk and Bandipur were also aware of the seasonal landscape colours that varied with the crops. Their sense of aesthetics may vary with the seasons measured by the amount of work involved in a particular planting or harvesting season. Likewise, a good year of harvesting may appear more pleasing than the drought or flooded years. This indicates the visual aspects of the landscape are important to the residents as indicators of the healthy harvest, which impacts their livelihood and in turn, overall well-being. The agricultural landscapes, such as well-maintained plots and rows of grapes in vineyards are well-known for their visual aesthetics and are popular tourist attractions (de San Eugenio Vela, Nogué, \& Govers, 2017). However, for local economies that depend on farming, these landscapes extend beyond visual aesthetics becoming everyday landscapes with multiple meanings and attachment (Berleant, 2005a, 2005b, Saito, 2007, 2010).

While those observing the landscape for recreational purposes may marvel at the different visual impact, such as the mountains peeking between the clouds or mists playing over the mountains, the residents who work in the landscape link the climatic conditions to the crops. The mists or clouds would inform the farmer resident of the year's annual rain pattern and its effects on the crops, chores that need to be carried out that day, or maintenance work that requires attention. The landscape enters their everyday life and integrates them into it.

An important point is that the different resident groups within the same village have different perspectives on the landscape. For example, in Sauraha, the Tharu community have greater ties to the land than the hill migrants. Their culture is tied to the land and festivals are associated with different aspects of the forests and rivers. Thus, the landscape has more cultural significance for the Tharu people than the hill people who initially migrated for the farming and recently for tourism potential. However, the position of the indigenous community within the village also plays a role in their perceptions of the landscape and landscape aesthetics. For example, the Gurung community in Ghandruk is in a relatively stronger position in their community and actively involved in local development through ACAP as well as benefiting from tourism (section 4.3). On the other hand, the Tharu community in Sauraha are not involved in 
decision-making processes and not enjoying a fair share of the benefits from CNP (section 6.3).

This is also the outcome of the processes in which the CNP and the ACAP were established. While the national park was established to protect the biodiversity and took a top-down approach at the beginning, ACAP was established with the involvement of the local people from the planning process. The national park has adapted to "park and people" policies, however, they remain guided by biodiversity conservation. Although fifty percent of the income is allocated for local development, the local community has not been fully involved in the decision-making process and are hence not satisfied with the park. On the other hand, ACAP has established several committees such as hotel management, hydropower development, road, women development, and forest through which the local development works are implemented. ACAP provides training to empower the local communities to preserve, promote and develop Ghandruk and has garnered community support.

The lenses of the past tend to overshadow the present landscape values when people have nostalgic memories of the past. The image of the pleasant memories of the past adds aesthetic values to the land that may not have existed. On the other hand, the present landscape could evoke memories of the lost past that cloud over visual aesthetics. For example, the abandoned terraces in Ghandruk for the residents evoked memories of the past when there was extensive farming, which was compounded by larger harvests, memories of working in the land and the associated celebrations. While, the residents may agree that the regeneration is visually pleasing, their eyes seldom disassociate from the past. In Ghandruk, the increase in forests is generally appreciated by the residents, however, they are also reminded of its consequences such as an increase in wildlife that invades and destroys their farms and crops. The wildlife in Chitwan National Park also does not distinguish between the core and buffer zones and the farmlands are reduced to mere sources of food. This creates a tension between those who work for conservation and the farmers that may reduce the aesthetic value of the land. Unpleasant incidents in the past may reduce the attractiveness of a place. Natural disasters such as floods, forest fires and droughts may evoke unpleasant memories. These memories could be associated with personal loss and hardship decreasing the value of the land in terms of aesthetic appeal. This duality resonates with the nature of everyday routines that are comforting 
and constraining at the same time adding to the complex nature of everyday aesthetics and becomes problematic in preservation or development of landscapes (Highmore, 2004).

The complexity of everyday landscape is compounded by the contemporary needs of the society also forming part of the landscape. These needs include facilities such as education, health and transportation as part of their everyday landscape. As the landscape is primarily a place to live, good access to these facilities are important components of the landscape. In Bandipur and Sauraha, the on-site facilities or proximity to larger towns and convenient accessibility have added value to the landscape. In contrast, lack of higher education and health facilities, as well as inaccessibility in Ghandruk, associate the landscape with hardship. Access to good education and health are basic needs of contemporary society, hence becomes an important characteristics of landscape aesthetics.

In addition to the facilities, economic prospect is an attractive aesthetic quality. Economic prospects are not only sources of income, but also attract investors and migrants making a place lively. This is clearly evident in the revival of Bandipur with increasing investment in the tourism industry. The downturn and out-migration had made the town a ghost town, while the return of businesses has livened the town, making it more liveable and attractive. With more people investing and the town prospering, facilities also improve adding to the attractiveness of the town. The prosperity also reflects in the maintenance of the houses that augments further economic potential. For the residents, economic viability is important in the landscape as a live-in place, and that in turn influences their perception of landscape aesthetics.

The nuances of the everyday life in a living landscape such as an agricultural landscape are missed by the outside observer. In the short duration of their visits, the changes in the landscape will also not be visible for tourists, except for repeat tourists. The external observer would be able to assess only the present situation, whereas long-time residents would bring in past experiences and memories into the observation. The tourist may also view from their own experience in their hometowns or other familiar places with this worldview influencing the present experience and notions of aesthetic values. This 
confirms earlier studies that have found significant differences between residents and tourists regarding landscapes (Palmer, 2014; Stefanou, 2000; Urry, 2002).

The key aspect of everyday lives in Ghandruk and Bandipur that the tourists observed was the aesthetics of care or cleanliness and sense of safety. A well cared for landscape signifies an affluent community that evokes a sense of safety and security. This is prevalent in the western worldview where poverty is often associated with crime. In developing countries, where poverty is widespread and until recently settlements were not segregated, poverty does not indicate criminal activities. However, the cultural conventions of a clean and sanitised world as a healthy environment places high aesthetic values on clean environments.

\subsubsection{Change and landscape aesthetics}

The aspiration of people to improve their lifestyles influences their perceptions of landscape aesthetics. When tradition and traditional practices are associated with less civilised societies or backwardness, the new and modern has a higher value. The traditional becomes restricting and oppressive, while the new symbolises modernity. This newness quality often becomes associated with an image of a higher status. For example, in Sauraha, migrants returning from working abroad often demonstrate their change in new wealth and status by upgrading their homes or building with new modern materials (section 6.3). As more people build in the new style, this modern character becomes a cultural convention that others follow and aspire to. However, these modern buildings tend to be standardised and disconnected from the local context, losing its distinctive character. The loss of distinctive character breaks the continuity from the past, which, according to Relph (1976), leads people to a state of placelessness (section 2.4). This is important for the Tharu community in Sauraha where traditional ties with the land is a strong defining character. In Bandipur, this loss may result in decreasing tourism revenue due to the loss of distinctiveness.

The ready acceptance of the materials and newness aesthetics is partly due to the low awareness of the historical and architectural values of the traditional buildings among the local communities. The vernacular architecture usually evolves through decades and centuries of adapting to local needs and climate. However, most also require regular 
maintenance. This was a key deterring factor with regard to traditional buildings in Sauraha and Ghandruk, especially for the women who are responsible for the daily maintenance and cleaning (sections 4.3 and 6.3). The construction materials were obtained from natural sources, such as trees and plants, making it a seasonal activity associated with festivals. The change in family structures with smaller and nuclear families has restricted the continuation of traditions that were carried out by extended family members and associated with festivals. This need for regular maintenance becomes less attractive without the associated celebrations that provide cultural meanings. The maintenance work hence becomes a chore and an unattractive aspect of the traditional building. On the other hand, the cultural expectations and newness factor overlooks the inconveniences of the modern building such as poor adaptability to the climate and lack of local vernacular character. The poor adaptability to local climatic conditions is seen as a temporary issue that can be overcome with additional appliances such as heaters, fans and air conditioning. The need to break away from the past and its association with a hard life and backwardness overshadow the aesthetics of the vernacular. The unpleasant or unwanted memories of the past become synonymous with traditional buildings and hence hold no aesthetic values.

In contrast, the convenient accessibility to modern materials enhances the attractiveness of new styles and materials. In Ghandruk, the cumbersome and expensive process of manually transporting construction materials has been eased with the new road (section 4.3.2). Modern materials are usually industrially produced and economical compared with manually made traditional materials. The traditional houses are dependent on natural resources such as wood that is becoming a scarce resource and protected by conservation policies. As discussed in section 7.2.1, the processes to obtain restricted and limited products are often cumbersome, thus losing their attractiveness compared to readily available industrialised materials, as in the cases of Ghandruk and Sauraha. The restrictive conservation policies that are focussed on a particular element of the landscape (biodiversity in the cases of Ghandruk and Sauraha), transform landscapes that in turn influences the perceptions of landscape aesthetics.

As the world gets more homogenised, the demand for unique experience and location is bound to rise. Interest and investment in restoring traditional houses is increasing in Bandipur. The main motivation for this revival is led by the increase in tourism potential. 
The location of Bandipur on a ridge limits its potential for industrial development, however, it constitutes ideal conditions as a cultural destination. The historical importance of Bandipur is well-known in Nepal and has gained a considerable reputation in recent years in the domestic market making up more than eighty percent of the tourists visiting the town. In order to maintain its reputation as a "cultural" destination, the preservation of the vernacular houses and settlement pattern becomes imperative. In comparison, the motivations of tourists in Ghandruk and Sauraha are focussed on the natural aspects of the landscape and the activities such as trekking or wildlife viewing. This decreases the perceived importance of the built landscape at the risk of their loss.

One of the conditions that allow Bandipur to successfully adapt its vernacular buildings is the type of construction that is distinctly different from the Gurung or Tharu houses in Ghandruk and Sauraha. The Newar houses in Bandipur are larger multi-storied structures with separate rooms and are elaborately decorated following the common cultural conventions of a beautiful traditional house. The Gurung houses are also relatively large with the potential of adapting to modern facilities, however, it may require an expertise and knowledge of building in traditional materials that is disappearing with the increase in the adoption of new materials. There is a growing awareness among the residents involved in tourism related businesses of the importance of the built landscape, which can be observed in some of the new buildings in Ghandruk using the traditional stone facades. Although the scale and interior configuration is changed, the application of traditional materials on the façade, to a large extent, blends with the traditional built landscape. In Sauraha, the earlier tourist accommodations also applied similar concepts of maintaining the exterior façade to provide the tourists with an "authentic" experience and blending into the existing built environment. This middle path is also accepted by the national park with their building guidelines emphasising the use of exterior colours and scale to blend into the existing landscape (and not disturb the wildlife with artificial colours).

This raises the question of authenticity and the aim of preserving the built landscape. Family structures and traditional occupation are changing. For example, in Sauraha manual and animal-based farming is changing to mechanised farming, transforming the animal sheds to garages for the tractors. In Bandipur, the adaption of traditional residences that have spaces allocated for specific purposes become unnecessary in tourist 
accommodations. In addition, the type of tourists is changing, and this is placing demands that require further adaptations. The change from traditional European tourists trekking in Ghandruk or seeking wildlife in Sauraha to the increase in leisure tourists from the Asian markets requires facilities that may not adhere to the size, scale and materials of the traditional landscape and draw heavily from the local resources. For example, the new hotels in Sauraha are installing swimming pools that require materials and spaces that are difficult to conform to the traditional landscape. For destinations dependent on tourism, building style choices are often driven by commerce and demands of tourists (Weaver, 2009). This leads to the development of contrived places, according to Relph (1976) other-directed places that are detached from the local communities. Due to its commercial value, the attraction to the contrived landscape increases blurring the distinction between the traditional and the new styles with the contrived becoming part of the traditional landscape (section 2.4.1).

With the rapid and ubiquitous development, the concept of what constitutes "authentic" needs to be revisited. Village tourism in Nepal is a growing industry and homestay is gaining popularity in the domestic market. These tourists expect to experience the village life in an authentic setting with the local families. Most of the traditional houses were built before the plethora of technological gadgets were invented, however, it is also unfair to expect the indigenous communities not to adopt new technology. The traditional villages provide potential for tourism and in turn employment and income, but the local people also seek improvements in their lifestyles. This puts the residents in an interesting juxtaposition. Their desire to "modernise" and the new economic value through tourism creates a conflicting dilemma. This economic value often overrides and overshadows the traditional landscape and results in the emergence of built landscapes that are removed from the local context (Avieli, 2015). The social change with people abandoning traditional occupations, such as farming, which are usually labour intensive in favour of service-oriented occupations transforms their perceptions. However, this is a slow process and noticed when the character is mostly changed as in the case of Sauraha. In other words, the perception of landscape aesthetics is guided by its economic value. 


\subsubsection{Landscape aesthetics}

In summary, the perceptions of landscape aesthetics are embedded in complex meanings derived from personal experience, socio-cultural environment, individual and community values, economic context and wider political contexts. While historic context and ties to the landscape are important in shaping perceptions of landscape aesthetics, as living spaces for the residents, the everyday lives within the landscapes guide these perceptions. In addition, the dynamic nature of the landscape, changing both naturally and through societal changes influences perceptions of landscape aesthetics. These perceptions guide the development of the landscape that in turn alter our perceptions of landscape aesthetics. This implies that perception of landscape aesthetics is also a driver of landscape change based on a diverse range of socio-cultural values and environmental context (Jorgensen, 2011).

\subsection{CONCLUSION}

This chapter has brought together both the commonalities and differences in the three cases with regard to the participants' perceptions of landscape change and landscape aesthetics. The natural, built and cultural values along with the everyday aesthetics and change constitute the key aspects of the landscape. While there are very few pristine landscapes untouched by human influence in this world, most landscapes are socially constructed products that evolved through time. Unique cultures and traditions also evolved from the natural and built landscapes. The people and the culture of a place provide the unique characteristics to a place that distinguishes the landscape. It is a living everyday landscape for the residents and a temporary escape for the tourists. Both these groups of people along with the inherently dynamic nature of the landscape continuously change. The drivers of change are both external and internal, influenced by global trends as well as local conditions. This dynamic nature along with the inherent natural, built, cultural and everyday aspects of the landscape in totality encompass landscape aesthetics.

People and communities are dependent on the landscape that provides a range of benefits to the well-being of the people. In addition to the natural resources and recreational values, landscapes provide economic potential such as revenue from tourism development that drives landscape changes. Traditional landscapes that have evolved 
adapting to local context provide distinctiveness, such as the Gurung settlement in Ghandruk, the lively bazaar in Bandipur and Tharu culture in Sauraha. This distinct landscape provides economic potential through tourism, at the same time becoming a driver of change. In addition, the development of information technology is accelerating change through urbanisation and globalisation. The impact of urbanisation and globalisation on local communities' results in societal changes, with landscapes adapting to reflect the transformation. Conservation of landscapes thus depends on their potential to adapt to new uses. The risk of expecting people, culture and their manifestations (in the buildings) to freeze in a one-time period may result in total rejection of the traditional and preference for drastic change. Allowing and accommodating change in people and their traditions to evolve would ensure their conservation. Tensions between different users, such as residents who dwell within the landscape as lived experience and objectification by those who visit or use for commercial gain exists. Management decisions have to consider the wider range of values held by the residents in addition to conservation or economic development. The different perspectives of the residents and tourists, through their complexity and conflicts, adds value to landscape aesthetics. A careful balance considering the landscape in totality with due attention to drivers of change and everyday lives of people living creates a sustainable landscape that can be appreciated by people from different worldviews.

Although landscape aesthetics have been studied by researchers across multiple disciplines such as geography, architecture, landscape architecture, and ecology, most of the literature is focussed on one aspect of landscape such as the natural or the built (section 2.3). While these two aspects of landscape are significant, the cultural context defined by the people who construct these landscapes are not well researched. Cultural ecosystem services studies have established the wider benefits of the landscape to the well-being of the people and landscape aesthetics (section 2.2.2). However, researchers are focused on the natural landscape independent of the built environment. The finding that attachments with the physical landscape incorporating the natural, built and cultural aspects, everyday lives and the drivers of change cumulatively define landscape aesthetics is a major contribution to literature (Figure 7.1). 


\section{CONTRIBUTIONS AND IMPLICATIONS}

\subsection{INTRODUCTION}

This study has developed a conceptual understanding of the drivers of landscape change and landscape aesthetics. Change is an essential component of landscapes as they evolve through natural and cultural processes. The findings reveal that at the local level, institutional drivers such as prevailing policies (planning, zoning, conservation) are instrumental in changing landscapes. Urbanisation is also a strong driver of change in the context of globalisation and the rapid development of information technology. These drivers direct the tourism industry and transform societies through economic changes that, in turn, are reflected in the landscapes. These findings are not surprising and have been identified as major drivers of change (Hersperger \& Bürgi, 2009). More interesting is the role and perception of the people and their everyday lives with respect to these changes that are reflected in their perspectives of landscape aesthetics. There exists a duality in how people respond to both landscape change and landscape aesthetics. For example, while conserving the past (traditions, culture) is important in shaping landscape identity and distinctiveness along with the individual and national identities, its sustainability depends on the acceptance of landscape change. In landscapes that have living communities, everyday lives are essential components and change is integral to landscape and landscape aesthetics. Policies and planning tools that consider change and everyday lives in the overall landscapes will have a holistic impact that includes the wellbeing of the people. Everyday lives and everyday aesthetics may be mundane and ordinary, yet their omnipresence, repetition and practicality have a significant collective impact on perceptions of landscape aesthetics that will shape future landscapes.

The participation of people in planning has been proven to be successful in both natural and cultural landscape conservation (Baral et al., 2007; Byrd, 2007). However, the perception of residents and tourists on landscape aesthetics has not been studied adequately. Their perceptions are vital due to the role in defining and changing landscapes according to how they perceive landscape aesthetics. Residents live in the landscapes and tourists are attracted to landscapes that have distinctive culture and characteristics. It is essential for planners and managers to understand their perceptions 
for sustainable landscapes that have people living in them. This final chapter revisits the research questions that have directed this research followed by methodological and theoretical contributions to tourism and landscape literature. Next, recommendations for the tourism industry and policy legislators regarding holistic conservation and development of landscapes and directions for future research are presented.

\subsection{RESEARCH QUESTIONS REVISITED}

Chapter one introduced the research questions that were expanded in chapter three outlining the rationale and information required to address the question. This section first addresses the supplemental questions that build up to address the overarching research question.

\section{Supplemental question 1: What are the drivers of change in the landscape that are influenced by tourism?}

Institutional drivers such as policies (zoning, planning, conservation) are instrumental in directing change. Conservation policies tend to be guided by specific objectives and predetermined goals, rarely looking at landscapes holistically. Policies are generally driven by those who are in position of authority as well as influenced by the political situation and contemporary trends. This tends to result in the preference for certain landscape components to others, which in turn has significant implications on landscape change - protection, improvement and in some cases degradation and destruction of certain landscapes. For example, the conservation policies of the natural areas such as national parks may restrict access to forest resources that are vital to maintaining the built landscape (traditional building materials). The dominance of one landscape component becomes stronger when conservation policies are driven by economic benefits, such as

tourism. Such policies often overlook other aspects resulting in their degradation. The conservation policies in Bandipur driven by tourism growth have protected the built landscape while expanding growth in the peripheral areas and degrading the natural landscapes (section 5.3). The restrictions placed on collecting forest resources have hindered residents in Sauraha not only from building new houses in traditional styles but also present difficulties in maintaining the existing structures (section 6.3). 
Urbanisation has also intensified landscape changes in the current context of rapid development of communication technology and globalisation. Roads are a basic necessity that link the rural areas to the infrastructure and facilities in the urban areas. While roads are bringing the rural and urban areas closer physically (time-wise), development of communication technology is bringing the world to people's homes and hands (mobile phones). These two factors have become instrumental in bringing changes in rural societies, such as Ghandruk (section 4.3). Another important impact is outmigration in rural communities, mostly for employment opportunities. This is resulting in abandoned farming practices and in some cases abandoned villages. The abandoned farms may return to the original vegetation and natural setting; however, the loss of the cultural component and community leads to the maintenance issues and impacts on the local economy.

Road construction in fragile landscapes and protected areas is already raising concerns affecting different aspects such as ecology, socio-economy and management (Lama \& Job, 2014). Road access intensifies land uses (farming, building) and has a visible impact on traditional landscapes that use locally sourced materials. Imported materials and technology tend to replace distinct traditional landscapes with standardised and disconnected landscapes breaking continuity with the past (Antrop, 2005; Relph, 1976). In addition, transportation accessibility also plays a significant role in intensifying urbanisation and hence landscape change. Of the three sites, Sauraha, located in the plains with convenient access to the highway has changed radically compared to less accessible Ghandruk. However, the new road in Ghandruk is already influencing changes that are not limited to the built physical landscape but also the type of tourists. This change in tourist type with different expectations and demands from the traditional trekkers leads to further changes in the physical landscape such as an increase in the number, size, style and type of buildings.

Tourism requires services and infrastructure that local, regional and national governments are usually content to accommodate, mainly due to the economic benefits. Infrastructure catering for the tourists changes the functions of the traditional buildings with tourism itself becoming a product and an attraction (Avieli, 2015). In tourismdependent locations, landscapes become staged breaking links with the local community, resulting in irreversible changes, especially when the local population is displaced. 
The findings confirm that residents who worked or had family members working in tourism-related jobs were more favourable towards tourism. The income or employment from tourism enables them to attribute local development to the tourism industry. In contrast, when benefits are not shared widely, the residents do not perceive tangible benefits and are found to be negative towards tourism (Gonzalez, Coromina, \& Galí, 2018; Teye, Sirakaya, \& Sönmez, 2002). Recently, there have been outcries of overtourism in developing and developed nations, in beaches, cities and heritage sites with diverse concerns from damage to the environment to overcrowding (Gonzalez et al., 2018). A better understanding of how tourism is changing landscapes along with short and long-term impacts is necessary to mitigate potential conflicts. The haste to cater to tourism for economic development focusing on select components of the landscape may have long-term consequences on the overall landscape, which in turn impacts on tourism.

\section{Supplemental question 2: What are the perspectives of residents and tourists with respect to the changing landscapes and landscape aesthetics?}

Change and landscape aesthetics are complex concepts. The perspectives of the residents and tourists reflect this complexity that varies with the individual and collective culture and context. As a social construct, landscapes and perceptions of landscape aesthetics also evolve with societal changes. For residents, their everyday lives surround their immediate landscapes and take priority over the visual aesthetics. Their everyday concerns include the individual social world (family, friends) and collective culture (community, identity, sense of place) along with the basic needs such as education, health and transportation conveniences. These factors are integrated into and influence their perceptions of landscape aesthetics. Change is usually not visible in the eyes of the tourists as they are temporary visitors. Their perceptions of landscape aesthetics are dependent on their activities and experiences while travelling through the landscape but are strongly influenced by their known landscapes as well as the individual and cultural context.

The perspectives of both the residents and tourists with regard to landscape change and landscape aesthetics are ambivalent and sometimes contradictory. While the traditional landscape (natural, built and culture) is valued, there is also a desire for contemporary lifestyle and conveniences that usually contradict the traditional. For example, the 
vernacular architecture generally uses natural products available locally and is timetested and climate responsive. While acknowledging the benefits of traditional buildings, residents are drawn towards materials and styles that are new and frequently not suitable for the local climate but reflect the universal trends and perceived notions of socioeconomic status in the present society. Likewise, the tourists also appreciate the distinctive characteristics of traditional buildings but seek modern amenities and home comforts that require changes. Change in the landscape is expected and accepted by both residents and tourists confirming its role and significance in landscape aesthetics that is vital for well-informed management and planning decisions.

\section{Supplemental question 3: How do the perceptions of the residents and tourists compare or inter-relate with respect to different landscapes?}

For the residents, the significance of everyday aesthetics and social relationships is present in all sites. The attachment to the land, in particular for the farming community, is significant in all landscapes, both in the hills and the plains. Likewise, the traditional dependence on forest resources and relationships that shaped their landscapes and culture is similar in all sites. In Sauraha and Ghandruk, farming traditions still prevail with strong ties to the land. In addition to the built landscape that is sourced from the local forests, their culture is also directly linked to the land. Thus, their perceptions of landscape and landscape aesthetics emphasise the relationship with the land as well as the cultural manifestations such as festivals and social networks. This is also evident in Bandipur, where the residents linked their sense of place to landscape aesthetics. The landscape as their home was an important aspect of landscape aesthetics.

This relationship weakens as urbanisation increases and dependence on land or forest resources decreases. While the building materials for Sauraha and Ghandruk are obtained from the forests, connecting people with nature, the bricks used in the houses in Bandipur are manufactured in factories. With a more town-like main bazaar and historical development as a commercial centre, the vernacular architecture of Bandipur is less dependent on forest resources. However, the culture there is strongly linked with the agricultural cycles and the physical location on the ridge in the low hills with terraced farming on the slopes is a potent characteristic. Similarly, the new centre of Sauraha with its urban character has severed the connection with the indigenous Tharu population and 
the traditional Tharu built landscape. This reinforces the urgency to have a holistic concept of landscape and understand the significance of conservation policies and planning in shaping landscapes.

For the tourists, activity or ways to engage with the landscape is more significant than the cultural aspects of the landscape. However, the choice of the destination is inevitably linked to the landscape and the selected activity. The more time tourists spend in a landscape, their interactions increase broadening their concepts of the landscape. This is also dependent on the type of landscape and the experiences sought. Ghandruk as a trekking destination in a picturesque mountain landscape, interactions such as scenery and contemplation with nature took precedence over the cultural aspects. In Bandipur, the tourists mostly preferred to spend longer time mingling in the local community and their culture and way of life were of higher interest. On the other hand, the national park is the primary attraction in Sauraha with the cultural landscape a distant second. This difference in the interactions of the tourists with the local community is reflected with greater changes in Sauraha compared with Bandipur.

In Ghandruk, where the length of stay is the shortest, the interactions with the local community and vernacular built landscape are ambivalent. The motivation to visit is primarily the natural landscape and the experience of trekking, hence change is likely to be more acceptable compared with Bandipur where culture is at the centre of the landscape. The unprecedented growth of villages such as Namche Bazaar on the way to Mount Everest is an example in Nepal (section 2.6.1). Namche Bazaar has grown from a scattered settlement to an urban town since the advent of international tourists in the 1980s (Pawson et al., 1984; SK Nepal, 2005). The expansion and change from a rural setting to a town-like character did not decrease tourist arrival numbers, however, construction has shifted to peripheral villages with the peak capacity reached (SK Nepal, 2005). This indicates the type of tourism is directly related to acceptable landscape change. With the emphasis on mountain tourism, the focus has been on the natural landscape and the environment with negative impact on the built landscape (Shackley, 1996). On the other hand, focusing on the culture the changes in the built landscape and local communities may have different consequences in destinations such as Bandipur. 


\section{Overall research question: How do residents and tourists perceive the aesthetic values of Nepal's changing landscapes?}

Both residents and tourists agree on certain aspects of change, however, there are differences in their perceptions of change and what constitutes landscape aesthetics. The residents were nostalgic for the past, yet they were also ambivalent and contradictory in their preference for the past or present landscapes. The traditions, culture, and society were seen to be better in the past compared to the present times. The conveniences (roads, economic activities) made the present situation more desirable. This indicates that tension between traditional (culture) and development (road, infrastructure, economic opportunities) exists in the residents' perceptions of landscape aesthetics. The separation of everyday life is also not possible from their landscapes. Landscape aesthetics include their life and the various levels of relationships they have with other members of the community. Ties with friends and families were linked to their perceptions of landscape aesthetics with most residents indicating their presence as part of their everyday lives.

An improvement (such as economic opportunity) is seen to contribute positively to landscape aesthetics. Thus, change when perceived to improve life adds to landscape aesthetics. This applies to the tourists as well. Compared to the barren hills, the green hills with greener forested lands were perceived as improved, healthier and preferred. The residents agreed that the green hills were visually attractive but were always reminded of the work or the loss of work represented by the increase in forested land. The increase in forests signified the loss of agricultural lands, which in turn indicated loss of prosperity and out-migration. This increased the wildlife that was seen as a threat to their crops. Thus, for the residents, the greener forested areas were not necessarily the preferred landscape as it indicated unworked land. This corresponds with the study in Norway, where tourists (local and international) also lamented about the loss of farming and were not pleased with the new uniform forests that were seen as representations of industrialised life (Vinge \& Flø, 2015). This Norwegian case study found residents and tourists prefer landscapes that are worked and reflects their heritage as an agriculturebased society. This finding confirms that the socio-cultural context of the people is linked to their understanding and appreciation of the landscapes. In line with this Norwegian example, for the residents interviewed in Nepal, farmlands representing local culture and traditions are valuable aspects of landscape aesthetics. 
With limited knowledge of the history and the nuances of everyday lives in the landscape, the tourists are concerned with the physical and visual aspects of the landscape, such as the condition of the hills, the state of the buildings and the open spaces and streets. Their focus confirms the relevance of visual experience as central for tourists, conceptualised by Urry (2002) as the tourist gaze. The tourists also noted the overall state, such as cleanliness, availability of modern conveniences, transportation facilities and tourism services such as the quality, availability and variety of food and rooms as well as community activities. These are indicators of not just the quality of tourism products but also the quality of everyday lives of the residents. The inclusion of the quality of residents' everyday lives as part of the landscape indicates its significance in the tourists' perceptions of landscape aesthetics. Integrating the everyday aspects of the landscape, the tourists are also accepting landscape changes. For example, cleanliness indicated that the community was economically stable providing a sense of safety that has been established as an element of landscape aesthetics. Tourists also appreciate and sometimes actively seek modern conveniences such as ensuite bathrooms and international cuisine in traditional settlements, which shows a dichotomy in their expectations of distinct local culture with modern home comforts.

Landscape aesthetics go beyond the natural, built and the cultural to place people and how they perceive the landscape, at present and in the future, at the core. The concept transcends the restrictions of the sensory, conceptual, experiential, cognitive or formal significance of aesthetics that is traditionally associated with arts. It should also be constantly reviewed with societal changes and in the specific cultural context as well as with wider cultural sensibilities and aesthetic consciousness.

In summary, everyday life is an important aspect of landscape aesthetics, particularly for the residents. It is inseparable from the landscape as it is their taskscape, where they work, live and have relationships with other people. Culture and traditions are also part of the landscape and are linked to the people (family and friends) as well as their identities (individual, communal and national). Visual aesthetics are important but are interlinked with the overall situation of the landscape, such as the local economy. The economic health, state of the people and quality of life is reflected in the perceptions of landscape aesthetics. In other words, a healthy, clean society with good economic potential is aesthetically pleasing. Although physical appearance is a significant element of the 
landscape, people are central to landscape aesthetics, for both the residents and tourists. Residents put themselves in the landscape and an overall state of their lives (health, work, culture, family, education, infrastructure, economic opportunities) is integrated into landscapes and landscape aesthetics. Tourists also connect the state of the people to the landscape. For example, a cleaner environment indicates a healthier, more prosperous local community and hence, makes landscapes aesthetically pleasing. Change is accepted by both residents and tourists when associated with perceived improvement such as green forests, restored buildings, children playing (for tourists) and convenience such as road, schools, health facilities (for the residents). The socio-cultural background of the people influences their understanding of the landscape and accordingly ascribe aesthetic values to it.

\subsection{METHODOLOGICAL AND THEORETICAL CONTRIBUTIONS}

This study applies a comprehensive multi-layered methodology and interpretivist paradigm to embrace the reflexive, interpretive and innovative lines of inquiry that are emerging in tourism research (Tribe, 2005). The use of the different methods enabled this qualitative study to encompass the broad concepts of landscapes, change and perceptions of landscape aesthetics. The three case studies were useful to compare and contrast different contexts, locations and types of destinations, the in-depth interviews with the insiders (residents) and outsiders (tourists) provided different perspectives and the field notes taken in multiple phases added to data quality. This also led to linking the data with the triangulation of the case studies, interviews and field notes to validate the findings and clarify meanings and perceptions of landscape aesthetics (Denzin \& Lincoln, 2005).

This study expanded the use of photographs by using past and repeat photographs during the in-depth interviews conducted on-site. This enabled the study to explore landscape changes and landscape aesthetics in multiple ways. Landscapes become less abstract to people (residents and tourists) when they are photographed. Photographs, when used in conjunction with interviews, become a means to access people's thoughts and insights regarding change over time as well as visual beauty. The photographs provided alternative views (past and repeat), in different seasons enabling the participants to 
articulate perceptions of landscape aesthetics and change. In addition, the on-site interviews reduced the disadvantages of the sole use of photographs allowing the participants to see and feel the landscape (Jacobsen, 2007; Tieskens, Van Zanten, Schulp, \& Verburg, 2018). It allowed the participants to reflect on the changes and aesthetic values in the landscape visually (photographs and the live landscape) as well as experience the landscape (sounds, smells, community activities). This methodology also contributes to the literature on photo-elicitation interviews conducted on site that is rare due to the related costs. This thesis has presented an alternative approach to assessing landscape change where official documents such as maps, plans and building records are unavailable. The use of past and repeat photographs in lieu of official documents has provided a useful record for assessing change. The selection of photographs included landscapes in totality with depictions of everyday life and local culture, which provided effective stimuli to collect a rich data set, especially in the rural communities.

Applying a multiple case studies approach allowed this study to explore the different contexts in three different locations. This study is based on the perceptions of landscape change and aesthetics that are dependent on cultural, historical, and physical contexts. The analytical approach (Figure 3-1) allowed for comparisons across case studies, themes and perspectives along with the analysis of documents. It also allowed for comparisons across the different groups of participants as well as differences within the groups: residents (tourism and non-tourism) and tourists (international and domestic). Considering the diversity of residents and tourists as participants, this research moved away from the preoccupation of tourism studies with tourists as consumers and residents as hosts and takes into consideration their perceptions on broader issues of change and landscape aesthetics to include everyday lives. This resulted in exploring the perceptions of the participants in different roles within their communities (as insiders and outsiders).

By applying an interpretivist paradigm this study embraces the understanding that human experiences are important and reveals that both residents and tourists place themselves within the landscape and also as observers. Incorporating the participants' experience in and with the landscape, this study has provided valuable insight to delve into the multiple visual and sensory aspects of the landscape. The selection of the participants drawn from a wide range of backgrounds, including tourists, who had sufficient time and insight for the in-depth interviews provided valuable data that are particularly difficult given the 
itinerant tourists with tight schedules. By applying a reflexive process my own position both as an insider (Nepalese citizen) and outsider (domestic tourist, expert with a background in architecture and conservation) has added value to the research process. This allowed for interaction with the participants and evolution of my own perspectives from the confines of architecture and historic preservation to emphasise the role of the people in the landscape (Berleant, 2005a) and everyday aesthetics in landscape aesthetics (Saito, 2007).

This study developed a framework (Figure 7.1) and conceptual understanding of landscape aesthetics that incorporates the multiple dimensions of landscapes, change and the diversity of perceptions. This study has attempted to conceptualise a holistic approach to landscape tourism studies that takes into consideration both the insider and outsider perspectives and the multiple components of landscapes: natural, built and people. Landscapes have been established as a social construct, where people shape landscapes and are shaped by them. This emphasises the role and significance of people in the landscape. Critics of anthropocentric landscape studies point to the damage caused by humans on biodiversity and the natural landscape. It is precisely for this reason that this study emphasises the role of the human in the landscape. There is no getting away from the human impact on the landscape. However, a thorough understanding of the perceptions of people can contribute towards mitigating the adverse impact on landscape and biodiversity. This study builds on Berleant's concepts of landscape where people are central and advances Saito's everyday aesthetics to provide a holistic concept of landscape and landscape aesthetics that incorporates change.

Landscapes have different meanings for different people, but it is essentially home and part of everyday life for the residents. This study emphasises their role in the landscape and incorporates their everyday experiences with and within the landscapes in defining landscape aesthetics. This study extends Saito's (2007) everyday aesthetics to encompass individual and collective societal changes into everyday aesthetics. Everyday aesthetics may be mundane and ordinary but the frequency (everyday) and size (resident population) collectively make a significant impact on perceptions of landscape aesthetics. Since landscape aesthetics are part of everyday lives for the residents, it becomes pertinent to understand their perceptions in order to make informed decisions regarding 
landscapes. In addition, the quality of the everyday life of residents has implications for the tourism industry due to its influence on tourists' perceptions of landscape aesthetics.

This study incorporates change into the concept of landscape and landscape aesthetics. As an integral part of the landscape, it is essential that change is incorporated into landscape aesthetics (Antrop, 1998). Landscapes and society (people, both residents and tourists) evolve naturally and through human-induced processes. This is reflected in the changing perceptions of landscapes aesthetics. This study examined the interrelationships between the internal and external drivers of change and their impact on landscape and landscape aesthetics. This understanding of change will enable planners and managers to forecast future trends and plan in a well-informed manner. In the current context of the rapid development of information technology, this study of the drivers of changes makes apposite and pertinent contributions.

Aesthetics has not been studied in the context of Nepal and researchers have neglected landscape aesthetics. The common definition of aesthetics in the Nepali language relates to beauty and does not incorporate the broader concepts of aesthetics. However, residents and domestic tourists tended to incorporate everyday life into the narratives of landscape aesthetics indicating their inclusion in its definition. This response also confirms that they place themselves in the landscape and their everyday lives, relationships, culture and traditions as well as their future are integral parts of the physical landscapes (natural and built). This study in the three sites in Nepal adds a new perspective to the study of tourism-landscape interactions. The concepts of landscape and landscape aesthetics are dependent on cultural, geographical and historical contexts. This study in Nepal provides a non-western perspective through the case studies in Nepal, the residents' perceptions and my reflections as a researcher as well as a citizen of Nepal. The diverse landscapes in Nepal provide different geographical and cultural contexts resulting in diverse perspectives that add to the literature on Nepal. The study of three sites with different tourism products adds to the contribution on landscape-tourism studies.

The foremost contribution of this thesis is the framework (Figure 7.1) that takes a holistic approach to landscape and looks across the natural, the built and the people components, at the same time integrating change and everyday aspects of the landscape. Most studies focus on one of the components negotiating the significance of another that creates 
conflicts between the different individuals and groups that live, work or visit with different motivations and interests. Applying a holistic approach and viewing landscapes in totality will give adequate consideration to all the components and address their interrelationships, interconnectedness and overlays mitigating potential conflicts. It has also viewed landscapes from multiple perspectives encompassing everyday aesthetics to the sublime landscapes.

\subsection{PRACTICAL IMPLICATIONS}

There is diversity in the interests and motivations of the different individuals and groups of people that interact in the landscapes. For residents, living and working in the landscape, it becomes their everyday life and they view it both from within as a part of it and from the outside as an observer. This everyday interaction reflects their perceptions of landscape aesthetics, changing and shaping landscapes. However, this group is complex with individual and collective differences, interests and motivations. As an example of this diversity, this study examined the perspectives of two groups: residents working and not working in the tourism industry, that revealed clear differences in how they perceived landscape changes and landscape aesthetics. A better understanding of the diverse perspectives has strong implications for the tourism industry due to their ramifications in maintaining or changing distinctive landscapes. The distribution of the benefits from tourism is a significant factor in the different perceptions. Those involved in the tourism industry take the interests of the tourists into consideration, while those who are not involved emphasise their culture, social networks and well-being in terms of everyday conveniences such education, health, transportation and employment. Their particular interests guide the values that they attach to their everyday landscapes and reflect in their perceptions of landscape aesthetics. This, in turn, directs the changes, particularly in the built and cultural landscapes. A sound understanding of the residents' perceptions of landscape is particularly significant to minimise potential conflicts in implementing planning and policy decisions. Understanding residents' perceptions and ensuring their participation in planning and decision-making processes would result in well-informed policies and plans. 
The tourists are also a complex group and their perspective depends on their historical, cultural, social and political context. This research has incorporated two distinct groups: international and domestic tourists that have similarities as well as differences in motivations, interests as well as expectations. A better understanding of the diversity of this group and their perspectives comes with strong implications for the tourism industry, especially with the change in the dynamics of tourist types. The ramifications of this change increase as the dependence on tourism increases. Converging the different perspectives would not only produce well-informed policies and management plans that guide landscape protection and development to benefit a wider group of communities but also contribute towards the mutual understanding of landscape aesthetics. Residents' understanding of the interests of the tourists and tourists' understanding of the residents' everyday landscape would enrich both groups' experience as well as help managers understand the conflicts with regard to the diverse perceptions.

Given that the landscape is constantly changing, it is pertinent to identify and understand the drivers of change. This research has identified three important factors that are driving landscape changes with implications for landscape aesthetics while also acknowledging that other drivers exist. The findings in all three sites have shown the impact of conservation policies that emphasise one landscape component and ignored other aspects creating conflicts with the potential loss of significant aspects. Urbanisation and globalisation are unavoidable, and societal changes are also inevitable. A better understanding of societal changes would result in well-informed policies, which in turn could be efficiently implemented. Most importantly, tourism reflects global and societal trends and is also changing, hence understanding tourism in the geographical, historical, political and socio-economic context would contribute towards sustainable protection of landscapes that benefits a wider local and global community.

The findings clearly demonstrated the conflicts arising from conservation policy decisions that emphasised one component of the landscape over another. The interdependence of the different landscape component necessitates a holistic approach to policies and planning to protect or develop all aspects of landscapes. The built landscape is dependent on the natural resources, while natural resources are better managed with the participation of the local communities. A balanced holistic approach will overcome the potential biases and result in their successful implementation of policy and planning 
decisions. The integrated approach to natural and cultural landscape will also minimise duplications and repetitions as well as overlaps in plans and policies. Including the perceptions of local people and their participation in decision-making processes raises awareness of the importance of landscape protection as well as eases the process of implementing policy and planning decisions. This will also ensure a fairer distribution of benefits from landscape conservation and in turn tourism, that will contribute towards the sustainability of the landscape.

\subsection{FUTURE RESEARCH DIRECTIONS}

This section addresses the limitations of this research and also considers future research directions. The limitation of this research as noted in section 3.6 is the scarcity of official building and planning documents that would have been useful to assess the physical changes in the landscape. These documents used in combination with the past and repeat photographs would better inform landscape changes. A record of such changes would also be useful in identifying future trends. It would be interesting for future studies to include historic and current maps to study the different perspectives with regard to the spatial expansion of built settlements. The inclusion of historic maps would also provide historic narration and information enriching the data collection. This could also provide a set of historic and recent events that have shaped the landscape and the people. While photographs have been used to assess different perspectives of spatial expansion or decrease of natural landscapes such as vegetation type and size and elements such as mountains and water, there is a scarcity of studies looking at the change in built landscapes. With new technologies such as Google Earth and drones, it would be interesting to combine them with historical documents to assess the perceptions of landscape change as well as landscape aesthetics.

This study has been limited to small sized rural towns or villages but the framework (Figure 7.1) would also be applicable to other landscapes such as historic towns, seaside towns and cities. The drivers of change could be more complex in these landscapes and the role of tourism difficult to assess in the process of landscape change. There are concerns of overtourism in historic towns and cities and second homes in rural towns that are changing the perceptions of the residents with regard to the benefits of tourism. 
Studying the perspectives of the residents and tourists on landscape aesthetics and change would result in better-informed management strategies to minimise conflicts.

This research focused on the perspectives of non-experts (residents and tourists) in order to gain wider insight on the multi-layered concept of landscape aesthetics. Future studies could include the perceptions of experts and decision makers such as managers and policymakers. This would be an interesting comparative study to examine the conflicts in the expert and non-expert perceptions of the drivers of landscape change and landscape aesthetics. Such a study would result in a better understanding of the diverse perspectives and contribute to well-informed policies and management decisions. It would also be interesting for future studies to examine the perceptions of residents and tourists on landscape aesthetics and change in emerging and established historic towns, cities, seaside towns. The studies in established landscapes would provide valuable lessons for emerging landscapes.

This research aimed to give a voice to residents and carefully selected participants that represented different sectors as well as social and economic groups. For this reason, this research has not taken into consideration the different social, economic and educational differences of the participants. Examining the differences in perceptions on landscape aesthetics and change of different age groups, educational levels and economic groups would offer an interesting perspective and be useful for managers to strategically plan interaction and awareness programmes. In addition, although care was taken to include gender balance, this research has not examined landscape aesthetics from a gendered perspective. Women and men interact differently with the landscape, especially in a traditional setting where the work division is more distinct. For example, women spend more time in and around the house and are mostly responsible for the day to day cleaning and maintenance. This gives them a different perspective from the men who are generally responsible for providing the materials and taking care of the major repair and maintenance works. Future research examining landscape aesthetics perceptions from this perspective would provide valuable insight for building regulations. 


\subsection{CONCLUSION}

As stated in the introduction chapter, I initially approached this topic from the perspective of an architect trained in western philosophies in architecture, historic preservation and cultural landscapes. I was born and spent most of my life working in Nepal, where nature is an integral part of culture and culture is embedded in nature. These two contexts were often contradictory with the addition of my work with the tourism industry, a strong economic initiative and a consumer of both natural and cultural landscapes. As such, my work as a historic preservation architect was intrinsically linked with tourism. My work was also strongly influenced by the local heritage and required working closely with the communities. This study took root during the many interactions with the communities where I grappled with the difficulties in implementing local and national plans and policies, in particular, building and conservation guidelines and bylaws. There was a clear separation of how the authorities viewed the landscapes (reflected in the policies and plans) and how the local communities viewed them (as present and future home). Hence, the perspective of the residents is central in this study along with the tourists, a group with increasing influence on landscape change.

The multi-layered qualitative approach using case studies, in-depth interviews with photo-elicitation techniques and field notes has proved to be exceptionally useful to explore the complex concepts of landscapes, change, tourism and perceptions of landscape aesthetics and their interconnectedness, interdependence and overlays. The findings revealed several paradoxical tensions in these concepts that arose from how different individuals and groups perceived their landscapes. Findings correspond to similar studies on perceptions of landscape aesthetics that are dependent on individual and collective context, worldview and social position and advance understanding of these diverse and interrelated concepts. In addition, the multi-layered method with in-depth interviews using past and repeat photographs conducted on-site allowed this study to explore the multiple cognitive and sensory aspects of landscapes and landscape aesthetics.

In looking at landscape change and landscape aesthetics from the insider and outsider perspectives, this study has taken into consideration both the approaches of detachment and an experience with tourists observing landscapes as scenery while residents live, 
work and play in it. On the other hand, residents also at times view and enjoy the scenery as observers while the tourists experience landscapes through activities, interactions and contemplations. These diverse perspectives of how different individual and groups of people view and experience landscapes shape their perceptions of landscape aesthetics and have ramifications in the preservation and transformation of landscapes.

Several conclusions can be drawn from the findings of this study and applied to the wider landscape-tourism context.

First, the interaction between humans and the natural environment is unavoidable and widespread, thus landscapes have to be considered in totality with the natural, built and cultural components, along with changes and everyday aspects. Natural landscapes may regenerate compared with cultural and built landscapes, which, while potent national and cultural symbols, can be irreversibly damaged. With regard to tourism, generally only the exceptional natural or built environments are highlighted neglecting the everyday aspects of the local community that support it, in some cases, human settlements are removed because they are considered less aesthetically pleasing or damaging to the exceptional landscapes. In addition, light has been shed on the significance of geographical, historical, socio-economic and political contexts in defining and shaping as well as changing landscapes. The interdependence of the different components and context requires landscapes to be approached holistically for their sustainable protection, management and development.

Secondly, given the dynamic nature of landscapes that are continuously evolving, it is important to identify and understand the internal and external drivers of change. More importantly, understanding the perspectives of different individual and groups of people on these drivers of change will help in implementing policies and plans. The rapid development of information technology and infrastructure is decreasing distances and increasing the pace of urbanisation changing societies, that in turn are changing landscapes. Globalisation is also changing perceptions of landscape aesthetics harmonising and standardising landscapes with the loss of distinctive landscapes. The ramifications of such changes may have a profound impact on the identity of the people and the nation, that is reflected in the landscapes, which in turn have ramifications in the tourism industry. 
Thirdly and most importantly, the findings have shown that landscapes are ingrained in the residents' everyday lives becoming an important component of their perception of landscape aesthetics. Residents are a complex group with multiple interests and motivation with regard to landscape qualities and aesthetics. As the group living and working in the landscape, disregarding their everyday aesthetics may have significant ramifications in implementing policies, especially when expert and non-expert concepts differ. This, in turn, has consequences for the tourism industry that has been proven to depend on distinctive landscapes that include the quality of everyday lives of the local communities. This proves the significant role of local communities in the perspectives of the tourists and their experience. Landscapes that have different aesthetic values for residents are attractive to tourists and well-visited landscapes in turn, have multiple benefits for local communities. Hence, it is clear that the inclusion of different perspectives and an understanding the factors that drive the perceptions of landscape aesthetics and change is paramount in formulating policies and plans to protect, sustain and develop landscapes. 


\section{REFERENCES}

Acharya, B., \& Halpenny, E. (2013). Homestays as an alternative tourism product for sustainable community development: A case study of women-managed tourism product in rural Nepal. Tourism Planning \& Development, 10(4), 367-387. https://doi.org/10.1080/21568316.2013.779313

Adams, V. (1992). Tourism and Sherpas, Nepal: Reconstruction of reciprocity. Annals of Tourism Research, 19(3), 534-554. https://doi.org/10.1016/01607383(92)90135-C

Adams, W., \& Infield, M. (2003). Who is on the gorilla's payroll? Claims on tourist revenue from a Ugandan national park. World Development, 31(1), 177-190. https://doi.org/10.1016/S0305-750X(02)00149-3

Adhikari, Y., \& Fischer, A. (2011). Tourism: Boon for forest conservation, livelihood, and community development in Ghandruk VDC, western Nepal. The Initiation, 4, 35-45. https://doi.org/http://dx.doi.org/10.3126/init.v4i0.5535

Adler, C., McEvoy, D., Chhetri, P., \& Kruk, E. (2013). The role of tourism in a changing climate for conservation and development. A problem-oriented study in the Kailash Sacred Landscape, Nepal. Policy Sciences, 46(2), 161-178. https://doi.org/10.1007/s11077-012-9168-4

Agergaard, J. (1999). Settlement and changing land use in the Chitwan district of Nepal. Geografisk Tidsskrift, Danish Journal of Geography, 01(SPEC. ISS. 1), 11-19.

Aitchison, C., MacLeod, N., \& Shaw, S. (2000). Leisure and tourism landscapes: Social and cultural geographies. Routledge.

Albert, M.-T., \& Gaillard, B. (2014). The Dresden Elbe Valley: An example for conflicts between political power and common interests in a World Heritage Site. In K. Taylor \& J. Lennon (Eds.), Managing cultural landscapes (pp. 325-344). Taylor \& Francis Group.

Allendorf, T. (2007). Residents' attitudes toward three protected areas in southwestern Nepal. Biodivers Conserv, 16, 2087-2102. https://doi.org/10.1007/s10531-0069092-z

Allendorf, T., Smith, J., \& Anderson, D. (2007). Residents' perceptions of Royal Bardia National Park, Nepal. Landscape and Urban Planning, 82, 33-40. https://doi.org/10.1016/j.landurbplan.2007.01.015

Amar, J. H. N. (2017). Conservation of cultural built heritage: An investigation of stakeholder perceptions in Australia and Tanzania. Unpublished doctoral dissertation, Bond University.

Antrop, M. (1997). The concept of traditional landscapes as a base for landscape evaluation and planning. The example of Flanders Region. Landscape and Urban Planning, 38(1-2), 105-117. https://doi.org/10.1016/S0169-2046(97)00027-3 
Antrop, M. (1998). Landscape change: Plan or chaos? Landscape and Urban Planning, 41(3-4), 155-161. https://doi.org/10.1016/S0169-2046(98)00068-1

Antrop, M. (2004). Landscape change and the urbanization process in Europe. Landscape and Urban Planning, 67, 9-26. https://doi.org/10.1016/S0169-2046(03)00026-4

Antrop, M. (2005). Why landscapes of the past are important for the future. Landscape and Urban Planning, 70(1-2), 21-34. https://doi.org/10.1016/j.landurbplan.2003.10.002

Antrop, M. (2006). Sustainable landscapes: Contradiction, fiction or utopia? Landscape and Urban Planning, 75(3-4), 187-197. https://doi.org/10.1016/j.landurbplan.2005.02.014

Antrop, M. (2013). A brief history of landscape research. In P. Howard, I. Thompson, \& E. Waterton (Eds.), The Routledge companion to landscape studies (pp. 12-22). Routledge.

Appleton, J. (1997). The integrity of the landscape movement. In P. Groth \& T. W. Bressi (Eds.), Understanding Ordinary Landscapes (pp. 189-199). Yale University Press.

Appleyard, D. (1979). The conservation of European cities. (D. Appleyard, Ed.). MIT Press.

Ashworth, G. J., \& Page, S. J. (2011). Urban tourism research: Recent progress and current paradoxes. Tourism Management, 32, 1-15. https://doi.org/10.1016/j.tourman.2010.02.002

Assche, K. Van, \& Lo, M. C. (2011). Planning, preservation and place branding: A tale of sharing assets and narratives. Place Branding and Public Diplomacy, 7(2), 116126. https://doi.org/10.1057/pb.2011.11

Avieli, N. (2015). The rise and fall (?) of Hội An, a UNESCO World Heritage Site in Vietnam. Journal of Social Issues in Southeast Asia, 30(1), 35-71.

Bajracharya, S. (2002). Replicating sucess: A model for conservation and development projects. Berlin: Berlin Institute for World Population and Global Development.

Bajracharya, S. (2011). Tourism development in Annapurna Conservation Area. In E. Kruk, H. Kreutszmann, \& J. Ritcher (Eds.), Proceedings of the Regional Workshop: Integrated Tourism Concepts to Contribute to Sustainable Mountain Development in Nepal (pp. 127-142). Kathmandu: ICIMOD. https://doi.org/10.13140/RG.2.1.2615.8807

Bajracharya, S., \& Dahal, N. (Eds.). (2008). Shifting paradigms in protected area management. Kathmandu: NTNC.

Bajracharya, S., Furley, P. A., \& Newton, A. C. (2006). Impacts of community-based conservation on local communities in the Annapurna Conservation Area, Nepal. Biodiversity and Conservation, 15, 2765-2786. https://doi.org/10.1007/s10531005-1343-x 
Banskota, K. (2012). Impact of tourism on local mmployment and incomes in three selected destinations: Case studies of Sauraha, Nagarkot and Bhaktapur. Nepal Tourism and Development Review, 2.

Baral, N. (2013). Evaluation and resilience of ecotourism in the Annapurna Conservation Area, Nepal. Environmental Conservation, 41(1), 84-92. https://doi.org/10.1017/S0376892913000350

Baral, N., \& Stern, M. (2011). A comparative study of two community-based conservation models in Nepal. Biodivers Conserv, 20, 2407-2426. https://doi.org/10.1007/s10531-011-9993-3

Baral, N., Stern, M., \& Bhattarai, R. (2008). Contingent valuation of ecotourism in Annapurna Conservation Area, Nepal: Implications for sustainable park finance and local development. Ecological Economics, 66, 218-227. https://doi.org/10.1016/j.ecolecon.2008.02.004

Baral, N., Stern, M., \& Heinen, J. (2007). Integrated conservation and development project life cycles in the Annapurna Conservation Area, Nepal: Is development overpowering conservation? Biodivers Conserv, 16(10), 2903-2917. https://doi.org/10.1007/s10531-006-9143-5

Baral, N., Stern, M. J., \& Hammett, A. L. (2012). Developing a scale for evaluating ecotourism by visitors: A study in the Annapurna Conservation Area, Nepal. Journal of Sustainable Tourism, 20(7), 975-989. https://doi.org/10.1080/09669582.2012.663379

Baral, N., Stern, M. J., \& Heinen, J. T. (2010). Growth, collapse, and reorganization of the Annapurna Conservation Area, Nepal: An analysis of institutional resilience. Ecology and Society, 15(3). https://doi.org/10

Barnekow Lillesø, J.-P., Shrestha, T. B., Dhakal, L. P., Nayaju, R. P., \& Shrestha, R. (2005). The map of potential vegetation of Nepal: A forestry/agroecological/biodiversity classification system. Hørsholm: Center for Skov, Landskab og Planlægning/Københavns Universitet. (Development and Environment; No. 2/2005).

Beazley, R., \& Lassoie, J. (2017). Himalayan mobilities: An exploration of the impacts of expanding rural road networks on social and ecological systems in the Nepalese Himalaya. Cham: Springer. https://doi.org/10.1007/978-3-319-55757-1

Bellentani, F. (2016). Landscape as text. In C. J. R. Higuera \& T. J. B. Bennett (Eds.), Concepts for Semiotics (pp. 76-87). University of Tartu Press.

Bender, B. (1993). Landscape: Politics and perspectives. Berg.

Berleant, A. (2005a). Aesthetics and environment: Variations on a theme. Ashgate Publishing Limited.

Berleant, A. (2005b). Ideas for a social aesthetic. In A. Light \& J. M. Smith (Eds.), The aesthetics of everyday life (pp. 23-38). New York: Columbia University Press. 
Berleant, A. (2017). Objects into persons: The way to social aesthetics. ESPES, 6(2), 918.

Berleant, A., \& Carlson, A. (2007). The aesthetics of human environments. Broadview Press.

Beza, B. B. (2010). The aesthetic value of a mountain landscape: A study of the Mt. Everest trek. Landscape and Urban Planning, 97(4), 306-317. https://doi.org/10.1016/j.landurbplan.2010.07.003

Bhandari, K. (2010). Tourism in Nepal: Post-monarchy challenges. Journal of Tourism and Cultural Change, 8(1-2), 69-83. https://doi.org/10.1080/14766825.2010.491917

Bhandari, K., \& Bhandari, T. (2012). Imagining the Nepali 'nation' through tourism. Journal of Heritage Tourism, 7(3), 239-254. https://doi.org/10.1080/1743873X.2012.701629

Bhusal, N. P. (2009). Chitwan National Park: A prime destination of eco-tourism in Central Tarai Region, Nepal. The Third Pole: Journal of Geography Education, 5(7), 70-75.

Bieling, C., Plieninger, T., Pirker, H., \& Vogl, C. R. (2014). Linkages between landscapes and human well-being: An empirical exploration with short interviews. Ecological Economics, 105, 19-30. https://doi.org/10.1016/j.ecolecon.2014.05.013

Bodach, S., Lang, W., \& Hamhaber, J. (2014). Climate responsive building design strategies of vernacular architecture in Nepal. Energy \& Buildings, 81, 227-242. https://doi.org/10.1016/j.enbuild.2014.06.022

Bookbinder, M. P., Dinerstein, E., Rijal, A., Cauley, H., \& Rajouria, A. (1998). Ecotourism's support of biodiversity conservation. Conservation Biology, 12(6), 1399-1404. https://doi.org/10.1111/j.1523-1739.1998.97229.x

Bourassa, S. C. (1988). Toward a theory of landscape aesthetics. Landscape and Urban Planning, 15(3-4), 241-252. https://doi.org/10.1016/0169-2046(88)90048-5

Bourassa, S. C. (1990). A paradigm for landscape aesthetics. Environment and Behaviour, 22(6), 787-812.

Brown, G., \& Raymond, C. (2007). The relationship between place attachment and landscape values: Toward mapping place attachment. Applied Geography, 27(2), 89-111. https://doi.org/10.1016/j.apgeog.2006.11.002

Brown, K., Turner, R. K., Hameed, H., \& Bateman, I. (1997). Environmental carrying capacity and tourism development in the Maldives and Nepal. Environmental Conservation, 24(4), 316-325.

Buckley, R. (2003). Environmental inputs and outputs in ecotourism: Geotourism with a positive triple bottom line? Journal of Ecotourism, 2(1), 76-82. https://doi.org/10.1080/14724040308668135org/10.1080/14724040308668135 
Buckley, R., Ollenburg, C., \& Zhong, L. (2008). Cultural landscape in Mongolian tourism. Annals of Tourism Research, 35(1), 47-61. https://doi.org/10.1016/j.annals.2007.06.007

Burch, W. R. (1969). The social circles of leisure: Competing explanations. Journal of Leisure Research, 1, 124-147. https://doi.org/10.1080/00222216.2009.11950176

Burke, P. (2001). Eyewitnessing: The uses of images as historical evidence. Cornell University Press.

Butler, R. W. (1995). Introduction. In R. W. Butler \& D. G. Pearce (Eds.), Change in tourism: People, places, processes (pp. 1-11). Routledge.

Butler, R. W. (1998). Tartan mythology: The traditional tourist image of Scotland. In G. D. Ringer (Ed.), Destinations: Cultural landscapes of tourism (pp. 121-139). Routledge.

Butler, R. W., \& Waldbrook, L. A. (2003). A new planning tool: the Tourism Opportunity Spectrum. The Journal of Tourism Studies, 14(1), 25-36.

Byers, A. (1987). An assessment of landscape change in the Khumbu Region of Nepal using repeat photography. Mountain Research and Development, 7(1), 77-81.

Byrd, E. T. (2007). Stakeholders in sustainable tourism development and their roles: Applying stakeholder theory to sustainable tourism development. Tourism Review, 62(2), 6-13. https://doi.org/10.1108/16605370780000309

Caletrío, J. (2011). Tourism, landscape change and critical thresholds. Annals of Tourism Research, 38(1), 313-316. https://doi.org/10.1016/j.annals.2010.07.009

Carlson, A. (2005). Environmental aesthetics. In B. Gaut \& D. M. Lopes (Eds.), The Routledge companion to aesthetics (2nd ed., pp. 541-555). Routledge.

Carlson, A. (2016). Environmental aesthetics. In E. N. Zalta (Ed.), The Stanford encyclopedia of philosophy. Stanford University.

Carneiro, M. J., Lima, J., \& Silva, L. (2015). Landscape and the rural tourism experience: identifying key elements, addressing potential, and implications for the future. Journal of Sustainable Tourism, 23(8-9), 1217-1235. https://doi.org/10.1080/09669582.2015.1037840

CBS. (2012). National population and housing census 2011 (Village Development Committee/Municipality). Kathmandu: Central Bureau of Statistics, Government of Nepal.

Chakraborty, S. (2010). Sustainable and value based tourism in Nepal - Travel writer's perspective. International Journal of Hospitality \& Tourism Systems, 3(1), 131138.

Chapagain, N. K. (2007). Revisiting conservation charters in context of Lomanthang, Nepal: Need to acknowledge local inhabitants and changing contexts. City \& Time, 
$3(2), 55-65$.

Chapagain, N. K. (2008). Heritage conservation in Nepal: Policies, stakeholders and challenges. In Third Annual Himalayan Policy Research Conference (pp. 1-26). Madison.

Chapagain, N. K. (2011). Rethinking cultural heritage conservation at historic settlements: The case of Lomanthang, Nepal. Unpublished doctoral dissertation, University of Wisconsin-Milwaukee.

Chen, Z., Xu, B., \& Devereux, B. (2016). Assessing public aesthetic preferences towards some urban landscape patterns: the case study of two different geographic groups. Environmental Monitoring and Assessment, 188(4). https://doi.org/10.1007/s10661-015-5007-3

Chitwan National Park. (2015). Chitwan National Park and it's buffer zone management plan 2013-2017. Chitwan.

Clark, C. D. (1999). The Autodriven interview: A photographic viewfinder into children's $\quad$ experience. Visual Studies, 14(1), 39-50. https://doi.org/10.1080/14725869908583801

Cochrane, J. (2012). National parks in Indonesia: an alien construct. In W. Frost \& C. M. Hall (Eds.), Tourism and national parks: International perspectives on development, histories and change (pp. 211-224). Routledge.

Cohen, D., \& Crabtree, B. (2006). Qualitative research guidelines project. Retrieved August 14, 2018, from http://www.qualres.org/HomeSemi-3629.html

Cohen, E. (1995). Contemporary tourism - trends and challenges: sustainable authenticity or contrived post-modernity? In R. W. Butler \& D. G. Pearce (Eds.), Change in tourism: people, places, processes (pp. 12-29). London: Routledge.

Collier, J. (1957). Photography in anthropology: A report on two experiments. American Anthropologist, 59(5), 843-859.

Conrad, E., Christie, M., \& Fazey, I. (2011). Understanding public perceptions of landscape: A case study from Gozo, Malta. Applied Geography, 31(1), 159-170. https://doi.org/10.1016/j.apgeog.2010.03.009

Cosgrove, D. E. (2003). Landscape: ecology and semiosis. In H. Palang \& G. Fry (Eds.), Landscape interfaces: Cultural heritage in changing landscapes (pp. 15-20). Kluwer Academic Publishers.

Cosgrove, D. E. (2008). Geography and vision: Seeing, imagining and representing the world. I.B. Tauris.

Costanza, R., de Groot, R., Braat, L., Kubiszewski, I., Fioramonti, L., Sutton, P., ... Grasso, M. (2017). Twenty years of ecosystem services: How far have we come and how far do we still need to go? Ecosystem Services, 28, 1-16. https://doi.org/10.1016/J.ECOSER.2017.09.008 
Council of Europe. (2000). European Landscape Convention. Report and Convention $\begin{array}{llll}\text { Florence, } & \text { ETS } & \text { No. } & \text { 17(176), }\end{array}$ https://doi.org/http://conventions.coe.int/Treaty/en/Treaties/Html/176.htm

Crang, M. (1999). Knowing, tourism and practices of vision. In M. Crang (Ed.), Leisure/Tourism Geographies: Practices and Geographical Knowledge (pp. 238256). Routledge.

Crang, M. (2006). Cultural geographies of tourism. In A. A. Lew, C. M. Hall, \& A. M. Williams (Eds.), A Companion to Tourism (pp. 74-84). John Wiley \& Sons.

Croes, K. D. (2007). Nature of a nation: monarch, development, and culture in Nepal's Annapurna Conservation Area Project. Princeton University.

Daconto, G., \& Sherpa, L. N. (2010). Applying scenario planning to park and tourism management in Sagarmatha National Park, Khumbu, Nepal. Mountain Research and Development, 30(2), 103-112. https://doi.org/10.1659/MRD-JOURNAL-D09-00047.1

Dahal, S., \& SK Nepal, S. K. (2016). Conservation for whom? Parks, people and tourism in Annapurna Conservation Area, Nepal. In Political Ecology and Tourism (pp. 130-144). Taylor \& $\quad$ Francis. https://doi.org/https://doi.org/10.4324/9781315723471

Dahal, S., SK Nepal, S. K., \& Schuett, M. A. (2014). Examining marginalized communities and local conservation institutions: The case of Nepal's Annapurna Conservation Area. Environment Management, 53, 219-230. https://doi.org/10.1007/s00267-013-0204-8

Daniel, T. C. (2001). Whither scenic beauty? Visual landscape quality assessment in the 21st century. Landscape and Urban Planning, 54(1-4), 267-281. https://doi.org/10.1016/S0169-2046(01)00141-4

Daniel, T. C., Muhar, A., Arnberger, A., Aznar, O., Boyd, J. W., Chan, K. M. A., ... Turner, B. L. (2012). Contributions of cultural services to the ecosystem services agenda. PNAS, 109(23), 8812-8819. https://doi.org/10.1073/pnas.1114773109

Daugstad, K. (2008). Negotiating landscape in rural tourism. Annals of Tourism Research, 35(2), 402-426. https://doi.org/10.1016/j.annals.2007.10.001

Davenport, M. A., \& Anderson, D. H. (2005). Getting from sense of place to place-based management: An interpretive investigation of place meanings and perceptions of landscape change. Society and Natural Resources, 18(7), 625-641. https://doi.org/10.1080/08941920590959613

de San Eugenio Vela, J., Nogué, J., \& Govers, R. (2017). Visual landscape as a key element of place branding. Journal of Place Management and Development, 10(1), 23-44. https://doi.org/10.1108/JPMD-09-2016-0060

Déjeant-Pons, M. (2006). The European Landscape Convention. Landscape Research, 31(4), 363-384. https://doi.org/10.1080/01426390601004343 
Denzin, N. K., \& Lincoln, Y. S. (2005). The SAGE handbook of qualitative research (3rd ed.). Thousand Oaks, Calif.: Sage Publications.

Dinerstein, E. (2003a). Does privately owned ecotourism support conservation of charismatic large mammals? In Return of the Unicorns: Natural history and conservation of the Greater-One Horned Rhinoceros. Columbia University Press. https://doi.org/10.7312/dine08450.17

Dinerstein, E. (2003b). Endangered phenomena: Rhinoceros as landscape architects. In Return of the Unicorns: Natural History and Conservation of the Greater-One Horned Rhinoceros. Columbia University Press. https://doi.org/10.7312/dine08450.15

Dowling, R. K., \& Newsome, D. (2010). Global geotourism perspectives. Goodfellow Publishers.

DuPuis, E. M. (2006). Landscapes of desires? In P. J. Cloke, T. Marsden, \& P. H. Mooney (Eds.), Handbook of Rural Studies (pp. 124-132). Sage Publications.

Dyer, C. (2009). Vernacular architecture and landscape history: The legacy of "The rebuilding of rural England" and "The making of the English landscape"., 37, 2432. https://doi.org/10.1179/174962906X158228

Eagles, P. F. J., \& McCool, S. F. (2002). Tourism in national parks and protected areas : planning and management. CABI Pub.

Emerson, R. M., Fretz, R. I., \& Shaw, L. L. (2001). Participant observation and fieldnotes. Handbook of Ethnography, 352-369. https://doi.org/http://dx.doi.org/10.4135/9781848608337

Ewen, M. A. (2007). Sustainable development through tourism: Conflicts between theory and practice. The case of the Annapurna Region of Nepal. Unpublished doctoral dissertation, Brunel University.

Fagerholm, N., Käyhkö, N., Ndumbaro, F., \& Khamis, M. (2012). Community stakeholders' knowledge in landscape assessments - Mapping indicators for landscape services. Ecological Indicators, 18, 421-433. https://doi.org/10.1016/J.ECOLIND.2011.12.004

Fisher, J. F. (1990). A torrent of tourists. In Sherpas: Reflections on Change in Himalayan Nepal. University of California Press. https://doi.org/10.1525/j.ctt1ppb51.12

Foley, D., \& Valenzuela, A. (2005). Critical ethnography: The politics of collaboration. In N. K. Denzin \& Y. S. Lincoln (Eds.), The SAGE handbook of qualitative research (pp. 217-234). Sage Publications.

Folmar, S. (2003). Caste and community participation in cultural tourism in Nepal. Practicing Anthropology, 25(2), 3-6.

Fontana, A., \& Frey, J. H. (2005). The interview: From neutral stance to political 
involvement. In N. K. Denzin \& Y. S. Lincoln (Eds.), The SAGE handbook of qualitative research (3rd ed., pp. 695-728). Thousand Oaks: Sage Publications.

Frost, W., \& Hall, C. M. (2012). Tourism and national parks: International perspectives on development, histories and change. (W. Frost \& C. M. Hall, Eds.). Routledge.

Gautam, B. P. (2014). Economic dynamics of tourism in Nepal: A VECM approach. MPRA Paper 58102, University Library of Munich, Germany.

Gerring, J. (2007). Case study research : principles and practices. Cambridge University Press.

Getz, D., \& Page, S. J. (2016). Progress and prospects for event tourism research. Tourism Management, 52, 593-631. https://doi.org/10.1016/j.tourman.2015.03.007

Ghimire, K. B. B., \& Pimbert, M. P. (2009). Social change and conservation. (K. B. Ghimire \& M. P. Pimbert, Eds.). London: Earthscan Publications Limited.

Giannakopoulou, S., \& Kaliampakos, D. (2016). Protection of architectural heritage: attitudes of local residents and visitors in Sirako, Greece. Journal of Mountain Science, 13(3), 424-439. https://doi.org/10.1007/S11629-015-3482-1

Gifford, R., Hine, D. W., Muller-Clemm, W., Shaw, K. T., \& Gijford, R. (2002). Why architects and laypersons judge buildings differently: Cognitive properties and physical bases. Journal of Architectural and Planning Research, 19(2), 131-148.

Gkoltsiou, A., \& Terkenli, T. S. (2012). An interdisciplinary analysis of tourist landscape structure. Tourismos: An Intenational Multidisciplinary Journal of Tourism, 7(2), $145-164$.

Gkoltsiou, A., Terkenli, T. S., \& Koukoulas, S. (2013). Landscape indicators for the evaluation of tourist landscape structure. International Journal of Sustainable Development \& World Ecology, 20(5), 461-475. https://doi.org/10.1080/13504509.2013.827594

Gobster, P. H., Nassauer, J., Daniel, T. C., \& Fry, G. (2007). The shared landscape: what does aesthetics have to do with ecology? Landscape Ecology, 22, 959-972. https://doi.org/10.1007/s10980-007-9110-x

Gonzalez, V. M., Coromina, L., \& Galí, N. (2018). Overtourism: Residents' perceptions of tourism impact as an indicator of resident social carrying capacity - case study of a Spanish heritage town. Tourism Review.

Gotham, K. F. (2005). Tourism gentrification: The case of New Orleans' Vieux Carre (French Quarter). Urban Studies, 42(7), 1099-1121. https://doi.org/10.1080/00420980500120881

Goulding, R., Horan, E., \& Tozzi, L. (2014). The importance of sustainable tourism in reversing the trend in the economic downturn and population decline of rural communities. PASOS. Revista de Turismo y Patrimonio Cultural, 12, 549-563. 
Government of Nepal, M. of U. D. Housing development, urban planning and building construction basic guidelines 2072 (2016). Nepal.

Graburn, N. H. H. (1995). The past in the present in Japan: Nostalgia and neotraditionalism in contemporary Japanese domestic tourism. In R. W. Butler \& D. G. Pearce (Eds.), Change in tourism: People, places, processes (pp. 47-70).

Grammatikopoulou, I., Pouta, E., Salmiovirta, M., \& Soini, K. (2012). Heterogeneous preferences for agricultural landscape improvements in southern Finland. Landscape and Urban Planning, 107, 181-191. https://doi.org/10.1016/j.landurbplan.2012.06.001

Guachalla, A. (2018). Perception and experience of urban areas for cultural tourism: A social constructivist approach in Covent Garden. Tourism and Hospitality Research, 18(3), 297-308. https://doi.org/10.1177/1467358416646820

Guha, R. (1997). Radical American environmentalism and wilderness preservation. In L. Robin, S. Sörlin, \& P. Warde (Eds.), The future of nature: Documents of global change (pp. 409-431). Yale University Press.

Gurung, C. P. (1993). Conservation for sustainable development: Myth or reality? A case of the Annapurna Conservation Area Project, Nepal. HIMALAYA, the Journal of the Association for Nepal and Himalayan Studies, 13(1), 31-38.

Gurung, H. (2004). Landscape change in the Nepal hills: Evidence from Lamjung. Kathmandu: ICIMOD.

Gurung, H. B. (2008). Fusioning: A grounded theory of participatory governance in the Annapurna Conservation Area, Nepal. Unpublished doctoral dissertation, Griffith University.

Gurung, H. B., Buckley, R., Castley, G., \& Jennings, G. (n.d.). Tourism and local communities in the Annapurna Region, Nepal, 1-24.

Guzzella, L., Salerno, F., Freppaz, M., Roscioli, C., Pisanello, F., \& Poma, G. (2016). POP and PAH contamination in the southern slopes of Mt. Everest (Himalaya, Nepal): Long-range atmospheric transport, glacier shrinkage, or local impact of tourism? Science of The Total Environment, 544, 382-390. https://doi.org/10.1016/J.SCITOTENV.2015.11.118

Hall, C. M. (2004). Reflexivity and tourism research: Situating myself and/with others. In L. Goodson \& J. Phillimore (Eds.), Qualitative research in tourism: Ontologies, Epistemologies and Methodologies (pp. 137-333). Routledge.

Hall, N. A. (2014). Aesthetic perception, nature and experience. Unpublished doctoral dissertation, University of Edinburgh.

Han, F. (2006). The Chinese view of nature: Tourism in China's scenic and historic interest areas. Unpublished doctoral dissertation, Queensland University of Technology. 
Harper, D. (1987). The visual ethnographic narrative. Visual Anthropology, 1(1), 1-19. https://doi.org/https://doi.org/10.1080/08949468.1987.9966457

Harper, D. (2002). Talking about pictures: A case for photo elicitation. Visual Studies, 17(1), 13-26. https://doi.org/10.1080/14725860220137345

Harrill, R., \& Potts, T. D. (2003). Tourism planning in historic districts: Attitudes toward tourism development in Charleston. Journal of the American Planning Association, 69(3), 233-244.

Harrison, D., \& Hitchcock, M. (2005). The politics of world heritage: Negotiating tourism and conservation. Channel View Publications.

Heinen, J. T., \& Kattel, B. (1992). Parks, people, and conservation: A review of management issues in Nepal's protected areas. Population and Environment: A Journal of Interdisciplinary Studies, 14(1), 49-84.

Hepburn, S. J. (2002). Touristic forms of life in Nepal. Annals of Tourism Research, 29(3), 611-630. https://doi.org/10.1016/S0160-7383(01)00070-6

Hersperger, A. M., \& Bürgi, M. (2009). Going beyond landscape change description: Quantifying the importance of driving forces of landscape change in a Central Europe case study. Land Use Policy, 26(3), 640-648. https://doi.org/10.1016/J.LANDUSEPOL.2008.08.015

Highmore, B. (2004). Homework: Routine, social aesthetics and the ambiguity of everyday life. Cultural Studies, 18(2-3), 306-327. https://doi.org/10.1080/0950238042000201536

Holden, A. (2010). Exploring stakeholders' perceptions of sustainable tourism development in the Annapurna Conservation Area: Issues and challenge. Tourism and Hospitality Planning \& Development, 7(4), 337-351.

Hollinshead, K. (1999). Surveillance of the worlds of tourism: Foucault and the eye-ofpower. Tourism Management, 20(1), 7-23. https://doi.org/10.1016/S02615177(98)00090-9

Holstein, J. A., \& Gubrium, J. F. (2005). Interpretive practice and social action. In N. K. Denzin \& Y. S. Lincoln (Eds.), The SAGE handbook of qualitative research (3rd ed., pp. 483-506). Thousand Oaks: Sage Publications.

Honggang, X., \& Chaozhi, Z. (2012). National parks in transition: Wuyishan scenic park in China. In W. Frost \& C. M. Hall (Eds.), Tourism and national Parks: International perspectives on development, histories and change (pp. 225-237).

Hoskins, W. G. (1953). The rebuilding of rural England, 1570-1640. Past \& Present, 4(Nov.), 44-59.

Howley, P. (2011). Landscape aesthetics: Assessing the general publics' preferences towards rural landscapes. Ecological Economics, 72, 161-169. https://doi.org/10.1016/j.ecolecon.2011.09.026 
Huang, S.-C. L. (2013). Visitor responses to the changing character of the visual landscape as an agrarian area becomes a tourist destination: Yilan County, Taiwan. Journal of Sustainable Tourism, 21(1), 154-171. https://doi.org/10.1080/09669582.2012.687739

Huberman, A. M., \& Miles, M. B. (1994). Data management and analysis methods. In N. K. Denzin \& Y. S. Lincoln (Eds.), Handbook of qualitative research (pp. 428445). Thousand Oaks, Calif.: Sage Publications.

Hull, R. B., \& Reveli, G. R. B. (1989). Cross-cultural comparison of landscape scenic beauty evaluations: A case study in Bali. Journal of Environmental Psychology, 9(3), 177-191. https://doi.org/10.1016/S0272-4944(89)80033-7

Hussain, A., Fisher, D., \& Espiner, S. (2017). Transport infrastructure and social inclusion: A case study of tourism in the region of Gilgit-Baltistan. Social Inclusion, 5(4), 196-208.

Iltis, L. L. (1980). An ethnohistorical study of Bandipur. Contributions to Nepalese Studies, 8(1), 81-145.

Jackson, J. B. (1970). “Other-directed houses.” In Landscapes: Selected writings of J. B. Jackson (pp. 55-72). Amherst University of Massachusetts Press.

Jackson, J. B. (1995). A sense of place, a sense of time. Design Quarterly, 164(Spring), 24-27.

Jacobsen, J. K. S. (2007). Use of landscape perception methods in tourism studies: A review of photo-based research approaches. Tourism Geographies, 9(3), 234-253. https://doi.org/10.1080/14616680701422871

Jacques, D. (1995). The rise of cultural landscapes. International Journal of Heritage Studies, 1(2), 91-101. https://doi.org/10.1080/13527259508722136

Jansen-Verbeke, M. (2008). Cultural landscapes and tourism dynamics: Explorative case studies. In M. Jansen-Verbeke, G. K. Priestley, \& A. P. Russo (Eds.), Cultural resources for tourism (pp. 125-144). Nova Science Publishers, Incorporated.

Janusz, K., Six, S., \& Vanneste, D. (2017). Building tourism-resilient communities by incorporating residents' perceptions? A photo-elicitation study of tourism development in Bruges. Journal of Tourism Futures, 3(2), 127-143. https://doi.org/10.1108/JTF-04-2017-0011

Jennings, G. (2010). Tourism research (2nd ed.). Queensland: John Wiley \& Sons.

Johnson, A. J. (2014). Visual methods in leisure research. World Leisure Journal, 56(4), 317-323. https://doi.org/10.1080/16078055.2014.958194

Jones, M. (2003). The concept of cultural landscape: discourse and narratives. In H. Palang \& G. Fry (Eds.), Landscape interfaces: Cultural heritage in changing landscapes (pp. 21-52). Kluwer Academic Publishers. 
Jorgensen, A. (2011). Beyond the view: Future directions in landscape aesthetics research. Landscape and Urban Planning, 100, 353-355. https://doi.org/10.1016/j.landurbplan.2011.02.023

Joshi, J. (2014). The Buddhist Stupa at Bauddhanath: A World Heritage Site under pressure. In T. R. Gensheimer \& C. L. Guicchard (Eds.), World Heritage and National Registers: Stewardship in Perspective. Transaction Publishers.

Kalivoda, O., Vojar, J., Skřivanová, Z., \& Zahradník, D. (2014). Consensus in landscape preference judgments: The effects of landscape visual aesthetic quality and respondents' characteristics. Journal of Environmental Management, 137, 36-44. https://doi.org/10.1016/J.JENVMAN.2014.02.009

Kaltenborn, B. P., Andersen, O., Nellemann, C., Bjerke, T., \& Thrane, C. (2008). Resident attitudes towards mountain second-home tourism development in Norway: The effects of environmental attitudes. Journal of Sustainable Tourism, 16(6), 664. https://doi.org/10.2167/jost792.0

Kaltenborn, B. P., \& Bjerke, T. (2002). Association between environmental value orientations and landscape preferences. Landscape and Urban Planning, 59(1), 111. https://doi.org/10.1016/S0169-2046(01)00243-2

Kaplan, R., \& Herbert, E. J. (1987). Cultural and sub-cultural comparisons in preferences for natural settings. Landscape and Urban Planning, 14, 281-293.

Kaplan, R., \& Kaplan, S. (1989). The experience of nature: A psychological perspective. Cambridge University Press.

Karanth, K. K., \& SK Nepal, S. K. (2012). Local residents perception of benefits and losses from protected areas in India and Nepal. Environmental Management, 49, 372-386. https://doi.org/10.1007/s00267-011-9778-1

KC, A., Rijal, K., \& Sapkota, R. P. (2015). Role of ecotourism in environmental conservation and socioeconomic development in Annapurna conservation area, Nepal. International Journal of Sustainable Development \& World Ecology, 22(3), 251-258. https://doi.org/10.1080/13504509.2015.1005721

KC, A., \& Thapa Parajuli, R. B. (2014). Climate change and its impact on tourism in the Manaslu Conservation Area, Nepal. Tourism Planning \& Development, 12(2), 225237. https://doi.org/10.1080/21568316.2014.933122

KC, B., Paudyal, R., \& Neupane, S. S. (2018). Residents' perspectives of a newly developed ecotourism project: An assessment of effectiveness through the lens of an importance-performance analysis. Asia Pacific Journal of Tourism Research, 23(6), 560-572. https://doi.org/10.1080/10941665.2018.1467938

Khadka, D., \& SK Nepal, S. K. (2010). Local responses to participatory conservation in Annapurna Conservation Area, Nepal. Environmental Management, 45(2), 351362. https://doi.org/10.1007/s00267-009-9405-6

Kianicka, S., Buchecker, M., Hunziker, M., \& Müller-Böker, U. (2006). Locals’ and 
tourists' sense of place: A case study of a Swiss Alpine village. Mountain Research and Development, 26(1), 55-63. https://doi.org/10.1659/02764741(2006)026[0055:LATSOP]2.0.CO;2

Kirillova, K., Fu, X., Lehto, X., \& Cai, L. (2014). What makes a destination beautiful? Dimensions of tourist aesthetic judgment. Tourism Management, 42, 282-293. https://doi.org/10.1016/j.tourman.2013.12.006

Kirillova, K., \& Lehto, X. (2015). Destination aesthetics and aesthetic distance in tourism experience. Journal of Travel \& Tourism Marketing, 32(8), 1051-1068. https://doi.org/10.1080/10548408.2014.958608

Knapp, R. G. (1992). Chinese landscapes: The village as a place (Illustrate). Hawaii: University of Hawaii Press.

Knudsen, D. C., Metro-Roland, M. M., Soper, A. K., \& Greer, C. E. (Eds.). (2008). Landscape, tourism, and meaning. Ashgate Publishing Limited. https://doi.org/10.1111/j.1745-5871.2010.00672.x

Knudsen, D. C., Metro-Roland, M., \& Rickly, J. M. (2015). Tourism, aesthetics, and touristic judgment. Tourism Review International, 19(4), 179-191.

Knudsen, D. C., Soper, A. K., \& Metro-Roland, M. (2007). Gazing, performing and reading: A landscape approach to understanding meaning in tourism theory. Tourism Geographies, 9(3), 227-233. https://doi.org/10.1080/14616680701422681

Krause, C. L. (2001). Our visual landscape: Managing the landscape under special consideration of visual aspects. Landscape and Urban Planning, 54, 239-254.

Krausler, C., \& Pröbstl-haider, U. (2016). Relevance of local architecture for destination choice in Austria. Sustainable Development and Planning, 11(3), 426-435. https://doi.org/10.2495/SDP-V11-N3

Kreutzmann, H. (1991). The Karakoram highway: The impact of road construction on mountain societies. Modern Asian Studies, 25(4), 711-736.

Kuniyal, J. C. (2005). Solid waste management in the Himalayan trails and expedition summits. Journal of Sustainable Tourism, 13(4), 391-410. https://doi.org/10.1080/09669580508668564

Lama, A. K., \& Job, H. (2014). Protected areas and road development: Sustainable development discourses in the Annapurna Conservation Area, Nepal. Erdkunde, 68(4), 229-250. https://doi.org/10.3112/erdkunde.2014.04.01

Leddy, T. (2005). The nature of everyday aesthetics. In A. Light \& J. M. Smith (Eds.), The aesthetics of everyday life (pp. 3-22). New York: Columbia University Press.

Lew, A. A. (2014). Managing and adapting to global change in tourism places. Tourism Geographies, 16(3), 343-345. https://doi.org/10.1080/14616688.2014.942234

Liechty, M. (2017). Far out: Countercultural seekers and the tourist encounter in Nepal. 
Chicago: University of Chicago Press.

Lim, F. K. G. (2007). Hotels as sites of power: Tourism, status, and politics in Nepal Himalaya. Journal of the Royal Anthropological Institute, 13, 721-738. https://doi.org/10.1111/j.1467-9655.2007.00452.x

Lim, F. K. G. (2008). Of reverie and emplacement: Spatial imaginings and tourism encounters in Nepal Himalaya. Inter-Asia Cultural Studies, 9(3), 375-394. https://doi.org/10.1080/14649370802184452

Lo, I. S., \& McKercher, B. (2015). Ideal image in process: Online tourist photography and impression management. Annals of Tourism Research, 52, 104-116. https://doi.org/10.1016/J.ANNALS.2015.02.019

Lothian, A. (1999). Landscape and the philosophy of aesthetics: Is landscape quality inherent in the landscape or in the eye of the beholder? Landscape and Urban Planning, 44(4), 177-198. https://doi.org/10.1016/S0169-2046(99)00019-5

Lowenthal, D. (1978). Finding valued landscapes. Progress in Human Geography, 2(3), 373-418.

Lundberg, E. (2017). The importance of tourism impacts for different local resident groups: A case study of a Swedish seaside destination. Journal of Destination Marketing \& Management, 6(1), 46-55. https://doi.org/10.1016/J.JDMM.2016.02.002

Mackay, K. J., \& Fesenmaier, D. R. (1997). Pictorial element of destination in image formation. Annals of Tourism Research, 24(3), 537-565. https://doi.org/10.1016/S0160-7383(97)00011-X

Mackay, K. J., \& Fesenmaier, D. R. (2000). An exploration of cross-cultural destination image assessment. Journal of Travel Research, 38(4), 417-423. https://doi.org/https://doi.org/10.1177/004728750003800411

Maitland, R., \& Smith, A. (2009). Tourism and the aesthetics of the built environment. In J. Tribe (Ed.), Philosophical issues in tourism (pp. 171-190). Channel View Publications.

Mandoki, K. (2007). Everyday aesthetics: Prosaics, the play of culture and social identities. Ashgate.

Matteucci, X. (2013). Photo elicitation: Exploring tourist experiences with researcherfound images. Tourism Management, 35, 190-197. https://doi.org/10.1016/j.tourman.2012.07.002

Mehta, J. N., \& Heinen, J. T. (2001). Does community-based conservation shape favorable attitudes among locals? An empirical study from Nepal. Environmental Management, 28(2), 165-177. https://doi.org/10.1007/s002670010215

Meier, T. (2012). "Landscape", "environment" and a vision of interdisciplinarity. In S. J. Kluiving \& E. B. Guttmann-Bond (Eds.), Landscape archaeology between art 
and science: From a multi- to an interdisciplinary approach (pp. 503-514). Amsterdam University Press.

Merey Enlil, Z., \& Dincer, I. (2004). The role of heritage conservation in the management of urban regions. In 40th IsoCaRP Congress.

Messerschmidt, D. A. (1980). Gateway-hinter relations in changing Nepal. Contributions to Nepalese Studies (CNAS), 8(1), 21-40.

Milcu, A. I., Hanspach, J., Abson, D., \& Fischer, J. (2013). Cultural ecosystem services: A literature review and prospects for future research. Ecology and Society, 18(3), art44. https://doi.org/10.5751/ES-05790-180344

Millennium Ecosystem Assessment. (2005). Ecosystems and human well-being: Synthesis. Washington, DC: Island Press.

Molnárová, K. J., Skřrivanová, Z., Kalivoda, O., \& Sklenička, P. (2017). Rural identity and landscape aesthetics in exurbia: Some issues to resolve from a Central European perspective. Moravian Geographical Reports, 25(1), 2-12. https://doi.org/10.1515/mgr-2017-0001

Morgan, G., \& Smircich, L. (1980). The Case for Qualitative Research. Academy of Management Review, 5(4), 491-500.

Múgica, M., \& De Lucio, J. V. (1996). The role of on-site experience on landscape preferences. A case study at Doñana National Park (Spain). Journal of Environmental Management, 47(3), 229-239. https://doi.org/10.1006/JEMA.1996.0049

Müller-Böker, U. (1999). The Chitawan Tharus in southern Nepal: An ethnoecological approach. Publications of the Nepal Research Centre. Stuttgart: Steiner.

Nassauer, J. (1995). Culture and changing landscape structure. Landscape Ecology, 10(4), 229-237. https://doi.org/10.1007/BF00129257

Nasser, N. (2003). Planning for urban heritage places: Reconciling conservation, Tourism, and sustainable development. Journal of Planning Literature, 17(4), 468479. https://doi.org/10.1177/0885412203251149

Naveh, Z. (1995). Interactions of landscapes and cultures. Landscape and Urban Planning, 32, 43-54.

Neupane, R., KC, A., \& Pant, R. (2013). Assessing tourism potential in Bhaktapur Durbar Square, Nepal. International Journal of Environment, 2(1), 250-261. https://doi.org/10.1016/0390-5519(77)90077-1

Nohl, W. (2001). Sustainable landscape use and aesthetic perception - preliminary reflections on future landscape aesthetics. Landscape and Urban Planning, 54, 223237.

NTNC. (n.d.). Nepal: People and nature. 
NTNC. (2015). Annual report 2015. Kathmandu.

Nyaupane, G., \& Budruk, M. (2009). South Asian heritage tourism: Conflict, colonialism and cooperation. In D. Timothy \& G. Nyaupane (Eds.), Cultural heritage and tourism in the developing world: A regional perspective (pp. 127-145). Routledge.

Nyaupane, G., Lew, A. A., \& Tatsugawa, K. (2014). Perceptions of trekking tourism and social and environmental change in Nepal's Himalayas. Tourism Geographies, 16(3), 415-437. https://doi.org/10.1080/14616688.2014.942233

Nyaupane, G., Morais, D., \& Dowler, L. (2006). The role of community involvement and number/type of visitors on tourism impacts: A controlled comparison of Annapurna, Nepal and Northwest Yunnan, China. Tourism Management, 27(6), 1373-1385. https://doi.org/10.1016/J.TOURMAN.2005.12.013

Nyaupane, G., \& Poudel, S. (2011). Linkages among biodiversity, livelihood, and tourism. Annals of Tourism Research, 38(4), 1344-1366. https://doi.org/10.1016/J.ANNALS.2011.03.006

Nyaupane, G., \& Poudel, S. (2012). Application of appreciative inquiry in tourism research in rural communities. Tourism Management, 33, 978-987. https://doi.org/10.1016/j.tourman.2011.10.009

Nyaupane, G., \& Thapa, B. (2004). Evaluation of ecotourism: A comparative assessment in the Annapurna Conservation Area Project, Nepal. Journal of Ecotourism, 3(1), $20-45$.

Nyaupane, G., \& Thapa, B. (2006). Perceptions of environmental impacts of tourism: A case study at ACAP, Nepal. International Journal of Sustainable Development \& World Ecology, 13, 51-61. https://doi.org/10.1080/13504500609469661

Oliver, T., \& Jenkins, T. (2003). Sustaining rural landscapes: The role of integrated tourism. Landscape Research, 28(3), 293-307. https://doi.org/10.1080/01426390306516

Orbasli, A. (2000). Tourists in historic towns: Urban conservation and heritage management. E \& FN Spon.

Orland, B. (1988). Aesthetic preference for rural landscapes: Some resident and visitor preferences. In J. L. Nasar (Ed.), Environmental aesthetics: Theory, research and applications (pp. 364-378). Cambridge: Cambridge University Press.

Palang, H., \& Fry, G. (Eds.). (2003). Landscape interfaces: Cultural heritage in changing landscapes. Dordrecht: Kluwer Academic Publishers.

Palmer, C. (2014). Tourism, changing architectural styles, and the production of place in Itacaré, Bahia, Brazil. Journal of Tourism and Cultural Change, 12(4), 349-363. https://doi.org/10.1080/14766825.2014.934378

Pandey, R. N., Chettri, P., Kunwar, R. R., \& Ghimire, G. (1995). Case study on the effects of tourism on culture and the environment: Nepal - Chitwan-Sauraha and Pokhara- 
Ghandruk. RACAP Series on Culture and Tourism in Asia, 4, 66.

Pandit, S. (2012). Marginalization of the Tharu ethnic group in tourism development in Nepal. TURIZAM, 16(2), 40-49.

Pariyar, M. (2016). Overseas caste among military migrants: The migration and settlement of Nepalese Gurkhas in Britain. Unpublished doctoral dissertation, Macquarie University.

Park, E., \& Kim, S. (2018). Are we doing enough for visual research in tourism? The past, present, and future of tourism studies using photographic images. International Journal of Tourism Research, 20(4), 433-441. https://doi.org/10.1002/jtr.2194

Parker, T. (1993). Nature tourism in Nepal. In J. Nenon \& P. B. Durst (Eds.), Nature tourism in Asia: Opportunities and constraints for conservation and economic development (pp. 20-30).

Parsons, R. (1991). The potential influences of environmental perception on human health. Journal of Environmental Psychology, 11, 1-23. https://doi.org/10.1016/S0272-4944(05)80002-7

Parsons, R., \& Daniel, T. C. (2002). Good looking: In defense of scenic landscape aesthetics. Landscape and Urban Planning, 60(1), 43-56. https://doi.org/10.1016/S0169-2046(02)00051-8

Pawson, I. G., Stanford, D. D., Adams, V., \& Nurbu, M. (1984). Growth of tourism in Nepal's Everest Region: Impact on the physical environment and structure of human settlements. Mountain Research and Development, 4(3), 237-246. https://doi.org/10.2307/3673144

Pearce, D. (1993). Comparative studies in tourism research. In D. Pearce \& R. Butler (Eds.), Tourism research: Critiques and challenges (pp. 20-35). Routledge.

Pearce, D., \& Butler, R. W. (1993). Tourism research: Critiques and challenges. Routledge in association with the International Academy for the Study of Tourism.

Pearce, P. (1977). Mental souvenirs: A study of tourists and their city maps. Australian Journal of Psycholocy, 29(3), 203-210. https://doi.org/10.1080/00049537708255282

Petrzelka, P., Krannich, R. S., Brehm, J., \& Trentelman, C. K. (2005). Rural tourism and gendered nuances. Annals of Tourism Research, 32(4), 1121-1137. https://doi.org/10.1016/J.ANNALS.2005.04.007

Phillimore, J., \& Goodson, L. (2004). Qualitative research in tourism: Ontologies, epistemologies and methodologies. Routledge.

Phillips, C. (2003). Sustainable Place: A Place of Sustainable Development. Chichester: Wiley.

Phillips, C., \& Yannas, S. (1999). Sustainable place: A place of sustainable development. 
AA Files, (39), 77-79.

Pink, S. (2006). The future of visual anthropology: Engaging the senses. New York: Routledge.

Pink, S. (2012). Advances in Visual Methodology. London: SAGE Publications Ltd. https://doi.org/10.4135/9781446250921

Pitkänen, K. (2008). Second-home landscape: The meaning(s) of landscape for secondhome tourism in Finnish Lakeland. Tourism Geographies, 10(2), 169-192. https://doi.org/10.1080/14616680802000014

Plieninger, T., Kizos, T., Bieling, C., Dû-Blayo, L. Le, Budniok, M. A., Bürgi, M., ... Verburg, P. H. (2015). Exploring ecosystem-change and society through a landscape lens: Recent progress in european landscape research. Ecology and Society, 20(2). https://doi.org/10.5751/ES-07443-200205

Plieninger, T., van der Horst, D., Schleyer, C., \& Bieling, C. (2014). Sustaining ecosystem services in cultural landscapes. Ecology and Society, 19(2). https://doi.org/10.5751/ES-06159-190259

Pons, P. O., Crang, M., \& Travlou, P. (2009). Cultures of mass tourism: Doing the Mediterranean in the age of banal mobilities. (P. O. Pons, M. Crang, \& P. Travlou, Eds.). Ashgate.

Poudel, S., \& Nyaupane, G. (2013). The role of interpretative tour guiding in sustainable destination management: A comparison between guided and nonguided tourists. Journal of Travel Research, 52(5), 659-672. https://doi.org/10.1177/0047287513478496

Poudel, S., Nyaupane, G., \& Budruk, M. (2016). Stakeholders' perspectives of sustainable tourism development: A new approach to measuring outcomes. Journal of Travel Research, 55(4), 465-480. https://doi.org/10.1177/0047287514563166

Poudel, S., Nyaupane, G., \& Timothy, D. (2013). Assessing Visitors Preference of Various Roles of Tour Guides in the Himalayas. Tourism Analysis, 18(1), 45-59. https://doi.org/10.3727/108354213X13613720283647

Pouta, E., Grammatikopoulou, I., Hurme, T., Soini, K., \& Uusitalo, M. (2014). Assessing the quality of agricultural landscape change with multiple dimensions. Land, 3(3), 598-616. https://doi.org/10.3390/land3030598

Pradhan, K. M. (2014). Cultural tourism and Nepal. Transnational Corporations Review, 6(3), 238-247. https://doi.org/10.5148/tncr.2014.6303

Pyakuryal, K. (1982). Ethnicity and rural development: A sociological study of four Tharu villages in Chitwan, Nepal. Unpublished doctoral dissertation, Michigan State Univesity.

Rakić, T., \& Chambers, D. (2012). An introduction to visual research methods in tourism. Routledge. 
Ramsay, J. (2015). The aesthetic value of landscapes: Background and sssessment guide.

Raspaud, M., \& Hallé, J. (2014). The transformations of values and aspirations by adventure tourism in Nepal: Example through the figures of three Sherpa. Tourismo Em Analise, 25(2), 373-391. https://doi.org/http://dx.doi.org/10.11606/issn

Relph, E. (1976). Place and placelessness. Pion.

Ringer, G. D. (1998). Destinations: Cultural landscapes of tourism. Routledge.

Ritzer, G., \& Liska, A. (1997). "McDisneyization" and "Post-tourism". Complementary perspectives on contemporary tourism. In C. Rojek \& J. Urry (Eds.), Touring cultures (pp. 96-109). London: Routledge.

Rojo, D. N., Vacas Álvarez, A., Alcántara, M. A. G., Díaz, L., \& Pino, D. (2015). The phenomenon of tourism: Redefining architecture and landscape. In C. Mileto, F. Vegas, L. García Soriano, \& V. Cristini (Eds.), Vernacular architecture: Towards a sustainable future (pp. 537-542). London: Taylor \& Francis Group.

Rovai, M., Andreoli, M., Gorelli, S., \& Jussila, H. (2016). A DSS model for the governance of sustainable rural landscape: A first application to the cultural landscape of Orcia Valley (Tuscany, Italy). Land Use Policy, 56, 217-237. https://doi.org/10.1016/j.landusepol.2016.04.038

Ruska, E. (2012). The road to recovery and rebirth: The social construction of tourism development in Bandipur, Nepal. Unpublished thesis, Wageningen University and Research Center.

Russo, A. P., \& Van Der Borg, J. (2002). Planning considerations for cultural tourism: A case study of four European cities. Tourism Management, 23, 631-637.

Ryan, R. L. (2002). Preserving rural character in New England: Local residents' perceptions of alternative residential development. Landscape and Urban Planning, 61(1), 19-35. https://doi.org/10.1016/S0169-2046(02)00066-X

Saarinen, J. (2008). Tourism and touristic representations of nature. In A. A. Lew, M. Hall, \& A. M. Williams (Eds.), A companion to tourism (pp. 438-449). John Wiley \& Sons. https://doi.org/10.1002/9780470752272.ch35

Sacareau, I. (2009). Changes in environmental policy and mountain tourism in Nepal. Revue de Géographie Alpine, 97(3). https://doi.org/10.4000/rga.1031

Saito, Y. (2007). Everyday aesthetics. Oxford University Press.

Saito, Y. (2010). Future Directions for Environmental Aesthetics. Environmental Values, 19(3), 373-391.

Sauer, C. O. (1963). Land and life: A selection from the writings of Carl Ortwin Sauer. (J. Leighly, Ed.). Berkeley, University of California Press.

Schuett, M. A., Dahal, S., \& SK Nepal, S. K. (2016). Local perspectives on benefits of 
an integrated conservation and development project: The Annapurna Conservation Area in Nepal. International Journal of Biodiversity and Conservation, 8(7), 138146. https://doi.org/10.5897/IJBC2016.0958

Scott, A. J. (2010). The cultural economy of landscape and prospects for peripheral development in the twenty-first century: The case of the English Lake District. European Planning Studies, 18(10). https://doi.org/10.1080/09654313.2010.504337

Scott, M. J., \& Canter, D. V. (1997). Picture or place? A multiple study of landscape. Journal of Environmental Psychology, 17(4), 263-281. https://doi.org/10.1006/JEVP.1997.0068

Setten, G. (2006). Fusion or exclusion? Reflections on conceptual practices of landscape and place in human geography. Norwegian Journal of Geography, 60(1), 32-45. https://doi.org/10.1080/00291950500537315

Shackley, M. (1994). The land of Lo, Nepal/Tibet: The first eight months of tourism. Tourism Management, 15(1), 17-26. https://doi.org/10.1016/0261-5177(94)90023$\mathrm{X}$

Shackley, M. (1996). Too much room at the inn? Annals of Tourm Research, 23(2), 449162. https://doi.org/10.1016/0160-7383(95)00072-0

Sigdel, T. P. (2014). Prospects of ecotourism in Bandipur. The Third Pole: Journal of Geography Education, 11(0), 50-55. https://doi.org/10.3126/ttp.v11i0.11555

Simmons, D. G. (2013). Tourism and ecosystem services in New Zealand. In J. R. Dymond (Ed.), Ecosystem Services in New Zealand (pp. 343-348). Lincoln: Manaaki Whenua Press.

SK Nepal, S. K. (2000a). Tourism, national parks and local communities. In S. W. Boyd \& R. W. Butler (Eds.), Tourism and national parks: issues and implications (pp. 73-94).

SK Nepal, S. K. (2000b). Tourism in protected areas: The Nepalese Himalaya. Annals of Tourism Research, 27(3), 661-681. https://doi.org/10.1016/S0160-7383(99)00105$\mathrm{X}$

SK Nepal, S. K. (2005). Tourism and remote mountain settlements: Spatial and temporal development of tourist infrastructure in the Mt Everest Region, Nepal. Tourism Geographies, 7(2), 205-227. https://doi.org/10.1080/14616680500072471

SK Nepal, S. K. (2007). Tourism and rural settlements: Nepal's Annapurna Region. Annals of Tourism Research, 34(4), 855-875. https://doi.org/10.1016/j.annals.2007.03.012

SK Nepal, S. K. (2008). Tourism-induced rural energy consumption in the Annapurna region of Nepal. Tourism Management, 29(1), 89-100. https://doi.org/10.1016/j.tourman.2007.03.024 
SK Nepal, S. K. (2009). Traditions and trends: A review of geographical scholarship in tourism. Tourism Geographies, 11(1), 2-22. https://doi.org/10.1080/14616680802643219

SK Nepal, S. K., \& Jamal, T. B. (2011). Resort-induced changes in small mountain communities in British Columbia, Canada. Mountain Research and Development, 31(2), 89-101. https://doi.org/10.1659/MRD-JOURNAL-D-10-00095.1

SK Nepal, S. K., \& Spiteri, A. (2011). Linking livelihoods and conservation: An examination of local residents' perceived linkages between conservation and livelihood benefits around Nepal's Chitwan National Park. Environmental Management, 47(5), 727-738. https://doi.org/10.1007/s00267-011-9631-6

SK Nepal, S. K., Verkoeyen, S., \& Karrow, T. (2015). The end of sustainable tourism? Re-orienting the debate. In M. Hughes, D. B. Weaver, \& C. Pforr (Eds.), The business of sustainable tourism: Resolving the paradox (pp. 52-65). New York: Routledge.

Smith, M., \& Ram, Y. (2017). Tourism, landscapes and cultural ecosystem services: A new research tool. Tourism Recreation Research, 42(1), 113-119. https://doi.org/10.1080/02508281.2016.1253206

Soini, K. (2001). Exploring human dimensions of multifunctional landscapes through mapping and map-making. Landscape and Urban Planning, 57(3-4), 225-239. https://doi.org/10.1016/S0169-2046(01)00206-7

Sparrowhawk, J., \& Holden, A. (1999). Human development: The role of tourism based NGOs in Nepal. Tourism Recreation Research, 24(2), 37-43. https://doi.org/10.1080/02508281.1999.11014874

Spiteri, A., \& SK Nepal, S. K. (2008). Evaluating local benefits from conservation in Nepal's Annapurna Conservation Area. Environmental Management, 42, 391-401. https://doi.org/10.1007/s00267-008-9130-6

Spoon, J. (2012). Tourism meets the sacred: Khumbu Sherpa place-based spiritual values in Sagarmatha (Mount Everest) National Park and buffer zone, Nepal. Sacred Natural Sites: Conserving Nature and Culture, 87-97. https://doi.org/10.4324/9781849776639

Stake, R. E. (2005). Qualitative case studies. In N. K. Denzin \& Y. S. Lincoln (Eds.), The SAGE handbook of qualitative research (3rd ed., pp. 443-466). Thousand Oaks: Sage Publications.

Stamps, A. E. (2000). Psychology and the aesthetics of the built environment. Kluwer Academic Publishers.

Starman, A. B. (2013). The case study as a type of qualitative research. Journal of Contemporary Educational Studies, 1, 28-43.

Stefanou, J. (2000). The contribution of the analysis of the image of a place to the formulation of tourism policy. In H. Briassoulis \& J. van der. Straaten (Eds.), 
Tourism and the environment: Regional, economic, cultural, and policy issues (pp. 229-237). Boston: Kluwer Academic Publishers.

Stephenson, J. (2008). The cultural values model: An integrated approach to values in landscapes. Landscape and Urban Planning, 84(2), 127-139. https://doi.org/10.1016/j.landurbplan.2007.07.003

Stevens, S. F. (1993a). Claiming the high ground: Sherpas, subsistence, and environmental change in the highest Himalaya. University of California Press.

Stevens, S. F. (1993b). Tourism, change and continuity in the Mount Everest Region, Nepal. American Geographical Society, 83(4), 410-427.

Stoffelen, A., \& Vanneste, D. (2015). An integrative geotourism approach: Bridging conflicts in tourism landscape research. Tourism Geographies, 6688(September), 1-17. https://doi.org/10.1080/14616688.2015.1053973

Stone, M. T., \& Nyaupane, G. (2018). Protected areas, wildlife-based community tourism and community livelihoods dynamics: Spiraling up and down of community capitals. Journal of Sustainable Tourism, 26(2), 307-324. https://doi.org/10.1080/09669582.2017.1349774

Swanwick, C. (2002). Landscape character assessment - Guidance for England and Scotland. London: The Countryside Agency and Scottish Natural Heritage.

Swanwick, C. (2009). Society's attitudes to and preferences for land and landscape. Land Use Policy, 26, 62-75. https://doi.org/10.1016/j.landusepol.2009.08.025

Taylor, K. (2009). Cultural landscapes and Asia: Reconciling international and Southeast Asian regional values. Landscape Research, 34(1), 7-31. https://doi.org/10.1080/01426390802387513

Taylor, K. (2014). Landscape and meaning: Context for a global discourse on cultural landscape values. In K. Taylor \& J. Lennon (Eds.), Managing cultural landscapes (pp. 21-44). Taylor \& Francis Group.

Tekken, V., Spangenberg, J. H., Burkhard, B., Escalada, M., Stoll-Kleemann, S., Truong, D. T., \& Settele, J. (2017). "Things are different now": Farmer perceptions of cultural ecosystem services of traditional rice landscapes in Vietnam and the Philippines. Ecosystem Services, 25, 153-166. https://doi.org/10.1016/J.ECOSER.2017.04.010

Terkenli, T. S. (2001). Towards a theory of the landscape: The Aegean landscape as a cultural image. Landscape and Urban Planning, 57(3-4), 197-208. https://doi.org/10.1016/S0169-2046(01)00204-3

Terkenli, T. S. (2002). Landscapes of tourism: Towards a global cultural economy of space? Tourism Geographies, 4(3), 227-254. https://doi.org/10.1080/14616680210147409

Terkenli, T. S. (2005). Human activity in landscape seasonality: The case of tourism in 
Crete. Landscape $\quad$ Research, 30(2), 221-239. https://doi.org/10.1080/01426390500044408

Terkenli, T. S. (2008). Tourism and landscape. In A. A. Lew, C. M. Hall, \& M. Williams (Eds.), A companion to tourism (pp. 339-348). John Wiley \& Sons. https://doi.org/10.1002/9780470752272.ch27

Teye, V., Sirakaya, E., \& Sönmez, S. F. (2002). Residents' attitudes toward tourism development. Annals of Tourism Research, 29(3), 668-688. https://doi.org/10.1016/S0160-7383(01)00074-3

Thapa, B. (2004). Tourism in Nepal. Journal of Travel \& Tourism Marketing, 15(2-3), 117-138. https://doi.org/10.1300/J073v15n02_07

Thing, S. J., Jones, R., \& Jones, C. B. (2017). The politics of conservation: Sonaha, riverscape in the Bardia National Park and buffer zone, Nepal. Conservation and Society, 15(3), 292-303. https://doi.org/10.4103/cs.cs_15_2

Tieskens, K. F., Van Zanten, B. T., Schulp, C. J. E., \& Verburg, P. H. (2018). Aesthetic appreciation of the cultural landscape through social media: An analysis of revealed preference in the Dutch river landscape. Landscape and Urban Planning, 177, 128137. https://doi.org/10.1016/J.LANDURBPLAN.2018.05.002

Tilley, C., \& Cameron-Daum, K. (2017). An Anthropology of Landscape. London: UCL Press. https://doi.org/10.14324/111.9781911307433

Tosun, C. (2002). Host perceptions of impacts: A comparative tourism study. Annals of Tourism Research, 29(1), 231-253. https://doi.org/10.1016/S0160-7383(01)000391

Tress, B., \& Tress, G. (2001). Capitalising on multiplicity: A transdisciplinary systems approach to landscape research. Landscape and Urban Planning, 57(3-4), 143-157. https://doi.org/10.1016/S0169-2046(01)00200-6

Tribe, J. (2005). New tourism research. Tourism Recreational Research, 30(2), 5-8. https://doi.org/10.1080/02508281.2005.11081468

Tuan, Y. (1974). Topophilia: A study of environmental perception, attitudes, and values. Prentice-Hall.

Tveit, M. S., Sang, Å. O., \& Fry, G. (2006). Key concepts in a framework for analysing visual landscape character. Landscape Research, 31(3), 229-255. https://doi.org/10.1080/01426390600783269

Tyrväinen, L., Silvennoinen, H., \& Kolehmainen, O. (2003). Ecological and aesthetic values in urban forest management. Urban Forestry \& Urban Greening, 1, 135149. https://doi.org/10.1078/1618-8667-00014

Tzanopoulos, J., \& Vogiatzakis, I. N. (2011). Processes and patterns of landscape change on a small Aegean island: The case of Sifnos, Greece. Landscape and Urban Planning, 99(1), 58-64. https://doi.org/10.1016/J.LANDURBPLAN.2010.08.014 
UNESCO. (2015). Statutes of the international geoscience and geoparks programme $(I G G P)$.

UNESCO World Heritage Centre. (2015). Operational Guidelines for the Implementation of the World Heritage Convention. Paris.

Upadhayaya, P. K., Müller-Böker, U., Sharma, S. R., \& Umar Upadhayaya, P. K. (2011). Tourism amidst armed conflict: Consequences, copings, and creativity for peacebuilding through tourism in Nepal. The Journal of Tourism and Peace Research, 1(2), 22-40. https://doi.org/10.5167/uzh-42464

Urry, J. (2002). The tourist gaze (2nd ed.). London: Sage Publications Ltd.

USFS. Wilderness act (1964). USFS.

Uusitalo, M. (2010). Differences in tourists' and local residents' perceptions of tourism landscapes: A case study from Ylläs, Finnish Lapland. Scandinavian Journal of Hospitality and Tourism, 10(3), 310-333. https://doi.org/10.1080/15022250.2010.489786

Vallejo, J. R., Cain, M., Hackney, S., Khadka, U., Park, S., \& Paul, B. (2015). The Nepal tourism cluster.

Van Eetvelde, V., \& Antrop, M. (2009). Indicators for assessing changing landscape character of cultural landscapes in Flanders (Belgium). Land Use Policy, 26(4), 901-910. https://doi.org/10.1016/j.landusepol.2008.11.001

Van Zanten, B. T., Verburg, P. H., Koetse, M. J., \& Van Beukering, P. J. H. (2014). Preferences for European agrarian landscapes: A meta-analysis of case studies. Landscape and Urban Planning, 132, 89-101. https://doi.org/10.1016/j.landurbplan.2014.08.012

Vinge, H., \& Flø, B. E. (2015). Landscapes lost? Tourist understandings of changing Norwegian rural landscapes. Scandinavian Journal of Hospitality and Tourism, 2250(April), 1-19. https://doi.org/10.1080/15022250.2015.1010283

Wall, G. (1998). Landscape resources, tourism and landscape change in Bali, Indonesia. In G. D. Ringer (Ed.), Destinations: Cultural landscapes of tourism (pp. 51-62). Routledge.

Wall, G., \& Mathieson, A. (2006). Tourism: Change, impacts, and opportunities. Pearson Prentice Hall.

Wang, D., Niu, Y., Lu, L., \& Qian, J. (2015). Tourism spatial organization of historical streets - A postmodern perspective: The examples of Pingjiang Road and Shantang Street, Suzhou, China. Tourism Management, 48, 370-385. https://doi.org/10.1016/j.tourman.2014.12.007

Watson, L. (2014). The continuing significance of rural landscapes in the urban century. Rural Landscapes, 1(1), 1-3. https://doi.org/10.16993/rl.ab 
Weaver, A. (2009). Tourism and aesthetic design: Enchantment, style, and commerce. Journal of Tourism and Cultural Change, 7(3), 179-189. https://doi.org/10.1080/14766820903259493

Webb, R. H., Boyer, D. E., \& Turner, R. M. (Eds.). (2010). Repeat photography: Methods and applications in the natural sciences. Island Press.

WEF. (2017). The travel \& tourism competitiviness report 2017. World Economic Forum. https://doi.org/ISBN-13: 978-1-944835-08-8

Wells, M. P. (1993). Neglect of biological riches: The economics of nature tourism in Nepal. Biodiversity and Conservation, 2(4), 445-464. https://doi.org/10.1007/BF00114046

Wickens, E., Bakir, A., \& Avgeli, V. (2017). Sustainable tourism. In Sustainable tourism development: Issues challenges \& debates (pp. 140-166). https://doi.org/10.1016/B978-0-7506-8946-5.50013-7

Willis, C. (2015). The contribution of cultural ecosystem services to understanding the tourism-nature-wellbeing nexus. Journal of Outdoor Recreation and Tourism, 10, 38-43. https://doi.org/10.1016/J.JORT.2015.06.002

WTTC. (2017). Travel and tourism: Economic impact 2017 Nepal. World Travel and Tourism Council.

Yang, B.-E., \& Brown, T. J. (1992). A cross-cultural comparison of preferences for landscape styles and landscape elements. Environment and Behavior, 24(4), 471507.

Yin, R. K. (2012). Applications of case study research. Thousand Oaks, Calif.: SAGE.

Yin, R. K. (2018). Case study research and applications: Design and methods (6th ed.). Thousand Oaks, Calif.: Sage Publications.

Young, M. (1999). Cognitive maps of nature-based tourists. Annals of Tourism Research, 26(4), 817-839. https://doi.org/10.1016/S0160-7383(99)00023-7

Zoderer, B. M., Tasser, E., Erb, K.-H., Stanghellini, P. S. L., \& Tappeiner, U. (2016). Identifying and mapping the tourists' perception of cultural ecosystem services: A case study from an Alpine region. Land Use Policy, 56, 251-261. https://doi.org/10.1016/j.landusepol.2016.05.004

Zube, E. H., Sell, J. L., \& Taylor, J. G. (1982). Landscape perception: Research, application and theory. Landscape Planning, 9(1), 1-33. https://doi.org/10.1016/0304-3924(82)90009-0

Zurick, D. N. (1992). Adventure travel and sustainable tourism in the peripheral economy of Nepal. Annals of the Association of American Geographers, 82(4), 608-628.

Zurick, D. N., \& Rose, A. (2009). Landscape change in Kathmandu valley. Focus on Geography, (Spring), 7-16. 


\section{APPENDICES}

Appendix A: Information sheet and consent form

Appendix B: Interview guidelines (Tourists and Residents)

Appendix C: Examples of past and repeat photograph sets used in the interviews 
APPENDIX A

Information sheet and consent form 


\section{Participant Information Sheet}

Research Project Title: Changing landscapes, aesthetic values and tourism development in Nepal

\section{Researcher: Jharna Joshi, School of Management, Victoria University of Wellington}

I am a PhD student in Tourism Management at Victoria University of Wellington and I am undertaking a research project leading to a thesis. The project involves examining the changing landscapes, the associated aesthetic values and tourism development in Nepal, specifically Ghandruk, Bandipur and Sauraha. This research project has received approval from the Victoria University of Wellington Human Ethics Committee. If there are any ethics related queries, please contact the HEC Convener, AProf Susan Corbett by email susan.corbett@vuw.ac.nz or telephone +64 44635480 .

As part of my research, I am interested in your views on how the landscape is changing and the role tourism may have in these changes. I will use historic and contemporary photographs to help you compare the landscapes during the interviews.

I am inviting you to take part in a half hour to an hour interview. With your permission, I will electronically record the interview and a summary of the transcript of the interview will be available. Participation is voluntary, and you will not be identified personally or professionally in any written report produced as a result of this research, including possible publication in academic conferences and journals.

All material collected will be kept confidential, and will be viewed only by myself and my supervisors. The thesis will be submitted for marking to the School of Management, and subsequently deposited in the University Library. Should you wish to withdraw from the project, you may do so until two weeks after receiving the transcript summary, and the data collected up to that point will be destroyed. All data collected from participants will be destroyed within five years after the completion of the project.

If you have any questions or would like to receive further information about the project, please contact me at Jharna.Joshi@vuw.ac.nz or telephone +977 984300 3641, +64 22323 1011, or you may contact my supervisors, Dr Adam Weaver at Adam.Weaver@vuw.ac.nz or telephone +64 $4463-5375$ and Prof Karen Smith at Karen.Smith@vuw.ac.nz or +64 44635721.

Thank you for your cooperation.

Jharna Joshi 


\section{Participant Consent Form}

Research Project Title: Changing landscapes, aesthetic values and tourism development in Nepal

\section{Researcher: Jharna Joshi, School of Management, Victoria University of Wellington}

I have been given and have understood an explanation of this research project. I have had an opportunity to ask questions and have them answered to my satisfaction.

I understand that I may withdraw myself (or any information I have provided) from this project, by e-mailing Jharna.Joshi@vuw.ac.nz within two weeks after receiving a summary of the transcript of the interview.

I understand that any information I provide will be kept confidential to the researcher and their supervisors, the published results will not use my name, and that no opinions will be attributed to me in any way that will identify me. I also understand that the final thesis will be deposited in the University Library and may be published in conferences and journal articles.

I understand that the data I provide will not be used for any other purpose or released to others.

I understand that, if this interview is audio recorded, the recording and transcripts of the interviews will be erased within five years after the conclusion of the project. Furthermore, I will have an opportunity to check the transcripts of the interview.

Please indicate (by ticking the boxes below) which of the following apply:

I agree to this interview being audio recorded.

I would like to receive a summary of the transcript of the interview.

I would like to receive a summary of the results of this research when it is completed.

Signed:

Name of participant:

Date:

Email:

Postal address:

Researcher: Jharna Joshi, Email: Jharna.Joshi@vuw.ac.nz, Tel: +977 984300 3641, +64 223231011

Supervisors: Dr Adam Weaver, Email: Adam.Weaver@vuw.ac.nz, Telephone: +64 4 463-5375

Prof Karen Smith, Karen.Smith@vuw.ac.nz, Telephone: +64 44635721. 


\section{APPENDIX B}

Interview guidelines 


\section{Interview Questions (Tourists)}

Research Project Title: Changing landscapes, aesthetic values and tourism development in Nepal

\section{Researcher: Jharna Joshi, School of Management, Victoria University of Wellington}

I will employ a photo-elicitation technique with semi-structured, in-depth interview questions. I will use photographs taken by others to guide open-ended interviews and provoke discussions to understand the perceptions of changing landscapes and their aesthetic values. Depending on the available photographs, I will take another photograph of the same location at the same angle to assist participants to compare the landscape in the past and present. In each case study, a set of 15-20 photographs are expected to be used during each interview. These interviews are expected to take place in situ, which will also provide an opportunity to stimulate the participant to reflect on the changes in the landscape.

The interviews are expected to last from half an hour to an hour; the interviews with the locals are likely to be longer than those with the tourists due to their familiarity to the site. Interviews will be conducted in small groups and individually and in Nepali and English, where appropriate. The interviews will explore both the physical and sensory aspects of the landscape to address the research questions.

Questions to collect are:

Opening questions:

- Is this your first visit to this place? To Nepal (international tourists only)?

- How long have you been in this place? In Nepal (international tourists only)?

- Would you mind sharing where you are staying here? (hotel, guesthouse, homestay)

- How would you describe yourself as a tourist? (travelling alone/group, first/repeat visitor, short/long stay visitor)

- Would like to share a little about your home and your visit/experience here so far?

- Why did you select to visit this place? Where did you hear about this place? Did it meet your expectations? What were they?

General questions:

- How would you describe this place to someone who has never visited?

- What colour(s) would you associate this place with?

- Would you associate this place with any particular smell(s)? How would you describe that smell?

- What kind of sound would you associate this place with?

Specific questions on landscape:

- Is there any particular feature(s) in the landscape (including the village) that you find distinct or striking? Any feature you like or dislike?

- Do you think this feature defines this place?

- What do the feature(s) mean to you? (Do you have a story to share about this landscape?) 
Views of the community:

- How would you describe the community/people/life/activities going you in this village/landscape?

- How would you describe your feelings when you look at the landscape?

- How would you describe the best and worst features of this landscape?

- What does this village/landscape remind you of?

Comparisons:

- Comparing the present landscape with these photograph from the past (from 1970s) do you see any differences? What are your impressions on the differences (if any)?

- Why do you think the landscape is changing?

- Which landscape would you prefer to see? Would you mind telling me your reasons?

- Do you think others would have the same view?

- If you have experience with similar landscapes in Nepal or elsewhere, how would you compare this landscape? Compared with your hometown?

Role of tourism:

- What are your impressions of the tourism potential of this place? What do you think attracts tourists to this place?

- Do you see the impact of tourism in the place/community? Impacts of other phenomenon such as globalization?

- What are your views on the impact of tourism and/or other phenomenon?

- What would you as a tourist like to see when you visit this place in the future?

Concluding questions:

- Are you familiar with the other two places (Ghandruk/Bandipur/Sauraha)? How would you compare this landscape with the others?

- Anything else you would like to add? 


\section{Interview Questions (Residents)}

Research Project Title: Changing landscapes, aesthetic values and tourism development in Nepal

\section{Researcher: Jharna Joshi, School of Management, Victoria University of Wellington}

I will employ a photo-elicitation technique with semi-structured, in-depth interview questions. I will use photographs taken by others to guide open-ended interviews and provoke discussions to understand the perceptions of changing landscapes and their aesthetic values. Depending on the available photographs, I will take another photograph of the same location at the same angle to assist participants to compare the landscape in the past and present. In each case study, a set of 15-20 photographs are expected to be used during each interview. These interviews are expected to take place in situ, which will also provide an opportunity to stimulate the participant to reflect on the changes in the landscape.

The interviews are expected to last from half an hour to an hour; the interviews with the locals are likely to be longer than those with the tourists due to their familiarity to the site. Interviews will be conducted in small groups and individually and in Nepali and English, where appropriate. The interviews will explore both the physical and sensory aspects of the landscape to address the research questions.

Questions to collect are:

Opening questions:

- How long have you lived in this place? This house?

- Where did you come here from? When? Why? (Only for recent migrants)

- Would you like to describe a little about yourself and your family? (number of family, occupation, residence, life)

General questions:

- How would you describe this place to someone who has never visited?

- What colour(s) would you associate this place with?

- Would you associate this place with any particular smell(s)? How would you describe that smell?

- What kind of sound would you associate this place with?

Specific questions on landscape:

- Is there any particular feature(s) in the landscape (including the village) that you find distinct or striking? Any feature you like or dislike?

- Do you think this feature defines this place?

- What do the feature(s) mean to you? (Do you have a story to share about this landscape?)

Views of the community:

- How would you describe the community/people/life/activities going you in this village/landscape?

- How would you describe your feelings when you look at the landscape?

- How would you describe the best and worst features of this landscape?

- What does this place mean to you?

Comparisons:

- Comparing the present landscape with these photograph from the past (from 1970s) do you see any differences? What are your impressions on the differences (if any)? 
- Why do you think the landscape is changing? What do you think are the main reasons for the change?

- How would you describe process of the changes?

- Which landscape would you prefer to see? Would you mind telling me your reasons?

- Do you think others would have the same view?

- If you have experience with similar landscapes in Nepal or elsewhere, how would you compare this landscape?

Role of tourism:

- What are your impressions of the tourism potential of this place? What do you think attracts tourists to this place?

- Do you see the impact of tourism in the place/community? Impacts of other phenomenon such as globalization?

- What are your views on the impact of tourism and/or other phenomenon?

- What would you as a tourist like to see when you visit this place in the future?

Concluding questions:

- Are you familiar with the other two places (Ghandruk/Bandipur/Sauraha)? How would you compare this landscape with the others?

- Anything else you would like to add? 


\section{APPENDIX C}

Examples of past and repeat photograph sets used in the interviews 

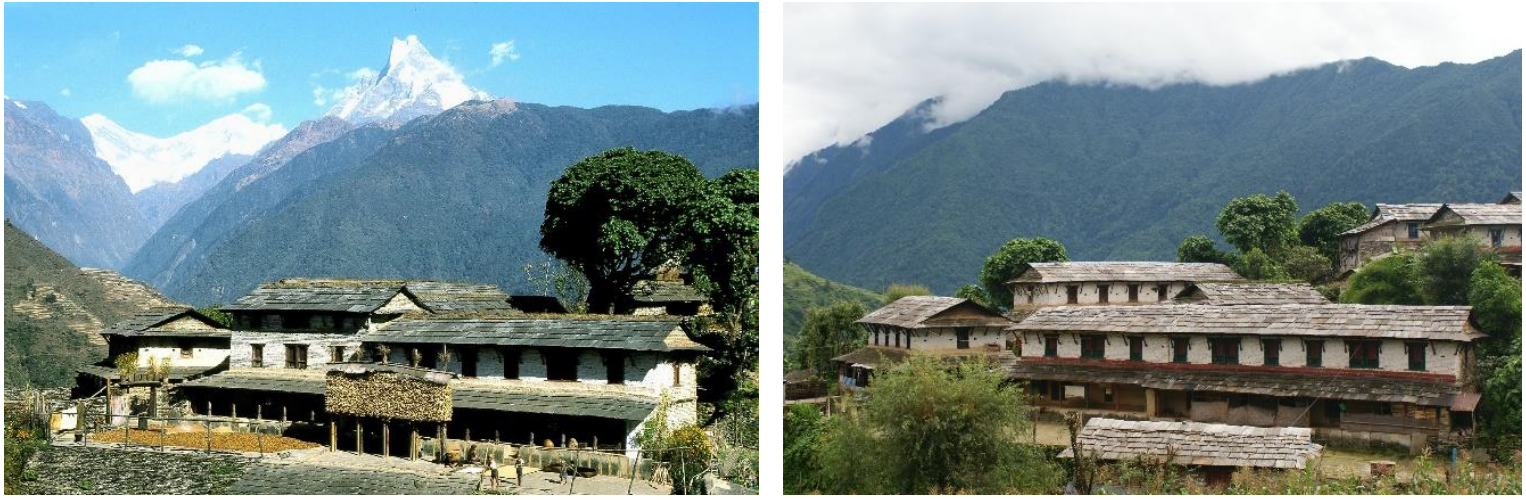

Gurung house in Ghandruk

Photo:

Left: Peter Von Mertens (PCNPP), 1974. Right: JJoshi, 2016
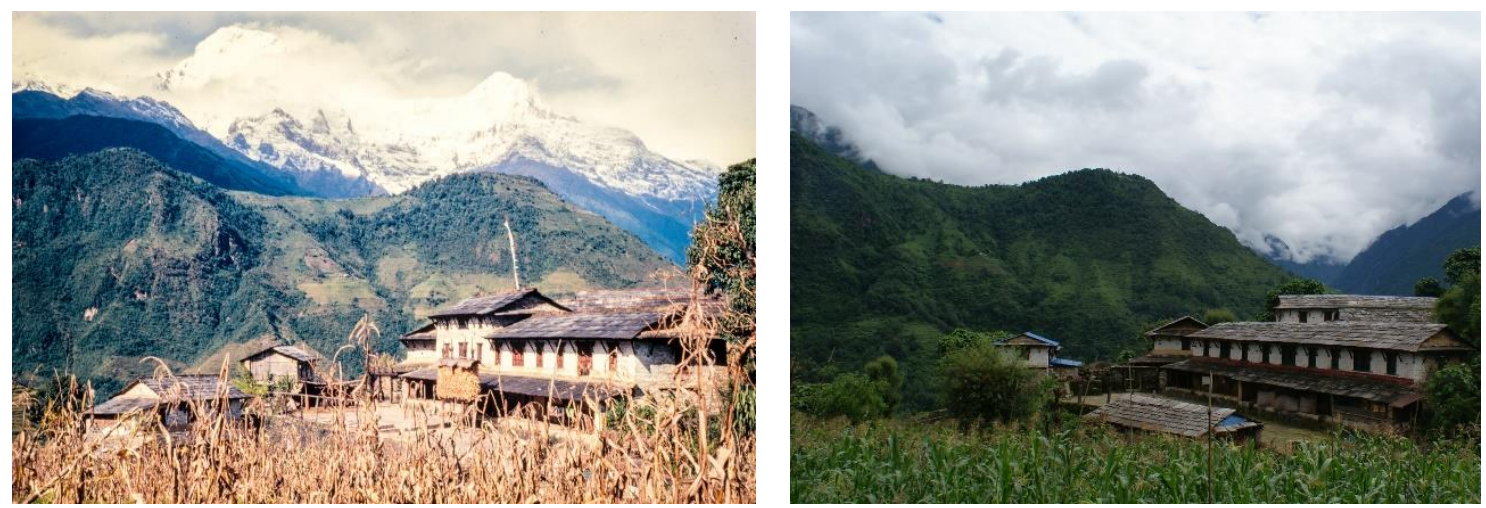

Gurung house in Ghandruk

Photo:

Left: Mike Gill \& Barbara Butterworth (PCNPP), 1973. Right: JJoshi, 2016
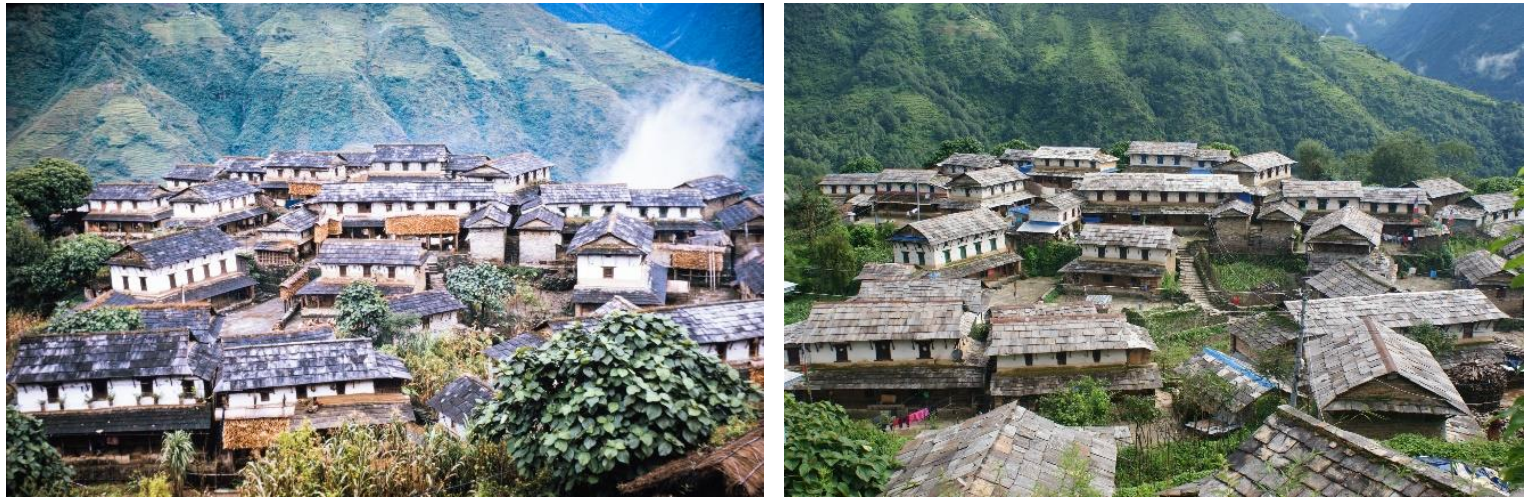

Cluster of houses in Ghandruk

Photo:

Left: Mike Gill \& Barbara Butterworth (PCNPP), 1973. Right: JJoshi, 2016

Image set 1: Ghandruk 

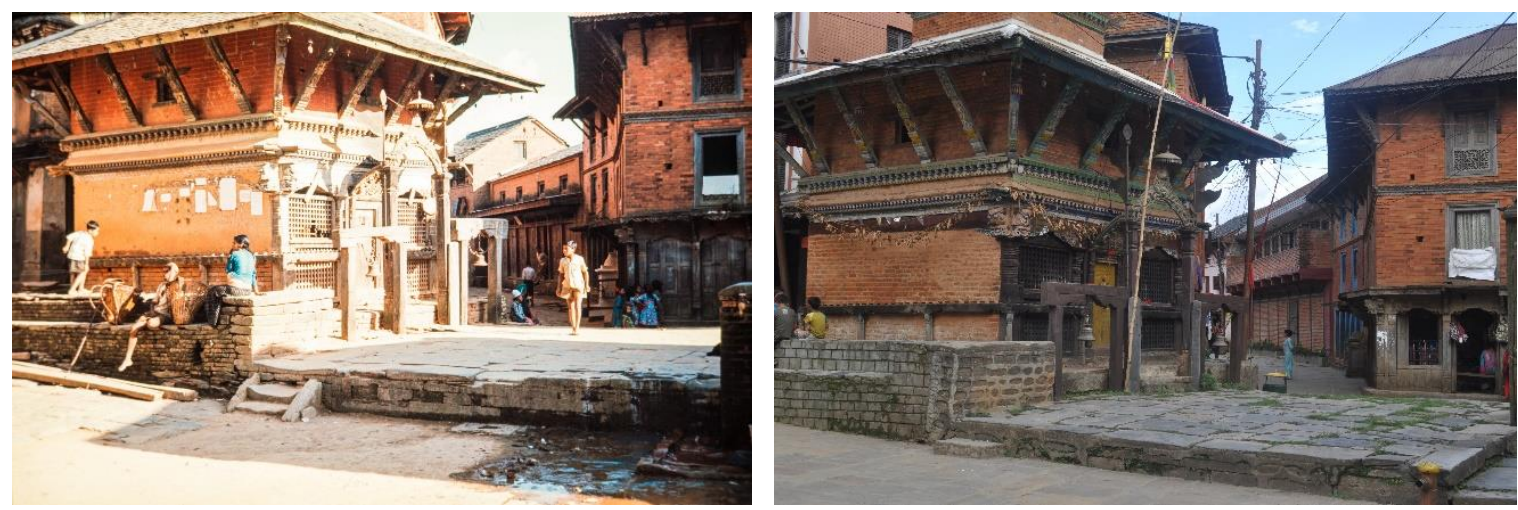

Brindabasini temple, Bandipur

Photo:

Left: Bill Hanson (PCNPP), 1965. Right: JJoshi, 2016
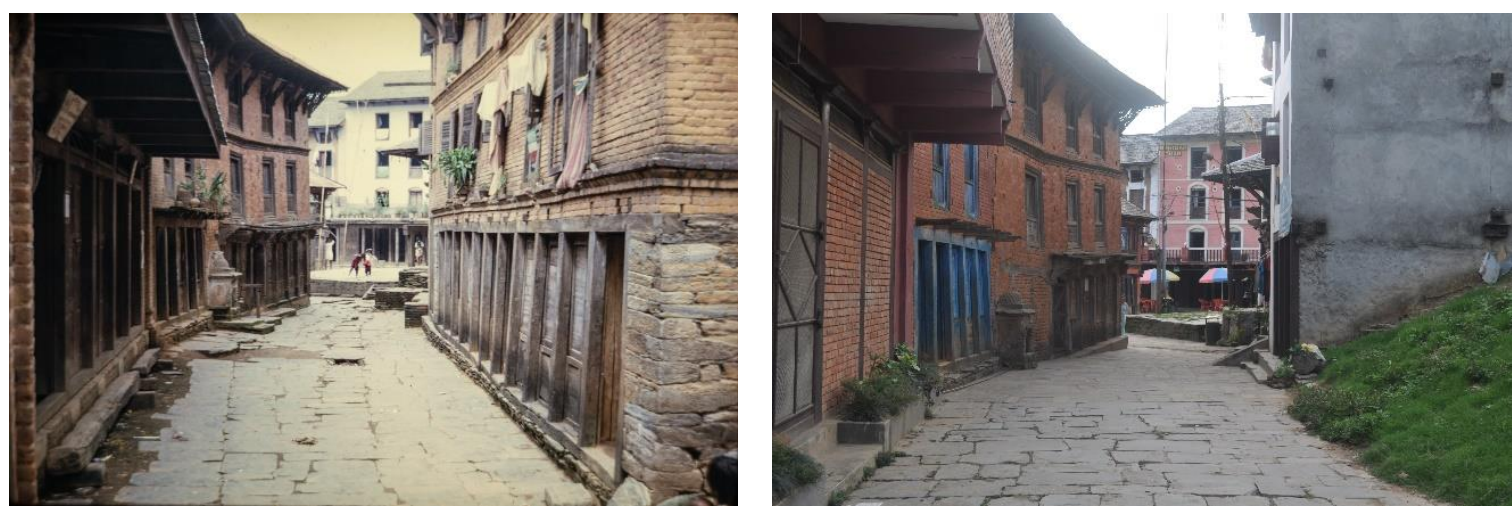

Street looking towards main bazaar, Bandipur

Photo:

Left: Bill Hanson (PCNPP), 1966. Right: JJoshi, 2016
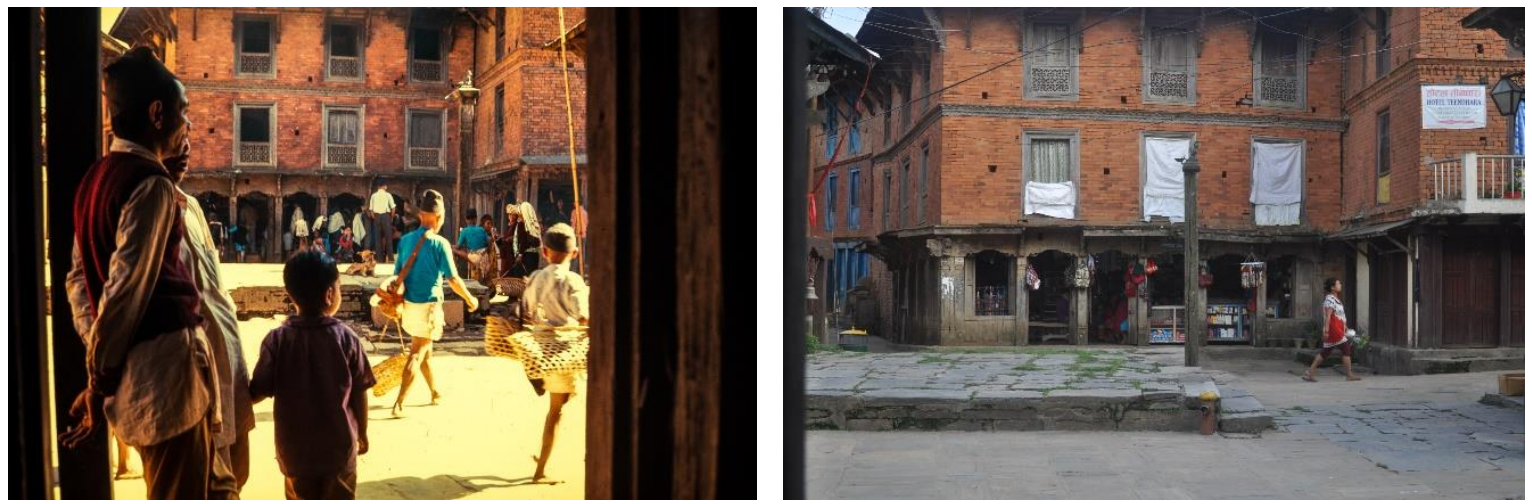

Bandipur bazaar

Photo:

Left: Bill Hanson (PCNPP), 1965. Right: JJoshi, 2016

\section{Image set 2: Bandipur}



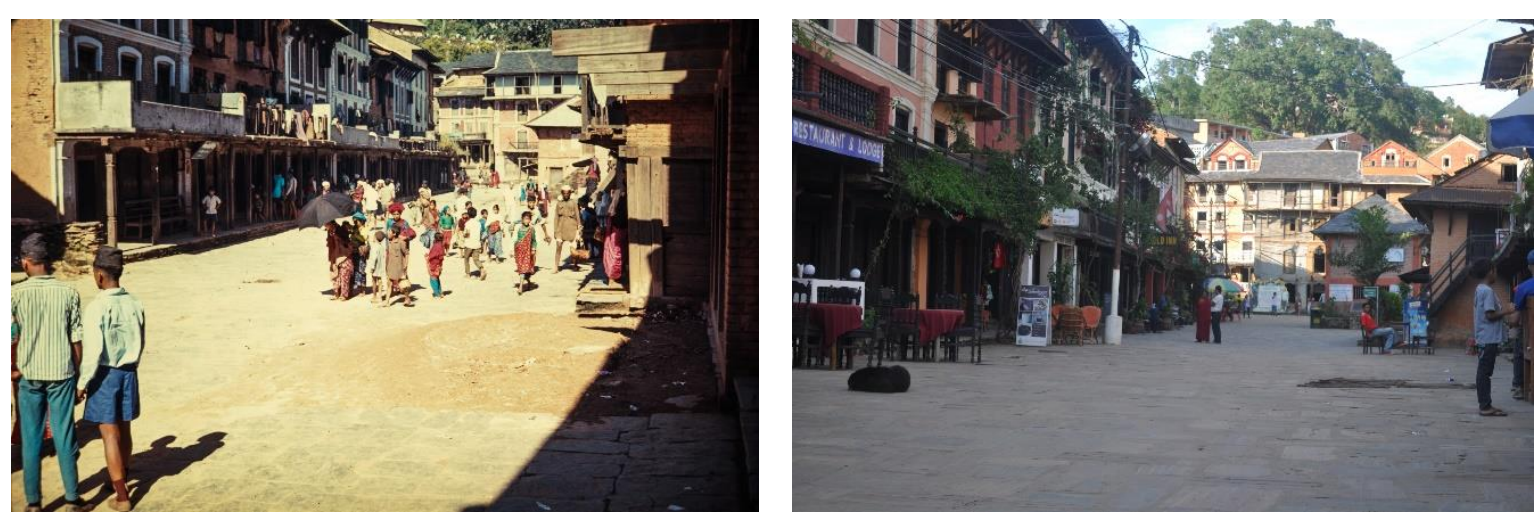

Bandipur bazaar

Photo:

Left: Bill Hanson (PCNPP), 1965. Right: JJoshi, 2016
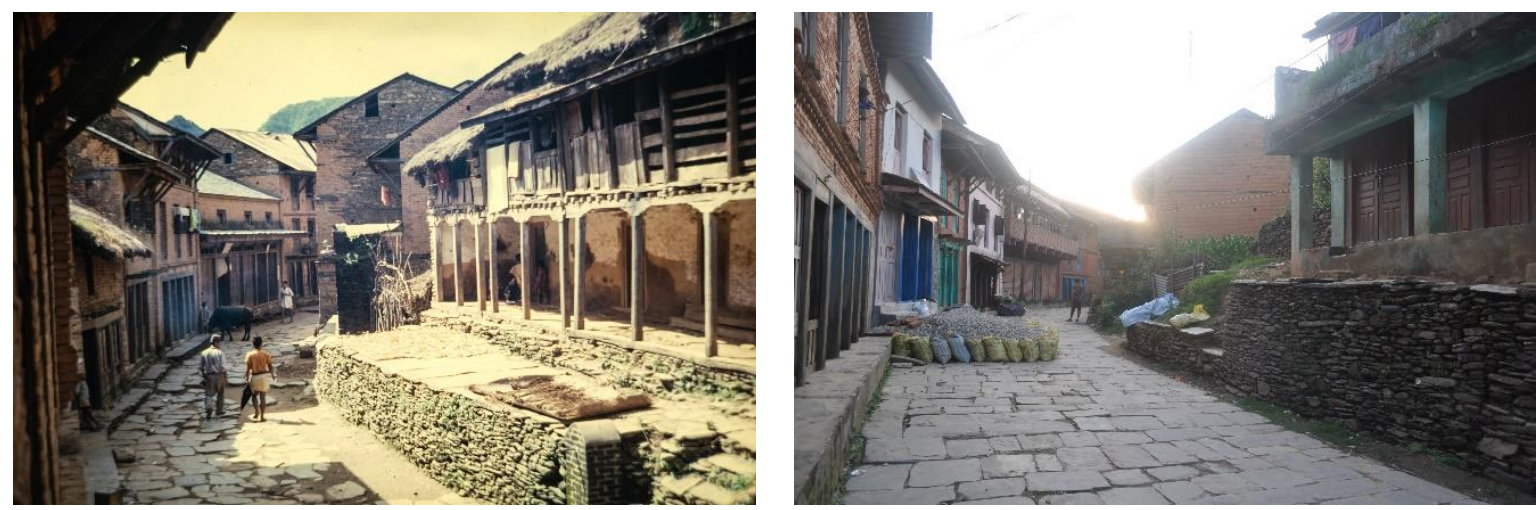

Bandipur bazaar

Photo:

Left: Bill Hanson (PCNPP), 1965. Right: JJoshi, 2016
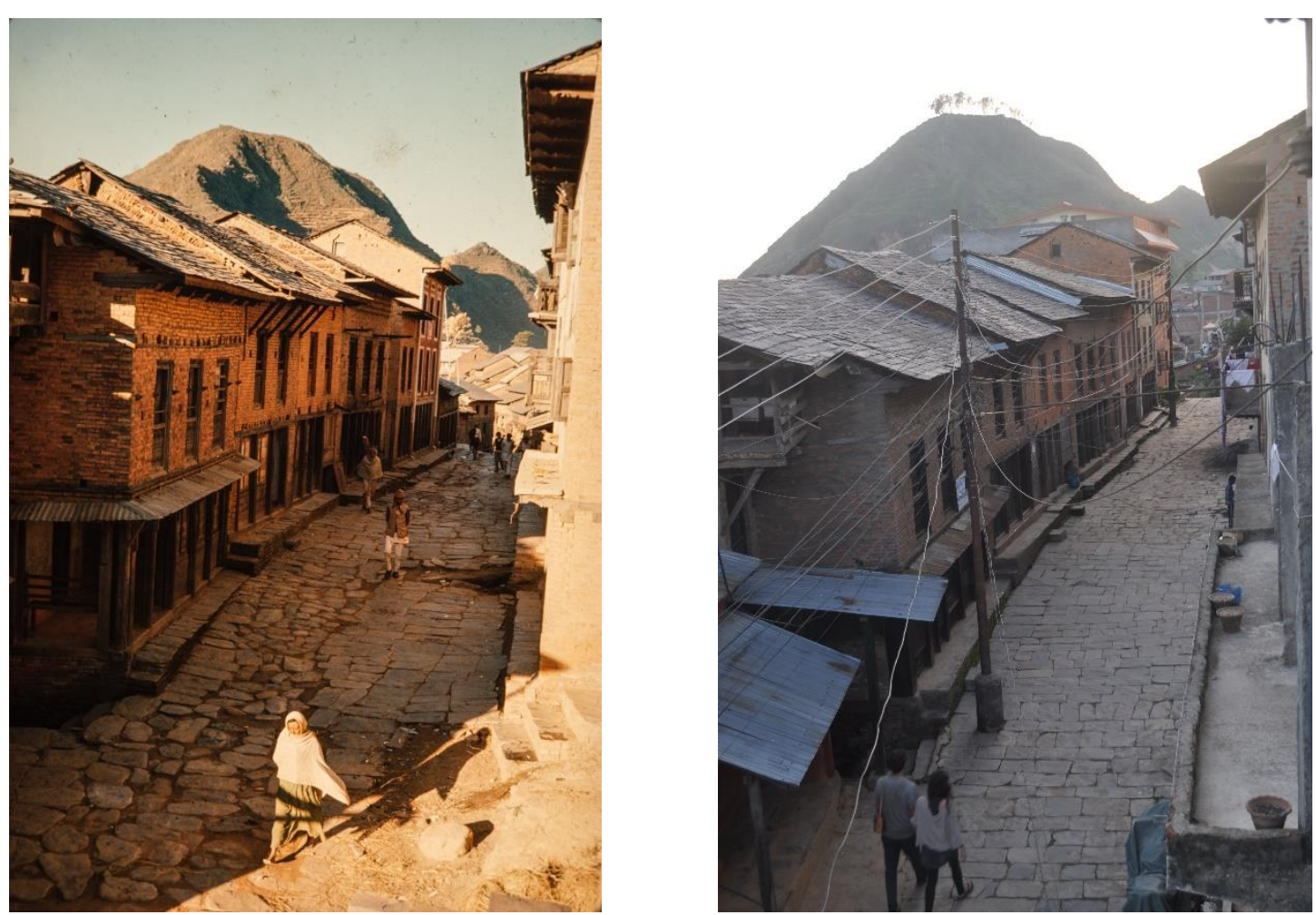

Bandipur bazaar

Photo:

Left: Bill Hanson (PCNPP), 1965. Right: JJoshi, 2016

Image set 3: Bandipur 


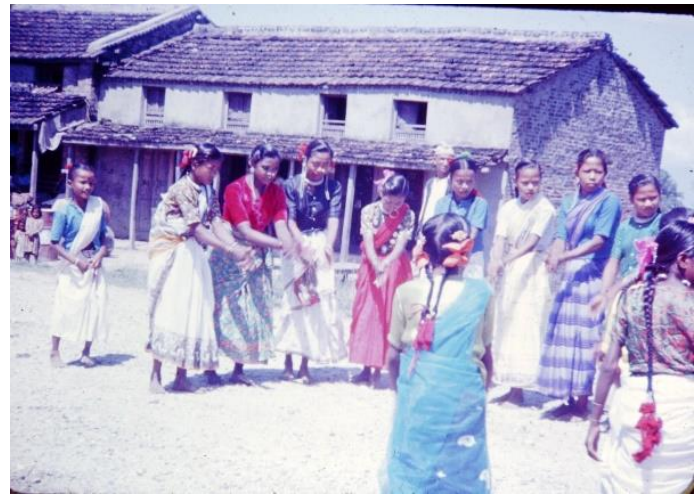

Jitiya festival, Chitwan

Photo:

Richard Pete Andrews (PCNPP), 1966

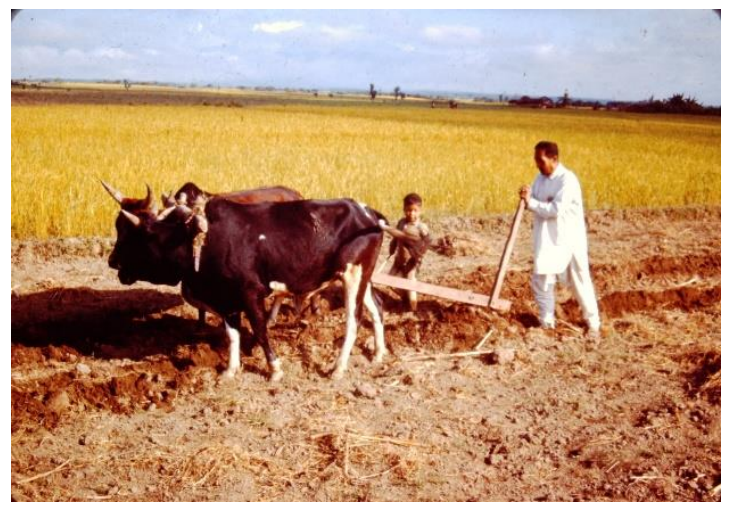

Traditional framing, Chitwan

Photo:

Richard Pete Andrews (PCNPP), 1967

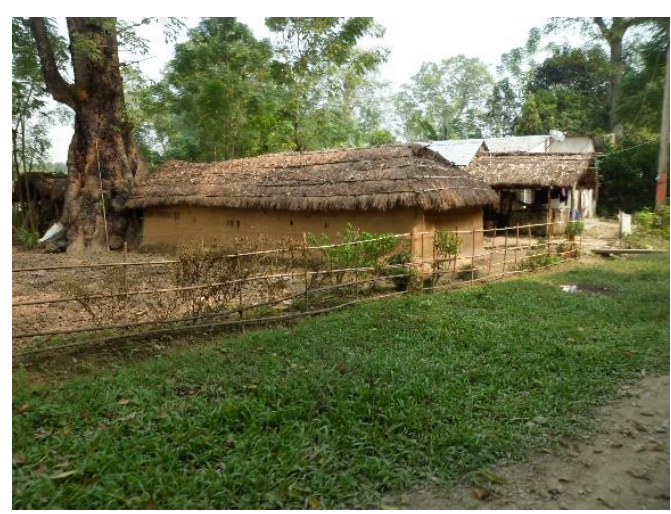

Traditional cottage, Sauraha Photo:

JJoshi, 2016

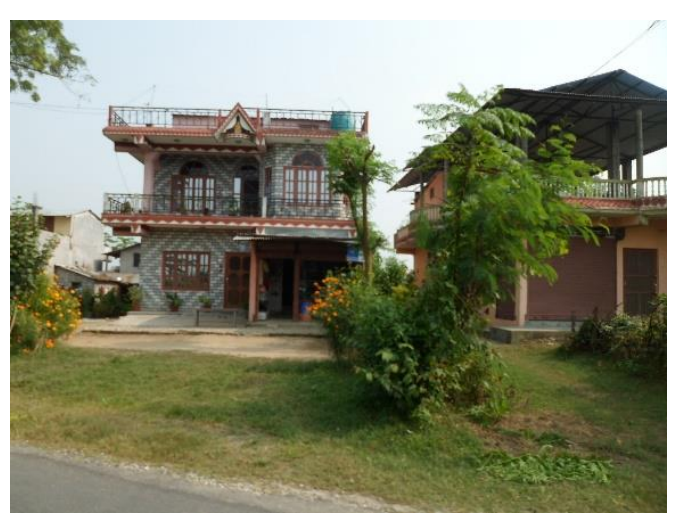

Typical new construction in Chitwan Photo:

JJoshi, 2016

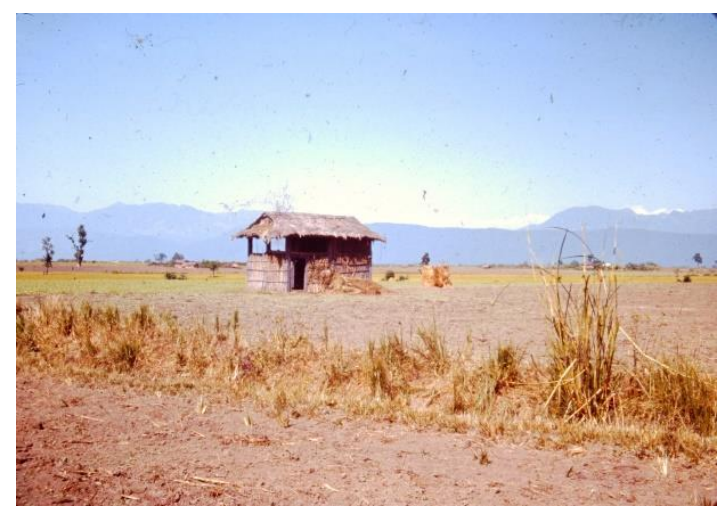

Gitanagar landscape, Chitwan

Photo:

Richard Pete Andrews (PCNPP), 1966

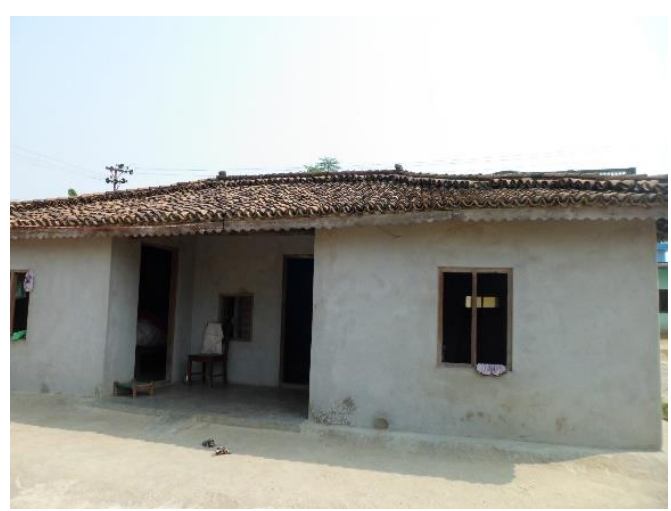

New construction in traditional scale, Sauraha Photo:

JJoshi, 2016

Image set 4: Sauraha (Repeat photographs were not possible in Sauraha due to the unavailability of relevant photographs and landscape change (section 3.4.2) 